\title{
CONTRIBUIÇÃO AO ESTUDO DAS ESTRUTURAS METÁLICAS ESPACIAIS
}

\section{ALEX SANDER CLEMENTE DE SOUZA}

Dissertação apresentada à Escola de Engenharia de São Carlos da Universidade de São Paulo, como parte dos requisitos para obtenção do Título de Mestre em Engenharia de Estruturas

ORIENTADOR: Prof. Dr. Roberto Martins Gonçalves

\section{São Carlos}

1998 
Class.

cult. 5755 T0158 98

Tonbo TOL 50198

1t 0979649

Ficha catalográfica preparada pela Seção de Tratamento da Informação do Serviço de Biblioteca - EESC-USP

Souza, Alex Sander Clemente de

S729c Contribuição ao estudo das estruturas metálicas espaciais / Alex Sander Clemente de Souza. -- São Carlos, 1998

Dissertação (Mestrado) -- Escola de Engenharia de São Carlos-Universidade de São Paulo, 1998.

Área: Engenharia de Estruturas.

Orientador: Prof. Dr. Roberto Martins Gonçalves.

1. Estruturas metálicas. 2. Estruturas espaciais. 3. Treliças espaciais. 4. Elementos tubulares. 5. Variação de inércia. I. Título. 
À minha mãe,

Ana Luzia Clemente.

Exemplo de mãe e de mulher 


\section{AGRADECIMENTOS}

Aos meus pais e irmãos pelo constante incentivo e por sempre estarem presentes, de alguma forma, em todos os momentos importantes da minha vida.

Meus agradecimentos a três mulheres, D. Terezinha, Cristina e tia Eunice, que me apoiaram bastante nos "duros" anos da graduação.

Aos colegas, agradeço àqueles que foram apenas colegas $e$ principalmente aos que se tornaram grandes amigos, com os quais vivi "estórias" dignas de serem contadas a filhos e netos.

Aos meus companheiros de moradia, Osvaldo Gomes de Holanda Jr. e Flávio José Craveiro Cunto, pela convivência harmoniosa e o aprendizado mútuo.

A todos os professores do Departamento de Estruturas, aos que foram apenas professores, aos que foram professores e amigos e aos que foram só amigos.

Agradeço também a todos os funcionários do departamento, em especial a Maria Nadir Minatel pela paciência e dedicação na biblioteca.

Ao Prof. Roberto Martins Gonçalves, que mais que orientador tornou-se um amigo, por quem tenho grande admiração. 


\section{SUMÁRIO}

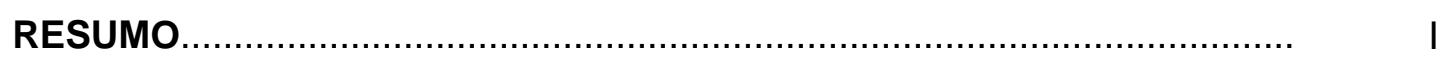

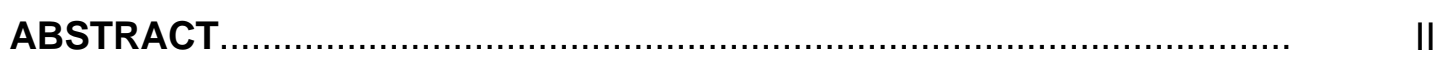

LISTA DE SÍMBOLOS III

LISTA DE FIGURAS .................................................................. IV

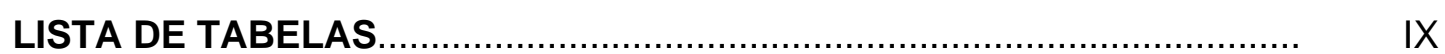

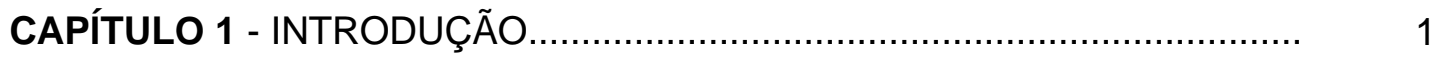

CAPÍTULO 2 - ESTRUTURAS ESPACIAIS: ASPECTOS GERAIS................. 3

2.1 Generalidades.............................................................. 3

2.1.1 Tipos de treliças espaciais .................................... 7

2.1.2 Métodos de análise................................................ 8

2.2 Ligações e elementos utilizados em estruturas espaciais............ 9

2.3 Comportamento não linear..................................................... 11

2.4 Mecanismos de colapso......................................................... 15

2.4.1 Acidentes com estruturas espaciais............................ 19

CAPÍTULO 3 - ELEMENTOS COMPRIMIDOS UTILIZADOS NAS ESTRUTURAS METÁLICAS ESPACIAIS ............................................... 21

3.1 Conceitos básicos - fundamentos............................................. 21

3.2Critérios de projeto para elementos comprimidos: Normalizações 23

3.2.1 Elementos comprimidos sem variação de inércia.......... 29

3.2.2 Elementos comprimidos com variação de inércia.......... 39

3.3 Análise de tubos comprimidos de seção circular com variação de $\quad 41$ inércia.

3.3.1 Análise teórica.......................................................... 42

3.3.2 Resultados experimentais........................................ 56

3.3.2.1 Ensaio de tubos de aço: GONÇALVES(1996)... 56

3.3.2.2 Ensaio de tubos de aço: MALITE(1997)............ 62 
CAPÍTULO 4 - LIGAÇÕES EM ESTRUTURAS METÁLICAS ESPACIAIS ..... 70

4.1 Dispositivos de ligação.............................................................. $\quad 70$

4.2 Dispositivos de ligação utilizados no Brasil................................ $\quad 76$

4.2.1 Nó típico ................................................................ 76

4.2.2 Nó típico com chapa complementar............................... $\quad 78$

4.2.3 Nó com chapa de extremidade (ponteiras).................... $\quad 78$

4.2.4 Nó de aço................................................................. 81

CAPÍTULO 5 - ANÁLISE EXPERIEMENTAL DE TRELIÇAS ESPACIAIS....... 85

5.1 Descrição da estrutura ensaiada................................................ 86

5.2 Instrumentação e metodologia do ensaio....................................... 89

5.3 Resultados experimentais.......................................................... 94

5.3.1 Ensaio de caracterização mecânica do aço................... 94

5.3.2 Ensaio da estrutura................................................ $\quad 95$

CAPÍTULO 6 - ANÁLISE NÃO LINEAR DE TRELIÇAS ESPACIAIS............... 105

6.1 Descrição da análise teórica não linear........................................ 106

6.1.1 Elemento finito utilizado.............................................. 106

6.1.2 Critérios para análise não linear geométrica................. 107

6.1.3Critérios para análise não linear física........................... 108

6.2 Resultado teórico do ensaio de treliça espacial........................... 109

6.2.1 Análise não linear geométrica....................................... 110

6.2.2 Análise não linear física.................................................

6.3 Exemplos de análise não linear de treliças espaciais................... 117

CAPÍTULO 7- CONCLUSÕES........................................................................ 133

REFERÊNCIAS BIBLIOGRÁFICAS .............................................. 137 


\section{RESUMO}

SOUZA, A.S.C. Contribuição ao estudo das estruturas metálicas espaciais. São Carlos, 1998. Dissertação (Mestrado) - Escola de Engenharia de São Carlos, Universidade de São Paulo.

Este trabalho apresenta um estudo sobre as estruturas metálicas espaciais abordando os seguintes aspectos: histórico e desenvolvimento, tipos, vantagens do sistema tridimensional e comportamento estrutural. Atenção especial é dispensada às tipologias de treliças espaciais mais comuns no Brasil, formadas por tubos circulares com variações de inércia nas extremidades. A influência da variação de inércia nas extremidades das barras no comportamento destes elementos isoladamente (resistência à compressão) e comportamento global da estrutura, foi estudada via elementos finitos. Descrevem-se vários sistemas de ligações patenteados utilizados em outros países e os comumente usados no Brasil. Apresentamse resultados experimentais e teóricos de uma treliça espacial com dimensões em planta de 7,5 x 7,5m. Na análise teórica foram considerados a variação de inércia nas barras e os efeitos da não linearidade geométrica. Analisou-se também, com as mesmas considerações anteriores, modelos de treliças espaciais de dimensões maiores que o modelo ensaiado.

Palavras-chave: Estruturas metálicas, estruturas espaciais, treliças espaciais, elementos tubulares, variação de inércia. 


\begin{abstract}
SOUZA, A.S.C. Contribution to the study of space steel structures. São Carlos, 1998. Dissertação (Mestrado) - Escola de Engenharia de São Carlos, Universidade de São Paulo.
\end{abstract}

This work presents a study of space steel structures including the following aspects: history and development, types, advantages of threedimensional system and structural behaviour. It is given special attention to the most common types of space trusses in Brazil, composed of tubular sections bars with flattened ends. The influence of the variable stiffness on each element's behaviour (compressive strength) and on the global structural behaviour has been studied with the use of finite elements. Various patent connection systems used in other countries and those commonly used in Brazil are described. Experimental and theoretical results of a 7,5mlong by $7,5 \mathrm{~m}$-wide space truss are presented. In the theoretical analysis, variable stiffness and effects of geometrical non-linearity have been considered. Still applying the above considerations, larger space truss models have been also analysed.

Keywords: Steel structures, space structures, space trusses, tubular elements, variable stiffness 


\section{LISTA DE SÍMBOLOS}

\section{Romanos maiúsculos}

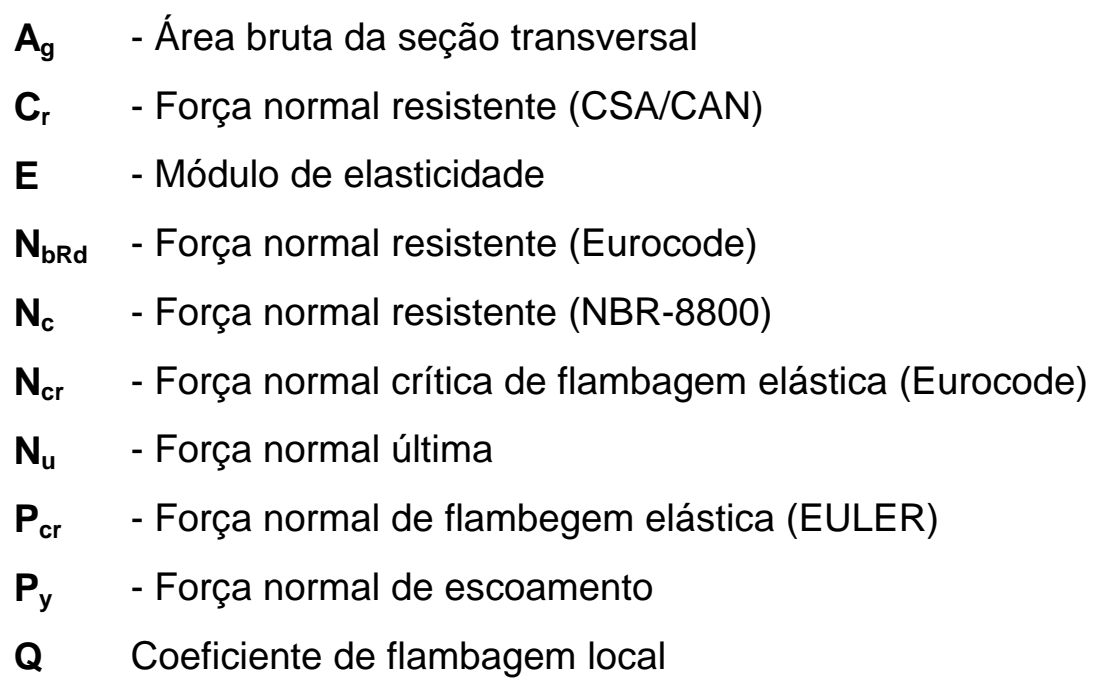

\section{Romanos minúsculos}

$\mathbf{f}_{\mathbf{a}} \quad$ - Tensão admissível à compressão (AISC/ASD)

$\mathbf{f}_{\mathrm{cr}} \quad$ - Tensão crítica de flambagem

$\mathbf{f}_{\mathbf{e}} \quad$ - Tensão de Flambagem elástica

$\mathbf{f}_{\mathbf{e}}{ }^{*} \quad$ - Tensão de flambagem elástica para barras com variação de inércia

$f_{p} \quad$ - Tensão de proporcionalidade

$\mathbf{f}_{\mathrm{u}} \quad$ - Tensão última

$\mathbf{f}_{\mathrm{y}} \quad$ - Tensão de escoamento

r raio de giração

\section{Gregos}

$\lambda \quad$ - Esbeltez

$\bar{\lambda} \quad$ - Esbeltez reduzida

$\bar{\lambda}^{*} \quad$ - Esbeltez reduzida para barras com inércia variável

$\rho \quad$ - Parâmetro de flambagem global

$\theta \quad$ - Diâmetro

$\chi \quad$ - Parâmetro de flambagem global (Eurocode)

$\beta_{\mathrm{A}} \quad$ - Parâmetro de flambagem local (Eurocode)

$\gamma_{\mathrm{M} 1}$ - Coeficiente de minoração da resistência (Eurocede) 


\section{LISTA DE FIGURAS}

Figura 2.1 Treplicas espaciais utilizadas como cobertura.............................. 4

Figura 2.2 Espaço de Celebração Papal, Maceió-AL 1992).......................... 5

Figura 2.3 Ginásio Poliesportivo Nilson Nelson, Brasília (1992/93)............... 6

Figura 2.4 Atrium do Shopping Morumbi, São Paulo-SP (1992)................... 6

Figura 2.5 Arranjo geométrico de estruturas espaciais................................ 7

Figura 2.6 Formas mais comuns de apoios em treliças espaciais................. 8

Figura 2.7 Sistemas de nós comerciais mais conhecidos........................... 10

Figura 2.8 Sistemas de nós utilizados no Brasil........................................... 11

Figura 2.9 Diagrama tensão x deformação para aço carbono (ensaio de tração de corpo de prova).......................................................................... 12

Figura 2.10 Diagrama tensão $x$ deformação para elementos comprimidos com diferentes valores de esbeltez.

Figura 2.11 Modelos constitutivos idealizados para elementos de aço utilizados em treliças espaciais.

Figura 2.12 Ruína progressiva em treliça espacial devido a retirada de um de seus elementos.

Figura 2.13 Colapso do Centro de Convenções de Manaus.

Figura 3.1 Diagrama tensão $x$ deformação para aço com e sem tensões residuais

Figura 3.2 Curvas de flambagem do ECCS (1976).................................... 25

Figura 3.3 Curva de flambagem do CRC................................................. 27

Figura 3.4 Curvas de flambagem do SSRC........................................... 28

Figura 3.5 Curvas de flambagem do EUROCODE.................................... 30

Figura 3.6 Curvas de flambagem da NBR-8800..................................... 33

Figura 3.7 Curva de flambagem do AISC/ASD......................................... 36

Figura 3.8 Curva de flambagem do AISC/LRFD...................................... 37

Figura 3.9 Curvas de flambagem para seções tubulares.............................. $\quad 39$

Figura 3.10 Tipos de extremidades de barras utilizadas em estruturas espaciais.

Figura 3.11 Elemento finito utilizado na análise numérica.

Figura 3.12 Gráfico $(\lambda \times \rho)$ com e sem variação de inércia, variação de 
inércia ao longo da barra $\phi 60 \times 2,0$.

Figura 3.13 Gráfico $(\lambda \times \rho)$ com e sem variação de inércia, variação de inércia ao longo da barra $\phi 64 \times 2,0$.

Figura 3.14 Gráfico $(\lambda \times \rho)$ com e sem variação de inércia, variação de inércia ao longo da barra $\phi 76 \times 2,0$.

Figura 3.15 Gráfico $(\lambda \times \rho)$ com e sem variação de inércia, variação de inércia ao longo da barra $\phi 88 \times 2,65$ (estampagem reta).

Figura 3.16 Gráfico $(\lambda \times \rho)$ com e sem variação de inércia, variação de inércia ao longo da barra $\phi 88 \times 2,65$ (estampagem tradicional)

Figura 3.17 Gráfico $(\lambda \times \rho)$ com e sem variação de inércia, variação de inércia ao longo da barra $\phi 88 \times 2,65$ (estampagem nova)

Figura 3.18 Gráfico $(\lambda \times \rho)$ com e sem variação de inércia, variação de inércia ao longo da barra $\phi 101 \times 3,0$.

Figura 3.19 Gráfico $(\lambda \times \rho)$ com e sem variação de inércia, variação de inércia ao longo da barra $\phi 114 \times 4,25$.

Figura 3.20 Tubo $\phi 88 \times 2,65$ (estampagem reta) chapa de apoio com baixa rigidez - variação de inércia ao longo da barra.

Figura 3.21 Protótipos ensaiados GONÇALVES (1996).

Figura 3.22 Resultados teóricos x experimentais $\phi 76 \times 2,65$ - variação de inércia ao longo da barra.

Figura 3.23 Resultados teóricos $x$ experimentais $\phi 101 \times 3,0$ - variação de inércia ao longo da barra.

Figura 3.24 Resultados teóricos $x$ experimentais $\phi 114 \times 4,25$ - variação de inércia ao longo da barra.

Figura 3.25 Modelos de estampagens ensaiados e aparelho de apoio.....

Figura 3.26 Comparação resultados teóricos x experimentais (estampagem reta)

Figura 3.27 Comparação resultados teóricos x experimentais (estampagem Tradicional)

Figura 3.28 Comparação resultados teóricos x experimentais (estampagem nova).

Figura 3.29 Resultados comparativos entre estampagens (reta, tradicional e nova) $\phi 88 \times 2,65$.

Figura 4.1 Sistema de nó OKTAPLATTE (Alemanha) 
Figura 4.2 Componentes de um sistema de ligação genérico tipo nó esférico.

Figura 4.3 Sistema de ligação MERO (Alemanha)..................................... 72

Figura 4.4 Sistema de ligação VESTRUT (Itália)........................................... 72

Figura 4.5 Sistema de ligação KT (Japão)................................................ 72

Figura 4.6 Sistema de ligação NS (Japão) .................................................. 72

Figura 4.7 Detalhe do sistema de nó VESTRUT.......................................... 73

Figura 4.8 Sistema de ligação Italiano........................................................ 73

Figura 4.9 Sistema de ligação ECO (Itália)................................................ 73

Figura 4.10 Sistema de ligação UNISTRUT (USA)..................................... 74

Figura 4.11 Sistema de ligação NODUS........................................................ 74

Figura 4.12 Sistema de ligação GRIAGAN (Itália).................................... 74

Figura 4.13 Sistema de ligação CATRUS.................................................. 75

Figura 4.14 Nó típico...................................................................... 76

Figura 4.15 Detalhe esquemático nó típico................................................ 77

Figura 4.16 Nó típico com chapa complementar........................................ 78

Figura 4.17 Nó com chapa de ponteira.................................................... $\quad 79$

Figura 4.18 Detalhe esquemático nó com chapa de ponteira....................... 79

Figura 4.19 Ponteiras com aletas perpendiculares enrijecedoras................. $\quad 80$

Figura 4.20 Modelo de ligação analisados por GONÇALVES \&

RIBEIRO(1995)............................................................................... 81

Figura 4.21 Nó de aço...................................................................... 82

Figura 4.22 Detalhe esquemático nó de aço - ALUSUD............................... 82

Figura 4.23 Detalhes diferentes de nós de aço........................................... 83

Figura 5.1- Detalhe da estrutura ensaiada.................................................. 87

Figura 5.2 Detalhe de ligação típico....................................................... 88

Figura 5.3 Detalhe de ligação dos nós de aplicação de carga....................... 89

Figura 5.4 Instrumentação da estrutura...................................................... 90

Figura 5.5 Detalhe da instrumentação da estrutura....................................... 91

Figura 5.6 Detalhe do sistema de aplicação de carga.................................... 92

Figura 5.7 Visão geral do ensaio.............................................................. 92

Figura 5.8 Deslocamentos verticais máximos durante o escorvamento.......... 93

Figura 5.9 Dimensões dos corpos de prova para ensaio de Tração (ASTMA370-92) - medidas em $\mathrm{cm}$. 
Figura 5.10 Configuração dos nós da estrutura após a ruína. 96

Figura 5.11 Numeração de nós e barras da estrutura ensaiada. 96

Figura 5.12 Força aplicada $x$ deslocamentos verticais nó 5 e 6. 97

Figura 5.13 Força aplicada $x$ deslocamentos verticais nó 7 e nó 8. 97

Figura 5.14 Força aplicada x deslocamentos nó 9 (nó central).... 98

Figura 5.15 Força aplicada $x$ deslocamento nó 1 98

Figura 5.16 Força aplicada x deslocamentos nó 2. 99

Figura 5.17 Força aplicada x deformação diagonais de apoio barras 11, 13, 15 e 16 100

Figura 5.18 Força aplicada x deformação banzo superior - barras 3 e $4 \ldots \ldots . .100$

Figura 5.19 Força aplicada $x$ deformação banzo superior - barras 5 e 6...... 101

Figura 5.20 Força aplicada x deformação banzo superior - barras 7 e 8...... 101

Figura 5.21 Força aplicada $x$ deformação banzo superior - barras 9 e 10.... 102

Figura 5.22 Força aplicada x deformação banzo inferior - barras 1 e 2......... 103

Figura 5.23 Força aplicada x deformação diagonais tracionadas - barras 12 e 14

Figura 6.1 Elemento finito utilizado na análise numérica 106

Figura 6.2 Modelo de barra adotado na análise teórica. 107

Figura 6.3 Modelos constitutivos do material adotados na análise...... 108

Figura 6.4 Variação de inércia ao longo do comprimentos das barras para nó típico.

Figura 6.5 Deslocamentos verticais teóricos e experimentais.

Figura 6.6 Deformações axiais teóricas e experimentais diagonais de apoio barras 11 e 13 .

Figura 6.7 Deformações axiais teóricas e experimentais diagonais de apoio barras 15 e 16

Figura 6.8 Deformações axiais teóricas e experimentais banzos superiores barras 3 e 4 .

Figura 6.9 Deformações axiais teóricas e experimentais banzos superiores barras 5 e 6 .

Figura 6.10 Deformações axiais teóricas e experimentais banzos superiores - barras 7 e 8 ......

Figura 6.11 Deformações axiais teóricas e experimentais banzos superiores - barras 9 e 10. 
Figura 6.12 Deformações axiais teóricas e experimentais diagonais tracionadas

Figura 6.13 Deformações axiais teóricas e experimentais banzos inferiores tracionados

Figura 6.14 Força aplica $x$ deslocamentos verticais modelo com NLF.

Figura 6.15 Força aplica $x$ deformação diagonal de apoio - barras 11 e 13...

Figura 6.16 Força aplica x deformação diagonal de apoio - barras 15 e 16...

Figura 6.17 Força aplica x deformação diagonal tracionada - barras 12 /14..

Figura 6.18 Força aplica x deformação banzo superior - barras 1 e 2........... 120

Figura 6.19 Força aplica x deformação banzo superior - barras 3 e 4........... 121

Figura 6.20 Força aplica $x$ deformação banzo superior - barras 5 e $6 \ldots \ldots \ldots \ldots . .121$

Figura 6.21 Força aplica x deformação banzo superior - barras 7 e 8 ........... 122

Figura 6.22- Treliça espacial.- modelo 1............................................... 123

Figura 6.23- Treliça espacial. - modelo 2 .............................................. 124

Figura 6.24-Diemensionamento banzo inferior - modelo 1 ......................... 126

Figura 6.25 Variação de inércia ao longo do comprimento das barras para o modelo 1

Figura 6.26 Variação de inércia ao longo do comprimento das barras para o modelo 2

Figura 6.27 Força aplicada $x$ deslocamentos máximos.

Figura 6.28 Força aplicada $x$ esforço normal - diagonal de apoio......

Figura 6.29 Força aplicada $x$ esforço normal - diagonal tracionada.

Figura 6.30 Força aplicada $x$ esforço normal - banzo superior 


\section{LISTA DE TABELAS}

Tabela 2.1 Recomendações para altura de treliças espaciais

Tabela 3.1 Classificação dos perfis por curvas de flambagem. EUROCODE (1992)

Tabela 3.2 Classificação dos perfis por curvas de flambagem. NBR-8800 (1988)

Tabela 3.3. Diâmetros selecionados para estudo.

Tabela 3.4 Resultados de coeficientes de flambagem (tubo $\phi 60 \times 2,0$ ).

Tabela 3.5 Resultados de coeficientes de flambagem (tubo $\phi 64 \times 2,0$ ).

Tabela 3.6 Resultados de coeficientes de flambagem (tubo $\phi 76 \times 2,0$ ).

Tabela 3.7 Resultados de coeficientes de flambagem (tubo $\phi 88 \times 2,65$ ) estampagem reta.

Tabela 3.8 Resultados de coeficientes de flambagem (tubo $\phi 88 \times 2,65$ ) estampagem tradicional.

Tabela 3.9 Resultados de coeficientes de flambagem (tubo $\phi 88 \times 2,65$ ) estampagem nova

Tabela 3.10 Resultados de coeficientes de flambagem (tubo $\phi 101 \times 3,0$ )

Tabela 3.11 Resultados de coeficientes de flambagem (tubo $\phi 114 \times 4,25) \ldots .$.

Tabela 3.12 Grupos de protótipos ensaiados por GONÇALVES (1996)

Tabela 3.13 Resultados experimentais de força normal resistente para barras circulares com variações de inércia. GONÇALVES (1996)......

Tabela 3.14 Comparação resultados teóricos $x$ experimentais (barra birotulada)

Tabela 3.15 Comparação resultados teóricos $x$ experimentais (barra rotulada - engastada)

Tabela 3.16 Resultados experimentais de força normal Resistente para barras circulares com extremidades estampadas. MALITE (1997).

Tabela 3.17 Estampagem reta (barra bi-rotulada)

Tabela 3.18 Estampagem tradicional (barra bi-rotulada)....

Tabela 3.19 Estampagem nova (barra bi-rotulada).

Tabela 3.20 Estampagem reta (barra engastada-rotulada). 66

Tabela 3.20 Estampagem tradicional (barra engastada-rotulada). 
Tabela 3.22 Estampagem nova (barra engastada-rotulada)........................ 66

Tabela 5.1- Seções dos elementos da treliça e resistência a compressão..... 87

Tabela 5.2 Resultados da caracterização mecânica do aço.......................... 95

Tabela 6.1- Força normal resistente das barras utilizadas nos protótipos..... 110

Tabela 6.2 Seções dos tubos utilizados nos modelos................................. 122 


\section{INTRODUÇÃO

Este trabalho tem como objetivo uma contribuição ao estudo do comportamento das estruturas espaciais e seus elementos.

Foram analisados, via método dos elementos finitos, os modelos de estruturas espaciais usadas no Brasil, ou seja, treliças espaciais formadas por elementos tubulares, predominantemente circular, com variação de inércia nas extremidades. As treliças em estudo são do tipo duas camadas paralelas e horizontais, interligadas por diagonais esconsas.

Para atingir tal objetivo faz-se necessário um estudo dos elementos comprimidos utilizados nestas estruturas, no que diz respeito ao seu comportamento enquanto barra isolada e como elemento de um sistema estrutural espacial. O comportamento destes elementos de uma estrutura espacial é influenciado por vários aspectos tais como: excentricidades nas ligações, rigidez dos nós, variação de inércia nas extremidades das barras (predominante no sistema de conexão entre barras, empregado no Brasil).

Inicialmente, no segundo capítulo, serão discutidos os aspectos gerais, histórico, pesquisas desenvolvidas e em desenvolvimento, sobre as estruturas espaciais.

Apresenta-se, no terceiro capítulo, o estudo de barras comprimidas usadas comumente no Brasil, ou seja, elementos tubulares de seção circular com variação de inércia nas extremidades, causadas por amassamento ou por associação de chapas para compor a ligação entre eles. 
As ligações entre elementos tubulares com e sem variação de inércia, foi o objeto de estudo do quarto capítulo. São discutidos os sistemas de nós mais utilizados em outros países e, os sistemas de ligações de uso comum no Brasil serão discutidos em detalhes.

Apresenta-se no quinto capítulo os resultados experimentais obtidos de um ensaio em uma treliça espacial com dimensões em planta de $7500 \mathrm{~mm} \times 7500 \mathrm{~mm}$ e altura de $1500 \mathrm{~mm}$.

No sexto capítulo, são analisados protótipos de estruturas espaciais, com o intuito de avaliar o seu comportamento quando são inseridas na análise, variação de inércia nas extremidades dos elementos, considerandose, também, os efeitos da não linearidades física e geométrica.

Finalmente apresenta-se algumas conclusões sobre 0 comportamento das estruturas espaciais e seus elementos.

Algumas dificuldades foram encontradas durante a realização deste trabalho. A principal delas foi a inadequação dos programas de análise estrutural disponíveis, ao tipo de problema tratado nesta dissertação. 0 programa LUSAS ${ }^{1}$, utilizado neste trabalho, devido às suas características (processamento e pós-processamento), são mais adequados para análise de estruturas contínuas (placas, cascas e etc.). Os elementos utilizáveis em estruturas reticuladas (barras e vigas) disponíveis no programa LUSAS oferecem limitações no que diz respeito a análise não linear. Entretanto, apesar das restrições realizou-se grande parte do que se propunha inicialmente.

${ }^{1}$ LUSAS: Finite Element Analysis (FEA), Revision 11, Surrey - UK, 1996. 


\section{ESTRUTURAS ESPACIAIS: ASPECTOS GERAIS}

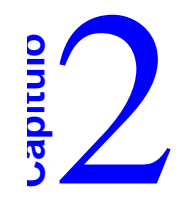

\subsection{Generalidades}

Os registros mais antigos de estruturas espaciais datam dos séculos XVIII e XIX, na França e Alemanha, respectivamente. Em 1906 Alexander Graham Bell desenvolveu um sistema de estrutura espacial pré-fabricado para construção de torres, trabalho este que pode ser considerado pioneiro como projeto racional de estruturas espaciais.

Nos dias atuais o uso de estruturas espaciais está consagrado e vem crescendo em todo o mundo. $O$ fator mais importante do desenvolvimento das estruturas espaciais foi o grande número de pesquisas, abordando diversos aspectos do seu comportamento e projeto.

O Committee on Spacial Structures - ASCE $(1972,1976)$ reúne uma vasta bibliografia contendo os principais trabalhos sobre estruturas espaciais até então publicados.

O termo estruturas espaciais é muito genérico, MAKOWSKI (1987) faz uma subdivisão em três grupos: estruturas em cabos, estruturas laminares e estruturas reticuladas, que são as mais utilizadas e nas quais estão incluídas as treliças espaciais.

MAGALHÃES (1996) ressalta ainda que o termo estrutura espacial pode se referir a uma infinidade de estruturas assim definidas, dependendo da interpretação e do tipo de hipótese de cálculo empregadas. Neste 
trabalho a designação estrutura espacial refere-se, exceto quando houver menção em contrário, à treliça espacial.

A Figura 2.1 apresenta dois exemplos de treliças espaciais: uma revenda de automóveis e um terminal de ônibus.
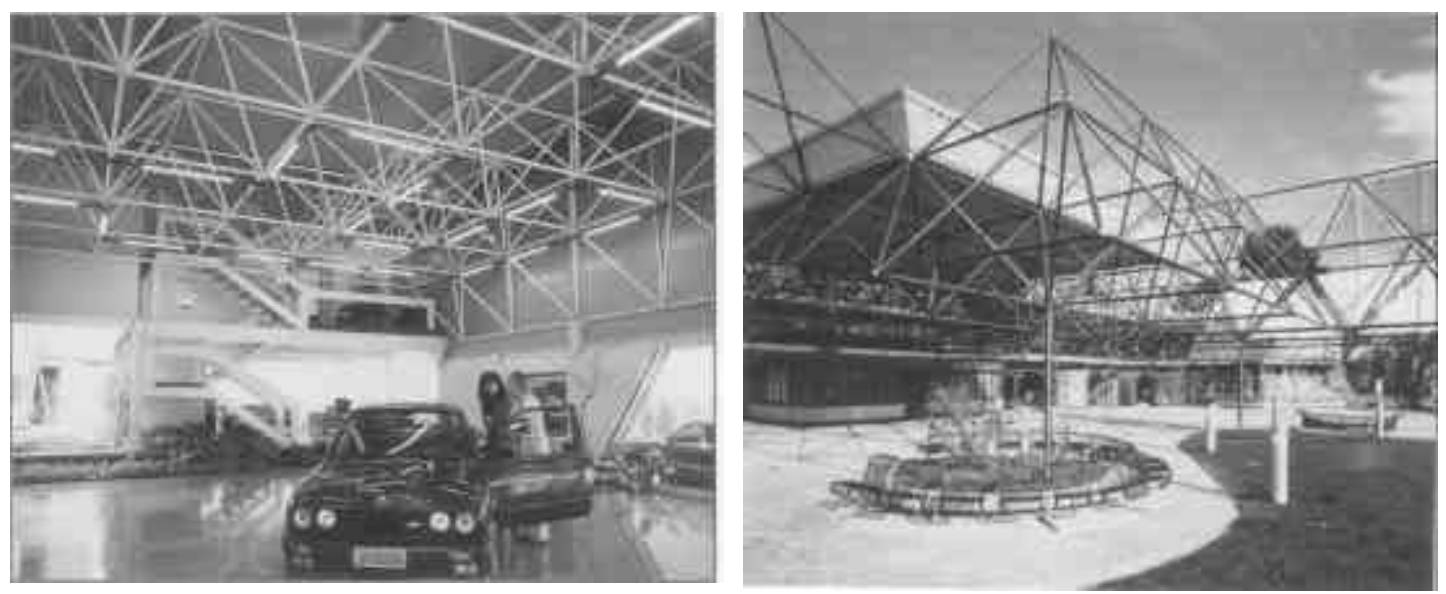

Figura 2.1 Treliças espaciais utilizadas como cobertura.

Outras razões para o desenvolvimento das estruturas espaciais são as vantagens que o sistema oferece. MAKOWSKI (1984), um dos principais pesquisadores sobre estruturas espaciais, aponta alguns aspectos dessas estruturas que as tornam um sistema estrutural vantajoso:

- as estruturas espaciais possuem peso próprio reduzido e grande rigidez sendo, portanto, uma solução viável para cobrir grandes vãos livres, tais como: ginásios esportivos, hangares, pavilhões de exposição, etc;

- devido ao seu comportamento tridimensional e alto grau de hiperasticidade apresentam boa redistribuição de esforços;

- por serem constituídas de elementos com peso próprio reduzido são facilmente transportadas, a fabricação é simples e apresenta grande repetitividade de elementos, o que resulta na redução de custos (basicamente para grandes vãos) se comparado com estruturas convencionais;

- as estruturas espaciais propiciam grande liberdade aos arquitetos, permitindo que esses projetem grandes vãos, atendendo à necessidade de 
espaço e ainda tirem partido arquitetônico da estrutura, conferindo ao mesmo tempo, estética e funcionalidade às edificações.

Treliça espacial é um sistema estrutural com aplicações das mais diversas. Exemplo de treliça espacial funcionando em conjunto com laje de concreto para suportar carregamento de piso é apresentado por GIULIANI \& GIULIANI (1996). Um estudo mais detalhado deste tipo de utilização das treliças espaciais como sistema misto de piso é apresentado por ELSHEIKH (1993).

As treliças espaciais podem ser utilizadas também em pontes. Estudos que indicam esta possibilidade foram realizados por SEBASTIAN et. al. (1993) e ASHRAF et al. (1993).

No entanto, a utilização predominante das treliças espaciais é, sem dúvida, em grandes coberturas em que se exige muito espaço livre acarretando vãos de comprimentos elevados.

Em seguida serão apresentados exemplos de algumas obras brasileiras que utilizam estruturas espaciais.

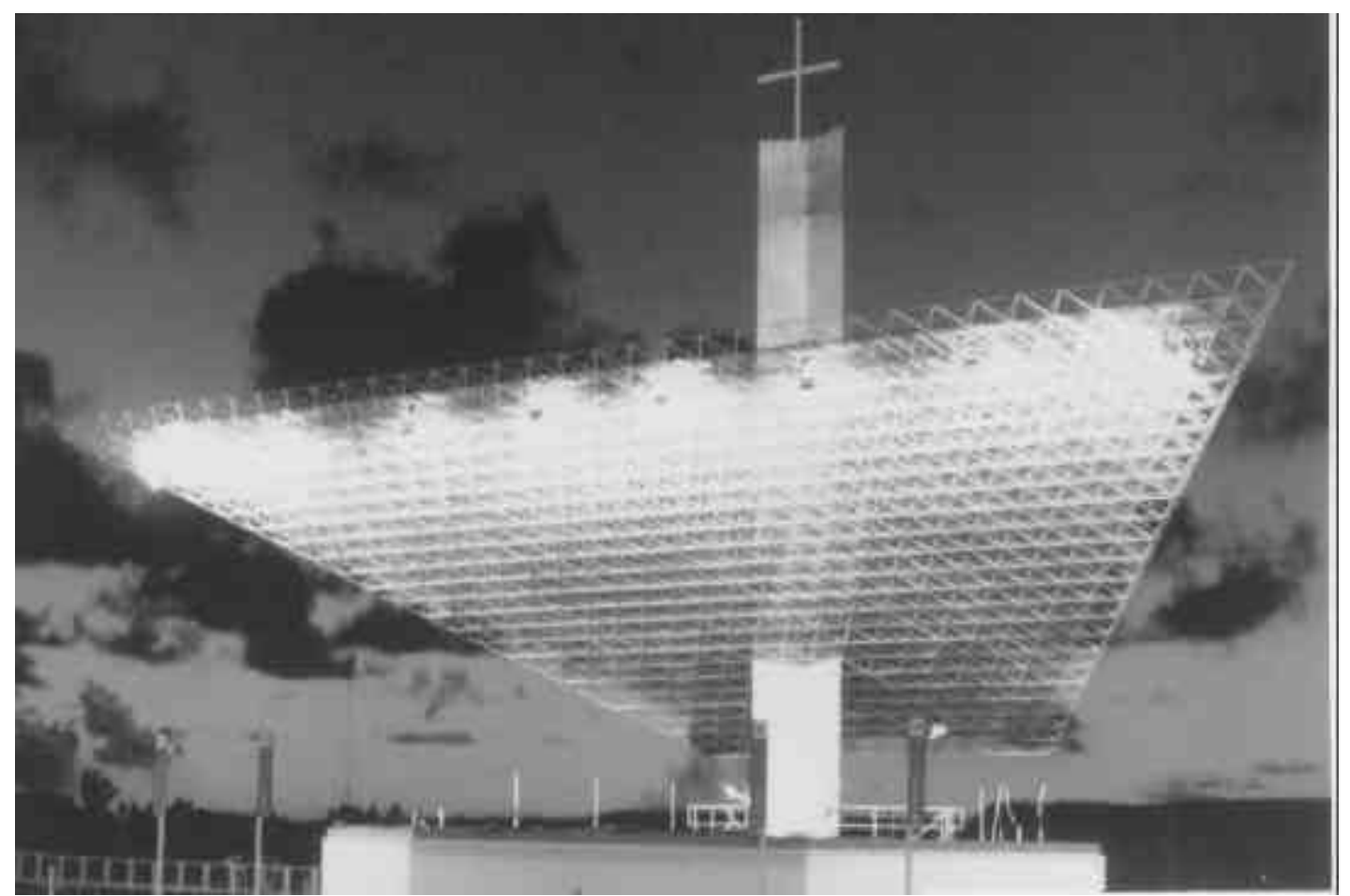

Figura 2.2 Espaço de Celebração Papal, Maceió-AL (1992) 


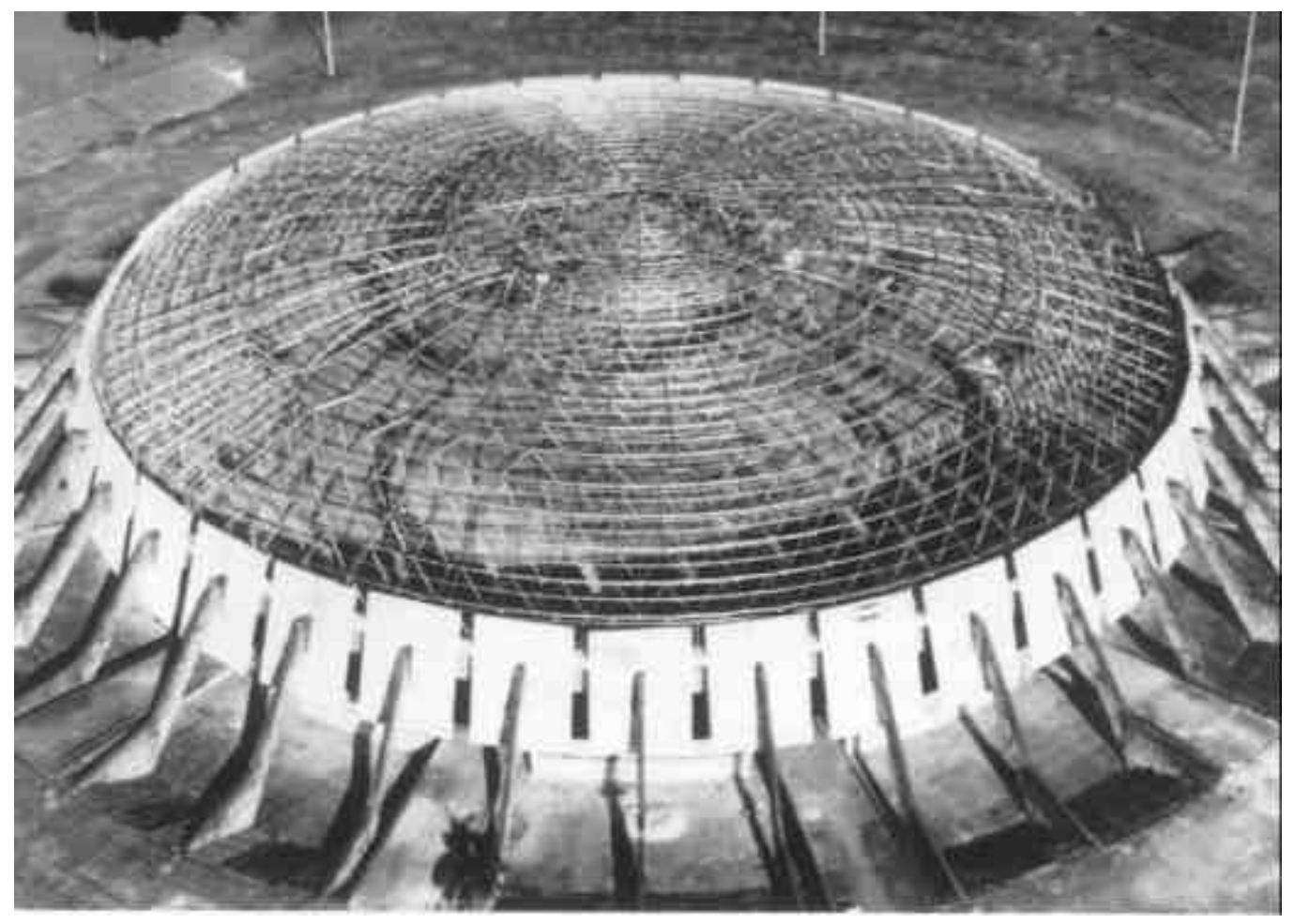

Figura 2.3 Ginásio Poliesportivo Nilson Nelson. Brasília (1992/93)

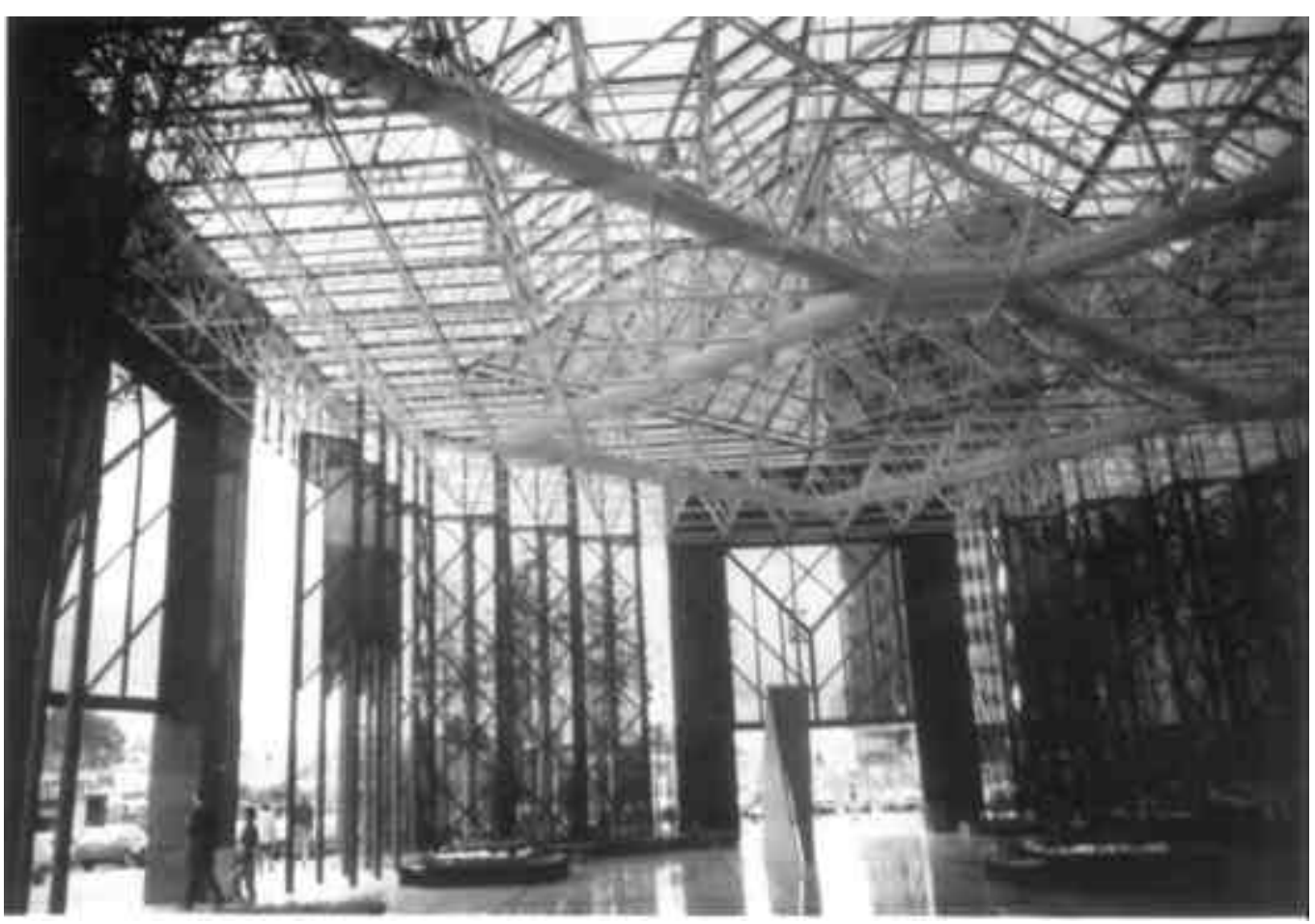

Figura 2.4 Atrium do Shopping Morumbi. São Paulo-SP (1992) 


\subsubsection{Tipos de treliças espaciais}

No que diz respeito ao projeto de estruturas espaciais MAKOWSKI (1981) e IFFLAND (1982) discutem critérios para elaboração de um projeto preliminar. São apresentadas várias possibilidades de arranjo dos elementos que, em elevação, podem ser de uma, duas ou três camadas paralelas. Quanto ao arranjo em planta tem-se: quadrado sobre quadrado (com ou sem aberturas internas), quadrado diagonal sobre quadrado diagonal, entre outras (Figura 2.5).

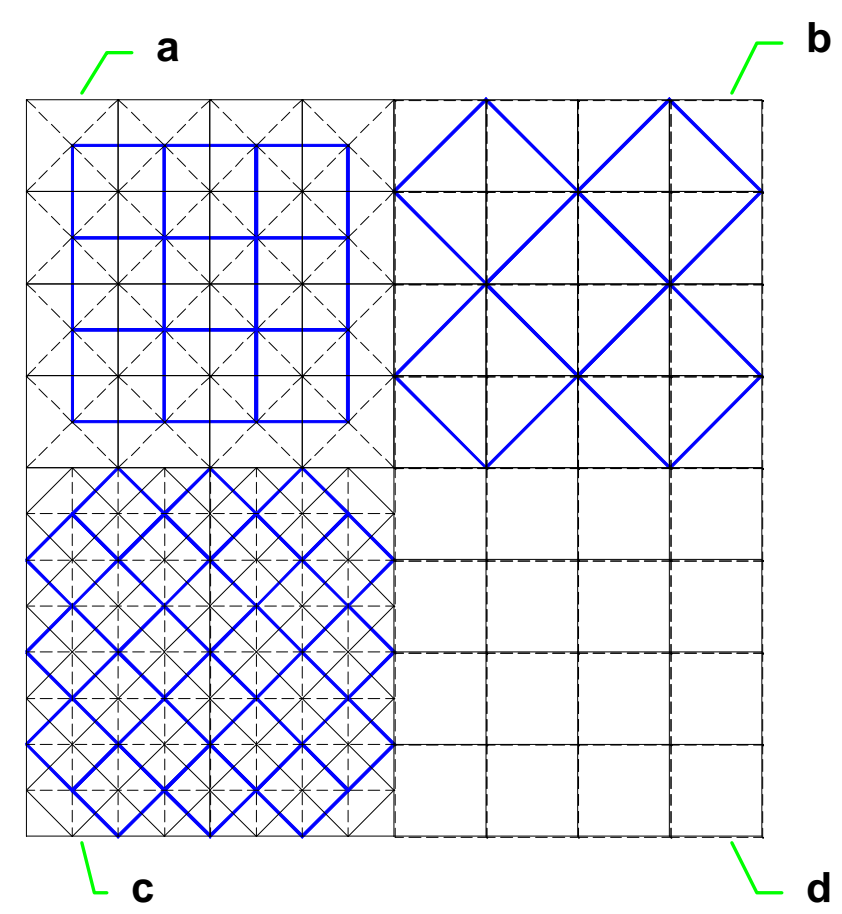

Figura 2.5- Arranjo geométrico de estruturas espaciais: a) quadrado sobre quadrado; b) quadrado sobre quadrado em diagonal, c) quadrado diagonal sobre quadrado diagonal; d) quadrado sobre quadrado sem diagonais esconsas.

Quanto à forma e tipo de apoio, são várias as possibilidades, os mais comuns são apresentados na Figura 2.6. 


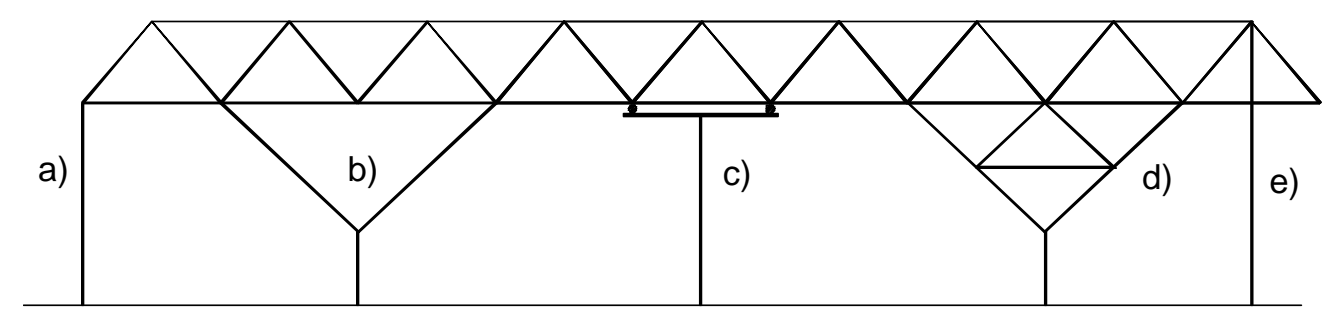

Figura 2.6 Formas mais comuns de apoios em treliças espaciais. a) apoio direto no banzo inferior; b)pé de galinha; c)apoio com viga de transição; d)pé de galinha com travejamento interno; e)apoio direto no banzo superior.

Para a altura das treliças espaciais, encontra-se na literatura as seguintes recomendações apresentadas na tabela 2.1 .

Tabela 2.1 Recomendações para altura de treliças espaciais.

\begin{tabular}{|c|c|}
\hline Altura da Treliça & $\begin{array}{c}\text { Recomendação } \\
\text { MORONI (1976) }\end{array}$ \\
\hline$\frac{\ell}{30} \mathrm{a} \frac{\ell}{40} \mathrm{a} \frac{\ell}{40}$ & MAKOWSKI (1981) \\
\hline$\frac{\ell}{20} \mathrm{a} \frac{\ell}{60}$ & IFFLAND (1982) \\
\hline$\frac{\ell}{15} \mathrm{a} \frac{\ell}{20}$ & AGERSKOV (1986) \\
\hline As variações entre as recomendações para altura das treliças
\end{tabular}

espaciais, pode ser atribuída a utilização de sistemas estruturais diferentes (sistemas de ligação e tipos de elementos), como também a consideração de carregamentos comuns em alguns países (neve e sismos por exemplo).

\subsubsection{Métodos de análise}

A evolução das técnicas de análise, juntamente com a utilização dos computadores, foi sem dúvida um fator impulsionador do desenvolvimento e 
uso de estruturas espaciais. Segundo BUTTERWORTH (1981) as técnicas de análise podem ser agrupadas como segue:

- métodos experimentais;

- métodos clássicos de mecânica do contínuo;

- método dos elementos finitos;

- análise empregando analogia com meio contínuo (analogia de placas);

- método das diferenças finitas.

Na prática corrente dos projetistas, o mais usado é o método dos elementos finitos, que é empregado na elaboração de programas comerciais. Para pré-dimensionamento, a analogia de placas apresenta resultados bastante satisfatórios como destaca FLOWER \& SCHMIDT (1971). MAGALHÃES (1996) faz uso e desenvolve exemplos de estruturas analisadas através dessas técnicas.

\subsection{Ligações e elementos utilizados em estruturas} espaciais

Em estruturas espaciais pode-se usar os mais variados tipos de perfis, tais como: cantoneiras, perfis cartola, tubos circulares e retangulares, entre outros. A escolha do tipo de perfil depende da finalidade da estrutura, nível de solicitação das barras e, principalmente, do sistema de conexão que se pretende ou se pode utilizar.

As conexões entre elementos de treliças espaciais são um dos fatores que tem maior influência no custo total da estrutura, além de exercer sensível influência em seu comportamento. MAKOWSKI (1981) apresenta uma grande variedade de sistemas de conexão patenteados e descreve, em detalhes, alguns dos mais conhecidos, os quais estão representados na Figura 2.7. 


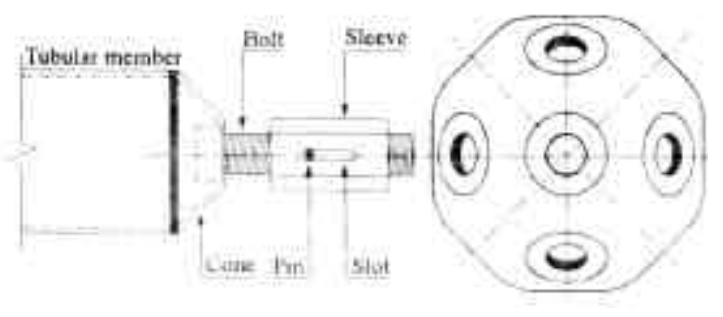

MERO

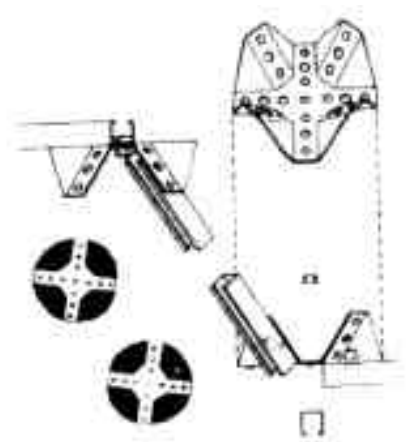

UNISTRUT

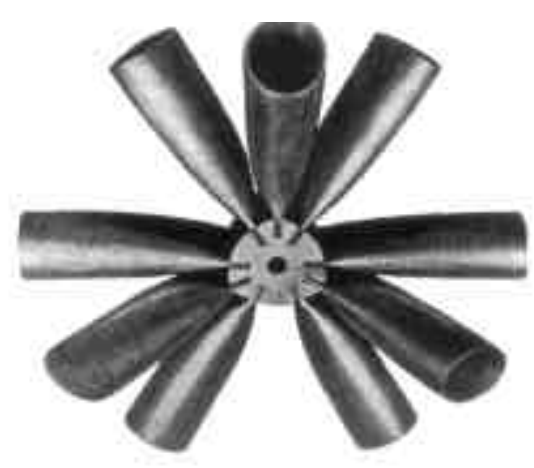

TRIODETIC

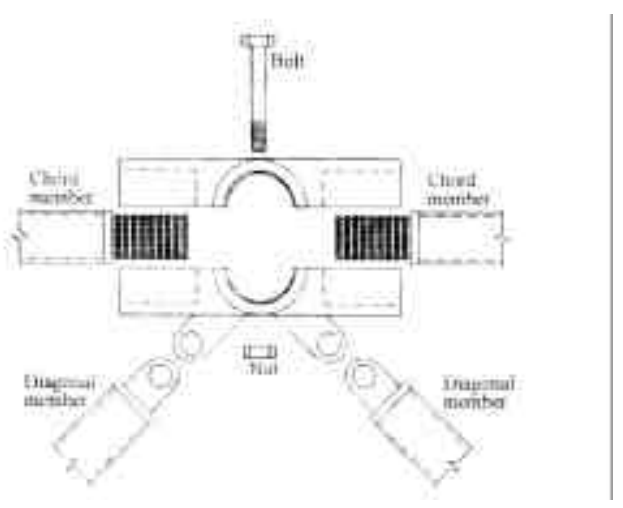

NODUS

Figura 2.7- Sistema de nós comerciais mais conhecidos.

No Brasil, os sistemas de nós patenteados são pouco utilizados; a maioria das estruturas espaciais compõem-se de barras de seção tubular circular com extremidades amassadas, unidas por um ou mais parafusos, compondo os nós, com e sem utilização de chapas de ligação. A Figura 2.8 ilustra detalhes desses nós. 


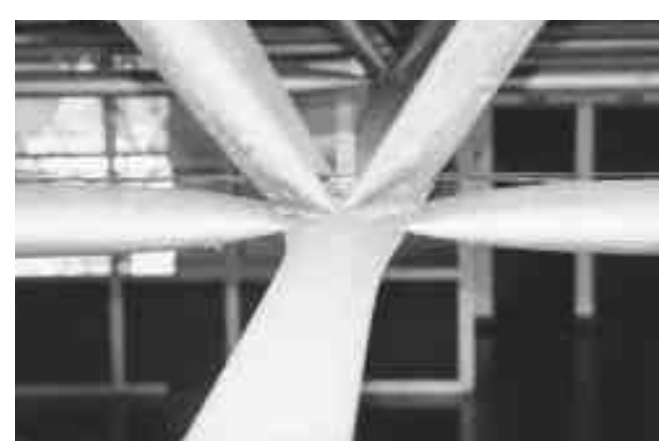

a) Nó típico parafuso único

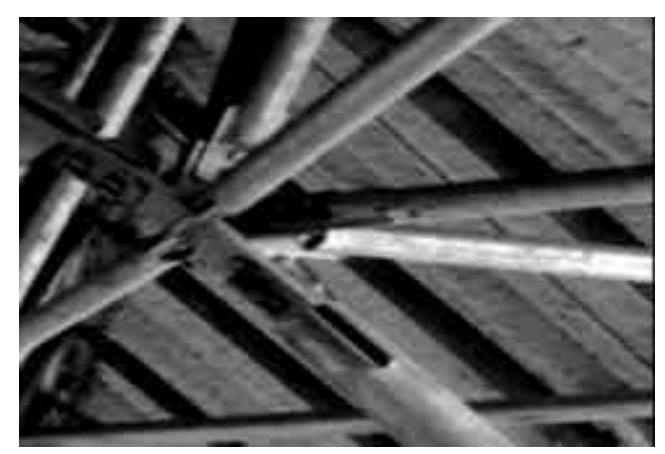

c) Nó com chapa de Ponteira

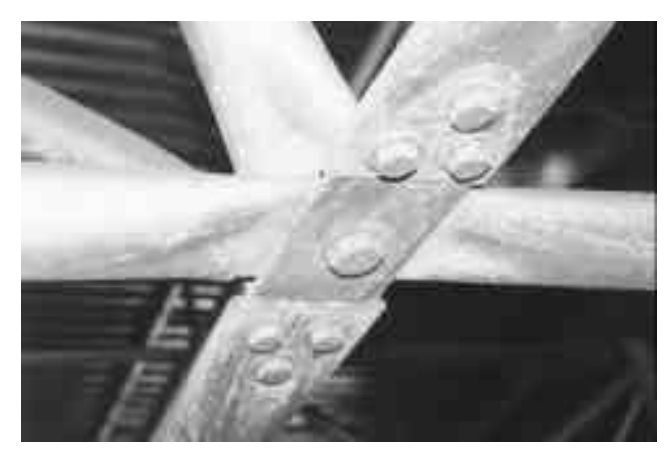

b) Nó típico com chapa complementar

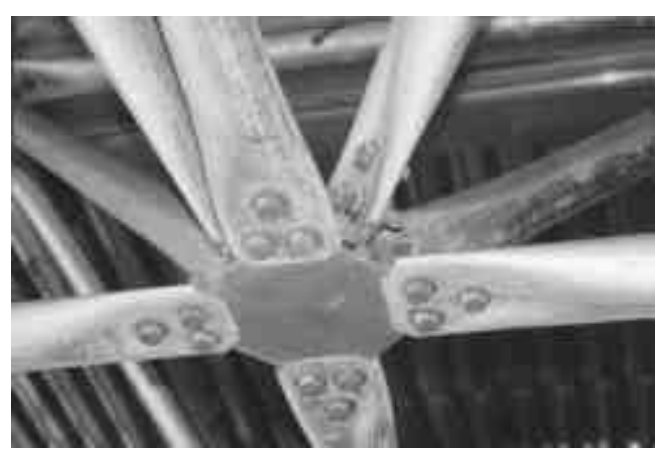

d) Nó de aço

Figura 2.8- Sistemas de nós utilizados no Brasil ${ }^{1}$.

Os sistemas de nós apresentados na Figura 2.8, têm larga aplicação no Brasil devido, principalmente, ao seu baixo custo em relação aos sistemas patenteados, porém, não existem estudos conclusivos que determinem o comportamento dessas ligações ou validem as hipóteses de cálculo normalmente assumidas pelos projetistas.

No capítulo 4 os sistemas de ligações utilizados em treliças espaciais serão apresentados e estudados com maiores detalhes.

\subsection{Comportamento não linear}

O comportamento não linear em algum elemento de uma treliça espacial gera características não lineares na estrutura como um todo.

\footnotetext{
${ }^{1}$ A nomenclatura apresentada para estes nós é utilizada quotidianamente no Departamento de Estrutura da EESC, portanto, não se trata de termo técnico reconhecido por toda comunidade cientifica.
} 
Entretanto, em função da alta redundância interna destas estruturas pode existir reservas de segurança.

Segundo HILL et al. (1989) o comportamento de sistemas estruturais espaciais, em sua grande maioria, só pode ser adequadamente avaliado quando ambas, não linearidade geométrica e física, são consideradas.

A não linearidade geométrica está associada ao equilíbrio de um sistema estrutural na posição deslocada. É necessária a consideração da não linearidade geométrica quando a configuração deformada da estrutura é significativamente diferente da configuração inicial (grandes deslocamentos).

A não linearidade física diz respeito ao comportamento não linear da relação tensão $x$ deformação do material.

Para se realizar uma análise não linear física, é necessário idealizar um modelo constitutivo (tensão $x$ deformação) para o material. Para os elementos tracionados o diagrama tensão $x$ deformação é facilmente obtido de um ensaio de tração. Pela Figura 2.9a é fácil perceber que um diagrama tensão $\mathrm{x}$ deformação elasto-plástico perfeito é uma boa aproximação para o comportamento de elementos tracionados.

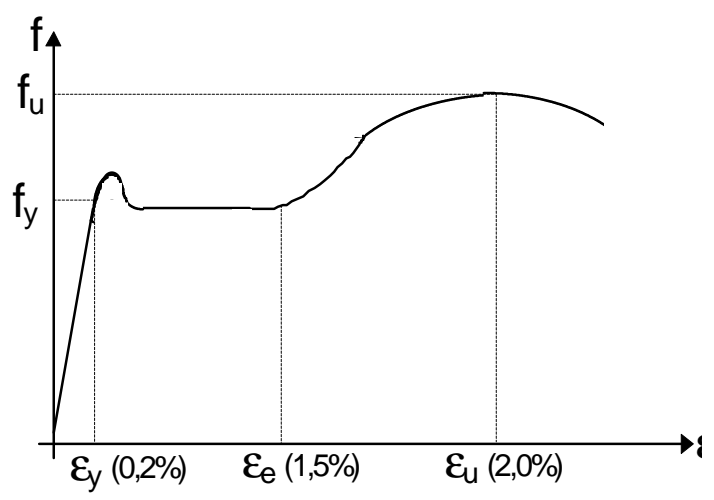

a)

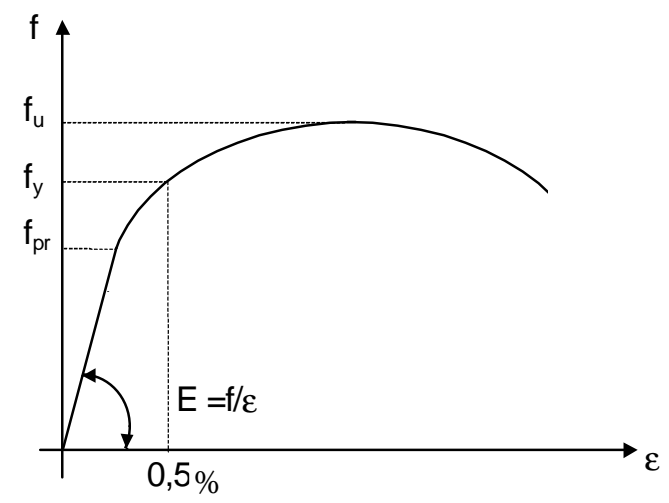

b)

Figura 2.9 a) Esquema do diagrama tensão $x$ deformação para aço carbono (ensaio de corpo de prova), b) Diagrama tensão $x$ deformação para aço carbono com a presença de tensões residuais 
Entretanto, para elementos comprimidos é um pouco mais complicado equacionar o comportamento tensão $x$ deformação, pois devese considerar 0 efeito da flambagem. A flambagem destes elementos depende, além das características do material, da esbeltez e das condições de vinculação. A Figura 2.10 mostra o comportamento tensão x deformação para elementos comprimidos com vários valores de esbeltez.

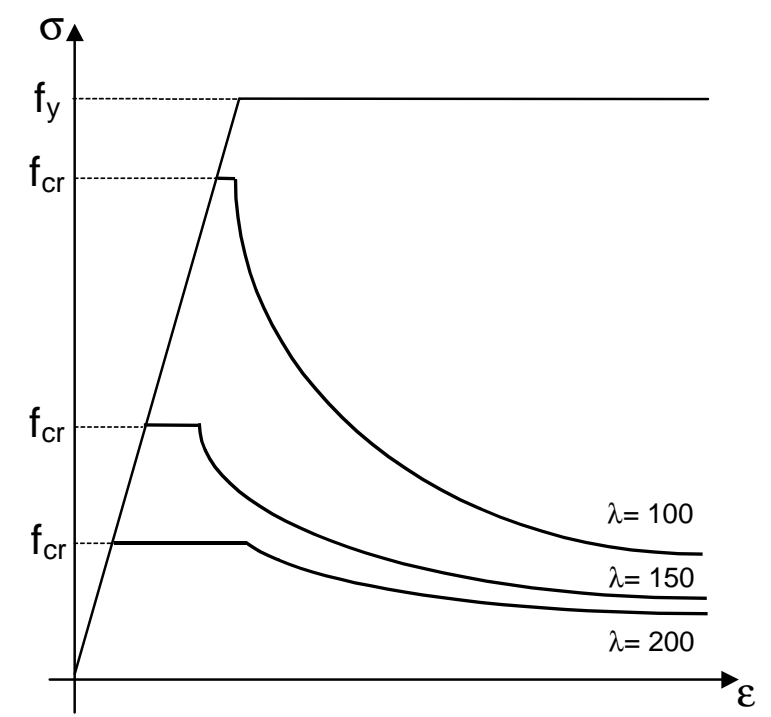

Figura 2.10 Diagrama esquemático do comportamento tensão $x$ deformação para elementos comprimidos com diferentes valores de esbeltez.

Segundo MADI (1984) o diagrama tensão x deformação para elementos comprimidos pode ser dividido em três fases: fase estável, iniciase com o carregamento e se estende até a carga crítica; fase de "amolecimento", que corresponde a manutenção da capacidade de carga com aumento de deformações; e a fase plástica onde consegue-se manter uma capacidade resistente residual constante. A figura $2.11 \mathrm{c}$ ilustra um diagrama tensão x deformação com as três fases descritas acima.

SUPPLA \& COLLINS (1981) e MADI (1984) apresentaram e discutiram alguns modelos constitutivos de material utilizados em análise não linear de estruturas espaciais de aço. Alguns desses são reproduzidos na Figura 2.11, nos gráficos desta figura as curvas do primeiro quadrante 
correspondem a tensões de compressão, enquanto as curvas do terceiro quadrante a tensões de tração.

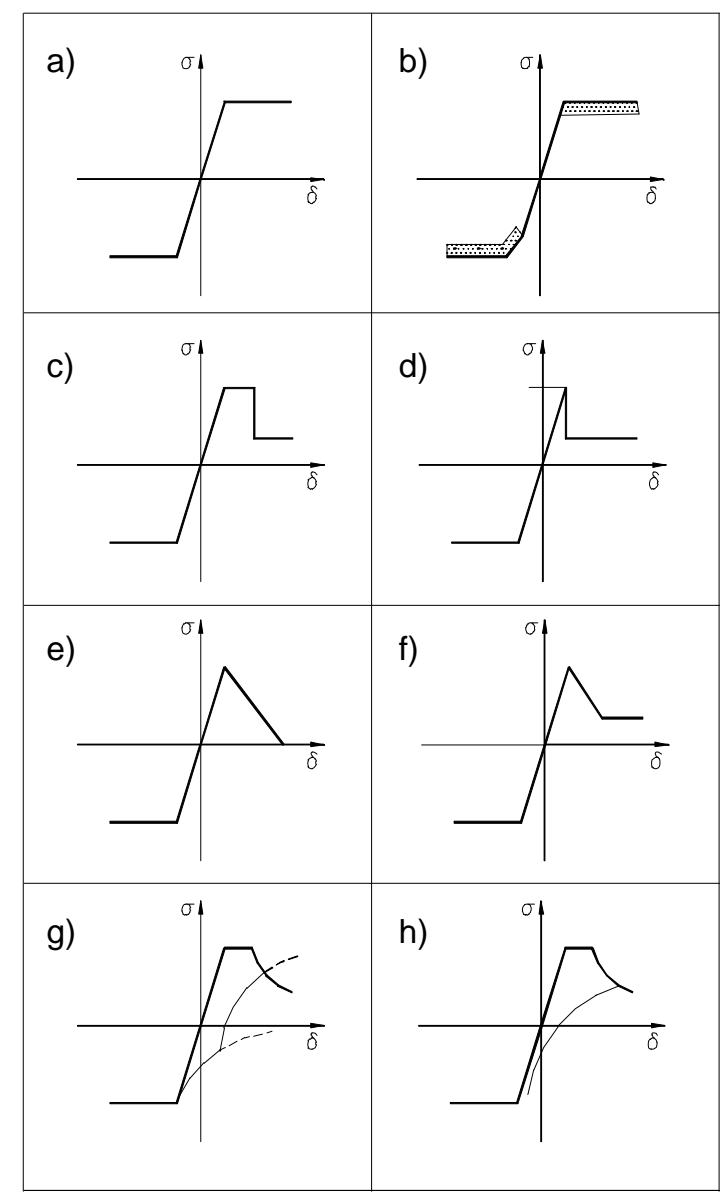

Figura 2.11- Modelos constitutivos idealizados para elementos de aço utilizados em treliças espaciais.

Para o caso a) é admitido comportamento elasto-plástico perfeito na tração e compressão, o que não é uma boa aproximação para elementos comprimidos.

Em b) são adicionadas faixas de ruína, ou seja, se a tensão crítica obtida se encontrar nesta faixa indicará a falha do elemento.

No gráfico c) existe um patamar com aumento de deformações para cargas constantes e em seguida uma brusca queda na capacidade resistente do elemento, conservando ainda uma capacidade resistente residual. 
Em d) o comportamento é semelhante, porém, o patamar referido acima não existe.

No comportamento representado pelos gráficos e) e f), após atingida a carga crítica, a capacidade resistente do elemento decresce linearmente. Em f) é admitida uma capacidade resistente residual.

Nos gráficos g) e h) são introduzidas características não lineares para o regime pós-crítico e curvas de descarregamento.

PAPADRAKAKIS (1983) usou expressões analíticas para representar vários modelos de comportamento, e objetivava traçar a curva ação aplicada $x$ deslocamentos para treliças espaciais além do ponto limite ,ou seja, em regime pós-crítico.

HILL et al. (1989) desenvolveram um modelo em elementos finitos baseado na formulação LAGRANGEANA para representar, de maneira mais realística, a resposta da estrutura. $O$ modelo traça a curva ação aplicada $x$ deslocamentos para a estrutura em regime pós-crítico usando equações constitutivas apropriadas para comportamento elástico, pós-flambagem elástica e inelástica, escoamento e plastificação.

\subsection{Mecanismos de colapso}

O colapso das estruturas espaciais é governado, predominantemente, pela flambagem sucessiva de elementos comprimidos.

Para índices de esbeltez usuais em projetos, a flambagem dos elementos comprimidos acarreta em perda de estabilidade repentina e por essa razão, as estruturas espaciais, de maneira geral, apresentam ruptura súbita sem grandes deformações. Este comportamento das treliças espaciais já havia sido confirmado experimentalmente por SCHMIDT et al. (1976).

Outro mecanismo de colapso possível é a instabilidade, elástica ou inélastica dos elementos de conexão (juntas ou nós). Algumas tipologias de nós utilizadas no Brasil são bastante suscetíveis a este problema. 
Segundo PAPADRAKAKIS (1983) a falha de um elemento não implica, necessariamente, no colapso da estrutura, uma vez que as estruturas espaciais podem possuir reservas de segurança devido ao seu alto grau de indeterminação estática.

LAN (1991) descreveu vários casos típicos de ruína em treliças espaciais. Tais catástrofes, caracterizadas por colapso repentino, mostram claramente a necessidade de modelos de análise que representem verdadeiramente 0 comportamento das estruturas espaciais. Muitas estruturas requerem apenas a consideração da não linearidade do material associada com o modelo de flambagem dos elementos. No entanto, algumas estruturas mais complexas e peculiares requerem ainda a consideração da não linearidade geométrica.

MURTHA-SMITH (1988) desenvolveu um método alternativo para analisar o ruína progressiva, (ou seja, propagação de falha nos elementos da estrutura que a leva a colapso) de estruturas espaciais devido a perda da capacidade resistente de um dos elementos nestas estruturas. O método avalia o efeito da perda de um dos elementos sobre a segurança da estrutura. $O$ fator de segurança dos elementos remanescentes, individualmente e da estrutura, foram avaliados usando a análise linear e não linear respectivamente.

$O$ autor analisa um modelo de treliça espacial removendo diferentes elementos. Constatou-se que a retirada de um elemento compromete a segurança de uma grande quantidade dos elementos remanescentes, principalmente se o elemento retirado for uma das diagonais de apoio ou banzos da região central.

A análise não linear demonstrou que, para o caso mais crítico de elementos removidos, a estrutura apresenta um baixo fator de segurança de apenas $6 \%$. É sugerido, pelo autor, que o prosseguimento dos estudos sobre ruína progressiva considere o efeito de alguns parâmetros, tais como: quantidade e localização dos apoios, tipos de elementos e razão vão/altura. 
Seguindo a sugestão de MURTHA-SMITH (1988), MURTHA-SMITH \& LEARY (1993) analisaram o comportamento de treliças espaciais sob a influência dos seguintes parâmetros:

- quantidade e localização dos apoios;

- relação vão/tamanho do módulo;

- relação altura/vão,

- relação maior vão/menor vão.

Dos parâmetros analisados, a localização dos apoios tem maior influência no comportamento das treliças espaciais, e sobretudo na propagação da ruína. A pior situação é aquela com apoios somente nos cantos. Os demais parâmetros não tem influência significativa na propagação da ruína das treliças espaciais. A Figura 2.12 apresenta o comportamento quanto à propagação de colapso, de duas treliças espaciais com diferentes condições de apoio, quando é retirado um elemento da estrutura.

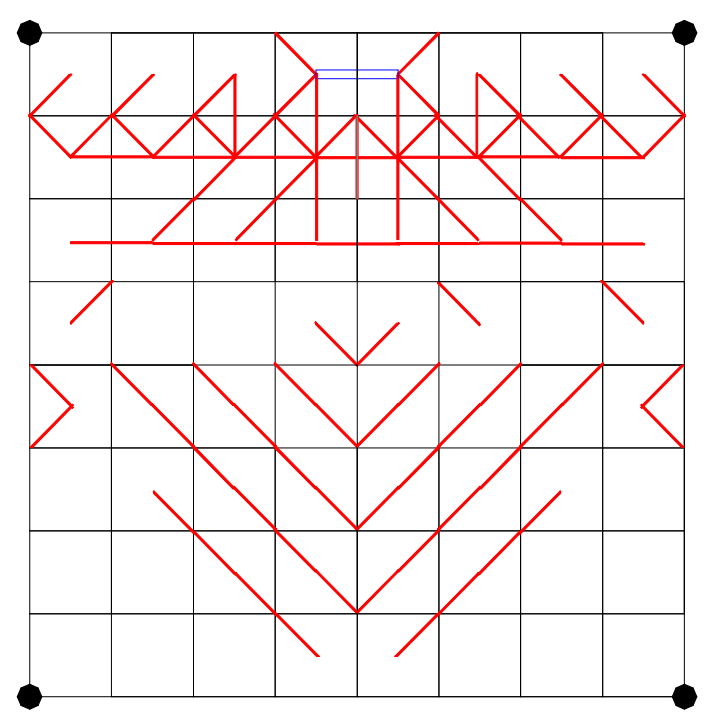

Elemento retirado

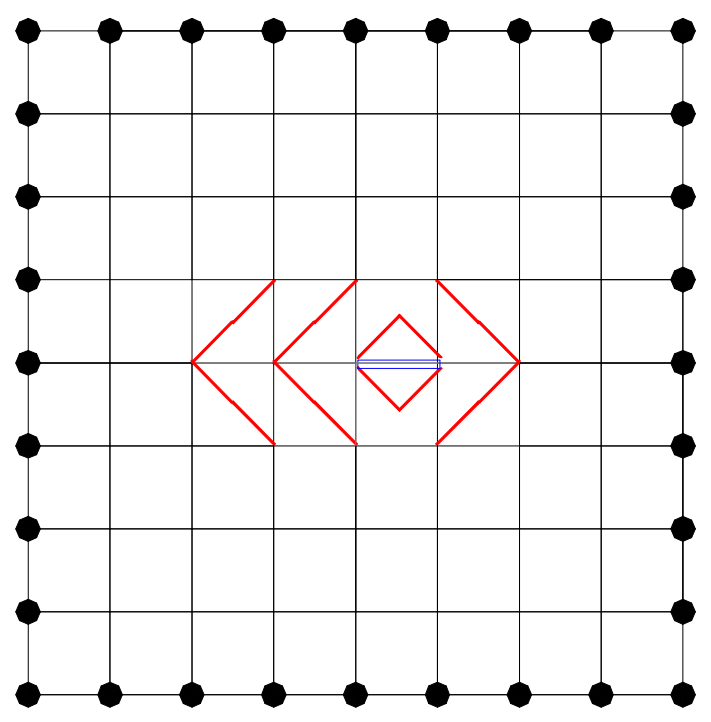

Elementos comprometidos

Figura 2.12 Ruína progressiva em treliça espacial devido a retirada de um de seus elementos.

As análises foram realizadas sem consideração dos efeitos não lineares, no entanto, os autores deixam clara a necessidade da análise não 
linear, bem como da consideração de efeitos dinâmicos que ocorrem durante a perda da capacidade resistente de um elemento.

Segundo HANAOR et al. (1989), dois importantes fatores que influenciam o comportamento das estruturas espaciais são: ductilidade e distribuição de esforços entre seus elementos. Trabalhando-se então com esses fatores pode-se produzir melhorias no comportamento dessas estruturas.

Os autores apresentam algumas estratégias para tornar as estruturas espaciais mais dúcteis, como por exemplo: o subdimensionamento das cordas tracionadas e superdimensionamento das comprimidas, causando um escoamento inicial nas primeiras e retardando a flambagem das outras. O mesmo efeito pode ser conseguido com pré-tensão dos elementos comprimidos.

Outro modo de se melhorar a ductilidade é usando mecanismos de força limite (FLD). FLDs são mecanismos que entram em escoamento com uma determinada carga, conhecida, e mantém a capacidade de carga do elemento ao qual está associado, evitando a perda repentina de estabilidade. Segundo SCHMIDT \& HANAOR (1979) esses mecanismos produzem bons resultados, mas têm custo muito alto e são de difícil manipulação.

O comportamento das treliças espaciais pode também ser melhorado pela remoção adequada de alguns de seus elementos. Consegue-se com isso redirecionar a distribuição de esforços para elementos capazes de resisti-los. MARSH (1988) analisou o comportamento de protótipos de treliças espaciais empregando esta técnica.

Percebe-se uma certa contradição, entre os autores apresentados, a respeito do tipo de ruína que predomina em estruturas espaciais. Alguns autores afirmam, baseados em seus estudos, que as estruturas espaciais apresentam forte ruína incremental, antes do colapso, quando sujeitas a um dano local. No entanto, outro grupo de autores afirma que essas estruturas 
possuem alto grau de redundância e, por essa razão, um dano local (perda de um elemento) não acarreta ruína da estrutura.

É importante notar que o tipo de ruína ou sua propagação depende de onde ela se inicia. A falha de uma diagonal de apoio, por exemplo, levará a estrutura ao colapso de forma repentina.

\subsubsection{Acidentes com estruturas espaciais}

Tem-se registros, nos últimos anos, de diversos acidentes ocorridos no Brasil com estruturas espaciais, a maioria ocorrida de forma repentina.

Infelizmente, não se pode analisar as causas desses acidentes, pois muitas vezes e por motivos diversos os fatos são omitidos, até mesmo do meio técnico. Resta, então, citar alguns acidentes mais recentes.

O ultimo acidente de grandes proporções de que se tem notícia foi colapso total do Centro de Convenções de Manaus ocorrido no final do ano de 1995. A estrutura era uma grande cobertura, em treliça espacial tubular em forma cilindrica (três raios), com vãos de 110,0m, as ligações entre barras foram realizadas utilizando chapas de ponteira (figura 2.8c). A estrutura ruiu de forma repentina, sem aviso prévio. As fotos da Figura 2.13 exibem a estrutura após o colapso.
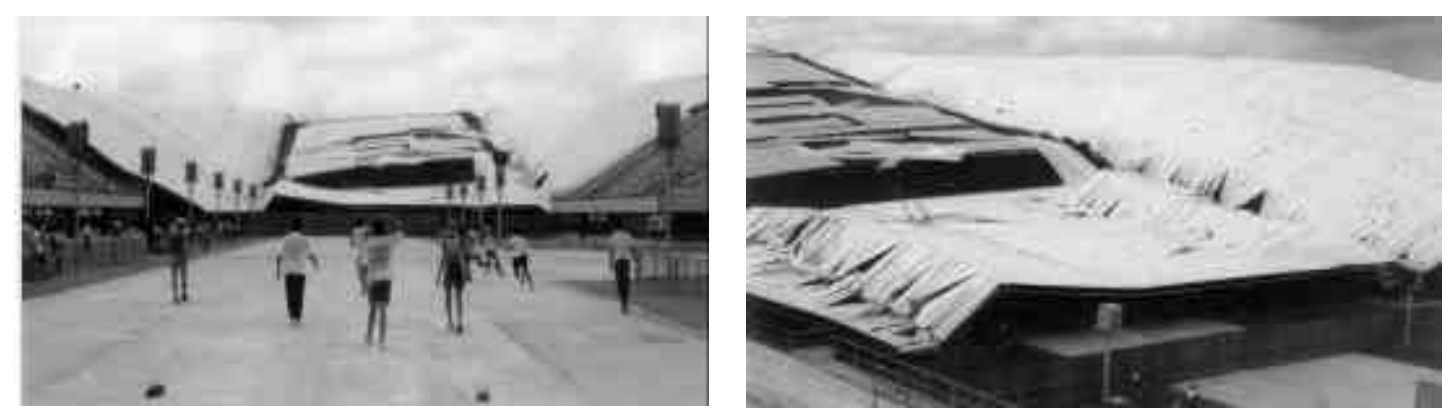

Figura 2.13 Colapso do Centro de Convenções de Manaus.

Outra estrutura que apresentou problemas e acabou sofrendo colapso foi o Ginásio Poliesportivo Nilson Nelson, em Brasília. O ginásio é uma estrutura espacial tubular, em alumínio, na forma de calota esférica com altura de aproximadamente 10,0m e vão de 100,0m. A estrutura foi 
substituída por outra em aço com seções tubulares e ligações entre barras realizadas com ponteiras.

Cita-se, também, a ruína parcial de uma treliça espacial da cobertura de um parque aquático com área de $5400,0 \mathrm{~m}^{2}$ na cidade de São Paulo.

Acidentes com estruturas não são "privilégios" do Brasil, tem-se registro de problemas em estruturas espaciais em vários outros países, que culminaram com o colapso parcial ou total das mesmas.

Um exemplo bastante citado que vale a pena comentar é o colapso do Hartford Coliseum nos Estados Unidos em 1978. A estrutura com dimensões de $110,0 \mathrm{~m}$ x 90,0m ruiu, de forma repentina, durante uma nevasca. O colapso desta estrutura teve grande repercussão no meio técnico internacional, gerando uma série de estudos e pesquisas sobre os modos de falha de treliças espaciais e técnicas de análise que permitissem avaliá-las com segurança. 


\section{ELEMENTOS COMPRIMIDOS UTILIZADOS NAS ESTRUTURAS METÁLICAS ESPACIAIS}

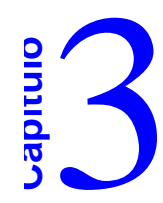

Neste capítulo será apresentado, de maneira geral, o problema da instabilidade de elementos comprimidos. Apresenta-se um breve histórico do desenvolvimento e entendimento do problema da instabilidade e serão analisadas também as recomendações da norma brasileira de aço e de algumas normas de outros países, no que diz respeito a projeto e verificação de elementos comprimidos. Apresenta-se um estudo detalhado de barras de seção tubular com extremidades estampadas, utilizadas nas estruturas espaciais brasileiras.

\subsection{Elementos comprimidos: Fundamentos}

O problema da instabilidade de estruturas em geral e de colunas (elementos comprimidos) em particular é tema de diversas pesquisas em todo mundo, tendo sua discussão iniciada em 1744. EULER estudou a estabilidade elástica de barras com força axial centrada e extremidades rotuladas, usando o recém desenvolvido cálculo integral e diferencial, conseguindo resolver a equação diferencial característica do problema, determinando a carga crítica de flambagem elástica ou carga crítica de Euler dada por:

$$
\mathrm{P}_{\mathrm{cr}}=\frac{\pi^{2} \mathrm{El}}{\mathrm{L}^{2}}
$$

No estudo desenvolvido por Euler supunha-se: material totalmente elástico linear e homogêneo, barras livres de imperfeições iniciais e tensões residuais, força centrada, barras com extremidades rotuladas e livre de 
instabilidade local e por flexo-torção. Essas considerações, inexistentes na prática, justificam a carga crítica obtida experimentalmente ser menor que a carga crítica de Euler, especialmente para barras curtas e intermediárias.

Em 1889 ENGESSER propôs a teoria do módulo tangente para avaliar a carga crítica de flambagem quando a bifurcação do equilíbrio se dá acima do limite de proporcionalidade do material, ou seja, em regime inelástico. As mesmas considerações admitidas por Euler continuam válidas, com exceção do material não ser totalmente elástico linear. $\mathrm{Na}$ teoria do módulo tangente, o módulo de elasticidade varia ponto a ponto, ao analisar-se a curva tensão $x$ deformação.

JASINSKY (1895) demonstrou haver incoerências na teoria do módulo tangente, pois desconsiderava a não reversibilidade plástica do diagrama tensão $x$ deformação. De fato, com o encurvamento da barra ocorre aumento de tensões nas fibras comprimida seguindo a curva tensão $x$ deformação no trecho elástico linear. Em contrapartida, nas fibras opostas estará ocorrendo um alívio de tensões que corresponde a um descarregamento segundo uma reta paralela ao trecho linear do diagrama.

Esse problema foi analisado por ENGESSER que, em 1898, reformula sua teoria e cria a teoria do módulo reduzido ou duplo módulo. Considerando a não reversibilidade do diagrama tensão $x$ deformação, na fase elástica os acréscimos de carga são governados pelo módulo tangente e os descarregamentos pelo módulo elástico.

As duas teorias, expostas acima, podem refletir a influência causada pela não linearidade do material, que é conseqüência das tensões residuais presentes nos perfis de aço. A Figura 3.1. apresenta o comportamento tensão $x$ deformação idealizado para aços com e sem tensões residuais. 


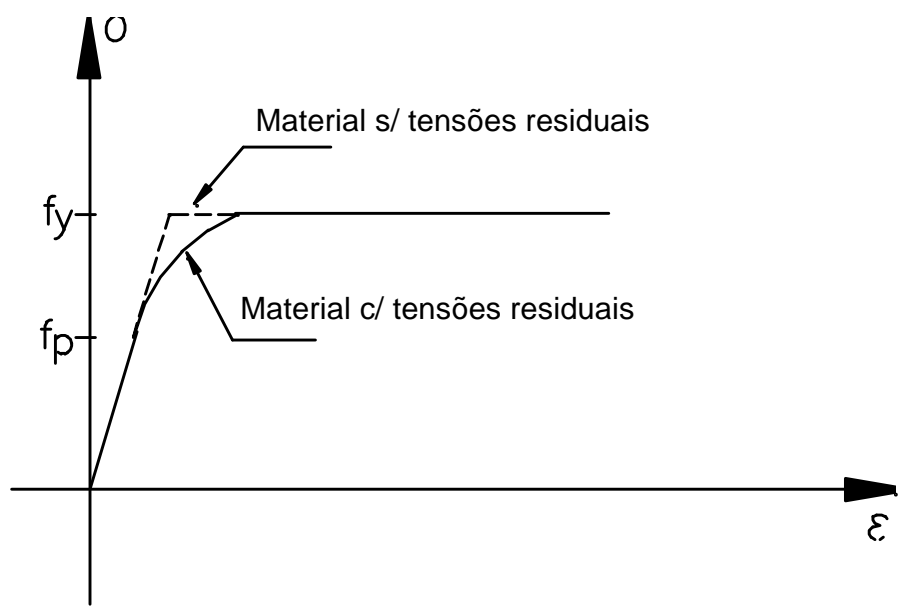

Figura 3.1- Diagrama tensão $x$ deformação para aço com e sem tensões residuais.

As tensões residuais nos perfis metálicos são decorrentes da transformação do aço em produto acabado, tendo origem nas deformações térmicas e mecânicas inerentes a esse processo. Os efeitos térmicos são: resfriamento diferenciado, soldagem e corte a maçarico. Os efeitos mecânicos são causados por: laminação a frio, dobramento e desempenamento.

A distribuição das tensões residuais em um perfil metálico é muito complexa e depende de vários fatores tais como: forma da seção transversal, temperatura de laminação, condições de resfriamento, processo de soldagem, dobramento, conformação a frio, etc.

\subsection{Critérios de projeto para elementos comprimidos: Normalização}

A importância do entendimento sobre estabilidade para o desenvolvimento da Engenharia Estrutural gerou a necessidade da criação de entidades ou associações, formadas por profissionais da área e pesquisadores, que se dedicam ao estudo da estabilidade em seus mais diversos aspectos. Algumas dessas associações mais representativas, que são descritas a seguir, desenvolveram uma série de trabalhos que se 
transformaram nas bases para as normalizações na Europa e América do Norte.

Criado em 1955 o "European Convention for Constructional Steelwork - ECCS" iniciou um ambicioso estudo teórico e experimental para analisar o comportamento de elementos comprimidos com o objetivo de padronizar os procedimentos para projetos desses elementos na Europa. Quinze anos de estudos geraram um conjunto de três curvas de resistência, para diferentes tipos de seções transversais. Logo depois, os estudos complementares conduziram à proposição de mais duas curvas de resistência completando assim as múltiplas curvas do ECCS.

As três primeiras curvas foram desenvolvidas para as seções transversais mais usuais, ou seja: curva a para tubos circulares, curva b para seções tipo caixa e curva c para perfis I laminados.

Em seguida, foram criadas mais duas curvas $\mathbf{a}_{0}$ e $\mathbf{d}$ que representam, respectivamente, seções transversais com baixa e alta influência das tensões residuais.

Apesar do avanço representado pelas múltiplas curvas do ECCS, as mesmas não possuíam uma formulação analítica que facilitasse a programação em computadores, como destacado por MAQUOI \& RONDAL (1978). Formulações analíticas que representassem as curvas de resistência só surgiram na década de 70 . Essas formulações combinaram simplicidade e precisão, uma vez que todas as curvas são diferenciadas apenas por um parâmetro, $\alpha$,que depende da forma da seção transversal e do eixo de flambagem.

$$
\rho=\frac{P_{c r}}{P_{y}}=\frac{\eta-\sqrt{\eta^{2}-4 \bar{\lambda}^{2}}}{2 \bar{\lambda}^{2}}
$$

onde:

$$
\eta=1+\alpha \sqrt{\bar{\lambda}^{2}-0,04}+\bar{\lambda}^{2}
$$




$$
\bar{\lambda}=\frac{k L}{r} \sqrt{\frac{f_{y}}{\pi^{2} E}}=\sqrt{\frac{f_{y}}{f_{e}}}
$$

Os valores do parâmetro $\alpha$ são os seguintes:

$$
\alpha= \begin{cases}0,093 & \text { curva } a_{0} \\ 0,158 & \text { curva a } \\ 0,281 & \text { curva b } \\ 0,384 & \text { curva c } \\ 0,587 & \text { curva d }\end{cases}
$$

A Figura 3.2 exibe as curvas de resistência do ECCS (1976).

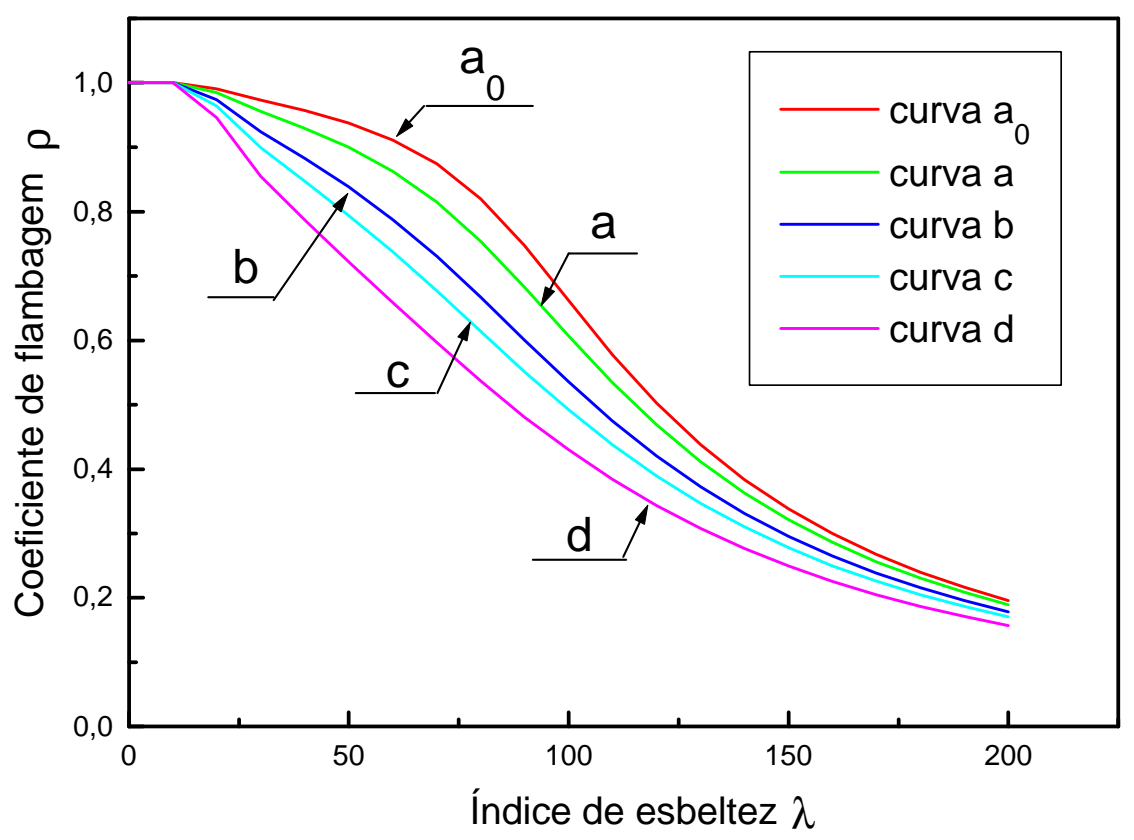

Figura 3.2 Curvas de resistência do ECCS (1976)

Em 1960 o "Column Research Council - CRC" publica a $1^{\text {a }}$ edição do "Guide to stability design criteria for metal structures". Este guia reúne critérios para análise de estabilidade para as mais diversas configurações estruturais, bem como uma farta bibliografia sobre o tema. 
A curva de flambagem para elementos comprimidos proposta pelo CRC é baseada na teoria do módulo tangente e inclui os efeitos das tensões residuais.

$$
\begin{aligned}
& \rho=\frac{P_{c r}}{P_{y}}=1-0,25 \bar{\lambda}^{2} \quad 0 \leq \bar{\lambda} \leq \sqrt{2} \quad \text { (regime inelástico) } \\
& \rho=\frac{P_{c r}}{P_{y}}=\frac{1}{\bar{\lambda}^{2}} \quad \bar{\lambda}>\sqrt{2} \quad \text { (regime elástico) } \\
& \bar{\lambda}=\frac{k L}{r} \sqrt{\frac{f_{y}}{\pi^{2} E}}=\sqrt{\frac{f_{y}}{f_{e}}} \\
& f_{e}=\text { tensão crítica de Euler }
\end{aligned}
$$

A curva proposta pelo $\mathrm{CRC}$ serviu de base e foi incorporada à normas de diversos países. Esta curva está apresentada na Figura 3.3.

Para o CRC as tensões residuais são o fator preponderante para a determinação da força normal resistente de barras comprimidas. No entanto, vale salientar que 0 padrão de tensões residuais utilizado para 0 desenvolvimento desta curva é típico de perfis I laminados a quente, por isso a curva de CRC deve ser usada com restrições para outros tipos de perfis. 


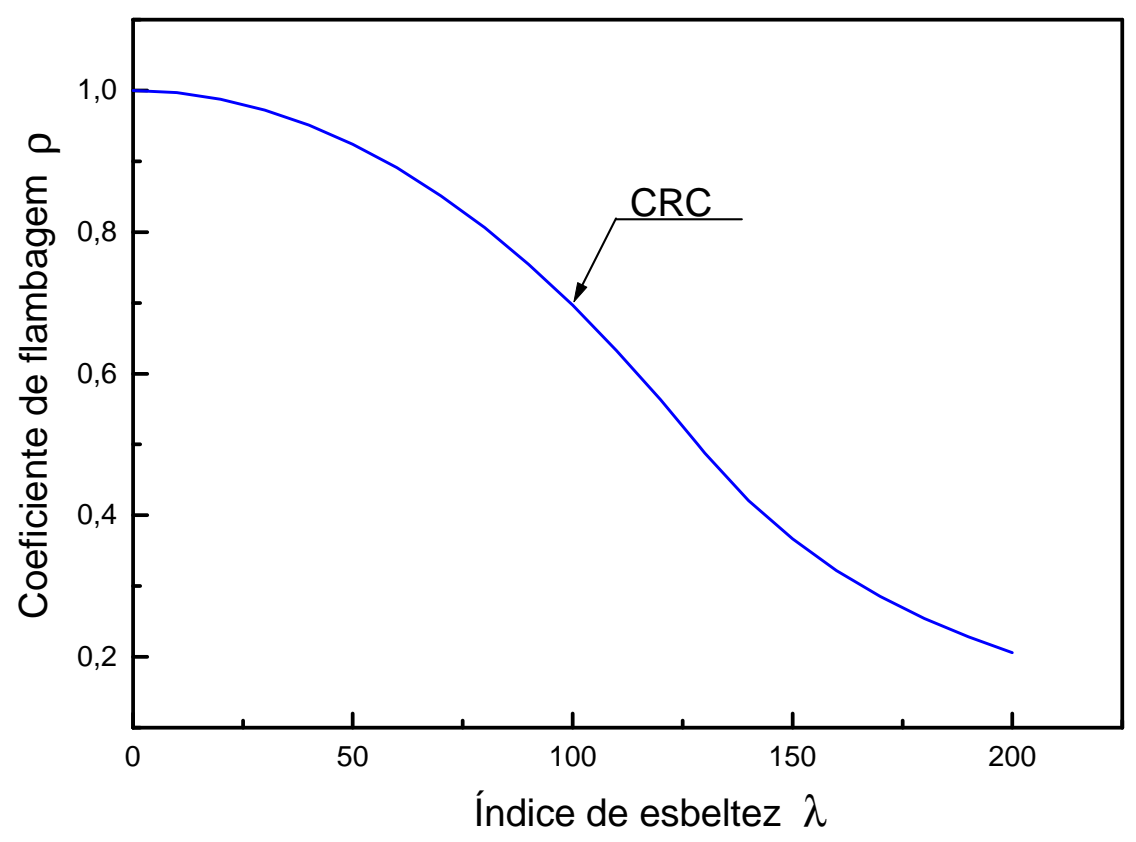

Figura 3.3 Curva de flambagem do CRC.

Em 1975 o "Structural Stability Research Council - SSRC" (que incorporou o $\mathrm{CRC}$ ) instituiu um grupo de trabalho para desenvolver pesquisas sistemáticas sobre estabilidade estrutural que deram origem às recomendações e normalizações em várias partes do mundo. O SSRC desenvolveu um conjunto de três curvas onde eram consideradas tensões residuais e imperfeições iniciais para várias formas de seções transversais.

As múltiplas curvas de resistência do SSRC são resultados da categorização de 112 curvas de resistência, com diferentes esbeltezes e imperfeições iniciais de $\mathbf{0 , 0 0 1 L}$, traçadas através de técnicas numéricas e confrontadas com resultados de ensaios de uma grande quantidade de colunas. Cada uma das três curvas é representativa de uma categoria de colunas, e são sinteticamente representadas pela equação de RondalMaquoi:

$$
\rho=\frac{P_{c r}}{P_{y}}=\frac{1+\eta+\bar{\lambda}^{2}}{2 \bar{\lambda}^{2}}-\frac{1}{2 \bar{\lambda}^{2}} \sqrt{\left[\left(1+\eta+\bar{\lambda}^{2}\right)^{2}-4 \bar{\lambda}^{2}\right]}
$$


onde:

$$
\begin{array}{r}
\eta=\alpha(\bar{\lambda}-0,15) \\
\bar{\lambda}=\frac{k L}{r} \sqrt{\frac{f_{y}}{\pi^{2} E}}=\sqrt{\frac{f_{y}}{f_{e}}}
\end{array}
$$

Os valores de $\alpha$ para cada curva sãos os seguintes:

$$
\alpha= \begin{cases}0,103 & \text { curva } 1 \\ 0,293 & \text { curva } 2 \\ 0,622 & \text { curva } 3\end{cases}
$$

A curva 1 é aplicável a seções tubulares retangulares e circulares sem costura. A curva 2 aplica-se a perfis I laminados, tubos circulares com costura e seção caixão soldada. Já a curva 3 é aplicável a perfis I soldados. Uma classificação mais detalhada dos perfis por curva pode ser encontrada em BJORHOUDE(1984).

A Figura 3.4 apresenta as curvas de resistência propostas pelo SSRC.

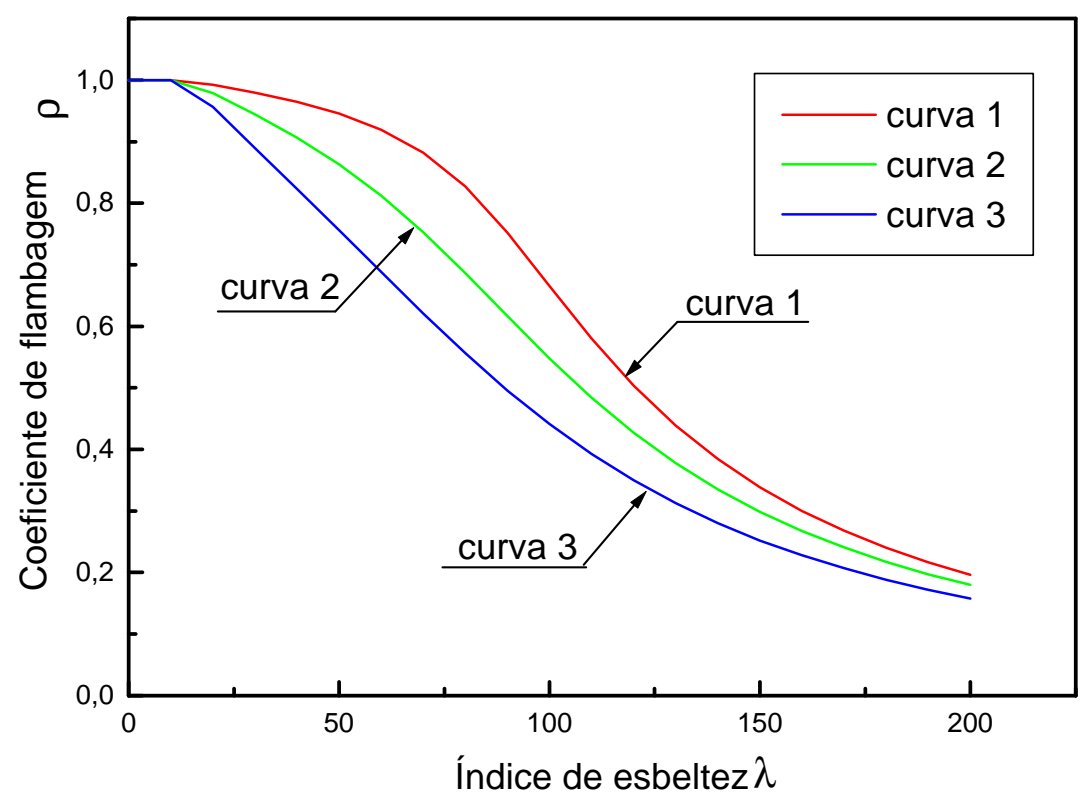

Figura 3.4 Curvas de resistência do SSRC 


\subsubsection{Elementos comprimidos sem variação de inércia}

Apresentam-se, a seguir, resumo e comentários sobre os procedimentos para dimensionamento de elementos comprimidos presentes em algumas normas de outros países e na norma brasileira NBR8800(1986).

\section{EUROCODE (1992)}

O EUROCODE 3 (1992) adota a filosofia de curvas múltiplas de flambagem e apresenta um conjunto de 4 curvas que são representadas por uma formulação analítica, sendo cada curva diferenciada em função da forma da seção e do eixo de flambagem pelo parâmetro $\alpha$, que também considera os efeitos das imperfeições iniciais e tensões residuais.

Estas curvas são as mesmas desenvolvidas pelo ECCS, entretanto, apresentam um equacionamento um pouco diferente para o parâmetro de imperfeições iniciais.

A força normal resistente à flambagem por flexão é dada por:

$$
\mathrm{N}_{\mathrm{b} . \mathrm{Rd}}=\frac{\chi \beta_{\mathrm{A}} \mathrm{Af}_{\mathrm{y}}}{\gamma_{\mathrm{M} 1}}
$$

$\gamma_{\mathrm{M} 1}$ : coeficiente de minoração do material.

$\beta_{A}$ : fator que considera a flambagem local dos elementos da seção.

$\chi$ : fator que considera o efeito da flambagem do elemento dado por:

$$
\begin{aligned}
& \chi=\frac{1}{\phi+\left[\phi^{2}-\bar{\lambda}^{2}\right]^{0.5}} \leq 1 \\
& \phi=0.5\left(1+\alpha(\bar{\lambda}-0.2)+\bar{\lambda}^{2}\right)
\end{aligned}
$$

$\bar{\lambda}$ : esbeltez reduzida

$$
\begin{aligned}
& \bar{\lambda}=\sqrt{\frac{\beta_{\mathrm{A}} \mathrm{Af}_{\mathrm{y}}}{\mathrm{N}_{\mathrm{cr}}}}=\frac{\lambda}{\lambda_{1}}\left(\beta_{\mathrm{A}}\right)^{1 / 2} \\
& \lambda_{1}=\sqrt{\frac{\pi^{2} \mathrm{E}}{\mathrm{f}_{\mathrm{y}}}}
\end{aligned}
$$


$\lambda_{1}$ : esbeltez limite entre flambagem elástica e plastificação

$\mathrm{N}_{\mathrm{cr}}$ : Força normal crítica elástica (Euler)

Os valores de $\alpha$ para cada curva são:

$$
\alpha= \begin{cases}0,210 & \text { curva a } \\ 0,340 & \text { curva b } \\ 0,490 & \text { curva c } \\ 0,760 & \text { curva d }\end{cases}
$$

A Figura 3.5 mostra as curvas de resistência do EUROCODE e a Tabela 3.1 apresenta a classificação dos perfis de acordo com as curvas de resistência. As seções não incluídas nesta tabela devem ser classificadas analogamente.

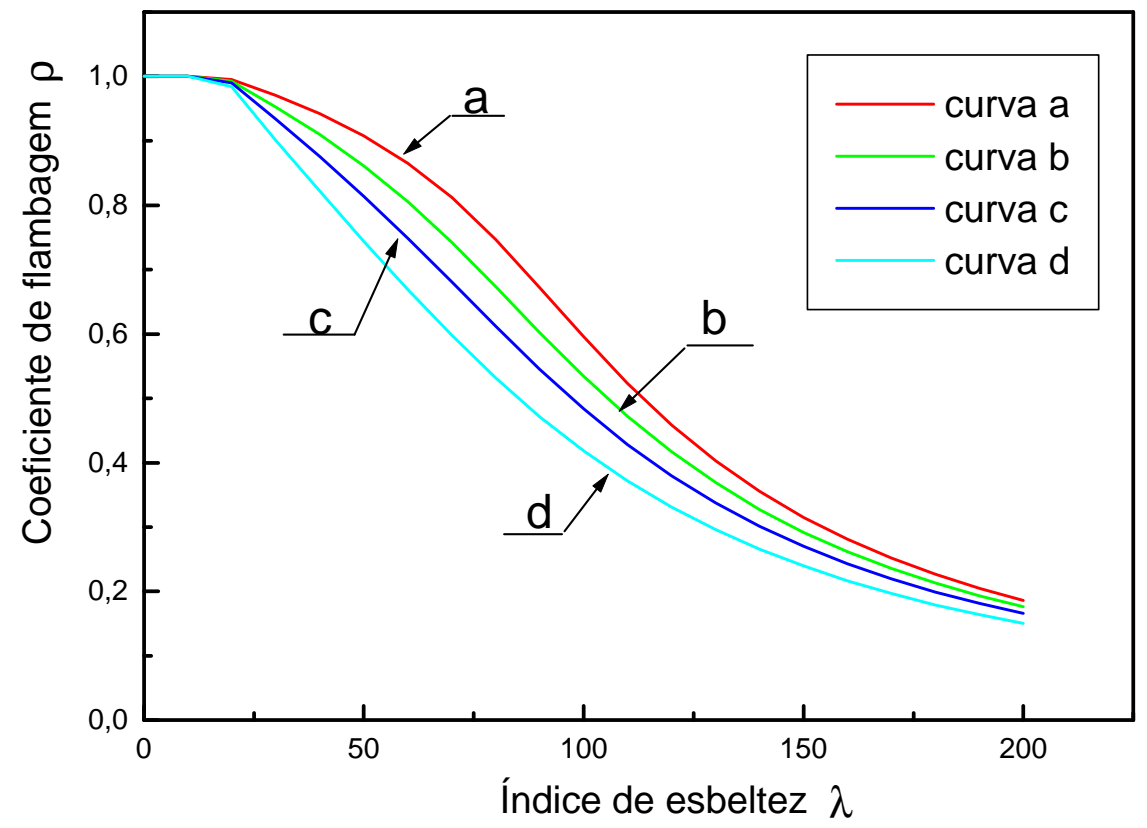

Figura 3.5 Curvas de resistência do EUROCODE. 
Tabela 3.1 Classificação dos perfis por curvas de resistência. EUROCODE (1992).

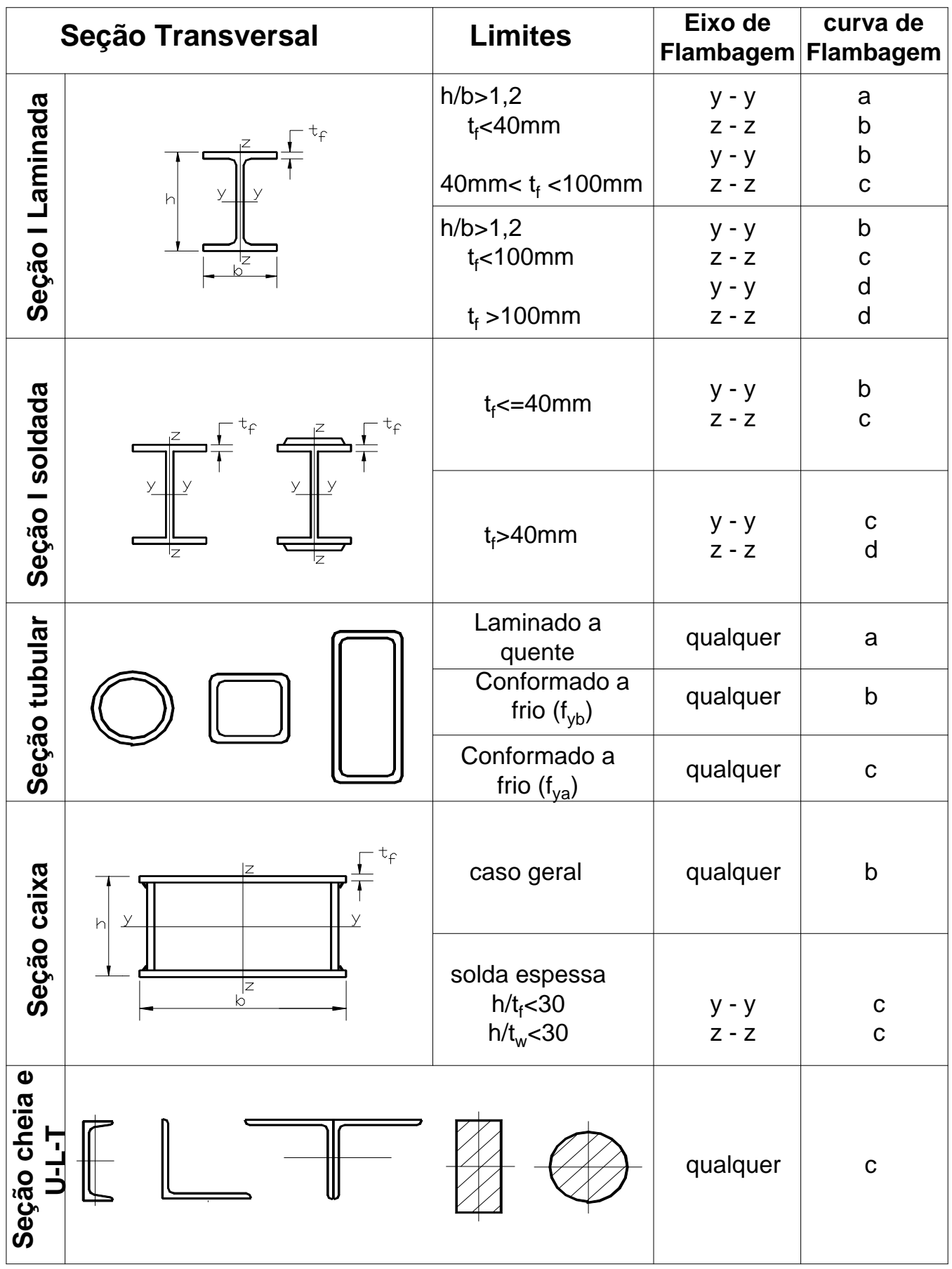

nota:

$f_{y a-:} f_{y b}$ : admitindo aumento de $f_{y}$ devido ao efeito do trabalho a frio 


\section{NBR-8800 (1986)}

A norma brasileira para estruturas metálicas, no item elementos comprimidos, é baseada nas recomendações do EUROCODE. Para elementos comprimidos adota, também, as múltiplas curvas de resistência provenientes do ECCS, com a seguinte formulação:

$$
\begin{aligned}
& N_{c}=\phi N_{n} \\
& N_{c}=\phi \rho Q A_{g} f_{y}
\end{aligned}
$$

$\phi$ : coeficiente de resistência do material.

Q: fator que considera a flambagem local dos elementos da seção.

$\rho$ : fator que considera o efeito da flambagem do elemento dado por:

$\rho=1 \quad 0 \leq \bar{\lambda} \leq 0,2$

$\rho=\beta-\sqrt{\beta^{2}-\frac{1}{\bar{\lambda}^{2}}} \quad \bar{\lambda}>0,2$

$\beta=\frac{1}{2 \bar{\lambda}^{2}}\left[1+\alpha \sqrt{\bar{\lambda}^{2}-0,04}+\bar{\lambda}^{2}\right]$

$\bar{\lambda}$ : esbeltez reduzida

$\bar{\lambda}=\frac{k L}{r} \sqrt{\frac{f_{y}}{\pi^{2} E}}=\sqrt{\frac{Q f_{y}}{f_{e}}}$

$f_{e}=$ Tensão crítica elástica (Euler)

Os valores de $\alpha$ para cada curva são:

$\alpha= \begin{cases}0,158 & \text { curva a } \\ 0,281 & \text { curva b } \\ 0,384 & \text { curva c } \\ 0,572 & \text { curva d }\end{cases}$ 
As curvas de resistência da NBR-8800(1986) e a classificação dos perfis por curva são apresentados respectivamente na Figura 3.6 e na Tabela 3.2.

Ressalta-se que, para o caso de seções tubulares a NBR-8800, ao contrário do Eurocode, não faz diferenciação entre tubos com e sem solda de costura. A curva a, desta norma, seria aplicada corretamente somente para seções tubulares sem costura.

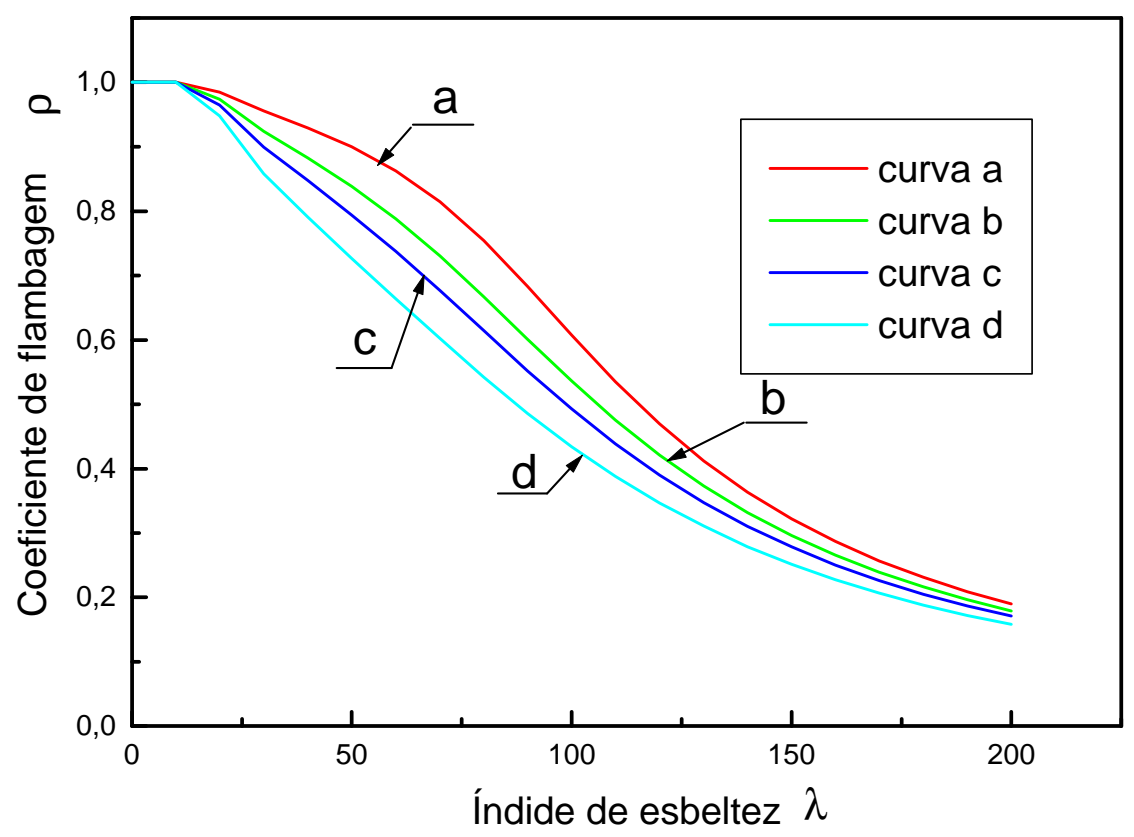

Figura 3.6 Curvas de resistência da NBR-8800 
Tabela 3.2 Classificação dos perfis por curvas de resistência. NBR8800 (1986).

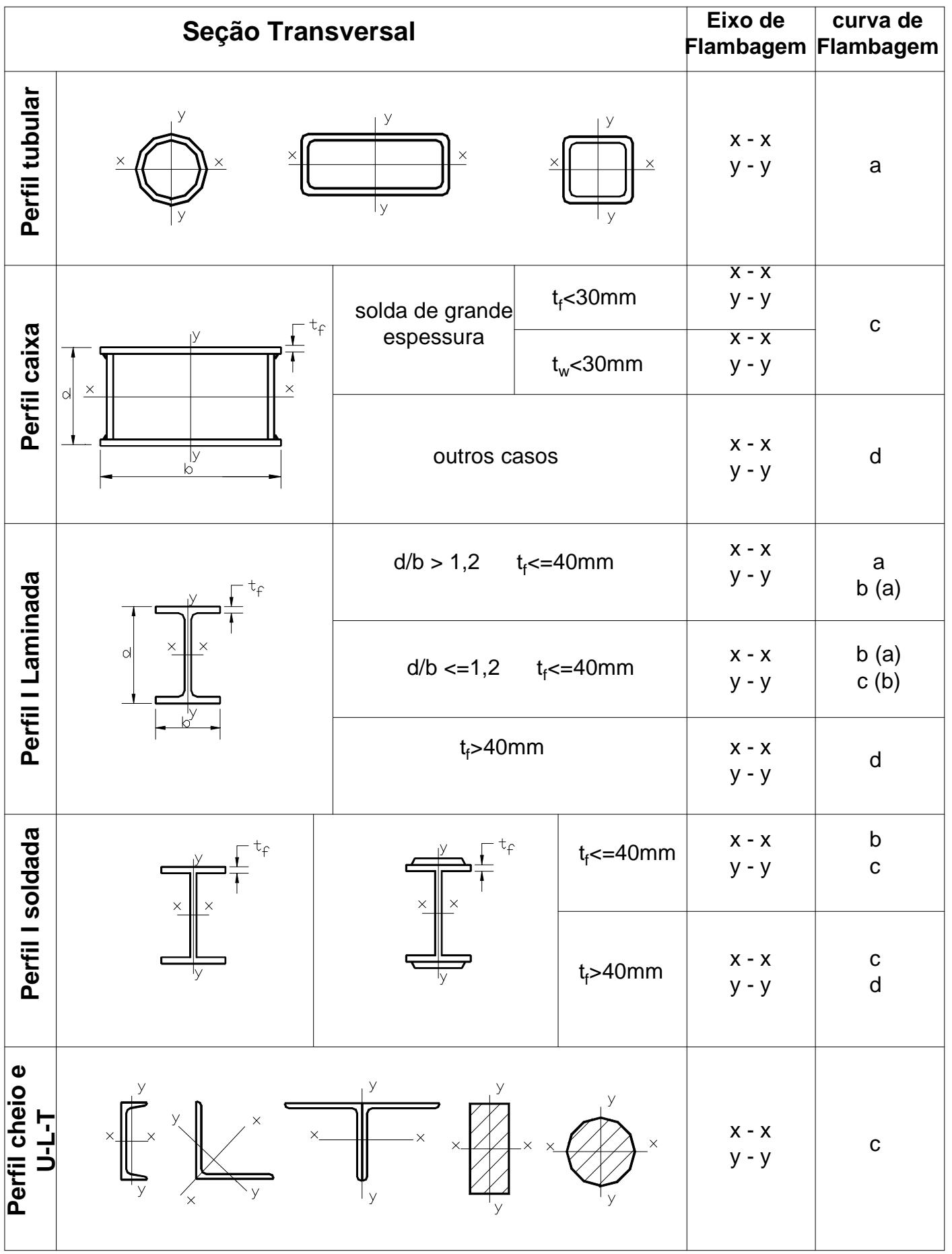

As seções não incluídas nesta tabela devem ser classificadas analogamente.

As curvas de resistência indicadas entre parênteses podem ser adotadas para aços de alta resistência, com $\mathrm{f}_{\mathrm{y}}>430 \mathrm{MPa}$. 


\section{AISC-ASD (1989)}

Desde 1960 o projeto de estruturas de aço segundo o AISC-ASD (tensões admissíveis) é baseado na curva do CRC. A curva apresentada pelo AISC-ASD é obtida dividindo a curva do CRC por um coeficiente de segurança global que considera todas as variabilidades e incertezas. A tensão admissível para elementos comprimidos é dada pelas equações abaixo. O coeficiente de segurança assume valores diferentes para a flambagem elástica e inelástica conforme percebe-se nos denominadores das expressões [3.23] e [3.24]

$$
\begin{aligned}
& f_{a}=\frac{\left[1-\frac{(k L / r)^{2}}{2 C_{c}^{2}}\right] F_{y}}{\frac{5}{3}+\frac{3(k L / r)}{8 C_{c}}-\frac{(k L / r)^{3}}{8 C_{c}^{2}}} \quad \frac{k L}{r} \leq C_{c} \\
& f_{a}=\frac{12 \pi^{2} E}{23(k L / r)^{2}} \quad \frac{k L}{r}>C_{c} \\
& C_{c}: \text { Esbeltez limite entre flambagem elástica e inelástica. } \\
& C_{c}=\sqrt{\frac{2 \pi^{2} E}{f_{y}}}
\end{aligned}
$$

A curva de flambagem do AISC/ASD pode ser vista na Figura 3.7, onde neste caso $\rho=\frac{f_{a}}{f_{y}}$. 


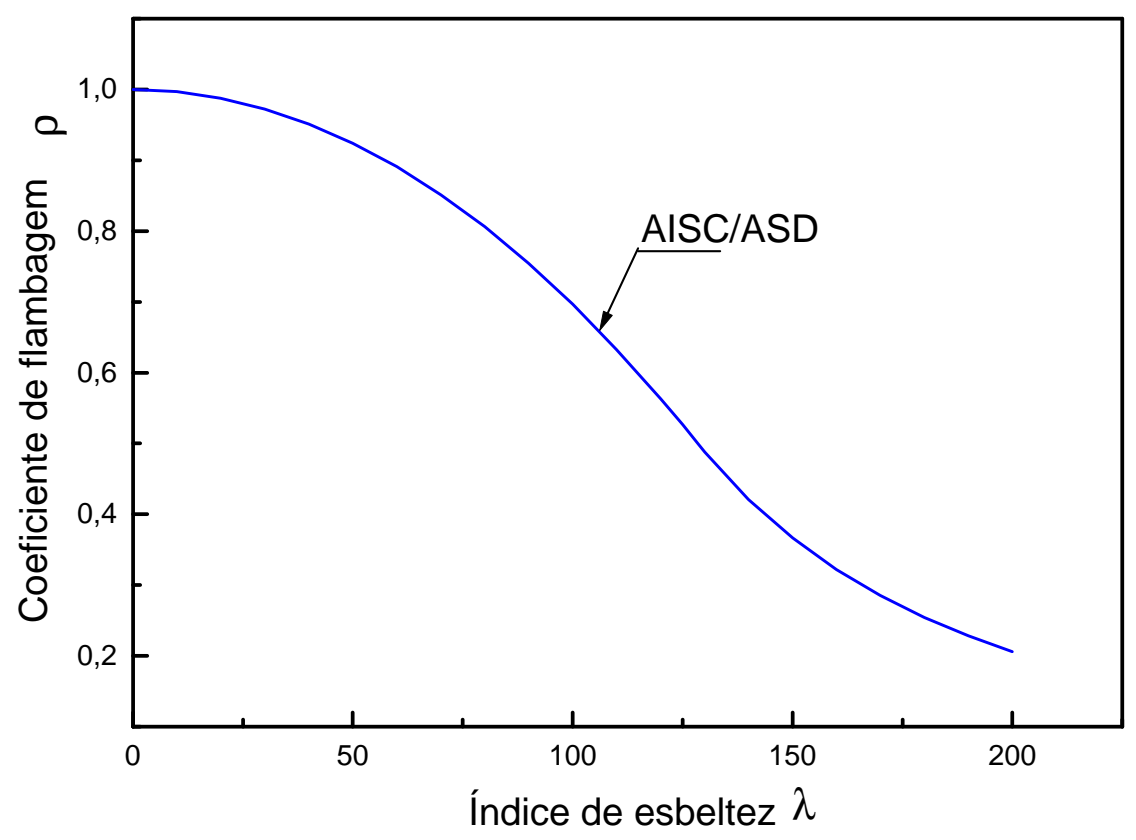

Figura 3.7 Curva de flambagem do AISC/ASD

\section{AISC-LRFD (1994)}

O AISC-LRFD também adota a filosofia de curva de flambagem única. A equação desta curva foi estabelecida tomando como base a curva 2 do SSRC e admitindo uma imperfeição inicial com valor máximo de 1/1500 no meio do elemento. A expressão matemática da curva 2 do SSRC foi modificada a fim de se obter uma forma mais simples.

$$
\begin{aligned}
& \rho=\frac{f_{a}}{f_{y}}=\left(0,658^{\bar{\lambda}^{2}}\right) \quad \bar{\lambda} \leq 1,5 \\
& \rho=\frac{f_{a}}{f_{y}}=\left(\frac{0,877}{\bar{\lambda}^{2}}\right) \quad \bar{\lambda}>1,5 \\
& \bar{\lambda}=\frac{k L}{r} \sqrt{\frac{f_{y}}{\pi^{2} E}}=\sqrt{\frac{f_{y}}{f_{e}}}
\end{aligned}
$$


Para considerar a instabilidade local nos elementos componentes de uma seção, o LRFD introduz o fator $Q$, que é função da relação $b / t$ dos elementos. Com isso as equações acima tornam-se:

$$
\begin{array}{ll}
\mathrm{f}_{\mathrm{a}}=\left(0,658^{\bar{\lambda}^{2}}\right) \mathrm{Qf}_{\mathrm{y}} \quad \bar{\lambda} \sqrt{\mathrm{Q}} \leq 1,5 \\
\mathrm{f}_{\mathrm{a}}=\left(\frac{0.877}{\bar{\lambda}^{2}}\right) \mathrm{Qf}_{\mathrm{y}} \quad \bar{\lambda} \sqrt{\mathrm{Q}}>1,5
\end{array}
$$

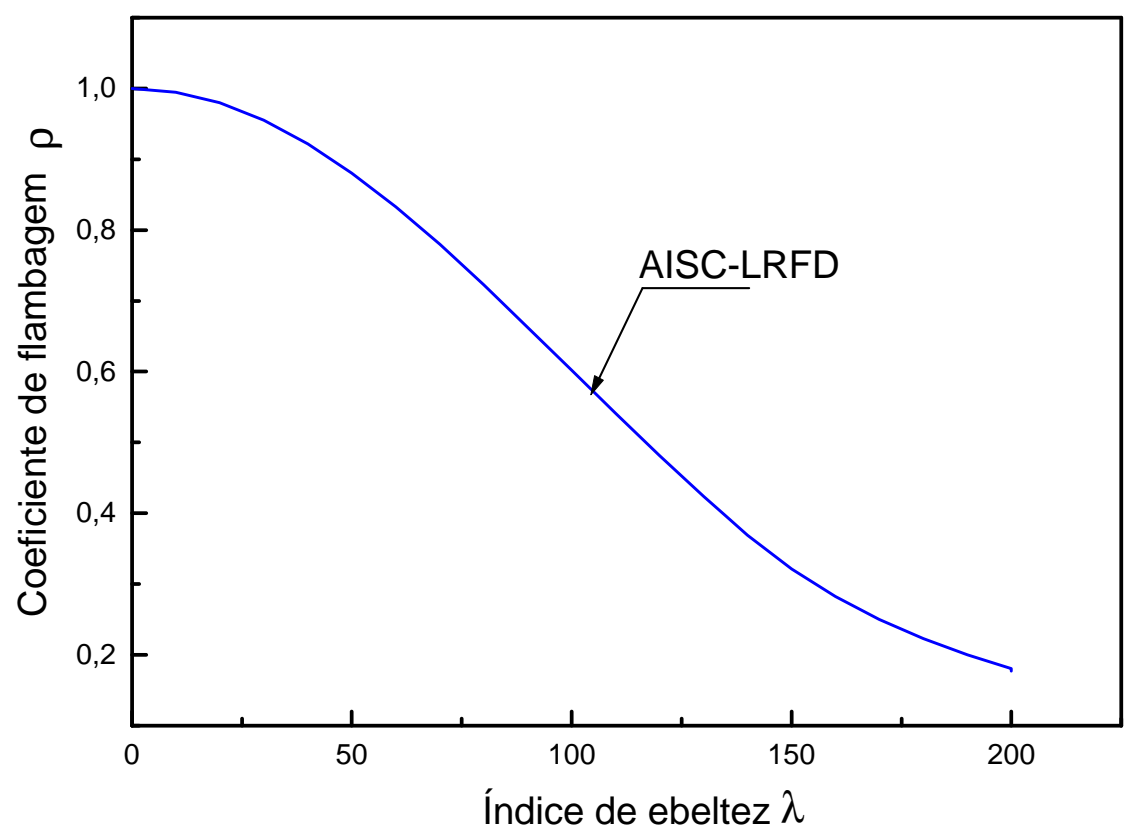

Figura 3.8 Curva de flambagem do AISC/LRFD.

\section{CAN/CSA S13.1-M89 (1989)}

A norma canadense também adota as curvas do SSRC, porém, apenas as curvas 1 e 2 estão presentes nesta norma.

Para seções tipo 'l' e seções classe C (CSA G4020) é utilizada a curva 2 do SSRC com as seguintes expressões:

$$
\mathrm{C}_{\mathrm{r}}=\phi \mathrm{F}_{\mathrm{y}} \quad 0 \leq \bar{\lambda} \leq 0,15
$$




$$
\begin{array}{lr}
C_{r}=\phi F_{y}\left(1,035-0,202 \bar{\lambda}-0,222 \bar{\lambda}^{2}\right) & 0,15<\bar{\lambda} \leq 1 \\
C_{r}=\phi F_{y}\left(-0,111+0,636 \bar{\lambda}^{-1}+0,087 \bar{\lambda}^{-2}\right) & 1<\bar{\lambda} \leq 2 \\
C_{r}=\phi F_{y}\left(0,009+0,877 \bar{\lambda}^{2}\right) & 2<\bar{\lambda} \leq 3,6 \\
C_{r}=\phi F_{y} \bar{\lambda}^{-2} & \bar{\lambda}>3,6
\end{array}
$$

Para seções tubulares, conformadas a frio ou a quente, classe $\mathrm{H}$ é utilizada a curva 1 do SSRC com as seguintes expressões:

$$
\begin{array}{ll}
\mathrm{C}_{\mathrm{r}}=\phi \mathrm{F}_{\mathrm{y}} & 0 \leq \bar{\lambda} \leq 0,15 \\
\mathrm{C}_{\mathrm{r}}=\phi \mathrm{F}_{\mathrm{y}}\left(0,99-0,122 \bar{\lambda}-0,367 \bar{\lambda}^{2}\right) & 0,15<\bar{\lambda} \leq 1,2 \\
\mathrm{C}_{\mathrm{r}}=\phi \mathrm{F}_{\mathrm{y}}\left(0,051+0,801 \bar{\lambda}^{-2}\right) & 1,2<\bar{\lambda} \leq 1,8 \\
\mathrm{C}_{\mathrm{r}}=\phi \mathrm{F}_{\mathrm{y}}\left(0,008+0,942 \bar{\lambda}^{-2}\right) & 1,8<\bar{\lambda} \leq 2,8 \\
\mathrm{C}_{\mathrm{r}}=\phi \mathrm{F}_{\mathrm{y}} \bar{\lambda}^{-2} & \bar{\lambda}>2,8 \\
\bar{\lambda}=\frac{\mathrm{kL}}{\mathrm{r}} \sqrt{\frac{\mathrm{F}_{\mathrm{y}}}{\pi^{2} \mathrm{E}}}=\sqrt{\frac{\mathrm{F}_{\mathrm{y}}}{\mathrm{F}_{\mathrm{e}}}} &
\end{array}
$$

Para efeito de comparação entre as normas descritas anteriormente, a Figura 3.9 apresenta as curvas de resistência aplicáveis a elementos tubulares. 


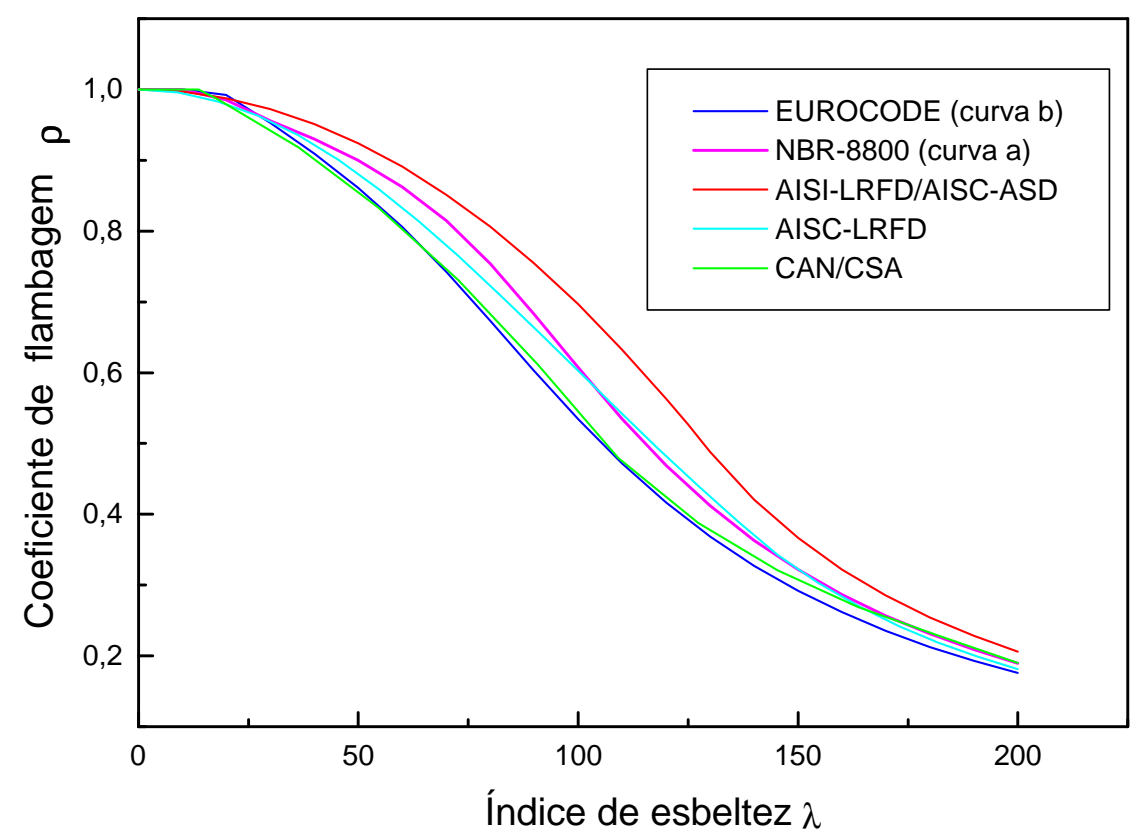

Figura 3.9- Curvas de resistência para seções tubulares.

\subsubsection{Elementos comprimidos com variações de inércia}

Com exceção do EUROCODE(1992) todas as normas citadas anteriormente são omissas em relação à determinação da força normal resistente para elementos comprimidos sujeitos a variação de inércia. Este fato, aliado a outras dificuldades do problema justifica, em parte, a não consideração da variação de inércia pelos projetistas.

Segundo o EUROCODE(1992) a força normal resistente para elementos que apresentem variações de inércia pode ser calculada utilizando as mesmas curvas de resistência para elementos de inércia constante. No entanto, a esbeltez reduzida $(\bar{\lambda})$ deve ser corrigida para levar em conta a variação de inércia. Fazendo uma analogia do EUROCODE (1992) com a NBR-8800(1988) tem-se: 
$\bar{\lambda}$ : esbeltez reduzida para elementos com inércia constante.

$$
\bar{\lambda}=\frac{k L}{r} \sqrt{\frac{f_{y}}{\pi^{2} E}}=\sqrt{\frac{f_{y}}{f_{e}}}
$$

onde:

$f_{e}$ : tensão de flambagem elástica (EULER)

$\bar{\lambda}^{*}$ : esbeltez reduzida para elementos comprimidos com variação de inércia.

$$
\bar{\lambda}^{*}=\sqrt{\frac{f_{y}}{f_{e}^{*}}}
$$

onde:

$\mathrm{f}_{\mathrm{e}}{ }^{*}$ : tensão de flambagem elástica considerando a variação de inércia.

O procedimento sugerido pelo EUROCODE(1992), e que será utilizado incorporando o conceito $\bar{\lambda}^{*}$ aplicando-o à NBR-8800(1986), tornase uma possível solução para o problema. No entanto, não é um procedimento prático para ser utilizado em escritórios de projeto.

A determinação da tensão de flambagem elástica $\mathbf{f}_{\mathbf{e}}{ }^{*}$ é muito trabalhosa, pois envolve equações bastante complexas e/ou simulações numéricas via MEF. As dificuldades agravam-se para o caso de elementos tubulares de seção circular com extremidades estampadas, uma vez que a variação de inércia, nestes elementos, não segue um padrão bem definido, de maneira que possibilite sua medição e equacionamento.

Nos itens subsequentes será aplicado o procedimento exposto anteriormente para se avaliar o comportamento de elementos comprimidos de seção tubular circular com extremidades estampadas. 


\subsection{Análise de tubos comprimidos de seção circular}

\section{com variações de inércia}

As estruturas espaciais projetadas e construídas no Brasil utilizam, predominantemente, barras de seção tubular circular com extremidades estampadas ou com chapas de extremidades (ponteiras). Os tipos mais comuns de estampagem são apresentados na Figura 3.10, sendo que vários modelos com essas estampagens foram ensaiados no LE-EESC ${ }^{1}$.

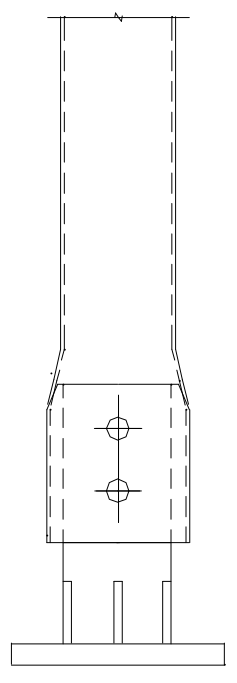

Reta

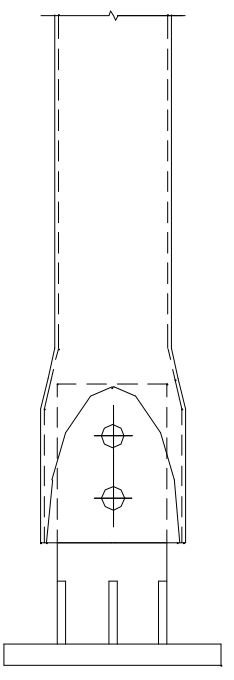

Tradicional

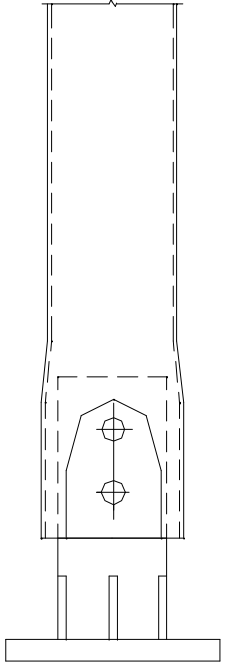

Nova

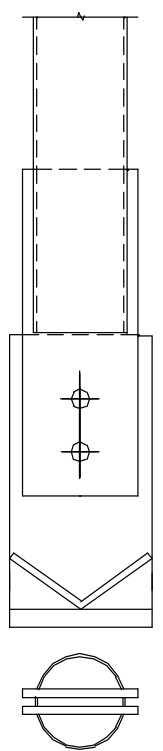

Ponteira

Figura 3.10- Tipos de extremidades de barras utilizadas em estruturas espaciais.

A denominação das estampagens apresentadas na figura acima é a utilizada no âmbito do LE-EESC, podendo haver outras nomenclaturas para as mesmas estampagens em lugares diferentes.

$\mathrm{Na}$ prática corrente de projeto de estruturas espaciais, os efeitos da variação de inércia não são considerados na determinação da força normal resistente desses elementos. Os motivos pelos quais esses efeitos são negligenciados já foram comentados anteriormente.

\footnotetext{
${ }^{1}$ LE-EESC: Laboratório de Estruturas da Escola de Engenharia de São Carlos.
} 
No entanto, percebe-se facilmente que a capacidade resistente dos elementos comprimidos é reduzida quando este apresenta variação de inércia. Essa redução é mais significativa para elementos com baixos valores de índice de esbeltez, onde a relação entre comprimento constante e variável é significativo.

Com o intuito de quantificar essa redução e propor procedimentos mais simplificados para o projeto destes elementos realizar-se-á, em seguida, uma análise numérica, via método dos elementos finitos, de elementos comprimidos com extremidades estampadas e com chapas de ponteiras.

\subsubsection{Análise teórica}

Utilizando as recomendações do EUROCODE(1992) para elementos comprimidos com variação de inércia e aplicando-as às curvas de resistência da NBR-8800(1986), fez-se um estudo dos elementos tubulares tipicamente utilizados nas estruturas espaciais no Brasil.

Este estudo consiste em determinar, para barras de seção tubular de vários diâmetros, a força normal resistente considerando a variação de inércia nas extremidades, analisando seu comportamento e comparando com barras de seção constante.

Segundo a NBR-8800(1986) a normal crítica de um elemento comprimido com inércia constante ao longo do comprimento é dada por:

$$
N_{c}=\phi \rho Q A_{g} f_{y}
$$

$\phi$ : coeficiente resistência do material.

$\mathbf{A}_{\mathbf{g}}$ : Área bruta da seção transversal.

$\mathbf{f}_{\mathrm{y}}$ : Tensão de escoamento do aço.

Q: fator que considera a flambagem local dos elementos da seção.

$\rho$ : fator que considera o efeito da flambagem global do elemento.

Neste estudo considerou-se sempre $Q=1$, ou seja, os elementos tubulares analisados estão livres de flambagem local. Para o material será utilizado aço tipo USI-SAC $41 \mathrm{com}$ tensão de escoamento $f_{y}=245 \mathrm{MPa} e$ 
módulo de elasticidade E=205000MPa, valores convencionais retirados de catálogos da USIMINAS. Recentemente a tensão de escoamento foi ampliada para $300 \mathrm{MPa}$ pela introdução de duas especificações para 0 mesmo aço: USI-SAC $41\left(f_{y}=245 \mathrm{MPa}\right)$ e USI-SAC 41E ( $\left.f_{y}=300 \mathrm{MPa}\right)$.

Para facilitar os estudos não serão calculadas as normais críticas, todas as análises serão realizadas em relação ao parâmetro de flambagem $\rho$.

Determinada a curva de flambagem específica, no caso de tubos; curva a (NBR-8800), tubos sem costura, e curva b, tubo com costura, o coeficiente $\rho$ é calculado em função do parâmetro $\bar{\lambda}$ (esbeltez reduzida) que como já visto é dada por:

Barras com inércia constante

\begin{tabular}{|l|l|}
\hline$\lambda=\frac{k L}{r} \sqrt{\frac{f_{y}}{\pi^{2} E}}=\sqrt{\frac{f_{y}}{f_{e}}}$ & $\bar{\lambda}^{*}=\sqrt{\frac{f_{y}}{f_{e}^{*}}}$ \\
\hline $\begin{array}{l}f_{e}=\text { tensão de flambagem elástica } \\
\text { (EULER) }\end{array}$ & $\begin{array}{l}f_{e}{ }^{*}=\text { tensão de flambagem elástica } \\
\text { com variação de inércia (LUSAS) }\end{array}$ \\
\hline
\end{tabular}

As extremidades das barras são assumidas rotuladas. Sabe-se que essa hipótese não reflete as condições reais de barras pertencentes a uma treliça espacial, na estrutura existe uma situação intermediária entre rótula e engastamento. No entanto, um estudo mais detalhado da rigidez do nó não está no escopo deste trabalho.

A tensão de flambagem elástica $\left(\mathbf{f}_{\mathrm{e}}{ }^{*}\right)$ para elementos com variação de inércia será determinada pelo método dos elementos finitos utilizando o programa LUSAS. O elemento finito utilizado foi o BM3, pertencente à biblioteca do programa. $O$ elemento possui três graus de liberdade por nó, sendo duas translações ( $u$ e $v$ ) ao longo dos eixos $X$ e $Y$ respectivamente $e$, uma rotação em torno do eixo Z, (Figura 3.11). 


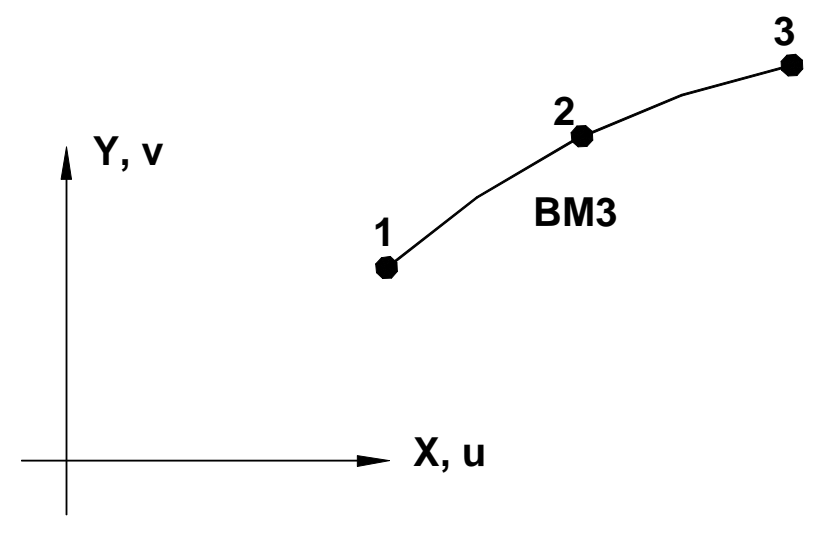

Figura 3.11. Elemento finito utilizado na análise numérica.

As seções nas extremidades estampadas dos tubos foram obtidas a partir de medições de pontos pré-definidos em seções distantes entre si em média $3,0 \mathrm{~cm}$. As coordenadas desses pontos foram medidas em uma Mesa de Precisão pertencente ao Departamento de Engenharia Elétrica da EESC. Com as coordenadas dos pontos da seção, esta foi plotada e suas propriedades geométricas calculadas no AUTOCAD - R13.

As estampagens estudadas podem ser divididas em três grupos: estampagem reta utilizada em barras unidas por nó típico (parafuso único), barras com aparelho de apoio nas estampagens retas, tradicional e nova, que foram os modelos ensaiados no LE-EESC; e, finalmente, barras com chapas de ponteiras, também ensaiadas no LE-EESC.

As dimensões dos tubos selecionados para estudos e os respectivos modelos de extremidades são apresentados na Tabela 3.3, sendo que esses diâmetros são os mais utilizados comercialmente e podem ser empregados em estruturas de médio e grande porte. 
Tabela 3.3. Dimensões e extremidades dos tubos selecionados para estudo.

\begin{tabular}{|c|c|}
\hline Tubos & \begin{tabular}{c} 
Modelo de extremidade \\
\hline$\phi 60 \times 2,0$
\end{tabular} \\
\hline$\phi 64 \times 2,0$ & Estampagem reta nó típico \\
\hline$\phi 76 \times 2,0$ & Estampagem reta nó típico \\
\hline \multirow{2}{*}{$\phi 88 \times 2,65$} & Estampagem reta nó típico \\
\cline { 2 - 2 } & Estampagem tradicional com aparelho de apoio \\
\cline { 2 - 2 } & Estampagem nova com aparelho de apoio \\
\hline$\phi 101 \times 3,0$ & Chapa de ponteira \\
\hline$\phi 114 \times 4,25$ & Chapa de ponteira \\
\hline
\end{tabular}

Os resultados da análise teórica, para cada um dos tubos da Tabela 3.3, serão apresentados comparando os "coeficientes de flambagem' $\rho$ (sem variação de inércia) e $\rho^{*}$ (com variação de inércia). Seguindo a apresentação dos resultados far-se-á uma discussão acerca dos mesmos. 
Tubo ф 60x2,0 (estampagem reta nó típico)

Tabela 3.4 Resultados de coeficientes de flambagem (tubo $\phi 60 \times 2,0$ ).

\begin{tabular}{|c|c|c|c|c|c|}
\hline$\lambda$ & $\bar{\lambda}$ & $\rho$ & $\bar{\lambda}$ & $\rho^{*}$ & $\rho / \rho^{*}$ \\
\hline 50 & 0,55 & 0,900 & 0,98 & 0,692 & 1,30 \\
\hline 60 & 0,66 & 0,863 & 1,01 & 0,669 & 1,29 \\
\hline 70 & 0,77 & 0,815 & 1,05 & 0,640 & 1,27 \\
\hline 80 & 0,88 & 0,754 & 1,10 & 0,605 & 1,25 \\
\hline 90 & 0,99 & 0,683 & 1,17 & 0,562 & 1,21 \\
\hline 100 & 1,10 & 0,608 & 1,24 & 0,515 & 1,18 \\
\hline 110 & 1,21 & 0,535 & 1,32 & 0,467 & 1,15 \\
\hline 120 & 1,32 & 0,469 & 1,41 & 0,420 & 1,12 \\
\hline 130 & 1,43 & 0,412 & 1,51 & 0,376 & 1,10 \\
\hline 140 & 1,54 & 0,364 & 1,61 & 0,337 & 1,08 \\
\hline 150 & 1,65 & 0,322 & 1,71 & 0,302 & 1,07 \\
\hline 160 & 1,76 & 0,287 & 1,81 & 0,272 & 1,06 \\
\hline 170 & 1,87 & 0,257 & 1,92 & 0,245 & 1,05 \\
\hline 180 & 1,98 & 0,231 & 2,02 & 0,222 & 1,04 \\
\hline 190 & 2,09 & 0,209 & 2,13 & 0,202 & 1,04 \\
\hline 200 & 2,20 & 0,190 & 2,24 & 0,184 & 1,03 \\
\hline
\end{tabular}
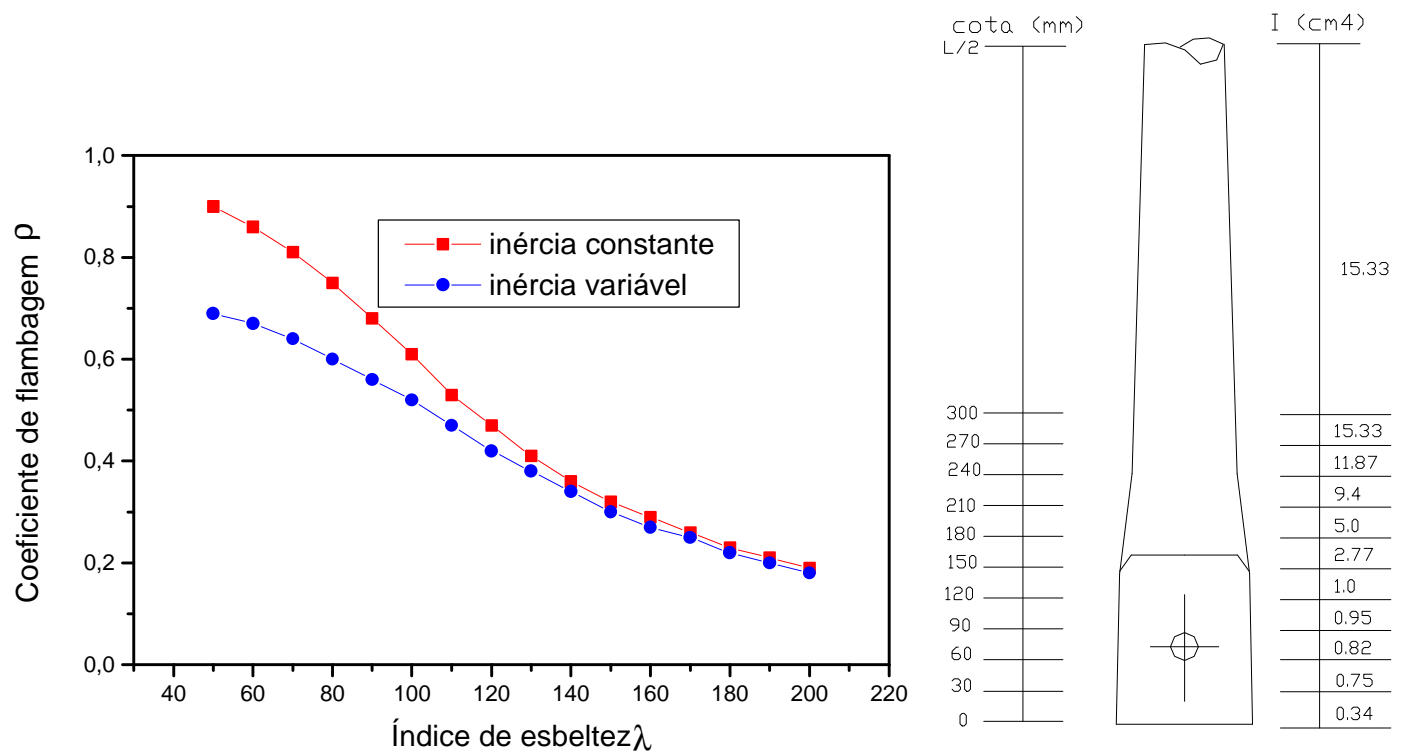

Figura 3.12 Gráfico $(\lambda \times \rho)$ com e sem variação de inércia, variação de inércia ao longo da barra $\phi 60 \times 2,0$. 


\section{Tubo ф 64×2,0 (estampagem reta nó típico)}

Tabela 3.5 Resultados de coeficientes de flambagem (tubo $\phi 64 \times 2,0$ ).

\begin{tabular}{|c|c|c|c|c|c|}
\hline$\lambda$ & $\bar{\lambda}$ & $\rho$ & $\bar{\lambda}$ & $\rho^{*}$ & $\rho / \rho^{*}$ \\
\hline 50 & 0,55 & 0,900 & 0,88 & 0,757 & 1,19 \\
\hline 60 & 0,66 & 0,863 & 0,92 & 0,730 & 1,18 \\
\hline 70 & 0,77 & 0,815 & 0,97 & 0,696 & 1,17 \\
\hline 80 & 0,88 & 0,754 & 1,04 & 0,651 & 1,16 \\
\hline 90 & 0,99 & 0,683 & 1,11 & 0,599 & 1,14 \\
\hline 100 & 1,10 & 0,608 & 1,20 & 0,542 & 1,12 \\
\hline 110 & 1,21 & 0,535 & 1,29 & 0,486 & 1,10 \\
\hline 120 & 1,32 & 0,469 & 1,39 & 0,433 & 1,08 \\
\hline 130 & 1,43 & 0,412 & 1,49 & 0,385 & 1,07 \\
\hline 140 & 1,54 & 0,364 & 1,59 & 0,343 & 1,06 \\
\hline 150 & 1,65 & 0,322 & 1,70 & 0,307 & 1,05 \\
\hline 160 & 1,76 & 0,287 & 1,80 & 0,275 & 1,04 \\
\hline 170 & 1,87 & 0,257 & 1,91 & 0,248 & 1,04 \\
\hline 180 & 1,98 & 0,231 & 2,02 & 0,224 & 1,03 \\
\hline 190 & 2,09 & 0,209 & 2,12 & 0,203 & 1,03 \\
\hline 200 & 2,20 & 0,190 & 2,23 & 0,185 & 1,03 \\
\hline
\end{tabular}
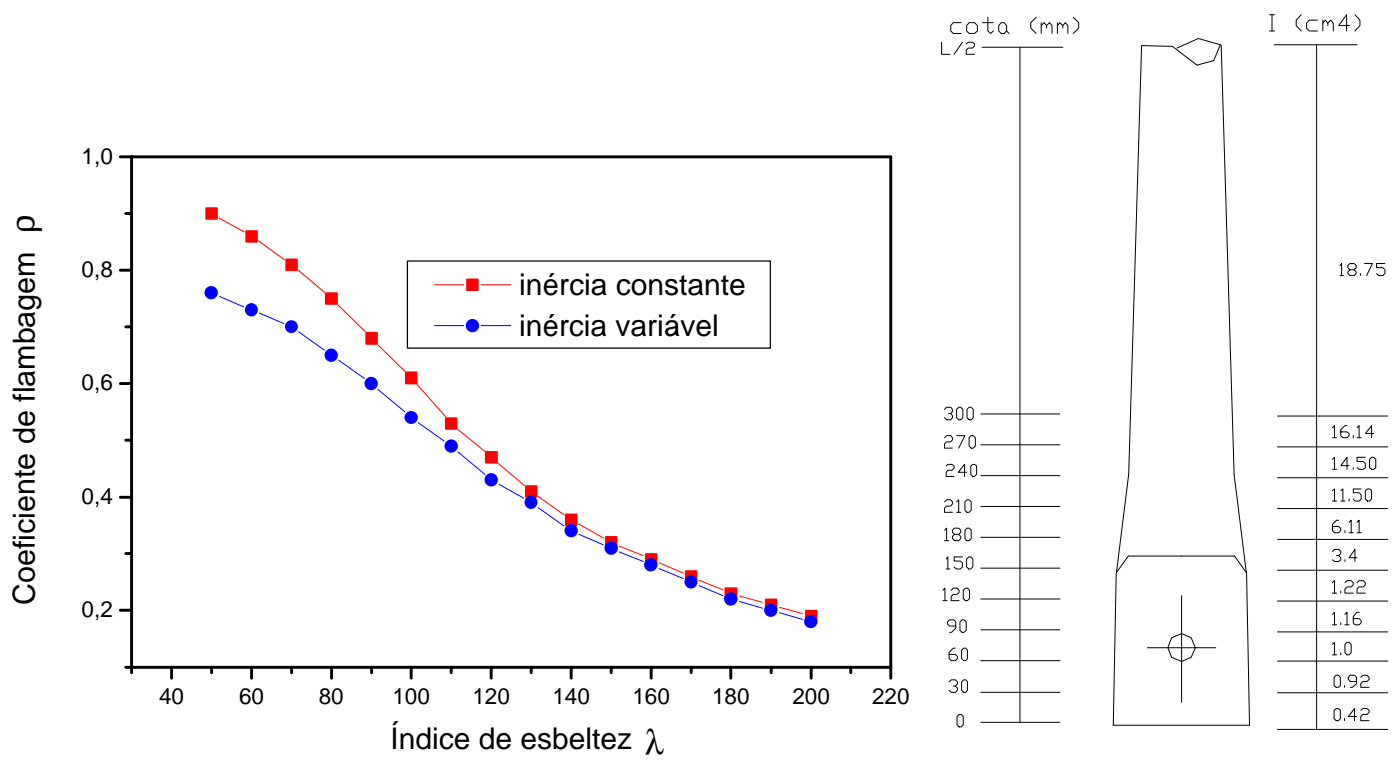

Figura 3.13 Gráfico $(\lambda \times \rho)$ com e sem variação de inércia, variação de inércia ao longo da barra $\phi 64 \times 2,0$. 
Tubo $\phi 76 \times 2,0$ (estampagem reta nó típico)

Tabela 3.6 Resultados de coeficientes de flambagem (tubo $\phi 76 \times 2,0$ ).

\begin{tabular}{|c|c|c|c|c|c|}
\hline$\lambda$ & $\bar{\lambda}$ & $\rho$ & $\bar{\lambda}$ & $\rho^{*}$ & $\rho / \rho$ \\
\hline 40 & 0,44 & 0,930 & 0,69 & 0,852 & 1,09 \\
\hline 50 & 0,55 & 0,900 & 0,73 & 0,832 & 1,08 \\
\hline 60 & 0,66 & 0,863 & 0,79 & 0,804 & 1,07 \\
\hline 70 & 0,77 & 0,815 & 0,86 & 0,764 & 1,07 \\
\hline 80 & 0,88 & 0,754 & 0,95 & 0,711 & 1,06 \\
\hline 90 & 0,99 & 0,683 & 1,04 & 0,649 & 1,05 \\
\hline 100 & 1,10 & 0,608 & 1,14 & 0,582 & 1,04 \\
\hline 110 & 1,21 & 0,535 & 1,24 & 0,517 & 1,03 \\
\hline 120 & 1,32 & 0,469 & 1,34 & 0,457 & 1,03 \\
\hline 130 & 1,43 & 0,412 & 1,45 & 0,405 & 1,02 \\
\hline 140 & 1,54 & 0,364 & 1,55 & 0,359 & 1,01 \\
\hline 150 & 1,65 & 0,322 & 1,66 & 0,319 & 1,01 \\
\hline 160 & 1,76 & 0,287 & 1,76 & 0,286 & 1,00 \\
\hline 170 & 1,87 & 0,257 & 1,87 & 0,256 & 1,00 \\
\hline 180 & 1,98 & 0,231 & 1,98 & 0,231 & 1,00 \\
\hline 190 & 2,09 & 0,209 & 2,09 & 0,210 & 1,00 \\
\hline 200 & 2,20 & 0,190 & 2,19 & 0,191 & 1,00 \\
\hline
\end{tabular}
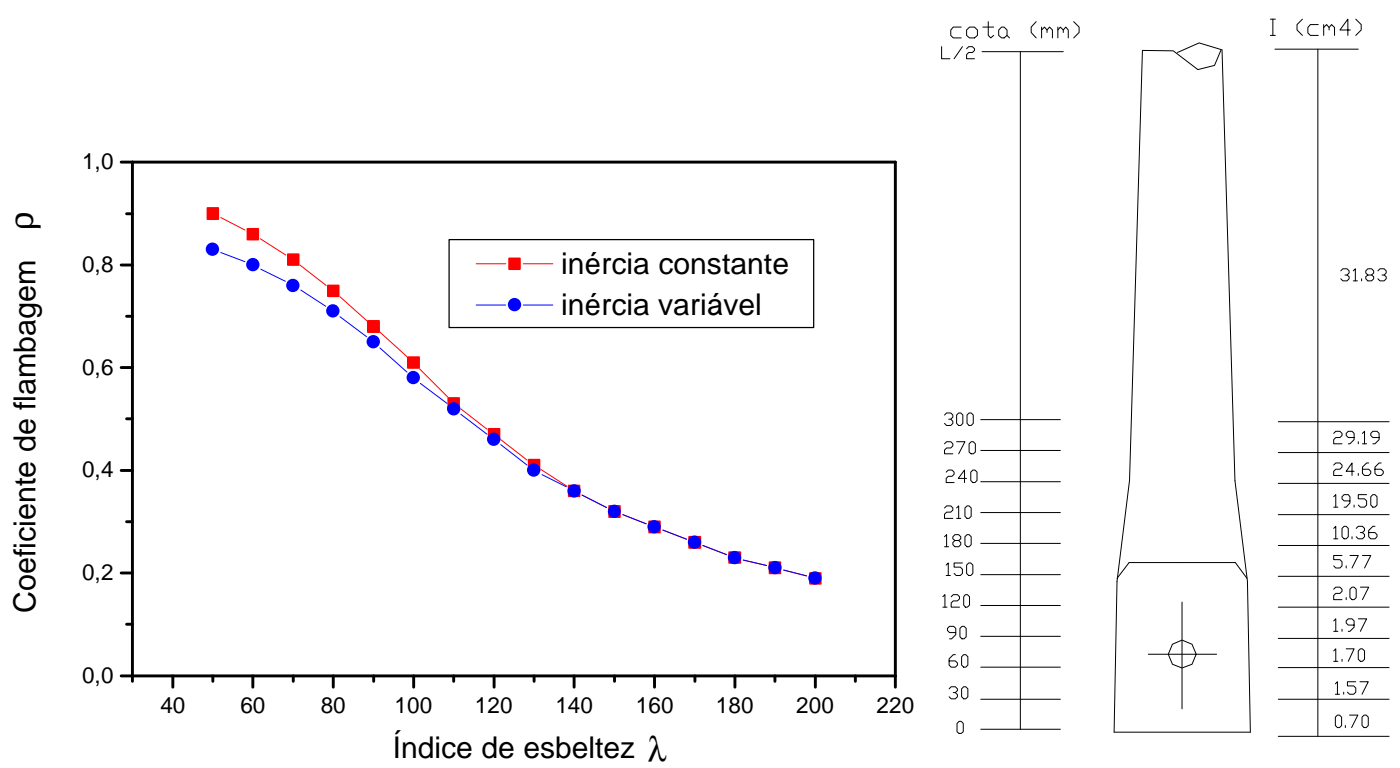

Figura 3.14 Gráfico $(\lambda \times \rho)$ com e sem variação de inércia, variação de inércia ao longo da barra $\phi 76 \times 2,0$. 
Tubos $\phi 88 \times 2,65$ (barra com aparelho de apoio estampagem reta)

Tabela 3.7 Resultados de coeficientes de flambagem (tubo $\phi$ $88 \times 2,65)$ estampagem reta.

\begin{tabular}{|c|c|c|c|c|c|}
\hline$\lambda$ & $\bar{\lambda}$ & $\rho$ & $\bar{\lambda}$ & $\rho$ & $\rho / \rho$ \\
\hline 40 & 0,44 & 0,930 & 0,66 & 0,790 & 1,18 \\
\hline 50 & 0,55 & 0,900 & 0,71 & 0,771 & 1,17 \\
\hline 60 & 0,66 & 0,863 & 0,77 & 0,745 & 1,16 \\
\hline 70 & 0,77 & 0,815 & 0,85 & 0,710 & 1,15 \\
\hline 80 & 0,88 & 0,754 & 0,94 & 0,665 & 1,14 \\
\hline 90 & 0,99 & 0,683 & 1,03 & 0,611 & 1,13 \\
\hline 100 & 1,10 & 0,608 & 1,13 & 0,553 & 1,12 \\
\hline 110 & 1,21 & 0,535 & 1,24 & 0,495 & 1,1 \\
\hline 120 & 1,32 & 0,469 & 1,34 & 0,441 & 1,08 \\
\hline 130 & 1,43 & 0,412 & 1,45 & 0,393 & 1,06 \\
\hline 140 & 1,54 & 0,364 & 1,55 & 0,350 & 1,05 \\
\hline 150 & 1,65 & 0,322 & 1,66 & 0,312 & 1,04 \\
\hline 160 & 1,76 & 0,287 & 1,77 & 0,280 & 1,03 \\
\hline 170 & 1,87 & 0,257 & 1,87 & 0,252 & 1,02 \\
\hline 180 & 1,98 & 0,231 & 1,98 & 0,228 & 1,02 \\
\hline 190 & 2,09 & 0,209 & 2,10 & 0,207 & 1,01 \\
\hline 200 & 2,2 & 0,190 & 2.20 & 0,188 & 1,01 \\
\hline
\end{tabular}
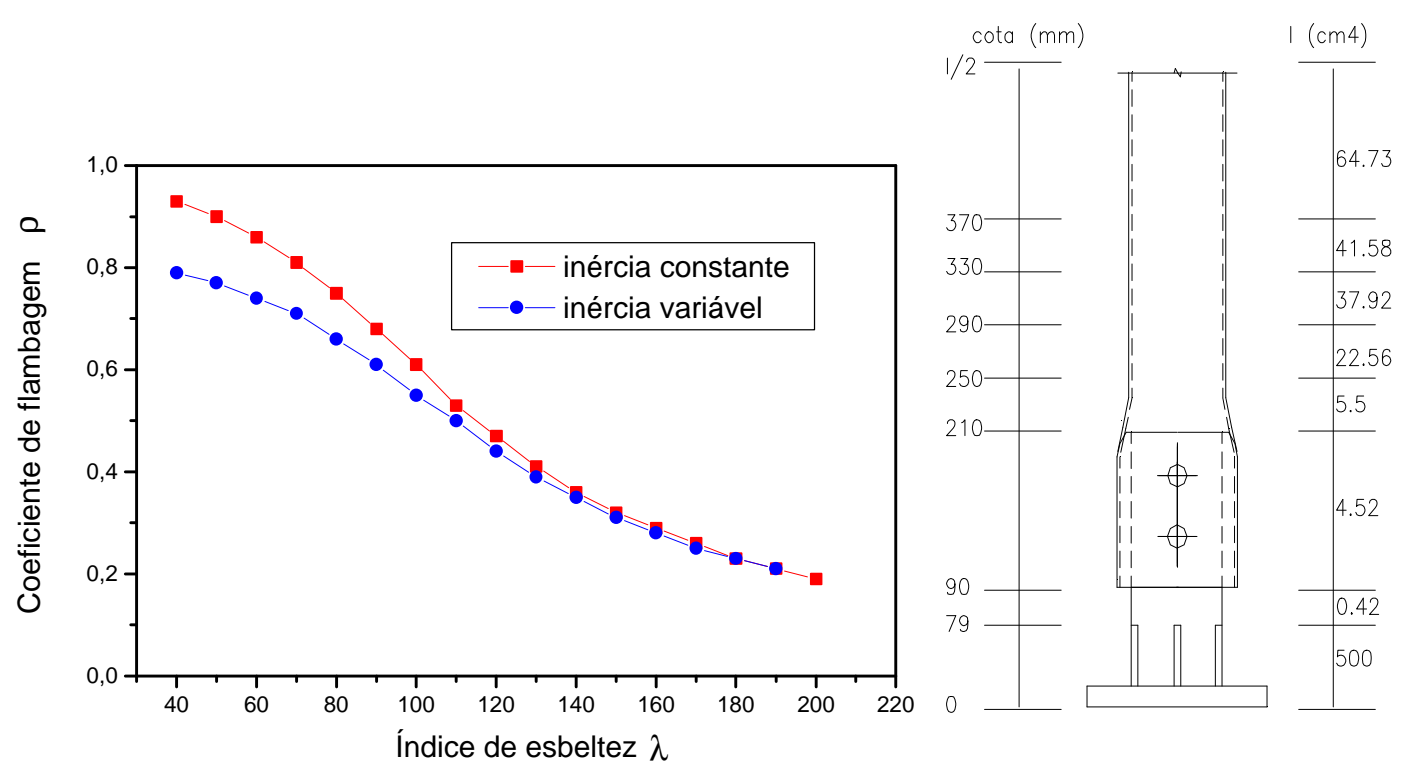

Figura 3.15 Gráfico $(\lambda \times \rho)$ com e sem variação de inércia, variação de inércia ao longo da barra $\phi 88 \times 2,65$ (estampagem reta). 
Tubos $\phi 88 \times 2,65$ (barra com aparelho de apoio estampagem tradicional).

Tabela 3.8 Resultados de coeficientes de flambagem (tubo $\phi$ $88 \times 2,65)$ estampagem tradicional.

\begin{tabular}{|c|c|c|c|c|c|}
\hline$\lambda$ & $\bar{\lambda}$ & $\rho$ & $\bar{\lambda}$ & $\rho^{*}$ & $\rho / \rho$ \\
\hline 40 & 0,44 & 0,930 & 0,66 & 0,863 & 1,08 \\
\hline 50 & 0,55 & 0,900 & 0,71 & 0,843 & 1,07 \\
\hline 60 & 0,66 & 0,863 & 0,77 & 0,814 & 1,06 \\
\hline 70 & 0,77 & 0,815 & 0,85 & 0,772 & 1,06 \\
\hline 80 & 0,88 & 0,754 & 0,94 & 0,717 & 1,05 \\
\hline 90 & 0,99 & 0,683 & 1,03 & 0,653 & 1,05 \\
\hline 100 & 1,10 & 0,608 & 1,13 & 0,585 & 1,04 \\
\hline 110 & 1,21 & 0,535 & 1,24 & 0,519 & 1,03 \\
\hline 120 & 1,32 & 0,469 & 1,34 & 0,458 & 1,02 \\
\hline 130 & 1,43 & 0,412 & 1,45 & 0,405 & 1,02 \\
\hline 140 & 1,54 & 0,364 & 1,55 & 0,359 & 1,01 \\
\hline 150 & 1,65 & 0,322 & 1,66 & 0,319 & 1,01 \\
\hline 160 & 1,76 & 0,287 & 1,77 & 0,285 & 1,01 \\
\hline 170 & 1,87 & 0,257 & 1,87 & 0,256 & 1,0 \\
\hline 180 & 1,98 & 0,231 & 1,98 & 0,231 & 1,0 \\
\hline 190 & 2,09 & 0,209 & 2,09 & 0,209 & 1,0 \\
\hline 200 & 2,2 & 0,190 & 2,20 & 0,190 & 1,0 \\
\hline
\end{tabular}
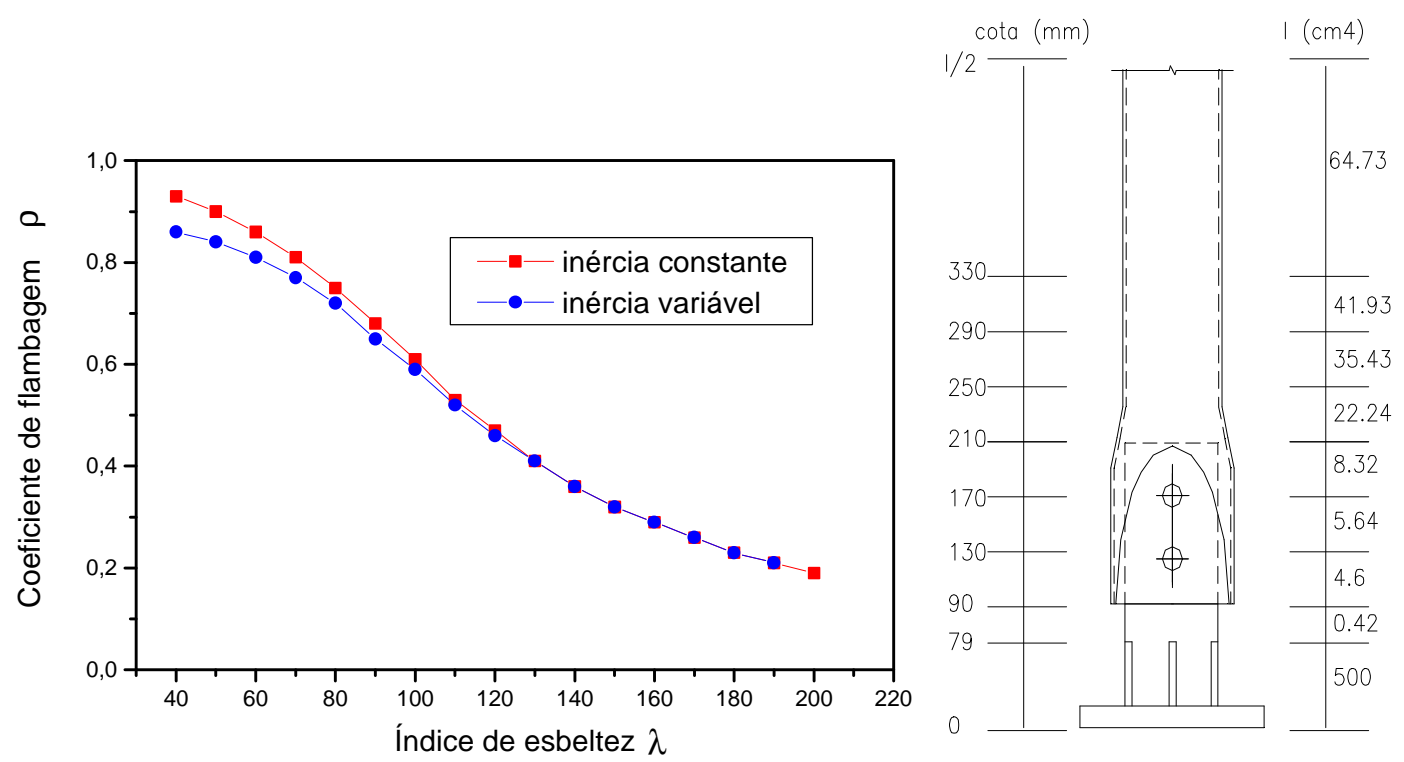

Figura 3.16 Gráfico $(\lambda \times \rho)$ com e sem variação de inércia, variação de inércia ao longo da barra $\phi 88 \times 2,65$ (estampagem tradicional). 
Tubos $\phi 88 \times 2,65$ (barra com aparelho de apoio estampagem nova)

Tabela 3.9 Resultados de coeficientes de flambagem (tubo $\phi$ $88 \times 2,65)$ estampagem nova.

\begin{tabular}{|c|c|c|c|c|c|}
\hline$\lambda$ & $\bar{\lambda}$ & $\rho$ & $\bar{\lambda}^{*}$ & $\rho^{*}$ & $\rho^{*} \rho^{*}$ \\
\hline 40 & 0,44 & 0,930 & 0,63 & 0,874 & 1,08 \\
\hline 50 & 0,55 & 0,900 & 0,68 & 0,854 & 1,07 \\
\hline 60 & 0,66 & 0,863 & 0,75 & 0,824 & 1,06 \\
\hline 70 & 0,77 & 0,815 & 0,83 & 0,781 & 1,06 \\
\hline 80 & 0,88 & 0,754 & 0,93 & 0,726 & 1,05 \\
\hline 90 & 0,99 & 0,683 & 1,02 & 0,660 & 1,05 \\
\hline 100 & 1,10 & 0,608 & 1,13 & 0,590 & 1,04 \\
\hline 110 & 1,21 & 0,535 & 1,23 & 0,523 & 1,03 \\
\hline 120 & 1,32 & 0,469 & 1,33 & 0,461 & 1,02 \\
\hline 130 & 1,43 & 0,412 & 1,44 & 0,407 & 1,02 \\
\hline 140 & 1,54 & 0,364 & 1,55 & 0,360 & 1,01 \\
\hline 150 & 1,65 & 0,322 & 1,66 & 0,320 & 1,01 \\
\hline 160 & 1,76 & 0,287 & 1,76 & 0,286 & 1,01 \\
\hline 170 & 1,87 & 0,257 & 1,87 & 0,256 & 1,0 \\
\hline 180 & 1,98 & 0,231 & 1,98 & 0,231 & 1,0 \\
\hline 190 & 2,09 & 0,209 & 2,09 & 0,209 & 1,0 \\
\hline 200 & 2,2 & 0,190 & 2,20 & 0,190 & 1,0 \\
\hline
\end{tabular}
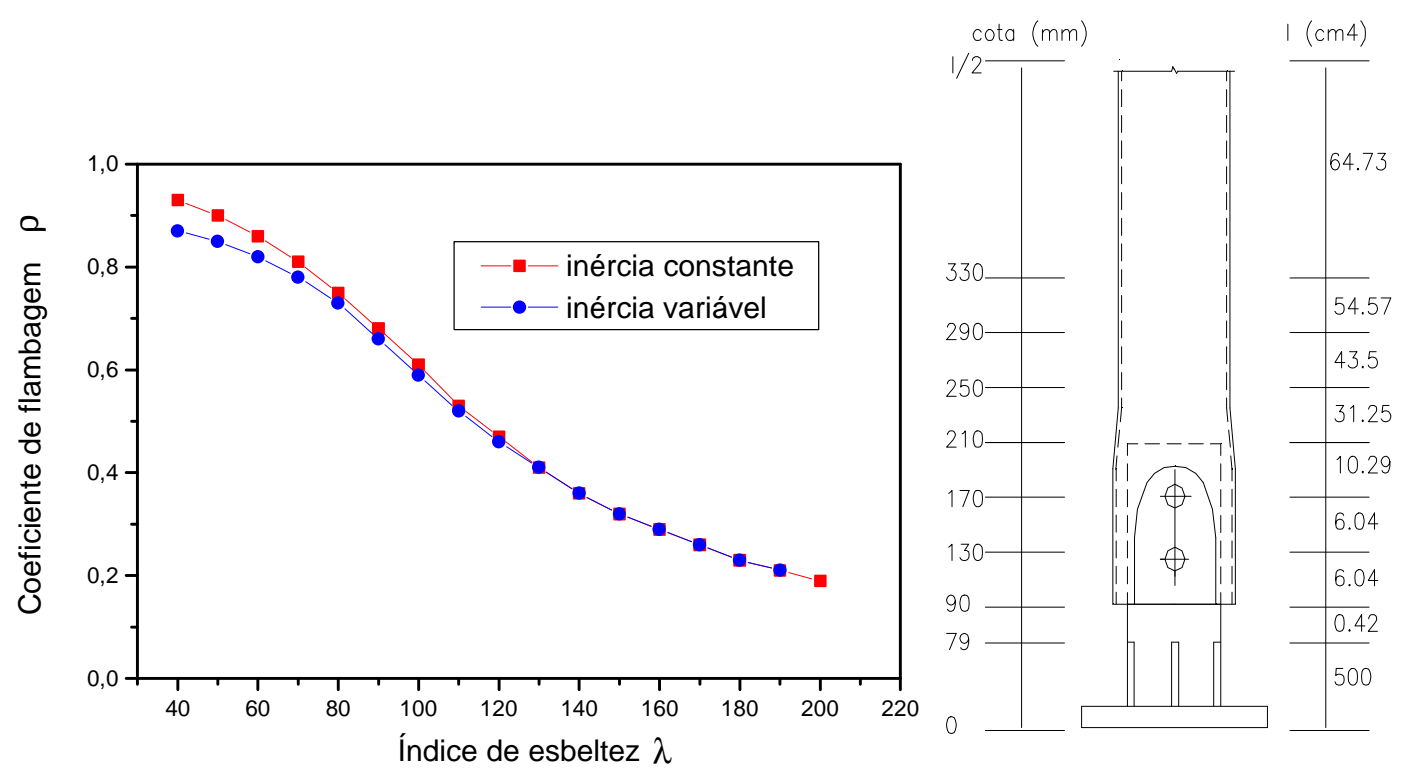

Figura 3.17 Gráfico $(\lambda \times \rho)$ com e sem variação de inércia, variação de inércia ao longo da barra $\phi 88 \times 2,65$ (estampagem nova). 


\section{Tubos $\phi 101 \times 3,0$ (barra com chapa de ponteira)}

Tabela 3.10 Resultados de coeficientes de flambagem (tubo $\phi$ $101 \times 3,0)$.

\begin{tabular}{|c|c|c|c|c|c|}
\hline$\lambda$ & $\bar{\lambda}$ & $\rho$ & $\bar{\lambda}$ & $\rho^{*}$ & $\rho / \rho$ \\
\hline 40 & 0,44 & 0,930 & 0,61 & 0,880 & 1,06 \\
\hline 50 & 0,55 & 0,900 & 0,67 & 0,859 & 1,05 \\
\hline 60 & 0,66 & 0,863 & 0,74 & 0,827 & 1,04 \\
\hline 70 & 0,77 & 0,815 & 0,83 & 0,783 & 1,04 \\
\hline 80 & 0,88 & 0,754 & 0,92 & 0,727 & 1,04 \\
\hline 90 & 0,99 & 0,683 & 1,02 & 0,661 & 1,03 \\
\hline 100 & 1,10 & 0,608 & 1,13 & 0,590 & 1,03 \\
\hline 110 & 1,21 & 0,535 & 1,23 & 0,523 & 1,02 \\
\hline 120 & 1,32 & 0,469 & 1,34 & 0,461 & 1,02 \\
\hline 130 & 1,43 & 0,412 & 1,44 & 0,407 & 1,01 \\
\hline 140 & 1,54 & 0,364 & 1,55 & 0,360 & 1,01 \\
\hline 150 & 1,65 & 0,322 & 1,66 & 0,320 & 1,01 \\
\hline 160 & 1,76 & 0,287 & 1,76 & 0,286 & 1,00 \\
\hline 170 & 1,87 & 0,257 & 1,87 & 0,256 & 1,00 \\
\hline 180 & 1,98 & 0,231 & 1,98 & 0,231 & 1,00 \\
\hline 190 & 2,09 & 0,209 & 2,09 & 0,209 & 1,00 \\
\hline 200 & 2,2 & 0,190 & 2,20 & 0,190 & 1,00 \\
\hline
\end{tabular}
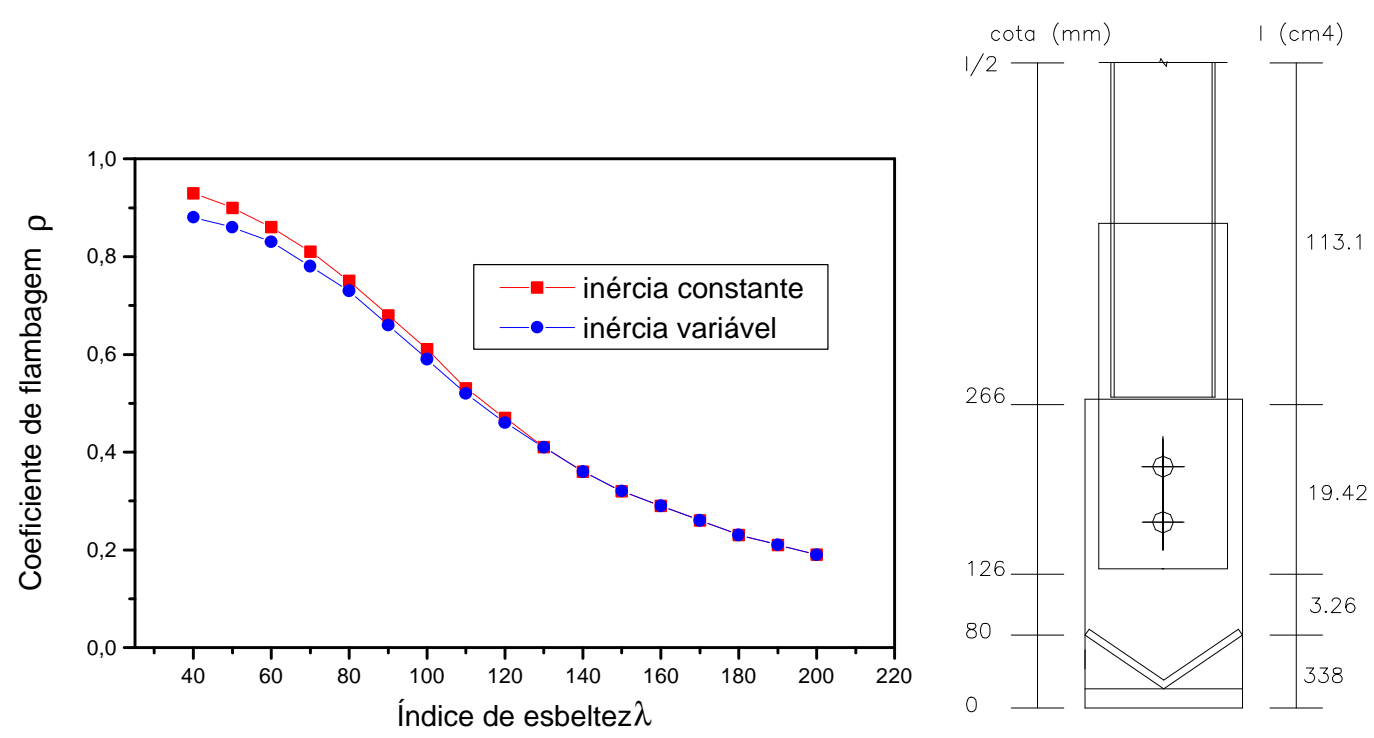

Figura 3.18 Gráfico $(\lambda \times \rho)$ com e sem variação de inércia, variação de inércia ao longo da barra $\phi 101 \times 3,0$.

Tubos $\phi 114 \times 4,25$ (barra com chapa de ponteira) 
Tabela 3.11 Resultados de coeficientes de flambagem (tubo $\phi$ $114 \times 4,25)$.

\begin{tabular}{|c|c|c|c|c|c|}
\hline$\lambda$ & $\bar{\lambda}$ & $\rho$ & $\bar{\lambda}$ & $\rho^{*}$ & $\rho / \rho^{*}$ \\
\hline 40 & 0,44 & 0,930 & 0,70 & 0,846 & 1,10 \\
\hline 50 & 0,55 & 0,900 & 0,74 & 0,828 & 1,09 \\
\hline 60 & 0,66 & 0,863 & 0,80 & 0,801 & 1,08 \\
\hline 70 & 0,77 & 0,815 & 0,87 & 0,762 & 1,07 \\
\hline 80 & 0,88 & 0,754 & 0,95 & 0,710 & 1,06 \\
\hline 90 & 0,99 & 0,683 & 1,04 & 0,648 & 1,05 \\
\hline 100 & 1,10 & 0,608 & 1,14 & 0,582 & 1,04 \\
\hline 110 & 1,21 & 0,535 & 1,24 & 0,517 & 1,04 \\
\hline 120 & 1,32 & 0,469 & 1,34 & 0,457 & 1,03 \\
\hline 130 & 1,43 & 0,412 & 1,45 & 0,404 & 1,02 \\
\hline 140 & 1,54 & 0,364 & 1,55 & 0,358 & 1,01 \\
\hline 150 & 1,65 & 0,322 & 1,66 & 0,319 & 1,01 \\
\hline 160 & 1,76 & 0,287 & 1,77 & 0,285 & 1,01 \\
\hline 170 & 1,87 & 0,257 & 1,87 & 0,256 & 1,00 \\
\hline 180 & 1,98 & 0,231 & 1,98 & 0,231 & 1,00 \\
\hline 190 & 2,09 & 0,209 & 2,09 & 0,209 & 1,00 \\
\hline 200 & 2,2 & 0,190 & 2,20 & 0,190 & 1,00 \\
\hline
\end{tabular}
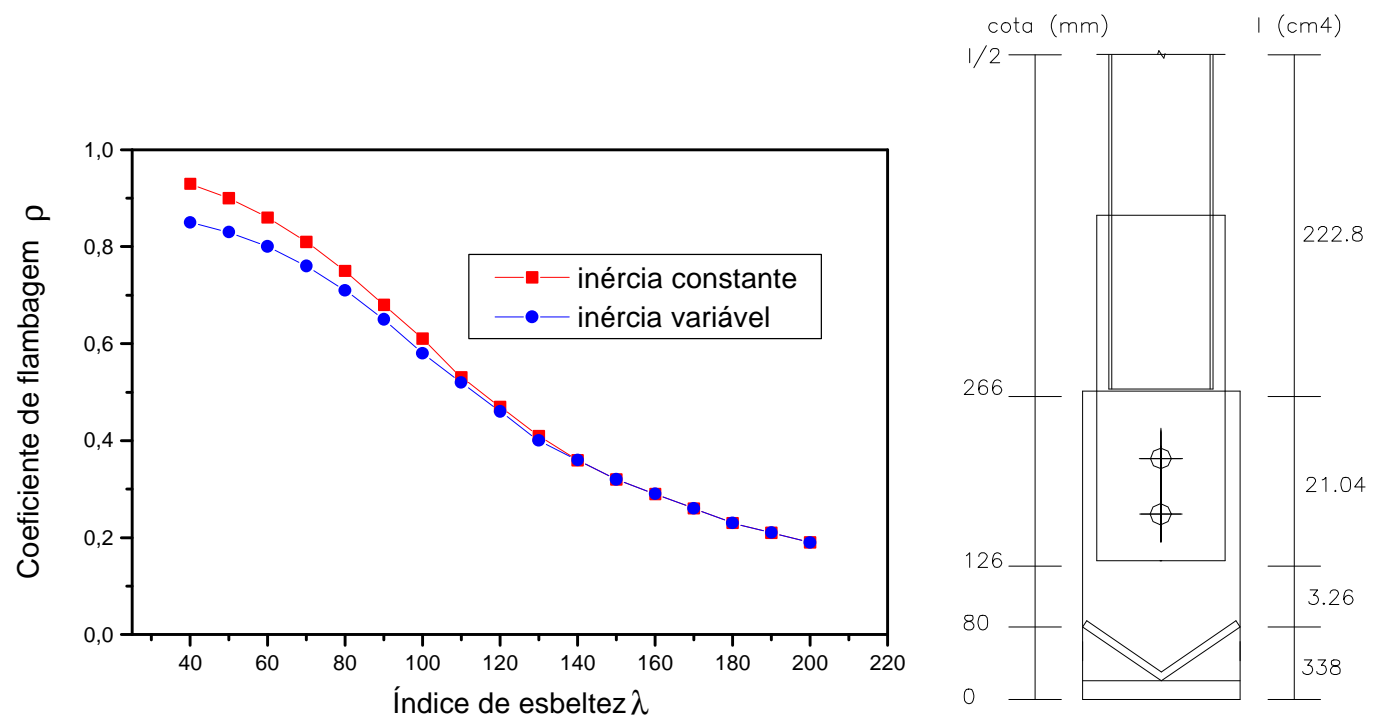

Figura 3.19 Gráfico $(\lambda \times \rho)$ com e sem variação de inércia, variação de inércia ao longo da barra $\phi 114 \times 4,25$. 
A análise teórica de tubos circulares com extremidades estampadas e com chapa de ponteira mostra que a variação de inércia tem influência na determinação da força normal resistente de um elemento comprimido.

Para as extremidades estampadas, obviamente cada padrão de estampagem leva a resultados diferentes, mas o comportamento é semelhante. Dentro do intervalo de esbeltez usual, que situa-se entre $\lambda=70$ e $\lambda=120$, tem-se reduções na capacidade resistente variando entre $5 \%$ e $10 \%$.

Para as extremidades com chapa de ponteira estudadas, a redução na capacidade resistente ficou abaixo dos $5 \%$ para os índices de esbeltez usuais. No entanto, a espessura e o comprimento não enrijecido da ponteira alteram sensivelmente esses resultados.

Barras com chapas de ponteira ou aparelho de apoio com chapas de espessuras reduzidas e comprimento não enrijecido significativo sofrem reduções na capacidade resistente superiores a $50 \%$ para as esbeltezes usuais. O gráfico da Figura 3.20 comprova este fato. No gráfico são apresentados resultados para tubos de $88 \times 2,65$ estampagem reta com aparelho de apoio, o mesmo apresentado anteriormente, só que neste caso o comprimento não enrijecido da chapa de apoio foi aumentado em cinco vezes. A nova variação de inércia na extremidade do tubo pode ser vista também na Figura 3.20. 

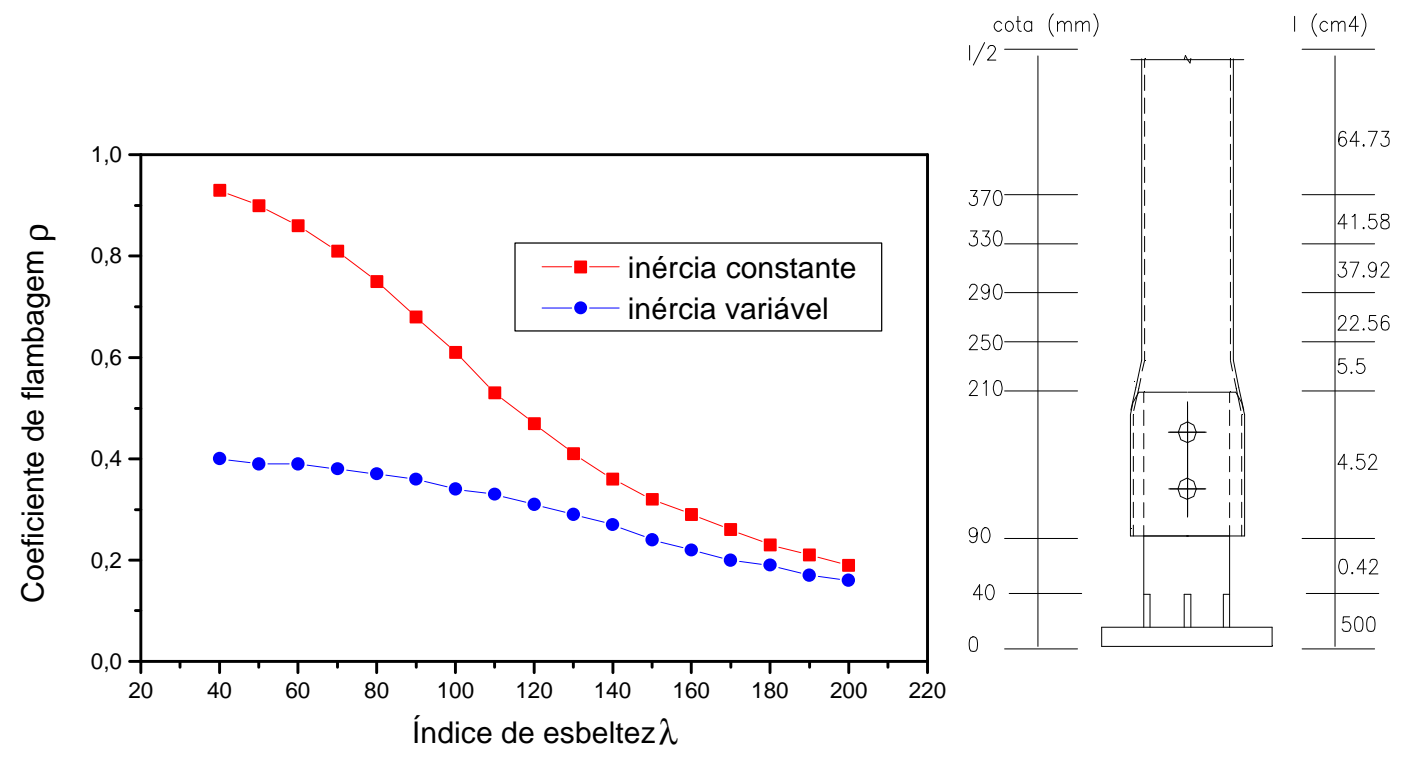

Figura 3.20 Tubo $\phi 88 \times 2,65$ (estampagem reta) chapa de apoio com baixa rigidez. Variação de inércia ao longo da barra

Percebe-se, também, que quando a flambagem ocorre em regime inelástico (baixo valores de índice de esbeltez) a redução na força normal resistente é bastante elevada, aproximando-se dos $20 \%$ em relação a calculada com inércia constante.

Como conclusão preliminar da análise de barras, pode-se afirmar que o dimensionamento de barras circulares com variação de inércia merece atenção especial por parte dos projetistas. Apesar dos resultados teóricos apresentados aqui não refletirem com total fidelidade o comportamento deste elementos na estrutura, é fácil perceber que uma barra dimensionada no limite de sua capacidade resistente, sem considerar a variação de inércia, pode conduzir a resultados insatisfatórios.

O procedimento para se considerar o efeito da variação de inércia, apesar de simples, é muito trabalhoso inviabilizando seu uso prático. Para os casos gerais, aqui estudados, recomenda-se então reduzir a capacidade resistente das barras em $20 \%$ para $\lambda<70 ; 10 \%$ para esbeltez entre $\lambda=70$ e $\lambda$ $=120$ e acima destes valores de esbeltez a redução é desnecessária. 
Atenção especial deve ser dada às ligações com ponteiras, quanto à sua rigidez, nas estruturas espaciais com grandes vãos (superiores a $25,0 \mathrm{~m}$ ), é aconselhável que as barras com variações de inércia sejam dimensionadas segundo as recomendação do EUROCODE(1992) apresentadas neste trabalho e adaptadas à norma brasileira NBR8800(1986), ou seja, considerando a variação de inércia.

\subsubsection{Resultados experimentais}

\subsubsection{Ensaio de tubos de aço: GONÇALVES(1996)}

GONÇALVES (1996) realizou estudos experimentais em tubos de aço retirados da cobertura espacial, do centro de convenções de Manaus, que sofreu colapso. O objetivo do estudo era comparar a capacidade resistente das barras com aquelas para as quais foram dimensionadas.

Foram ensaiados 12 protótipos, divididos em três grupos que são apresentados na Tabela 3.12.

Tabela 3.12 Grupos de protótipos ensaiados por GONÇALVES (1996)

\begin{tabular}{|c|c|c|c|}
\hline Grupo & Seção & Comp. (mm) & Extremidades \\
\hline A & $\phi 76 \times 2,26$ & 4162 & $\begin{array}{c}\text { Estampagem } \\
\text { reta }\end{array}$ \\
\hline B & $\phi 101 \times 3,0$ & 4354 & Ponteira \\
\hline C & $\phi 114 \times 4,25$ & 4354 & Ponteira \\
\hline
\end{tabular}

Os comprimentos constantes na Tabela 3.12 correspondem ao comprimento entre faces extremas dos aparelhos de apoio, utilizados nos ensaios de barras, que procuraram representar as condições de ligação da estrutura, ou seja, foram mantidas as distâncias de PT a PT (ponto de trabalho). O enrijecimento obtido com as cantoneiras soldadas ao aparelho de apoio (figura 3.21) procuram reproduzir as condições de rigidez devido às barras que concorrem no nó. 
A Figura 3.21 apresenta esquematicamente os grupos de protótipos ensaiados. Nota-se a variação de inércia nas extremidades das barras.

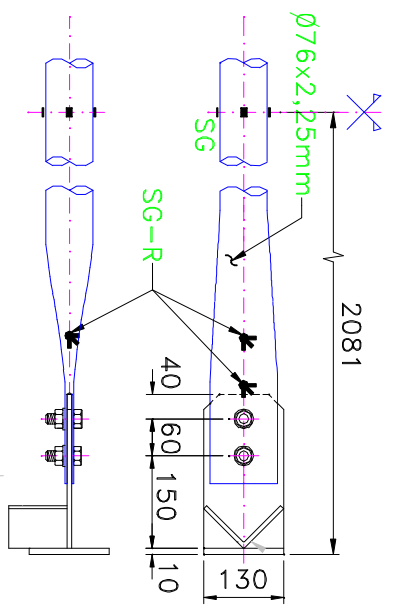

GRUPO A

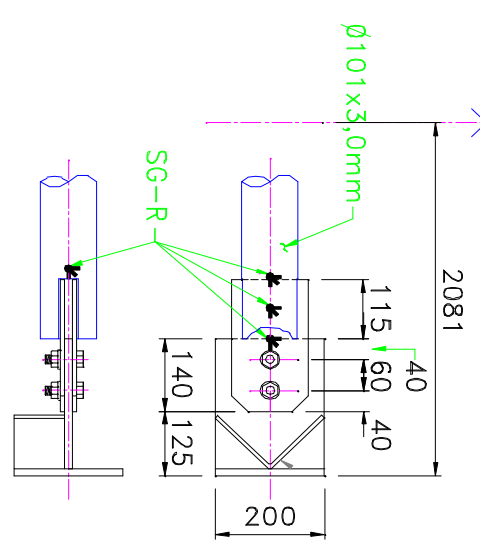

GRUPO B

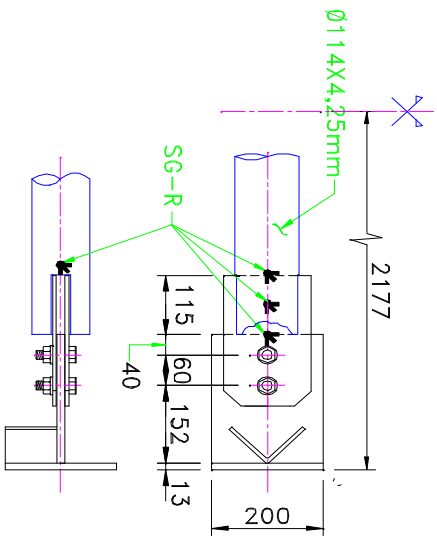

GRUPO C

Figura 3.21 Protótipos ensaiados GONÇALVES (1996)

Os tubos utilizados para realização dos ensaios são conformados a frio com solda de costura em aço USI-SAC41 ( $\left.\mathrm{f}_{\mathrm{y}}=245 \mathrm{MPa}\right)$ e as chapas de apoio em aço ASTM-A36. Os parafusos são do tipo ASTM-A325.

Os protótipos foram ensaiados a compressão axial na posição vertical. A extremidade superior foi simplesmente apoiada na estrutura de reação e a extremidade inferior apoiada em uma superfície esférica junto à célula de carga. Pretendia-se simular um modelo bi-rotulado, no entanto, é fácil perceber que a extremidade superior junto à estrutura de reação oferece certa restrição ao giro.

A Tabela 3.13 apresenta, em detalhes, os resultados experimentais de força normal para as barras. 
Tabela 3.13 Resultados experimentais de força normal resistente para barras circulares com variações de inércia. GONÇALVES (1996)

\begin{tabular}{|c|c|c|c|}
\hline \multicolumn{4}{|c|}{ Força normal última experimental Pu (kN) } \\
\hline Protótipos & Grupo A & Grupo B & Grupo C \\
\hline $\mathbf{1}$ & 18,2 & 165,1 & 258,3 \\
\hline $\mathbf{2}$ & 17,1 & 124,7 & 307,4 \\
\hline $\mathbf{3}$ & 23,8 & 164,9 & 240,1 \\
\hline $\mathbf{4}$ & 24,2 & 185,5 & 300,4 \\
\hline Média & $\mathbf{2 0 , 8}$ & $\mathbf{1 6 0 , 0}$ & $\mathbf{2 7 6 , 5}$ \\
\hline
\end{tabular}

\section{Comparação de resultados teóricos $\mathrm{x}$ experimentais}

A tabela 3.14 apresenta um resumo comparativo entre os valores experimentais e teóricos para as barras ensaiadas. Os valores teóricos da força normal resistente foram calculados utilizando a norma NBR-8800 (1986). Considerou-se também a variação de inércia nas extremidades das barras. Admitiu-se extremidades rotuladas e as propriedades do material as convencionais, uma vez que não se realizou ensaio de caracterização do material.

Tabela 3.14 Comparação resultados teóricos $x$ experimentais (barra bi-rotulada)

\begin{tabular}{|c|c|c|c|c|c|c|c|}
\hline & $\lambda$ & $\mathbf{N}_{\text {c(teor.) }}$ & $\mathbf{N}_{\text {c(teor.) }}^{*}$ & $\mathbf{N}_{\text {u(exp.) }}$ & $\mathbf{N}_{c} / \mathbf{N}_{c}$ & $\mathbf{N}_{u} / \mathbf{N}_{c}^{*}$ & $\mathbf{N}_{u} / \mathbf{N}_{c}$ \\
\hline A & 159 & 33,39 & 19,72 & 25,34 & 1,31 & 1,05 & 0,63 \\
\hline B & 119 & 96,77 & 88,84 & 160,0 & 1,09 & 1,79 & 1,34 \\
\hline C & 112 & 168,22 & 163,50 & 276,5 & 1,03 & 1,70 & 1,64 \\
\hline
\end{tabular}

Nc Normal crítica teórica considerando variação de inércia ao longo da barra.

Como foi discutido, as extremidades das barras junto à estrutura de reação não são exatamente rótulas uma vez que devido a sua configuração, podem oferecer restrições ao giro. Para efeito de comparação realizou-se uma análise teórica considerando a barra engastada na extremidade da 
estrutura de reação e rotulada na outra. Os resultados desta análise são apresentados na Tabela 3.15.

Tabela 3.15 Comparação resultados teóricos $x$ experimentais (barra rotulada - engastada)

\begin{tabular}{|c|c|c|c|c|c|c|c|}
\hline & $\lambda$ & $\mathbf{N}_{\mathrm{c} \text { (teor.) }}$ & $\mathbf{N}_{c \text { (teor.) }}^{*}$ & $\mathrm{~N}_{\mathrm{u}(\text { exp.) }}$ & $\mathbf{N}_{\mathrm{c}} / \mathbf{N}_{\mathrm{c}}$ & $\mathbf{N}_{\mathrm{u}} / \mathbf{N}_{\mathrm{c}}$ & $\mathbf{N}_{\mathrm{u}} / \mathbf{N}_{\mathrm{c}}$ \\
\hline A & 111,3 & 60,75 & 29,23 & 20,80 & 2,08 & 0,95 & 0,34 \\
\hline B & 83,3 & 148,94 & 113,90 & 160,0 & 1,31 & 1,41 & 1,07 \\
\hline C & 78,4 & 246,90 & 192,95 & 276,50 & 1,28 & 1,43 & 1,12 \\
\hline
\end{tabular}

Ncr Normal crítica teórica considerando variação de inércia ao longo da barra

Percebe-se pela Tabela 3.15 que os valores são mais próximos dos teóricos quando estes são determinados admitindo o modelo rotulado engastado. Esse comportamento, no entanto, não se verifica para as barras do Grupo A, o que pode ser atribuído a grande sensibilidade que o tipo de extremidade apresenta em relação às excentricidades, imperfeições iniciais e imperfeições relacionadas ao ensaio, bem como a grande possibilidade de formação de rótulas plásticas no região final da estampagem da barra próximo a chapa do aparelho de apoio que possui espessura reduzida.

Os gráficos das figuras 3.22 a 3.24 apresentam as curvas de resistência teóricas da NBR-8800(1986), "curva a" juntamente com os resultados experimentais (valores médios) obtidos para as barras ensaiadas. Nestes gráficos é plotado o lugar geométrico dos valores experimentais, ou seja, um segmento de reta horizontal entre as esbeltezes correspondentes ao modelo bi-rotulado e engastatado-rotulado. Adotou-se esse procedimento pois, como foi comentado anteriormente, não se pode precisar o índice de esbeltez efetivo da barra ensaiada. 

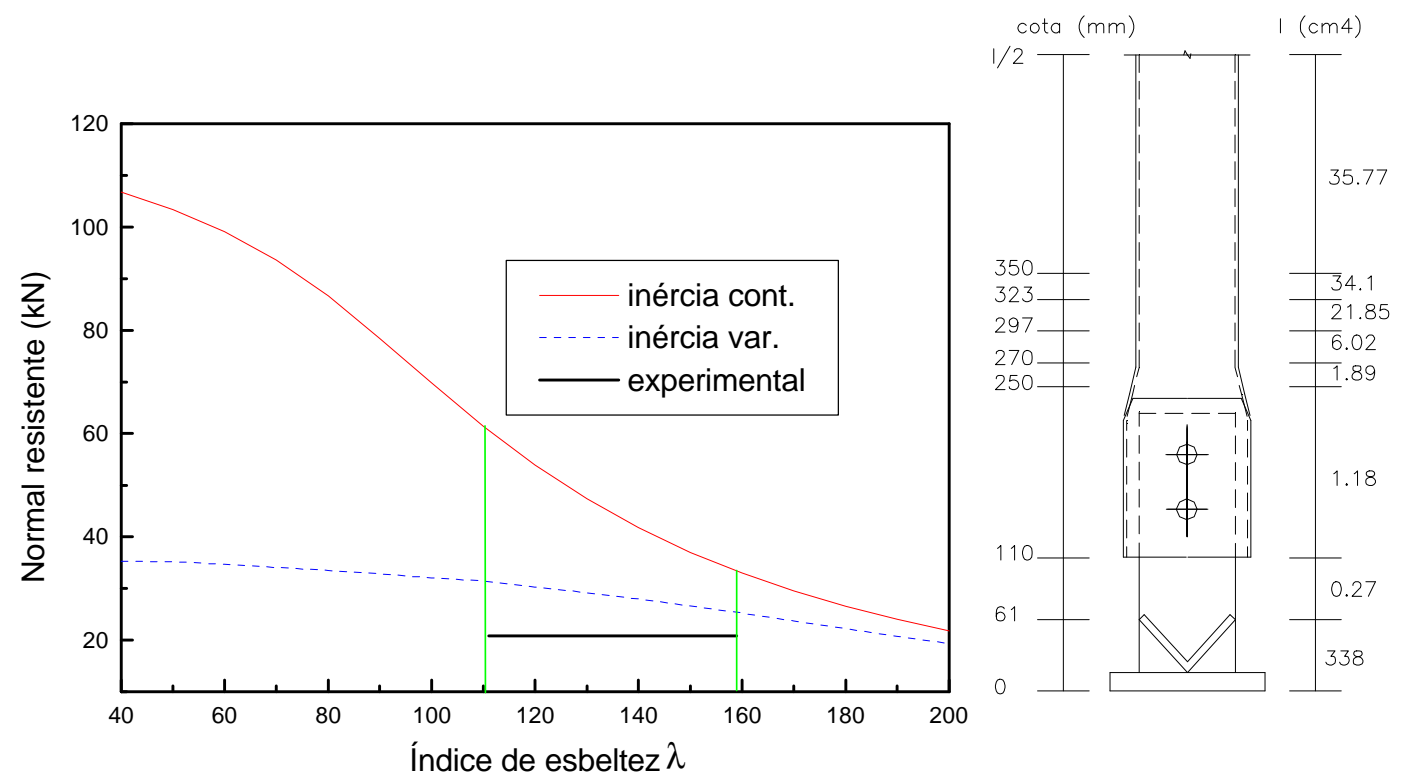

Figura 3.22 Resultados teóricos x experimentais $\phi 76 \times 2,25$ - variação de inércia ao longo da barra.

No gráfico da Figura 3.22 é assustadora a diferença entre os valores teóricos de força normal crítica com e sem variação de inércia. Analisando o detalhe da extremidade desta barra nota-se um trecho com uma rigidez muito baixa (chapa do aparelho de apoio), o que pode causar diferenças significativas como as apresentadas na figura acima. O que ocorre é que este trecho plastifica e as excentricidades aumentam significativamente, transformando-se em um ponto de inflexão, alterando as condições de vinculação do elemento. 

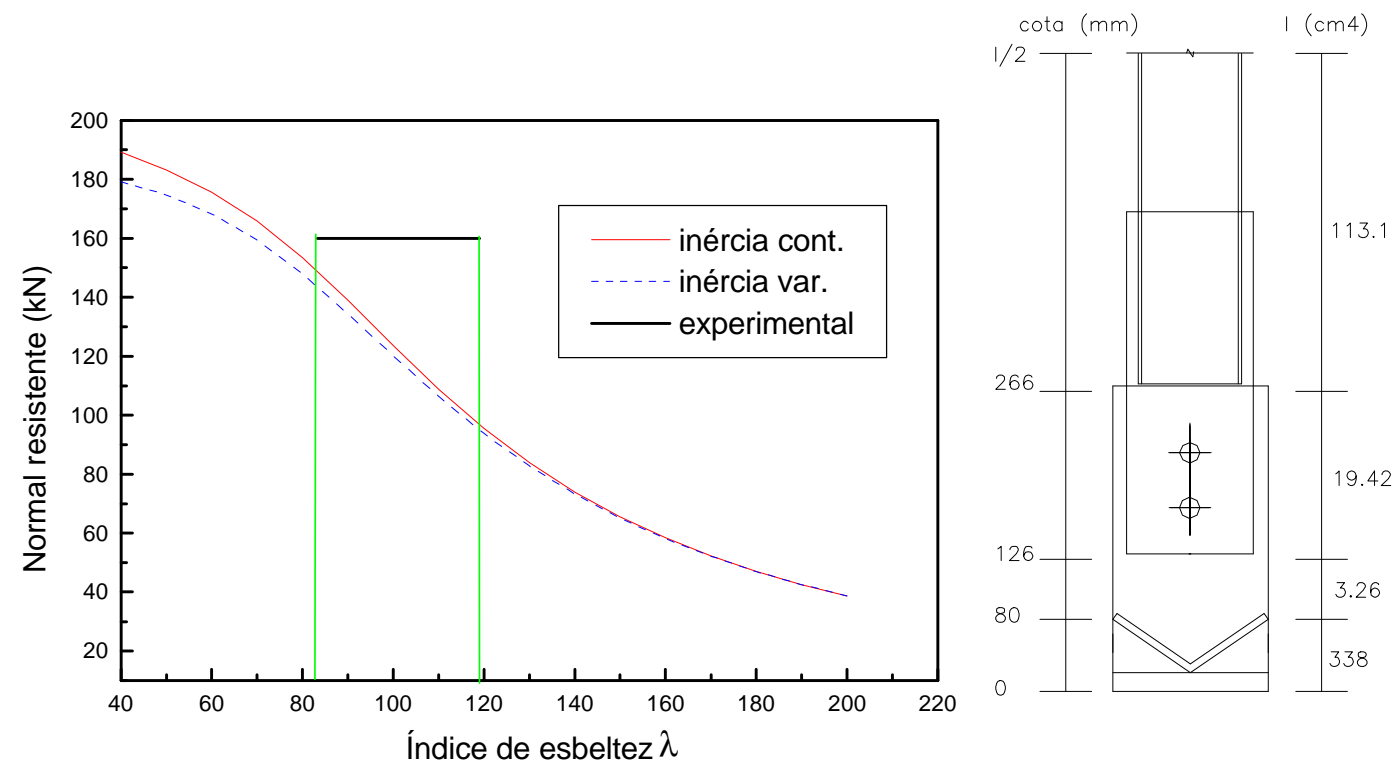

Figura 3.23 Resultados teóricos $x$ experimentais $\phi 101 \times 3,0$ - variação de inércia ao longo da barra.
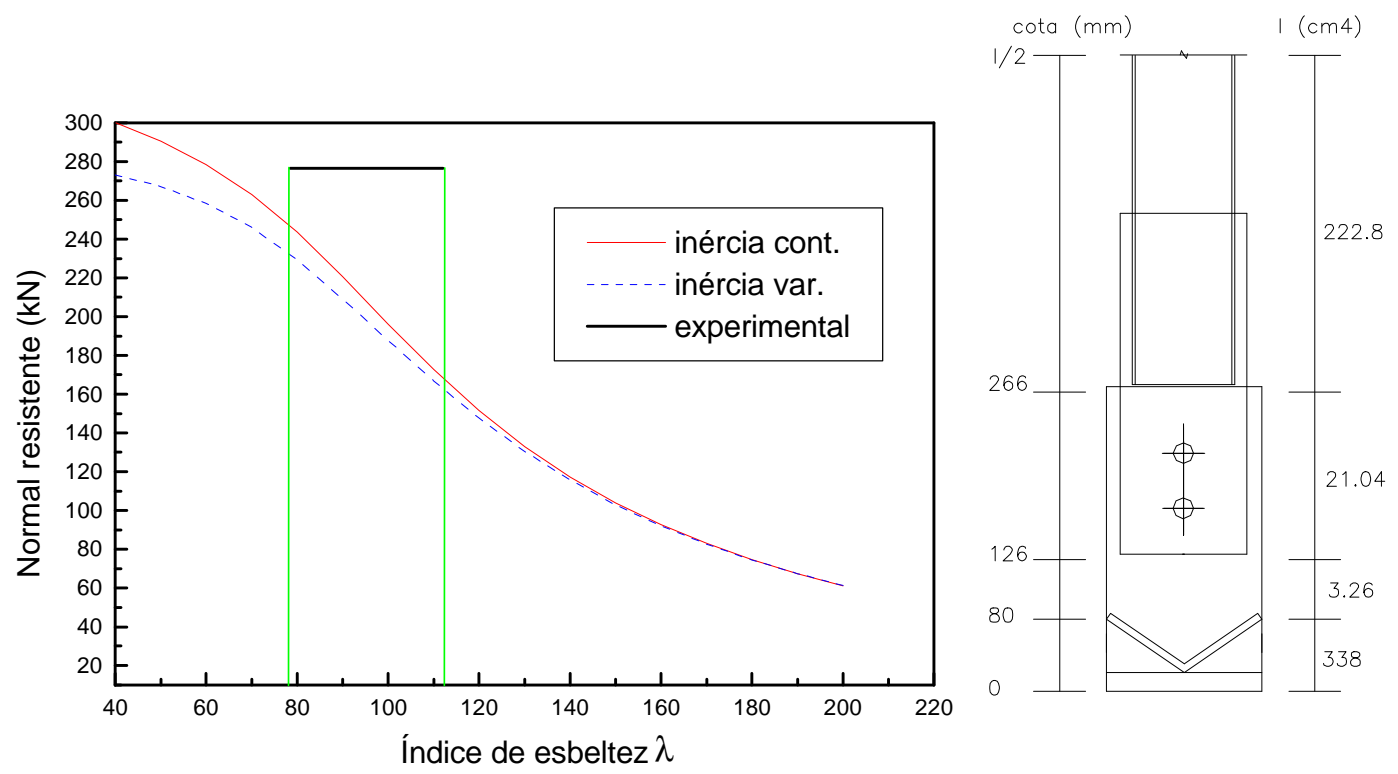

Figura 3.24 Resultados teóricos x experimentais $\phi 141 \times 4,25$ variação de inércia ao longo da barra.

Nos ensaios dos tubos $\phi 101 \times 3,0$ e $\phi 141 \times 4,25$, a forma de ruína predominante, nos ensaios, caraterizou-se pela plastificação das seções da 
chapa de ponteira na região da ligação entre a barra e as chapas de nó, devido a rotações na direção de menor inércia.

Para as barras do Grupo A, ao contrário dos outros grupos, os valores de força crítica experimentais resultaram menores que os teóricos. Isso pode ser explicado devido a grande influência da variação de inércia nas extremidades dessas barras que é mais sensível que as extremidades com chapas de ponteiras (grupos B e C). Este fato pode ser comprovado analisando a Tabela 3.14 onde percebe-se que a força crítica experimental aproxima-se bastante da teórica com variação de inércia.

Comparando-se os resultados teóricos com e sem variação de inércia percebe-se uma grande redução na capacidade resistente das barras. Para a estampagem do grupo A chega-se a reduções da ordem de 50\% da carga crítica ou de flambagem, para as esbeltezes usuais. Para as extremidades dos grupos $B$ e $C$ as reduções na carga de flambagem situam-se em torno de $5 \%$ para as esbeltezes usuais. A redução na carga crítica de flambagem, sob influência da variação de inércia, é mais significativa quando ocorre flambagem inélastica.

É necessário salientar que os ensaios de barras isoladas dificilmente representam seu comportamento na estrutura, pois pouco se sabe sobre 0 comportamento dos nós de tubos estampados e de chapa, que exercem grande influência no comportamento da barra e da estrutura como um todo.

\subsubsection{Ensaio de tubos de aço: MALITE(1997)}

MALITE et al.(1997) realizaram ensaios de compressão axial em tubos de aço, de seção circular, com extremidades estampadas. O objetivo dos ensaios foi comparar o comportamento estrutural na compressão axial de três diferentes tipos de estampagens de extremidades.

Foram ensaiados um total de 27 protótipos $(\phi 88 \times 2,65)$, sendo três tipos de estampagens diferentes e para cada uma, três diferentes valores de esbeltez $(\lambda=60,100,140)$ que correspondem a comprimentos, entre placas de apoios, de $1.800 \mathrm{~mm}, 3.000 \mathrm{~mm}$ e $4.200 \mathrm{~mm}$ respectivamente. 
Os protótipos utilizados para realização dos ensaios foram conformados a frio em aço USI-SAC41. A Figura 3.25 apresenta os modelos de barras e as estampagens (reta, tradicional, nova) ensaiados.

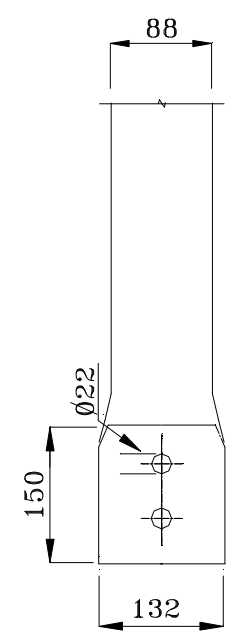

Reta

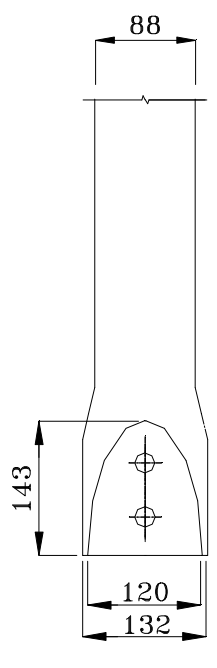

Tradicional

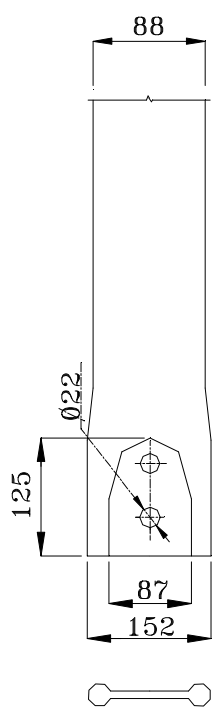

Nova
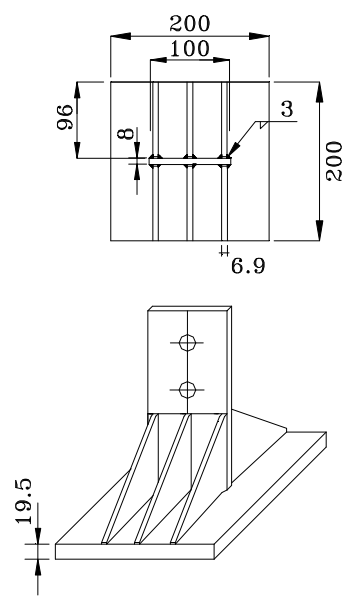

\section{Aparelho de}

apoio

Figura 3.25 Modelos de estampagens ensaiados e aparelho de apoio.

Os protótipos foram ensaiados em posição horizontal. Uma extremidade foi simplesmente apoiada na estrutura de reação e a outra extremidade apoiada em uma superfície esférica junto à célula de carga. $\mathrm{Na}$ posição horizontal a montagem do ensaio é facilitada e também representa uma das posições nas quais a barra se encontra dentro de uma treliça espacial, banzos horizontais ou diagonais inclinadas.

Realizou-se caracterização do material mediante ensaio de tração segundo recomendações da ASTM A370-92. Do ensaio determinou-se um valor de $\mathrm{f}_{\mathrm{y}}=421 \mathrm{MPa}$ para tensão de escoamento e $\mathrm{f}_{\mathrm{u}}=465 \mathrm{MPa}$ para limite de resistência a tração. A grande diferença entre tensão de escoamento convencional e experimental é devida ao fato do aço ensaiado ter sofrido trabalho a frio de conformação do tubo. 
A Tabela 3.16 apresenta, em detalhes, os resultados experimentais de força normal crítica para as barras ensaiadas.

Tabela 3.16 Resultados experimentais de força normal resistente para barras circulares com extremidades estampadas. MALITE (1997).

\begin{tabular}{|c|c|c|c|}
\hline \multicolumn{4}{|c|}{ Força normal última experimental (kN) } \\
\hline \multirow{2}{*}{$\begin{array}{c}\text { Estampagem } \\
\text { reta }\end{array}$} & 124,0 & 108,0 & 75,0 \\
\cline { 2 - 4 } & 105,0 & 115,0 & 74,0 \\
\cline { 2 - 4 } & 100,0 & 101,0 & 74,0 \\
\hline \multirow{2}{*}{$\begin{array}{c}\text { Média } \\
\text { tradicional }\end{array}$} & 109,67 & $\mathbf{1 0 8 , 0}$ & $\mathbf{7 4 , 3 3}$ \\
\cline { 2 - 4 } & 123,0 & 125,0 & 76,0 \\
\cline { 2 - 4 } & 154,0 & 115,0 & 82,0 \\
\hline Média & $\mathbf{1 5 1 , 7}$ & $\mathbf{1 2 1 , 0}$ & $\mathbf{7 4 , 3 3}$ \\
\hline Estampagem & 135,0 & 130,0 & 70,0 \\
\cline { 2 - 4 } & 159,0 & 139,0 & 70,0 \\
\cline { 2 - 4 } nova & 145,0 & 123,0 & 74,33 \\
\hline \multirow{2}{*}{ Média } & $\mathbf{1 4 6 , 3 3}$ & $\mathbf{1 3 0 , 6}$ & $\mathbf{6 9 , 6 7}$ \\
\hline
\end{tabular}

\section{Comparação de resultados teóricos $\mathrm{x}$ experimentais}

As tabelas 3.17 a 3.19 apresentam um resumo comparativo entre os valores experimentais e teóricos para cada estampagem das barras ensaiadas. Os valores teóricos da força normal resistente foram calculados utilizando a norma NBR-8800 (1986), considerou-se também a variação de inércia nas extremidades das barras. Admitiu-se extremidades rotuladas e as propriedades do material as convencionais. 
Tabela 3.17 Estampagem reta

\begin{tabular}{|c|c|c|c|c|c|c|}
\hline$\lambda$ & $\mathbf{N}_{\text {c(teor.) }}$ & $\mathbf{N}_{\text {c(teor.) }}$ & $\mathbf{N}_{\text {u(exp.) }}$ & $\mathbf{N}_{\mathrm{c}} / \mathbf{N}_{\mathrm{c}}$ & $\mathbf{N}_{\mathrm{u}} / \mathbf{N}_{\mathrm{c}}$ & $\mathbf{N}_{\mathrm{u}} / \mathbf{N}_{\mathrm{c}}$ \\
\hline 60 & 134.64 & 117,40 & 109,67 & 1,15 & 0,93 & 0,81 \\
\hline 100 & 95,50 & 86,10 & 108,0 & 1,11 & 1,25 & 1,13 \\
\hline 140 & 56,36 & 54,80 & 74,33 & 1,03 & 1,36 & 1,32 \\
\hline
\end{tabular}

Tabela 3.18 Estampagem tradicional

\begin{tabular}{|c|c|c|c|c|c|c|}
\hline$\lambda$ & $\mathbf{N}_{\text {c(teor.) }}$ & $\mathbf{N}_{\text {c(teor.) }}$ & $\mathbf{N}_{\text {u(exp.) }}$ & $\mathbf{N}_{\mathrm{c}} / \mathbf{N}_{\mathrm{c}}^{*}$ & $\mathbf{N}_{\mathrm{u}} / \mathbf{N}_{\mathrm{c}}{ }_{\mathrm{c}}$ & $\mathbf{N}_{\mathrm{u}} / \mathbf{N}_{\mathrm{c}}$ \\
\hline 60 & 134.64 & 127,80 & 151,7 & 1,06 & 1,19 & 1,13 \\
\hline 100 & 95,50 & 92,37 & 121,0 & 1,03 & 1,31 & 1,27 \\
\hline 140 & 56,36 & 56,36 & 74,33 & 1,0 & 1,32 & 1,32 \\
\hline
\end{tabular}

Tabela 3.19 Estampagem nova

\begin{tabular}{|c|c|c|c|c|c|c|}
\hline$\lambda$ & $\mathbf{N}_{\text {c(teor.) }}$ & $\mathbf{N}_{\text {c(teor.) }}^{*}$ & $\mathbf{N}_{\text {u(exp.) }}$ & $\mathbf{N}_{\mathrm{c}} / \mathbf{N}_{\mathrm{c}}^{*}$ & $\mathbf{N}_{\mathrm{u}} / \mathbf{N}_{\mathrm{c}}^{*}$ & $\mathbf{N}_{\mathrm{u}} / \mathbf{N}_{\mathrm{c}}$ \\
\hline 60 & 134.64 & 128,38 & 146,33 & 1,05 & 1,14 & 1,09 \\
\hline 100 & 95,50 & 92,37 & 130,6 & 1,04 & 1,41 & 1,38 \\
\hline 140 & 56,36 & 56,36 & 69,67 & 1,0 & 1,24 & 1,24 \\
\hline
\end{tabular}

Da mesma forma do ensaio apresentado anteriormente, fez-se uma análise comparativa de valores teóricos e experimentais, sendo que a barra, neste caso, foi considerada rotulada em uma das extremidades (superfície esférica) e engastada na outra (extremidade junto à estrutura de reação). Para essas condições de vinculação os índices de esbeltez passam a $\lambda=42$, 70,98 , com $K=0,7$. Os resultados desta análise estão presentes nas tabelas 3.20 a 3.22 . 
Tabela 3.20 Estampagem reta (barra engastada-rotulada)

\begin{tabular}{|c|c|c|c|c|c|c|}
\hline$\lambda$ & $\mathbf{N}_{\text {c(teor.) }}$ & $\mathbf{N}_{\text {c(teor.) }}$ & $\mathbf{N}_{\text {u(exp.) }}$ & $\mathbf{N}_{\mathrm{c}} / \mathbf{N}_{\mathrm{c}}$ & $\mathbf{N}_{\mathrm{u}} / \mathbf{N}_{\mathrm{c}}^{*}$ & $\mathbf{N}_{\mathrm{u}} / \mathbf{N}_{\mathrm{c}}$ \\
\hline 42 & 144,70 & 119,80 & 109,67 & 1,21 & 0,92 & 0,76 \\
\hline 70 & 135,05 & 91,78 & 108,0 & 1,47 & 1,18 & 0,80 \\
\hline 98 & 97,5 & 58,81 & 74,33 & 1,67 & 1,26 & 0,76 \\
\hline
\end{tabular}

Tabela 3.21 Estampagem tradicional (barra engastada-rotulada)

\begin{tabular}{|c|c|c|c|c|c|c|}
\hline$\lambda$ & $\mathbf{N}_{\text {c(teor.) }}$ & $\mathbf{N}_{\text {c(teor.) }}^{*}$ & $\mathbf{N}_{\text {u(exp.) }}$ & $\mathbf{N}_{\mathrm{c}} / \mathbf{N}_{\mathrm{c}}^{*}$ & $\mathbf{N}_{\mathrm{u}} / \mathbf{N}_{\mathrm{c}}$ & $\mathbf{N}_{\mathrm{u}} / \mathbf{N}_{\mathrm{c}}$ \\
\hline 42 & 144,70 & 130,70 & 151,7 & 1,11 & 1,16 & 1,05 \\
\hline 70 & 135,05 & 98,80 & 121,0 & 1,37 & 1,22 & 0,90 \\
\hline 98 & 97,5 & 63,33 & 74,33 & 1,54 & 1,17 & 0,76 \\
\hline
\end{tabular}

Tabela 3.22 Estampagem nova (barra engastada-rotulada)

\begin{tabular}{|c|c|c|c|c|c|c|}
\hline$\lambda$ & $\mathbf{N}_{\text {c(teor.) }}$ & $\mathbf{N}_{\text {c(teor.) }}^{*}$ & $\mathbf{N}_{\text {u(exp.) }}$ & $\mathbf{N}_{\mathrm{c}} / \mathbf{N}_{\mathrm{c}}^{*}$ & $\mathbf{N}_{\mathrm{u}} / \mathbf{N}_{\mathrm{c}}^{*}$ & $\mathbf{N}_{\mathrm{u}} / \mathbf{N}_{\mathrm{c}}$ \\
\hline 42 & 144,70 & 132,21 & 146,33 & 1,09 & 1,11 & 1,01 \\
\hline 70 & 135,05 & 100,11 & 130,6 & 1,35 & 1,30 & 0,98 \\
\hline 98 & 97,5 & 64,21 & 69,67 & 1,52 & 1,08 & 0,71 \\
\hline
\end{tabular}

Os gráfico das figuras 3.26 a 3.28 apresentam as curvas de resistência teóricas da NBR-8800(1986), "curva a", utilizando a tensão de escoamento convencional e experimental, juntamente com os resultados experimentais (valores médios) obtidos para as barras ensaiadas. Nestes gráficos está plotado o lugar geométrico dos valores experimentais, ou seja, um segmento de reta horizontal entre as esbeltezes correspondentes ao modelo bi-rotulado e engastatado-rotulado. Adotou-se esse procedimento pois, como foi comentado anteriormente, não se pode precisar o índice de esbeltez efetivo da barra ensaiada. 


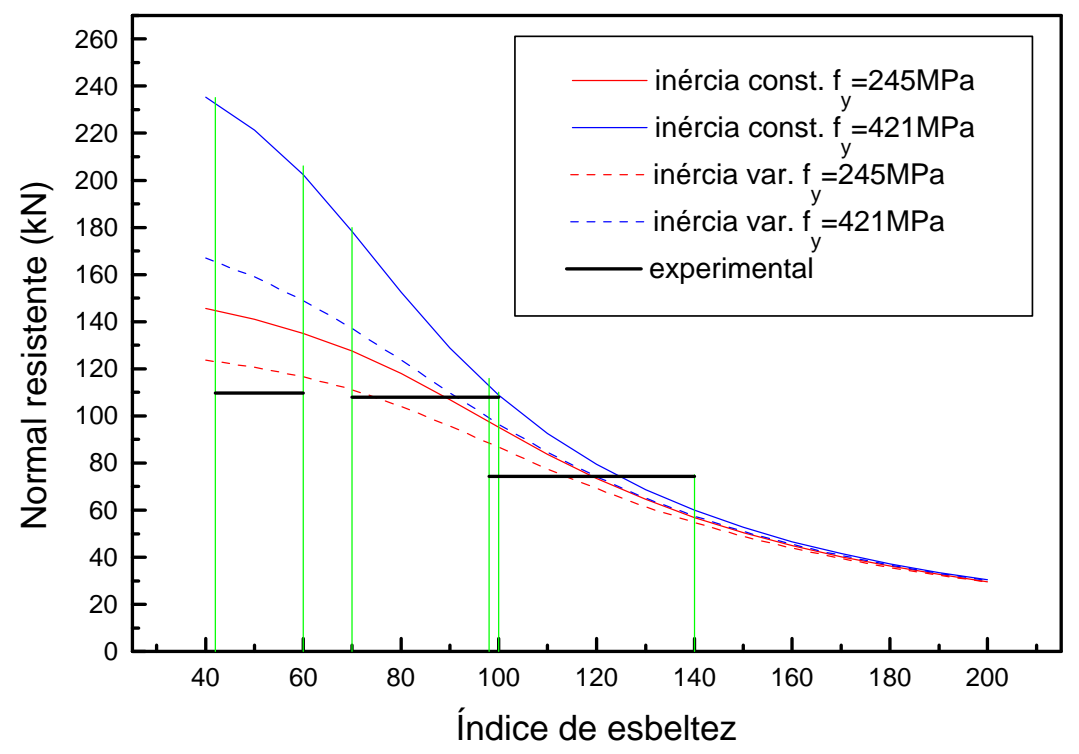

Figura 3.26 Comparação resultados teóricos $\mathrm{x}$ experimentais (estampagem reta)

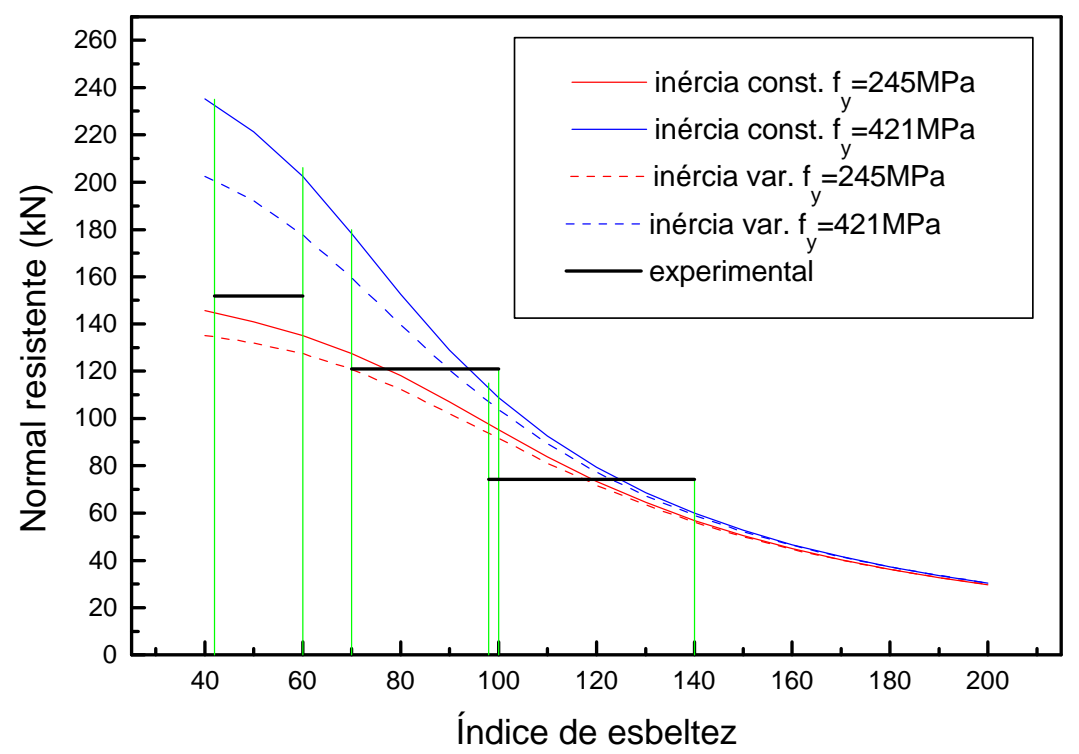

Figura 3.27 Comparação resultados teóricos $\mathrm{x}$ experimentais (estampagem tradicional) 


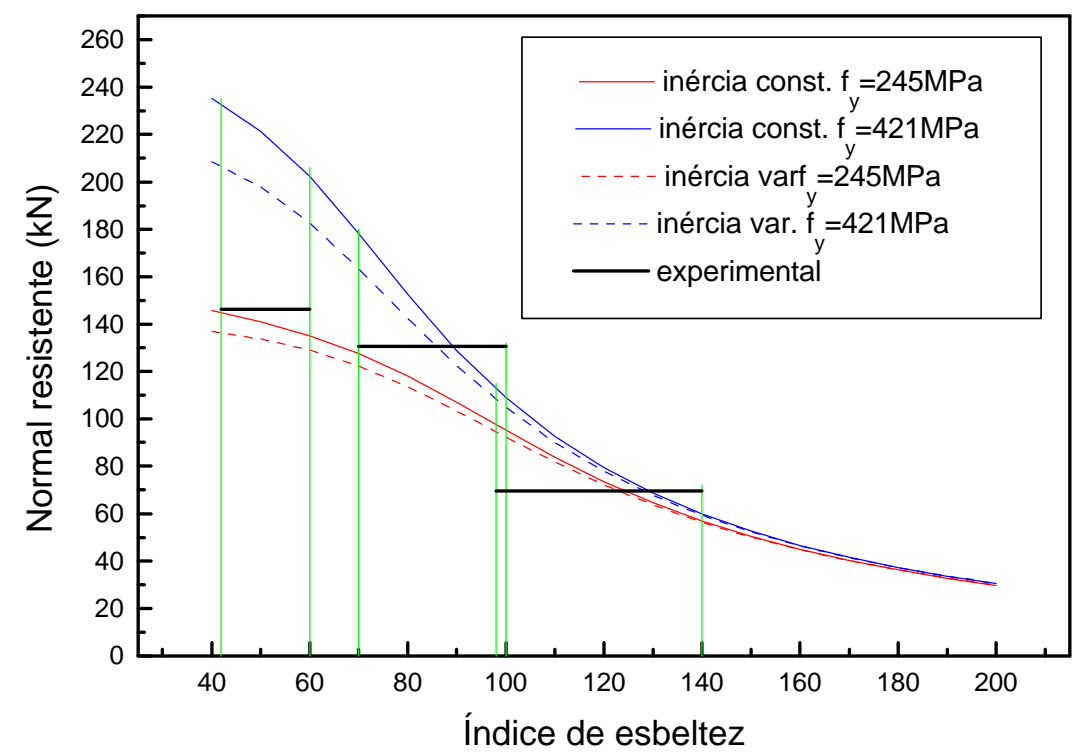

Figura 3.28 Comparação resultados teóricos $x$ experimentais (estampagem nova)

O gráfico da Figura 3.29 apresenta uma análise teórica comparativa entre as três estampagens estudadas, com barras de mesmas dimensões e inércia constante ao longo do comprimento. As curvas representam a capacidade resistente, considerando a variação de inércia, para as barras com os três modelos de estampagens. 


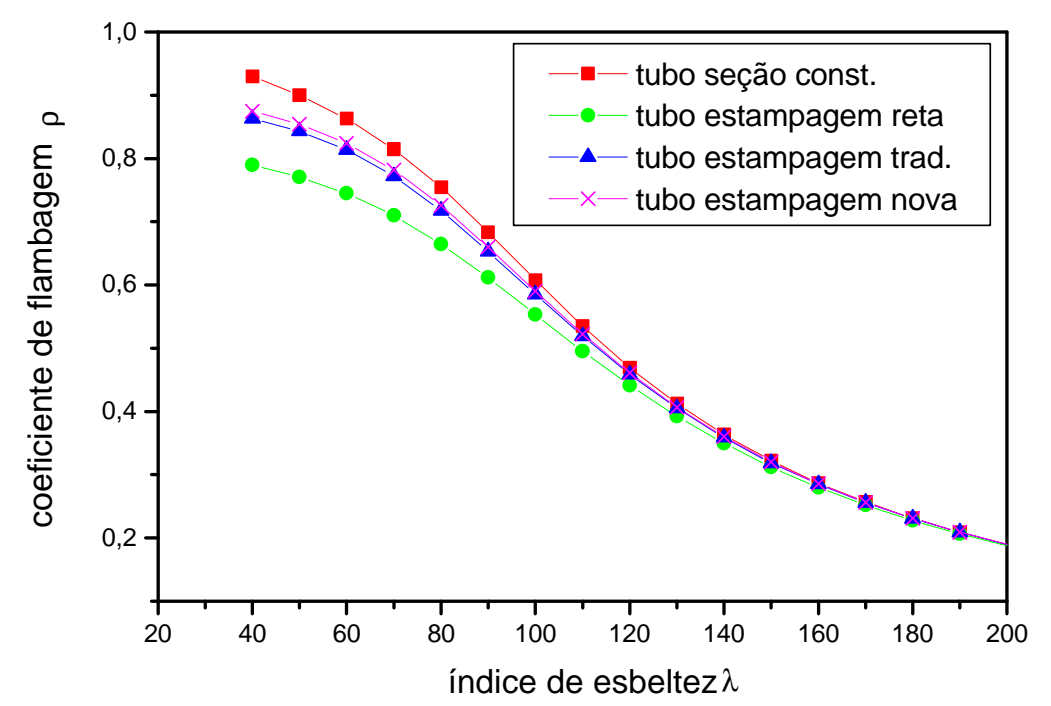

Figura 3.29 Resultados comparativos entre estampagens (reta, tradicional e nova) tubos $\phi 88 \times 2,65$.

Analisando os resultados experimentais percebe-se, como era esperado, grande dispersão para baixos índices de esbeltez. Este fato comprova a influência das estampagens de extremidade, bem como as imperfeições iniciais e de ensaio sob o comportamento das barras isoladas.

As estampagens tradicional e nova apresentaram desempenho superior ao da estampagem reta, no entanto, essa diferença praticamente desaparece quando aumenta-se $o$ índice de esbeltez.

Ressalta-se que a análise de barras isoladas, tanto teórica quanto experimental, é uma aproximação que provavelmente não reflete o real comportamento destes elementos em uma estrutura espacial. 


\section{LIGAÇÕES EM ESTRUTURAS METÁLICAS ESPACIAIS

O tipo de ligação a ser utilizada em estruturas espaciais é resultado da combinação dos seguintes fatores: forma da estrutura, disposição dos elementos e tipos de seção transversal destes.

Normalmente os esforços solicitantes em treliças espaciais são determinados considerando nós rotulados, porém, um detalhe de ligação que garanta esse comportamento é muito difícil e, sendo assim, a rigidez da ligação influencia sensivelmente o comportamento da estrutura.

Em estruturas metálicas, de modo geral, as ligações entre elementos costumam ser um item oneroso em termos de custo, principalmente quando não é adequadamente detalhada.

Pelas razões acima citadas o estudo de ligações em estruturas espaciais assume um papel importante para o desenvolvimento desse sistema estrutural, principalmente no Brasil, como se verá adiante.

Neste capítulo serão apresentados e comentados alguns sistemas de ligações utilizados em todo o mundo. As ligações tipicamente utilizadas em estruturas espaciais brasileiras serão discutidas e analisadas mais detalhadamente.

\subsection{Dispositivos de ligação}

Existe uma infinidade de sistemas de ligações utilizáveis em estruturas espaciais. Alguns destes são sistemas patenteados, bem caracterizados experimentalmente. Outros, no entanto, são detalhes de ligações geralmente empíricos, projetados na base da intuição e 
experiência, sem quaisquer estudos que confirmem seu comportamento, ou baseado em hipóteses simplistas.

Não é comum o uso de ligação completamente soldadas, já que esta apresenta custo elevado e dificuldades construtivas quando comparada a ligações parafusadas. Um dos poucos exemplos de ligações soldadas pode ser visto na Figura 4.1.

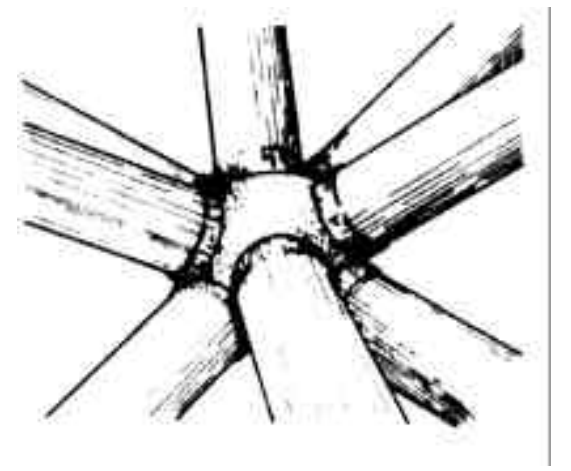

Figura 4.1 Sistema de nó OKTAPLATTE (Alemanha).

A grande maioria dos sistemas de nós patenteados são desenvolvidos para estruturas formadas por elementos de seção tubular. Neste caso, o sistema pode ser divido em: elemento estrutural (tubo), nó esférico (ou de formato aproximadamente esférico) e um dispositivo conector, como esquematizado na Figura 4.2.

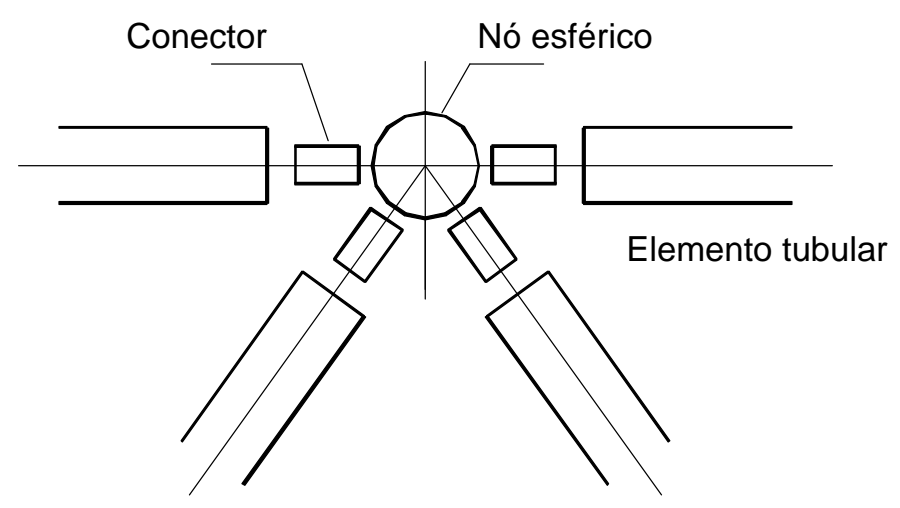

Figura 4.2 Componentes de um sistema de ligação genérico tipo nó esférico. 
As figuras subsequentes apresentam sistemas de ligações que seguem este padrão.

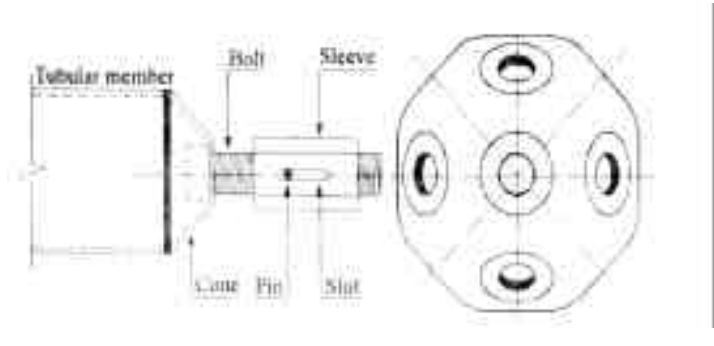

Figura 4.3 Sistema de ligação MERO (Alemanha)

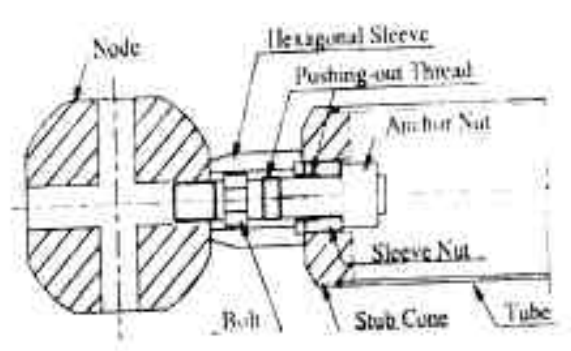

Figura 4.5 Sistema de ligação KT (Japão)

O sistema MERO foi um dos primeiros sistemas de ligação patenteados para estruturas espaciais. Foi desenvolvido na Alemanha em 1942-43 pelos Engenheiros MENGERINGHAUSEN e ROHBAUWWISE. O MERO é formado por um esfera de aço com dimensões padronizadas, função dos diâmetros das barras a serem ligadas; podem ser conectadas com este sistema até dezoito barras em planos diferentes, sem gerar excentricidades na ligação. O nó MERO é de uso mais difundido em todo mundo, inclusive no Brasil onde encontra-se várias estruturas que utilizam o sistema alemão.

LANDOLFO(1993) realizou uma análise experimental para caracterizar um novo sistema de conexão denominado VESTRUT. O VESTRUT tem o mesmo conceito do MERO, sendo composto por duas 
esferas achatadas separadas por um disco central e conectadas por um parafuso de alta resistência (Figura 4.7). A conexão nó-barra é feita através de uma barra de ligação de aço de alta resistência

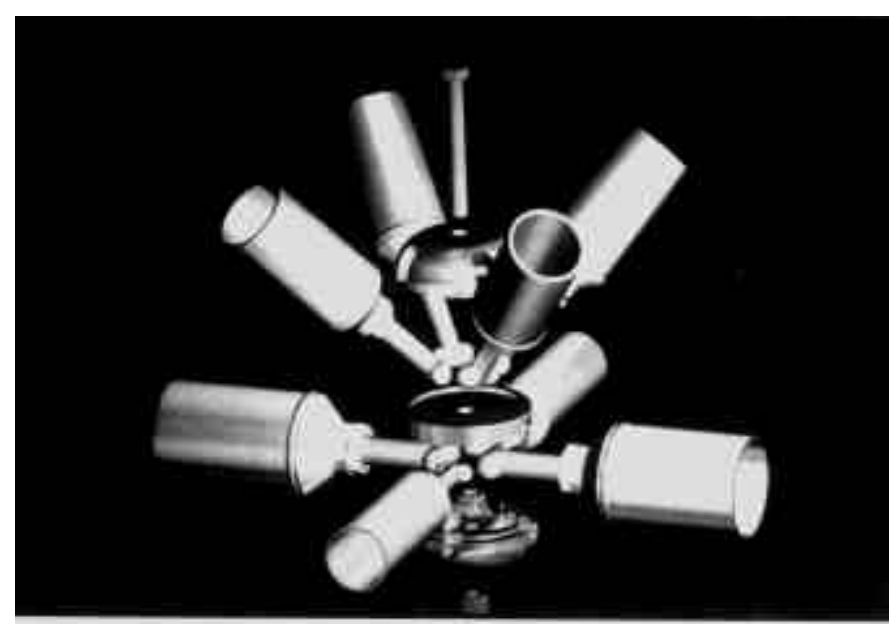

Figura 4.7 Detalhe do sistema de nó VESTRUT

Em alguns sistemas de ligações, bastante comuns, o nó é formado por associação de chapas planas que são conectadas às barras através de parafusos. As figuras abaixo mostram alguns desses sistemas.

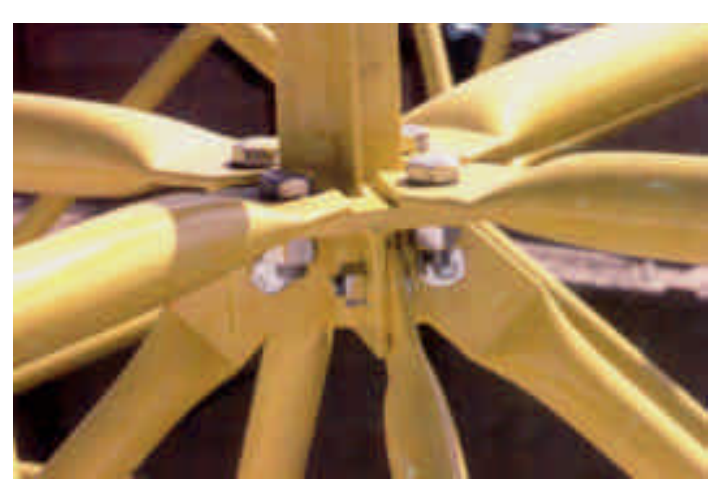

Figura 4.8 Sistema de ligação Italiano

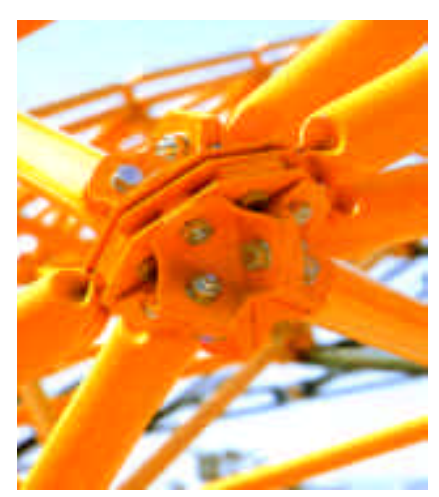

Figura 4.9 Sistema de ligação ECO (Itália) 


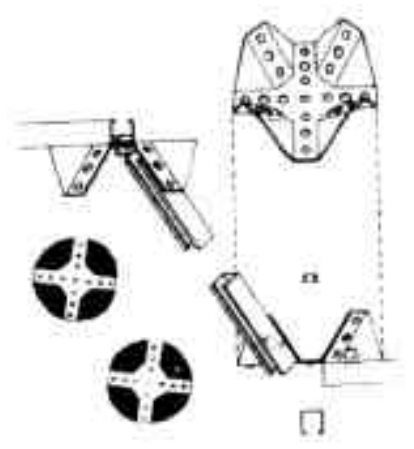

Figura 4.10 Sistema de ligação Figura 4.11 Sistema de ligação UNISTRUT (USA)

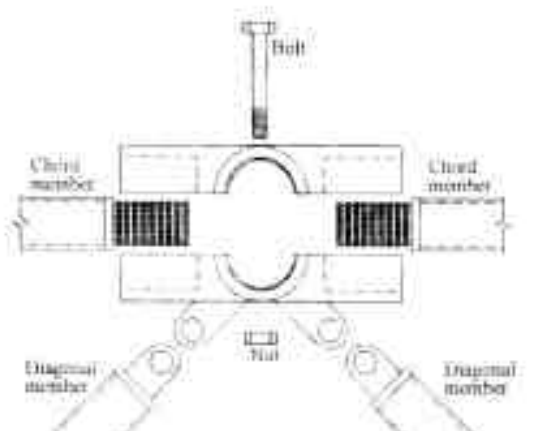
NODUS

As ligações em estruturas espaciais podem ser realizadas sem qualquer tipo de dispositivo especial, neste caso as barras são conectadas juntas através de parafusos. Neste tipo de detalhe de nó, muitas vezes é necessário variar a seção nas extremidades dos elementos, para facilitar a ligação entre eles. As figuras abaixo exemplificam este tipo de ligação.
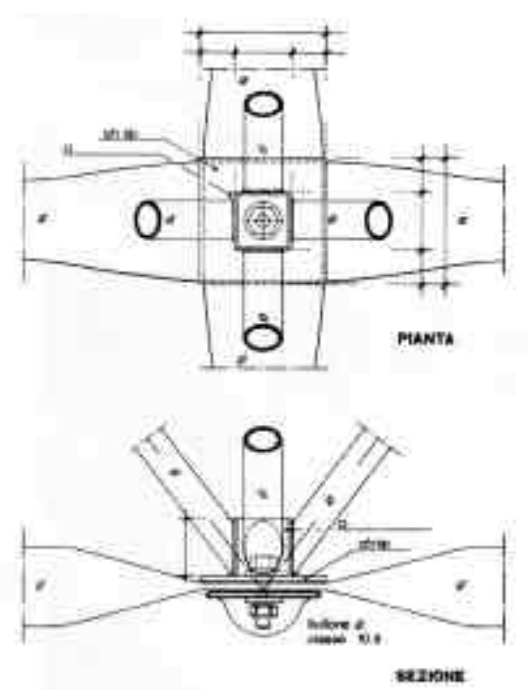

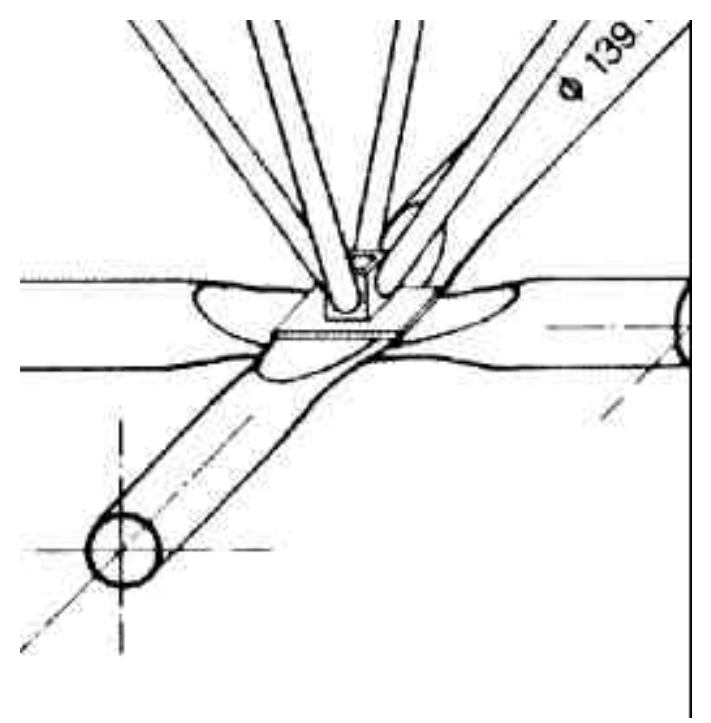

Figura 4.12 Sistema de ligação GRIAGAN (Itália) 

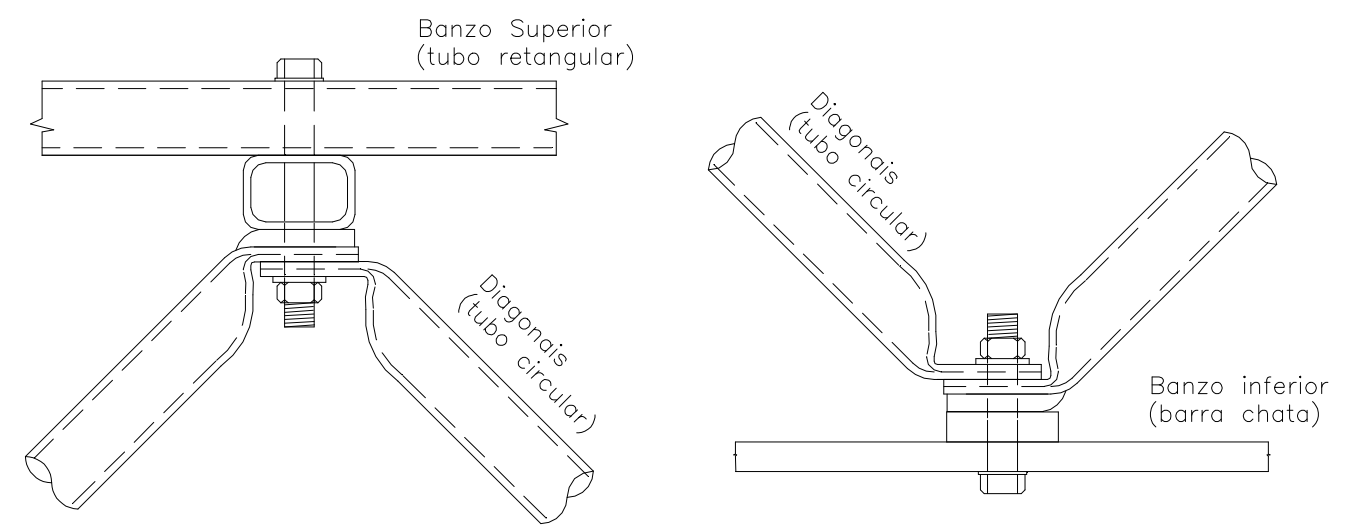

Figura 4.13 Sistema de ligação CATRUS

EL-SHEIKH (1996a, 1996b) realizou um estudo teórico e experimental com o sistema de conexão CATRUS (Figura 4.13). Esse sistema é bastante parecido com os nós empregados no Brasil, as cordas são contínuas e os elementos são parafusados juntos, produzindo ligações excêntricas.

As seções utilizadas, neste sistema, são: tubo quadrado ou retangular nas cordas superiores, barra chata nas inferiores e tubo circular nas diagonais.

Os resultados experimentais com o novo sistema demostraram que há um aumento na ductilidade da estrutura devido à continuidade das cordas, em contrapartida a emenda de cordas, quando necessária, causa perda de rigidez, mas não chega a comprometer o desempenho da estrutura.

Em uma análise comparativa, segundo o autor, o sistema CATRUS apresentou melhores resultados quando comparado com o sistema MERO.

Ensaios de compressão em elementos das diagonais conduziram a valores de capacidade de carga $25 \%$ maiores que os valores teóricos considerando a barra bi-rotulada. No entanto, nada foi comentado pelos autores sobre a influência da variação de inércia nas extremidades das barras no comportamento da estrutura. Outro aspecto a se observar é a não consideração da inversão de esforços entre os banzos. 


\subsection{Dispositivos de ligação utilizados no Brasil}

No Brasil, com exceção de algumas obras que utilizam o sistema MERO, as ligações em treliças espaciais são realizadas por amassamento das extremidades das barras que são justapostas, para formar um nó, e conectadas por um único parafuso.

Utiliza-se também ligações através de chapas de aço isoladas ( ponteiras) ou associações de chapas formando um nó capaz de receber barras em várias direções.

Os principais sistemas de ligações utilizados no Brasil serão descritos a seguir, ressalta-se que a denominação dos detalhes de nó apresentados aqui não são padronizados o que não impede que se encontre, em textos ou catálogos técnicos, o mesmo nó com outras denominações.

\subsubsection{Nó típico}

É o mais comum e também o que merece mais atenção quanto ao seu desempenho dentre os sistemas de ligações brasileiros. A Figura 4.14 apresenta um exemplo desta conexão em que oito barras com extremidades amassadas são unidas por um único parafuso e a Figura 4.15 um detalhe esquemático do nó típico.

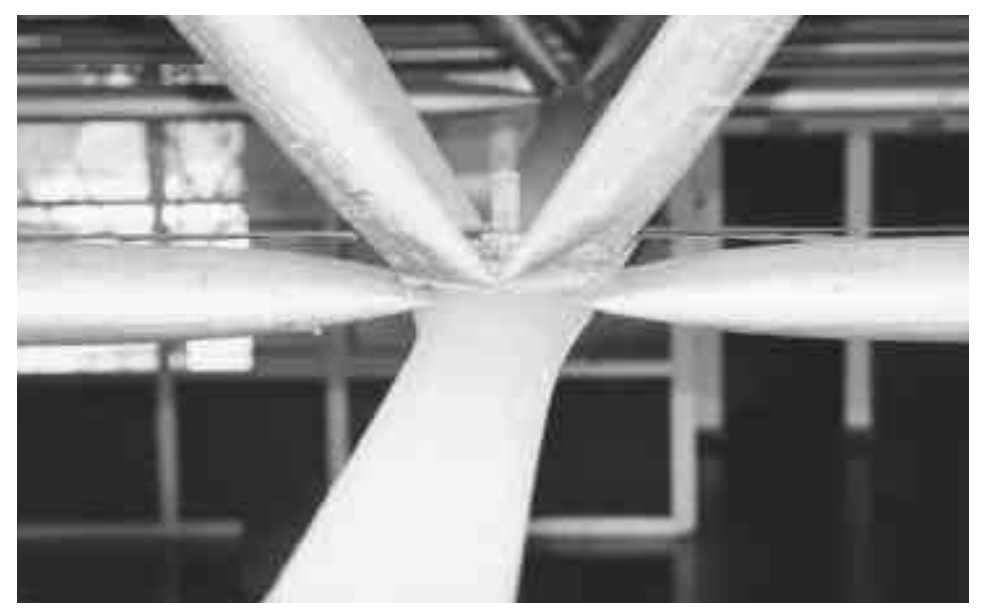

Figura 4.14 Nó típico 


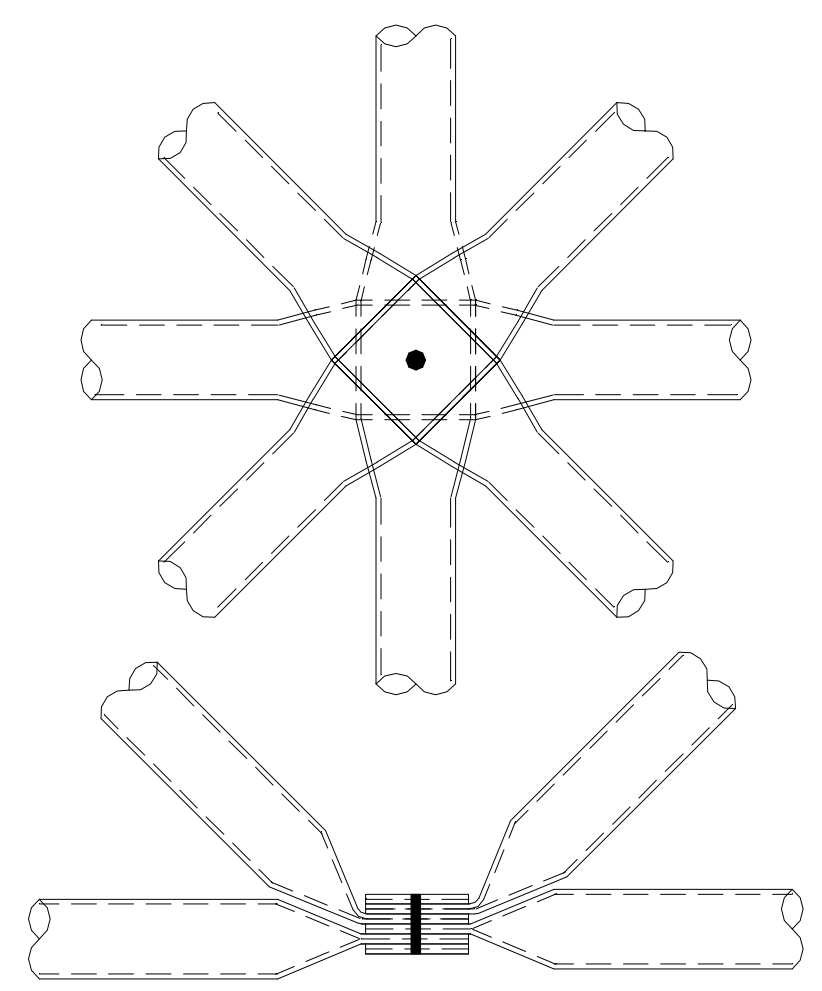

Figura 4.15 Detalhe esquemático nó típico.

Esse sistema de nó apresenta alguns problemas. Em primeiro lugar o fato das barras serem ligadas por apenas um parafuso, contrariando as recomendações correntes de utilizar no mínimo dois parafusos para ligações.

Em segundo lugar, é fácil perceber excentricidades na ligação, o que provoca o surgimento de momentos fletores nas barras, que pode acarretar em plastificação precoce nas extremidades amassadas das barras, sobretudo nas diagonais que também tem as extremidades dobradas. A plastificação precoce, oriunda da flexão devido a forças normais excêntricas, aliada à variação de inércia das extremidades, como discutido no capítulo 3 , reduz a capacidade resistente das barras.

Um dos problemas, dignos de nota, deste tipo de ligação é o escorregamento entre as barras que são conectadas por um único parafuso. O escorregamento relativo entre as barras que formam o nó produz aumento significativo nos deslocamentos verticais da estrutura. 


\subsubsection{Nó típico com chapa complementar}

O nó típico com chapa complementar é bastante semelhante ao detalhe típico apresentado na Figura 4.14, a diferença é que são utilizadas chapas horizontais para ligar as barras do banzo (Figura 4.16). Essas chapas são empregadas quando os esforços nos banzos são elevados e de tal ordem que o uso de apenas um parafuso torna-se inviável, ou seja, um único parafuso não tem resistência suficiente para o esforço solicitante, sendo necessário maior número de parafusos a fim de aumentar a capacidade da ligação.

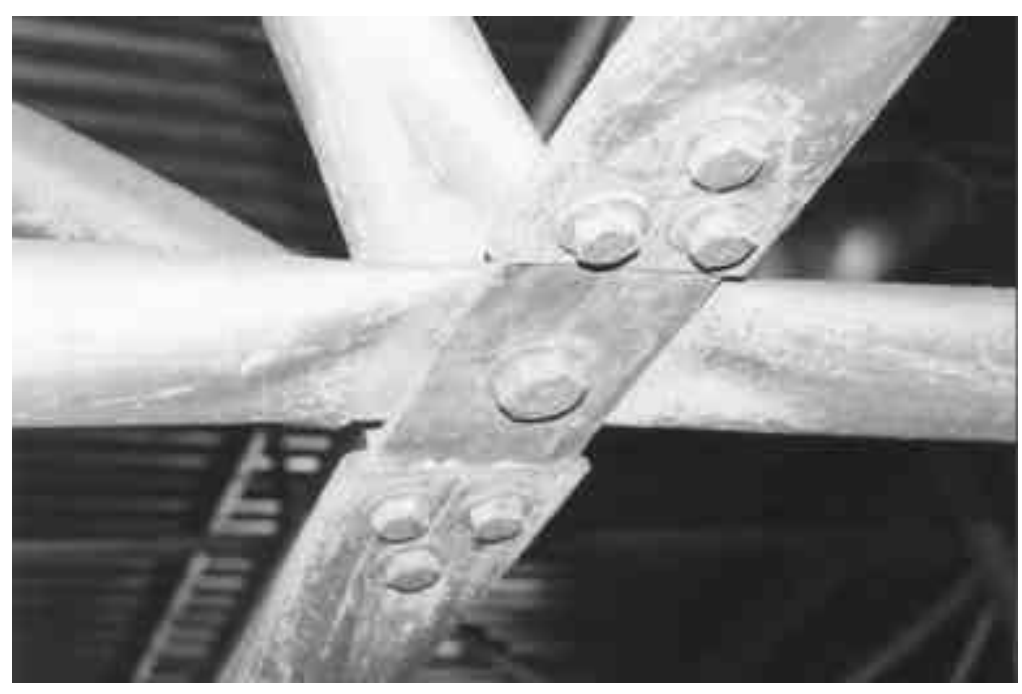

Figura 4.16 Nó típico com chapa complementar

Esta ligação apresenta, além dos aspectos relatados para o nó típico, um problema adicional que é o fato das chapas que fazem a ligação dos banzos possuírem pequena rigidez. Para os banzos comprimidos a menor excentricidade, perpendicular ao plano da chapa, pode comprometer o desempenho da chapa.

\subsubsection{Nó com chapa de extremidade (ponteiras)}

O nó é formado por duas chapas paralelas soldadas em um rasgo na extremidade do tubo e conectadas a chapas de apoio por meio de parafusos. A Figura 4.17 apresenta uma foto, na estrutura, de um nó com ponteira e na Figura 4.18 um detalhe esquemático de ligação com ponteira. 


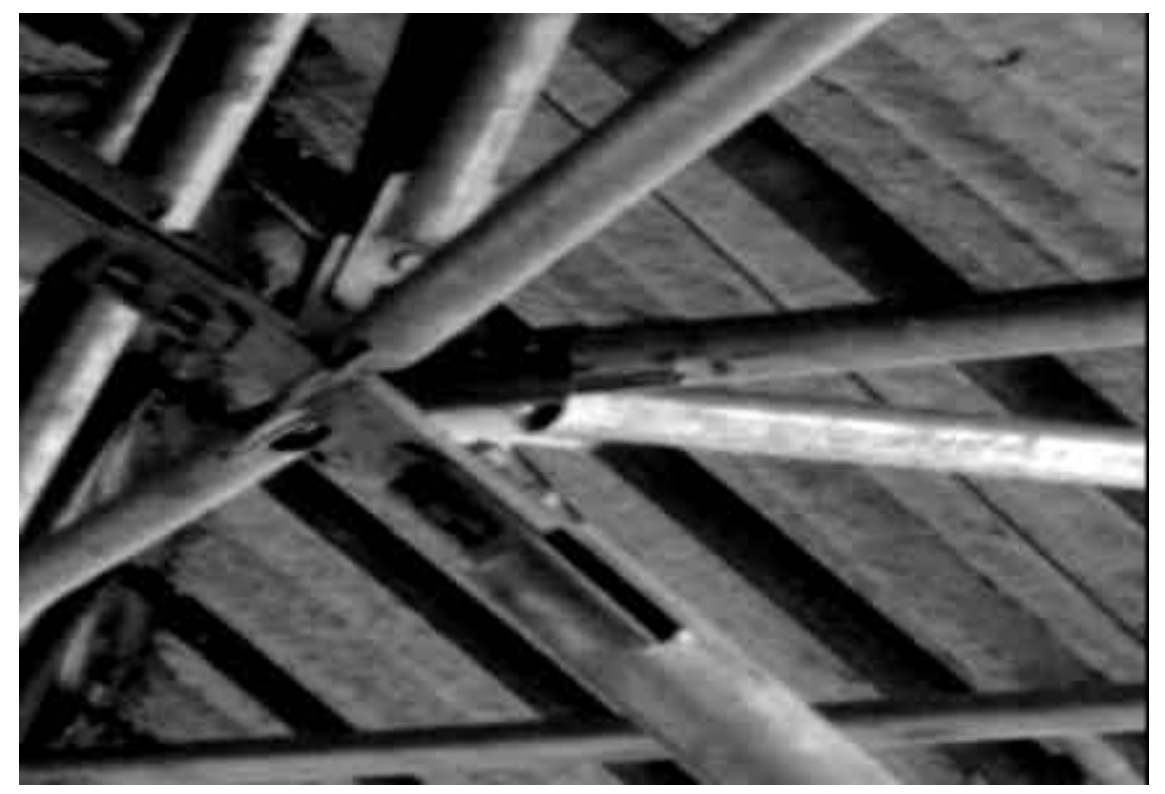

Figura 4.17 Nó com chapa de ponteira

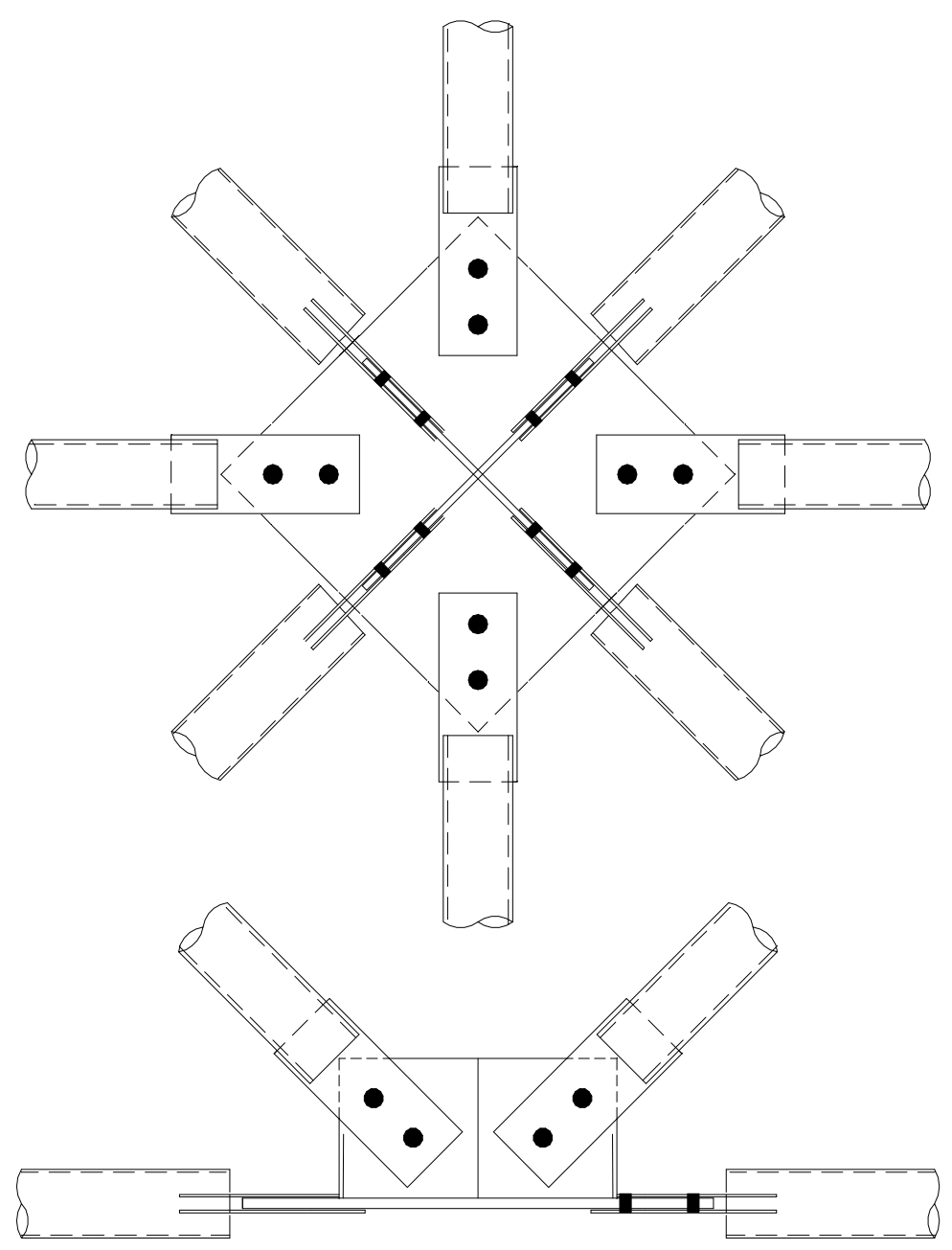

Figura 4.18 Detalhe esquemático nó com chapa de ponteira. 
Exceto devido a problemas construtivos, este detalhe de nó não introduz excentricidades nas ligações. No entanto, as chapas de extremidades apresentam baixa rigidez perpendicular a seu plano.

Como foi visto no capítulo 3, barras com extremidades em ponteiras com chapas muito esbeltas podem apresentar reduções na capacidade de força normal resistente. Uma alternativa para minimizar este problema é a adoção de chapas (aletas) soldadas perpendicularmente às ponteiras, que funcionam como enrijecedores melhorando o desempenho da ligação. A foto da Figura 4.19 apresenta uma ligação com chapas de ponteira enrijecidas com aletas perpendiculares.

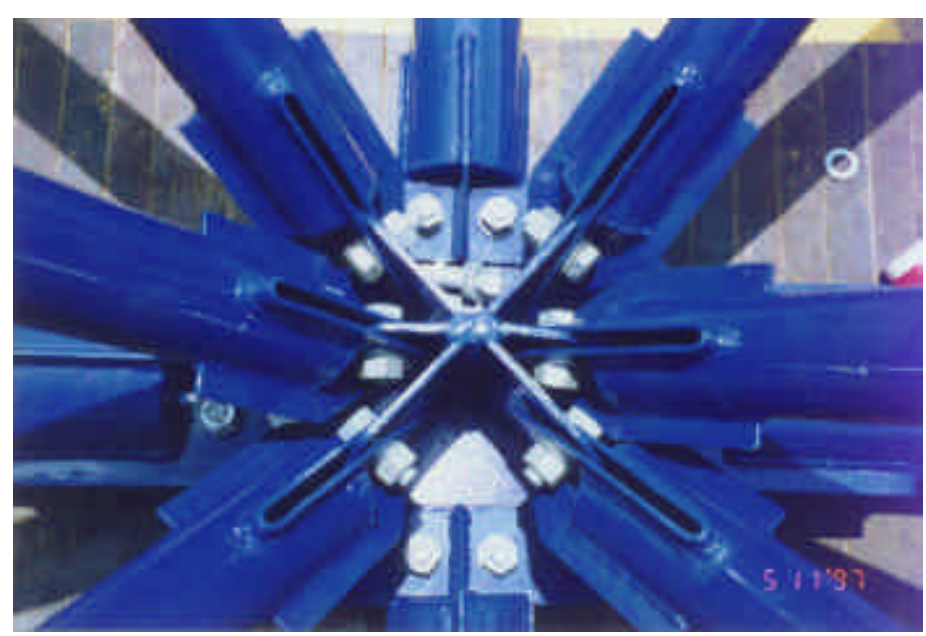

Figura 4.19 Ponteiras com aletas perpendiculares enrijecedoras.

GONÇALVES \& RIBEIRO (1995) analisaram numericamente nós típicos de estruturas espaciais utilizados no Brasil. O tipo de ligação analisada consiste em duas chapas, soldadas axialmente na extremidade do tubo e parafusadas a um aparelho de apoio constituído por chapas. (Figura 4.20 detalhe denominado ponteira). Foram simuladas barras de seção tubular com as dimensões: $\phi 100 \times 3,0 \mathrm{~mm}$ e $\phi 114 \times 4,0 \mathrm{~mm}$ com comprimentos de quatro vezes o diâmetro externo.

Para o dispositivo de ligação (aparelho de apoio) adotou-se um perfil T com mesa de $12,5 \mathrm{~mm}$ e alma de $10,0 \mathrm{~mm}$ enrijecida por uma cantoneira soldada, reproduzindo os modelos ensaiados no LE-EESC e relatados no Capítulo 3. 

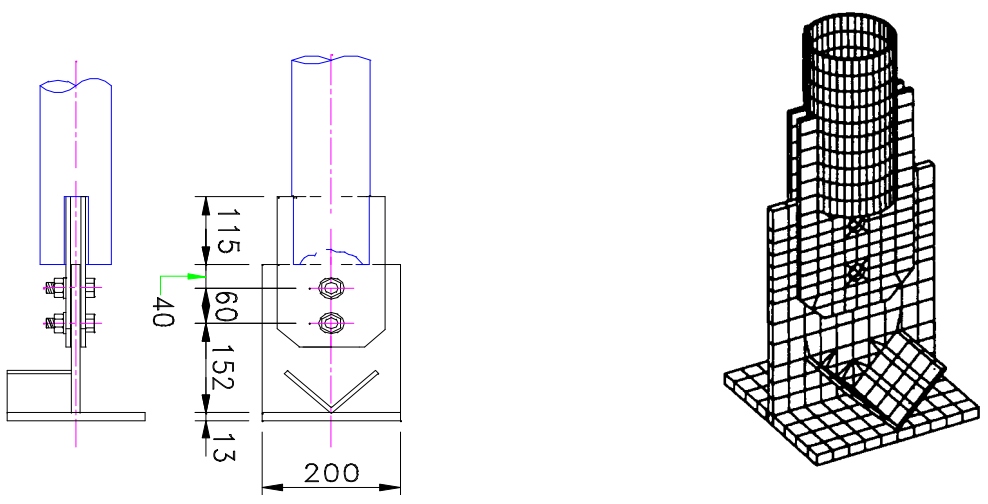

Figura 4.20 Modelo de ligação analisados por GONÇALVES \& RIBEIRO(1995).

$\mathrm{Na}$ análise, a extremidade oposta ao aparelho de apoio foi considerada engastada. Adotou-se três tipos de carregamento, sendo dois excêntricos em relação ao plano médio da alma do aparelho de apoio. Foram consideradas na análise a não linearidade física e a geométrica.

Comprovou-se que este tipo de ligação, por produzir variações bruscas de inércia, diminui a capacidade resistente dos elementos comprimidos. A região crítica é exatamente a transição entre a chapa de ligação e o tubo, onde se desenvolvem altas concentrações de tensão. As altas concentrações de tensões são, em grande parte, provenientes da não uniformidade da transferência de esforços através dos parafusos, associada as excentricidades. Em virtude das excentricidades, há um aumento de tensões na região da ligação devido à superposição de efeitos com as tensões provenientes da flexão dos parafusos e das chapas que constituem o nó.

\subsubsection{Nó de aço}

Dentre os sistemas de ligação apresentados, o nó de aço é o que tem melhor desempenho, produzindo efetivamente um nó de melhor comportamento estrutural. A foto da Figura 4.21 apresenta um nó de aço na estrutura e a Figura 4.22 um detalhe deste nó que é utilizado pela empresa 
ALUSUD. A figura 4.23 apresenta detalhes de outros nós que também podem ser genericamente denominados de nós de aço.

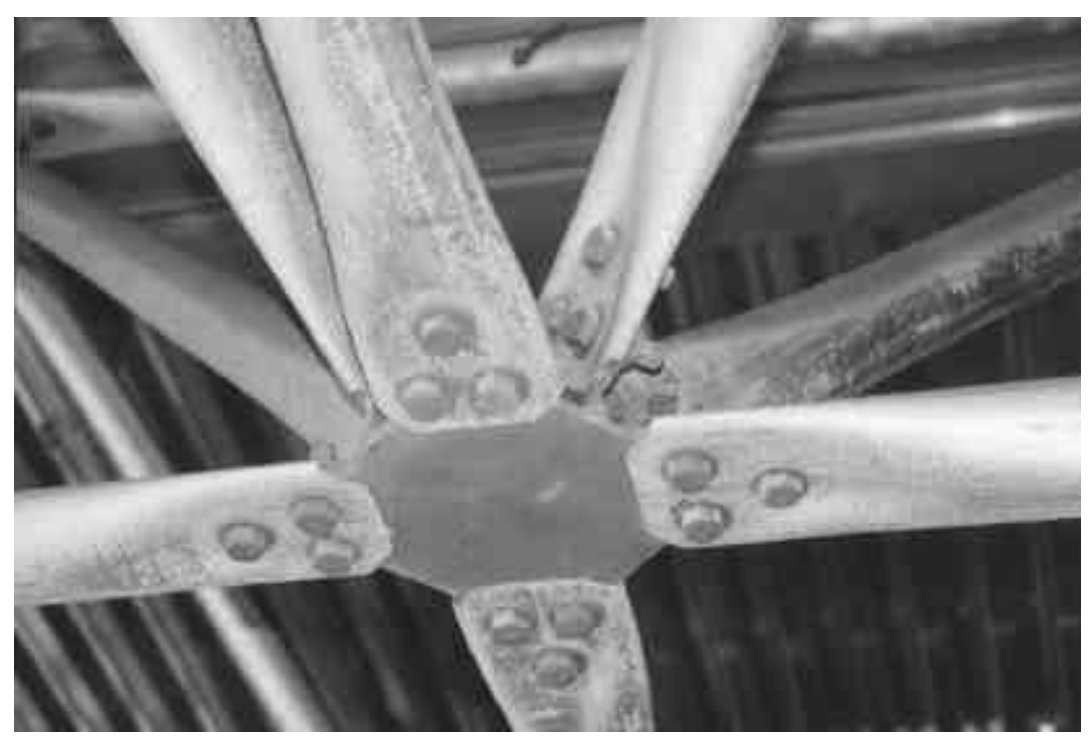

Figura 4.21 Nó de aço

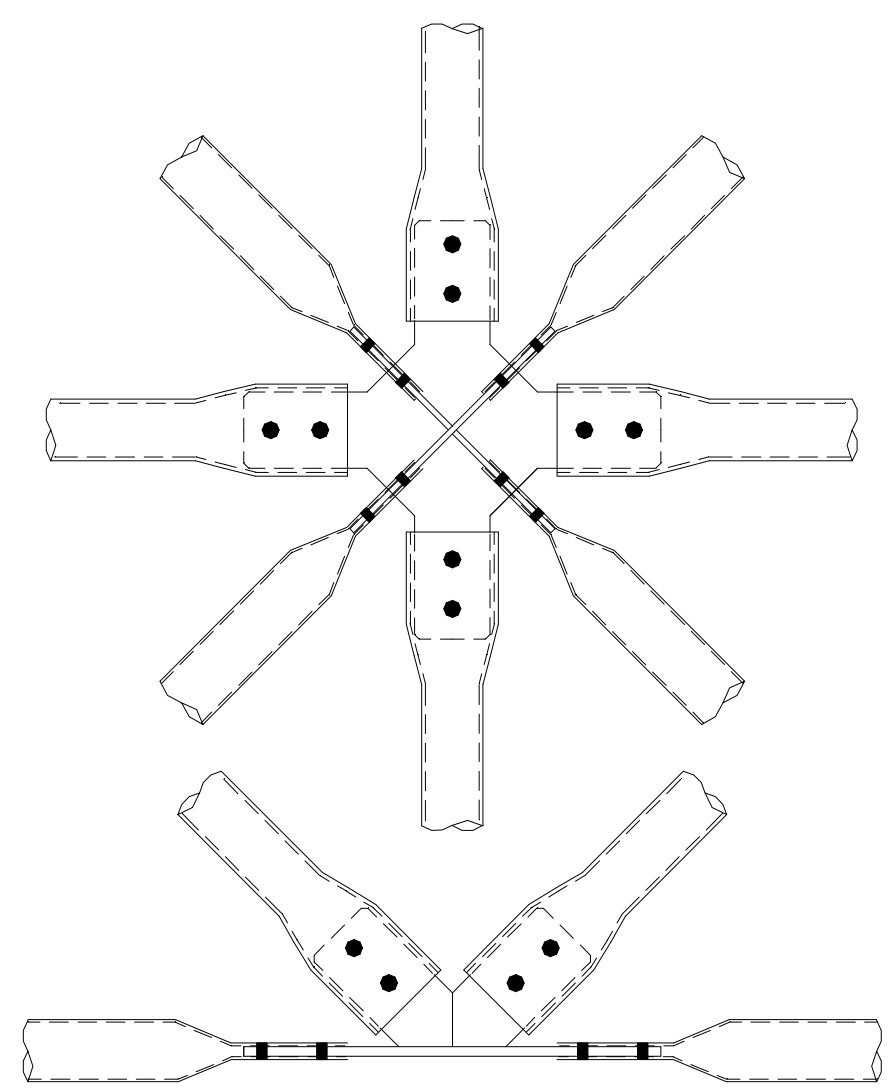

Figura 4.22 Detalhe esquemático nó de aço ALUSUD. 

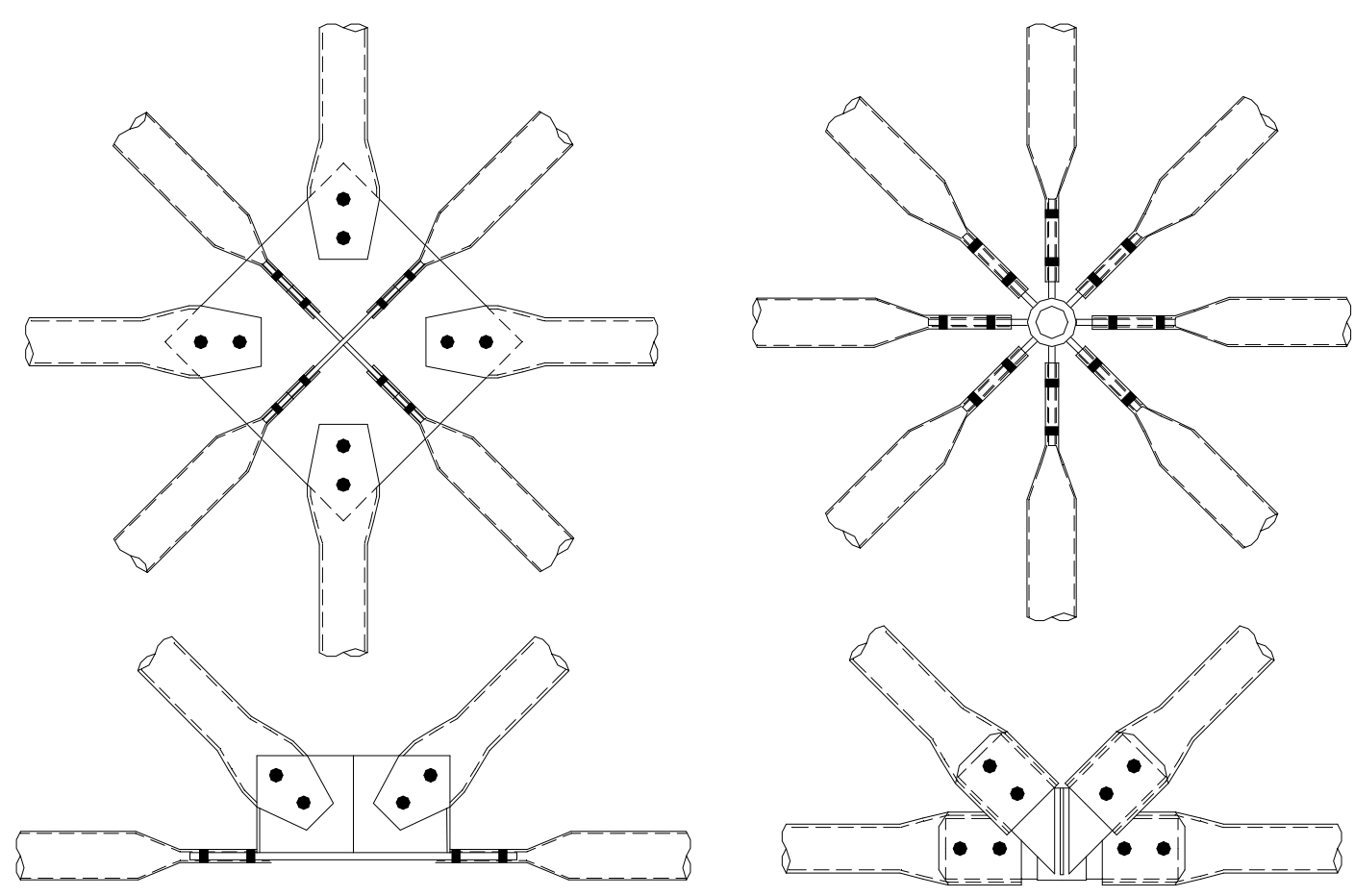

Figura 4.23 Detalhes diferentes de nós de aço.

As chapas de composição utilizadas para formar o nó podem ser convenientemente escolhidas de modo que confiram boa rigidez ao conjunto.

Não existem problemas com excentricidade, uma vez que as barras concorrem para o único ponto. Resta somente neste sistema de ligação, o problema da variação de inércia nas extremidades das barras.

É importante ressaltar que, na prática corrente de projetos, os esforços solicitantes nos elementos de treliças espaciais são determinados supondo-se o modelo de treliça ideal, ou seja, nós rotulados e barras com inércia constante ao longo do seu comprimento.

Os detalhes de ligações de uso comum, aqui apresentados, não reproduzem bem as hipóteses de cálculo assumidas. Por outro lado, não existem estudos que expliquem detalhadamente o comportamento destas ligações como também não existem programas práticos que considerem a rigidez da ligação no comportamento da estrutura. 
Fica então o alerta para o uso cauteloso desses detalhes de ligação e a sugestão para pesquisas mais específicas sobre o comportamento e análise das ligações em estruturas espaciais empregadas no Brasil. Esses estudos devem ter embasamento experimental aliado a análises numéricas. Poderiam ser ensaios de protótipos, em que atenção especial seria dada ao nó, observando-se o seu comportamento e a interação com a estrutura. Outra alternativa seria ensaios de modelos representativos das ligações onde poderiam ser simuladas diversas combinações de carregamento. Essa duas alternativas poderiam ser classificadas respectivamente, como macro e micro análise das ligações. 


\section{ANÁLISE EXPERIMENTAL DE TRELIÇA ESPACIAL

A utilização de estruturas espaciais, no Brasil, tem crescido bastante nos últimos anos, em contrapartida tem crescido também os problemas com este tipo de estrutura acarretando, como já comentado, colapso parcial e total de algumas obras com esse sistema estrutural.

A grande maioria dos problemas deve-se ao escasso conhecimento sobre o comportamento das estruturas espaciais, principalmente nas tipologias empregadas no Brasil, apresentadas anteriormente.

Com o intuito de suprir a deficiência sobre o comportamento das estruturas espaciais em seus diversos aspectos, o Depto. de Estruturas da Escola de Engenharia de São Carlos vem desenvolvendo há alguns anos pesquisas sobre o comportamento, projeto e construção de estruturas metálicas espaciais.

A análise experimental é imprescindível na busca do conhecimento do funcionamento estrutural das estruturas espaciais, devido às suas características especiais e, em particular, à dificuldade de simulação e análise dos nós que as compõem.

A primeira fase dos estudos experimentais consistiu em ensaios de barras isoladas com extremidades estampadas, que foram apresentados de forma resumida no Capítulo 3. Inicia-se agora um programa experimental em que serão ensaiados protótipos de treliças espaciais. Estão previstos inicialmente ensaios em quatro protótipos, com elementos tubulares e ligações em nós típicos e nós de aço, com dimensões em planta de $7,5 \times 7,5 \mathrm{~m}$. 
A análise experimental do primeiro desse conjunto de protótipos será apresentada neste capítulo. Uma análise completa de todos os protótipos faz parte de outra dissertação de mestrado ${ }^{1}$ que encontra-se em desenvolvimento, paralelamente a esta, com conclusão prevista para o início do ano de 1999.

Pretende-se, com esses estudos, detectar os principais problemas inerentes às estruturas espaciais comumente utilizadas no Brasil e buscar soluções para os mesmos possibilitando uma utilização segura do sistema estrutural em treliças espaciais, explorando todas as suas vantagens.

\subsection{Descrição da estrutura ensaiada}

A estrutura ensaiada é uma treliça espacial formada por elementos tubulares de seção circular. Os tubos são conformados a frio com solda de costura em aço USI-SAC-41 ( $\mathrm{f}_{\mathrm{y}}=245 \mathrm{MPa}$ - convencional). A geometria e dimensões da estrutura ensaiada são apresentadas na Figura 5.1.

\footnotetext{
${ }^{1}$ Análise teórica e experimental de treliças espaciais constituídas por barras com extremidades estampadas.

Autor: Eng. Carlos Henrique Maiola Orientador: Prof. Dr. Maximiliano Malite
} 

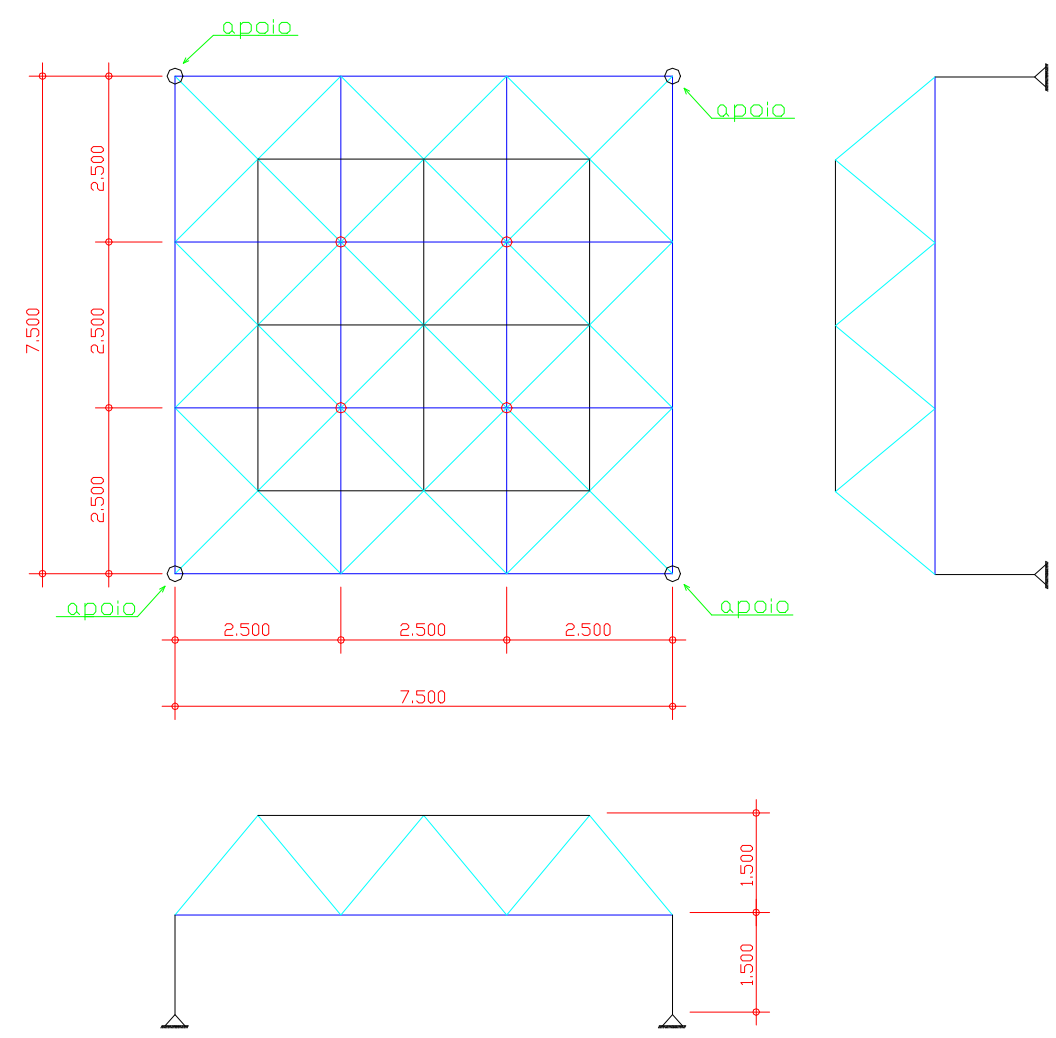

Figura 5.1- Detalhe da estrutura ensaiada.

As seções dos elementos utilizados na treliça espacial e suas respectivas resistências à compressão são apresentadas na Tabela 5.1. A resistência à compressão das barras foi calculada segundo a NBR8800(1986). Determinou-se, também, a resistência à compressão considerando a variação de inércia nas extremidades das barras segundo o procedimento apresentado no Capítulo 3.

Tabela 5.1- Seções dos elementos da treliça e resistência a compressão.

\begin{tabular}{|c|c|c|c|c|c|}
\hline Tubo & Utilização & Comp. $(\mathbf{m m})$ & Esbeltez & $\mathbf{N}_{\mathrm{c}}(\mathbf{k N})$ & $\mathbf{N}_{\mathrm{c}}{ }^{\prime}(\mathbf{k N})$ \\
\hline$\phi 60 \times 2,0$ & diagonal & 2318 & 113,0 & 41,0 & 35,3 \\
\hline$\phi 76 \times 2,0$ & banzo & 2500 & 95,4 & 70,7 & 66,6 \\
\cline { 2 - 6 } & diagonal & 2318 & 88,5 & 65,6 & 61,5 \\
\hline$\phi 88 \times 2,65$ & diagonal & 2318 & 77,0 & 120,5 & 112,7 \\
\hline
\end{tabular}

$\mathrm{N}_{\mathrm{c}}{ }^{*}$ Força normal resistente considerando variação de inércia na barra. 
O sistema de ligação utilizado é o denominado nó típico, formado pela superposição de barras com extremidades estampadas e conectadas por um único parafuso.

Nos pontos de aplicação de carga foram utilizados nós de aço para facilitar a montagem do atuador hidráulico. Os parafusos utilizados em todas as ligações são do tipo ASTM-A325.

As Figuras 5.2 e 5.3 apresentam detalhes esquemáticos das ligações empregadas na estrutura ensaiada.

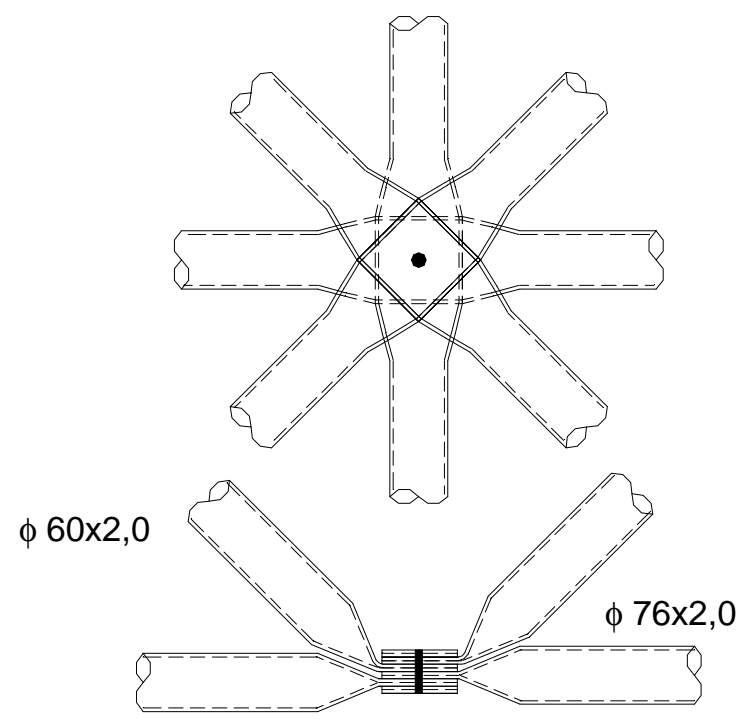

Figura 5.2 Detalhe de ligação típico. 


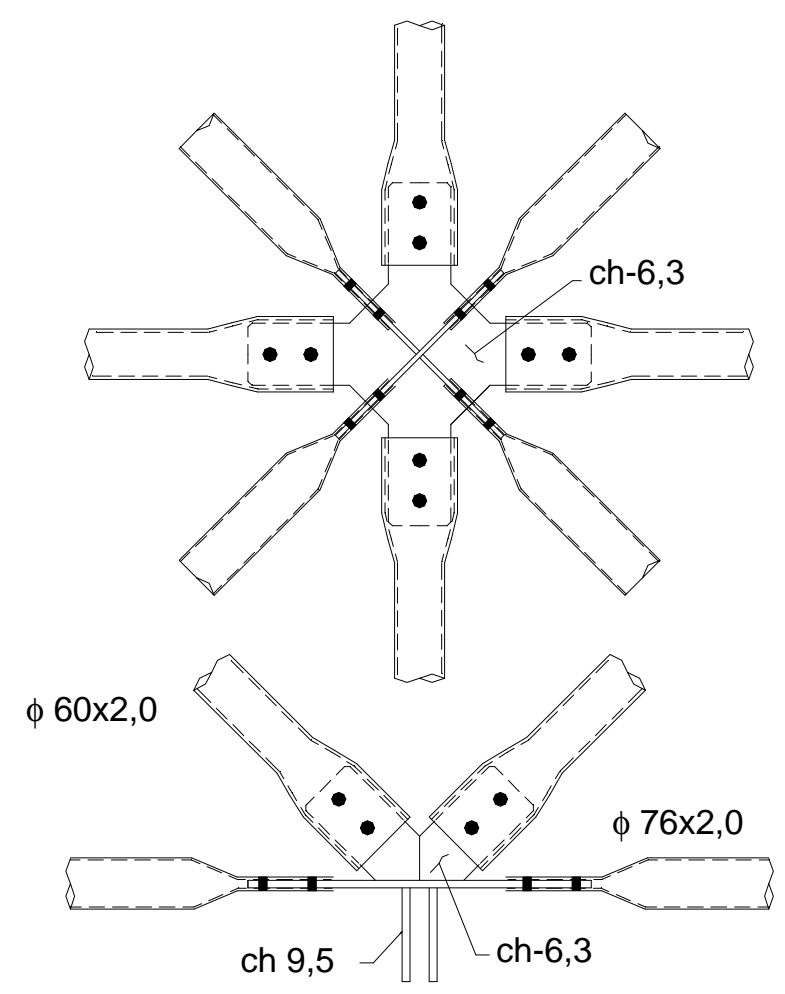

Figura 5.3 Detalhe de ligação dos nós de aplicação de carga.

\subsection{Instrumentação e metodologia do ensaio}

Os deslocamentos verticais e horizontais da estrutura foram medidos por meio de transdutores de deslocamentos da marca KYOWA, com sensibilidade de 0,02 e 0,04 e fundo de escala de 50,0mm e $100,0 \mathrm{~mm}$ respectivamente. $O$ posicionamento dos transdutores na estrutura é apresentado na Figura 5.4.

Para a medição das deformações nas barras utilizou-se extensômetros elétricos de resistência da marca KYOWA, modelo KFG-5120C1-11, com base de 5,0mm, resistência de $120 \Omega$ e 'gage factor' de 2,15.

Foram instrumentadas a seção central de 16 barras da estrutura, sendo algumas barras com dois e outras com quatro extensômetros por seção transversal.

A instrumentação completa da estrutura pode ser vista na Figura 5.4 com as respetivas numerações das barras e nós em que foram feitas 
medições de deformações e deslocamentos e, a Figura 5.5 apresenta, com mais detalhes, o posicionamento da instrumentação na estrutura.

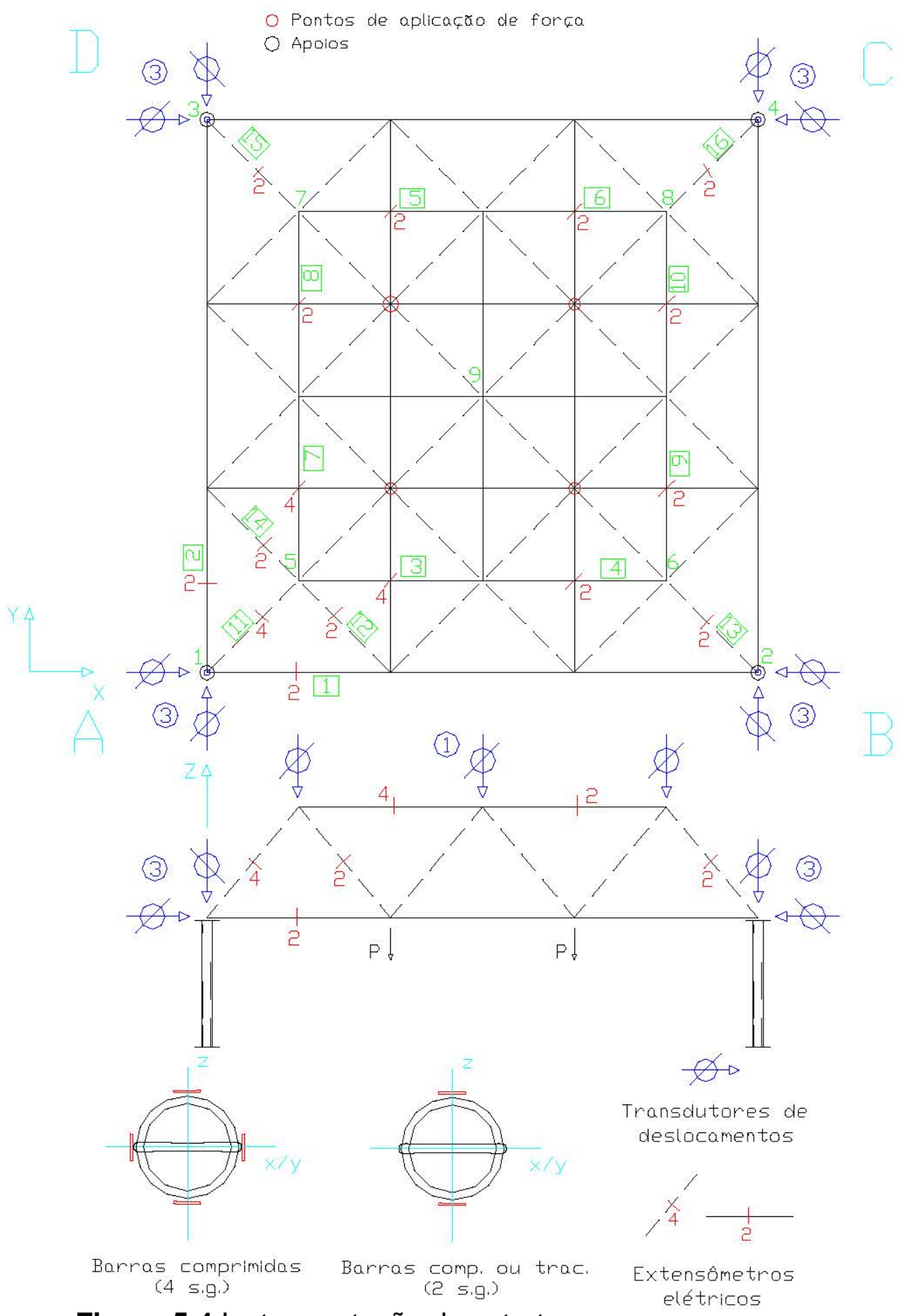

Figura 5.4 Instrumentação da estrutura. 

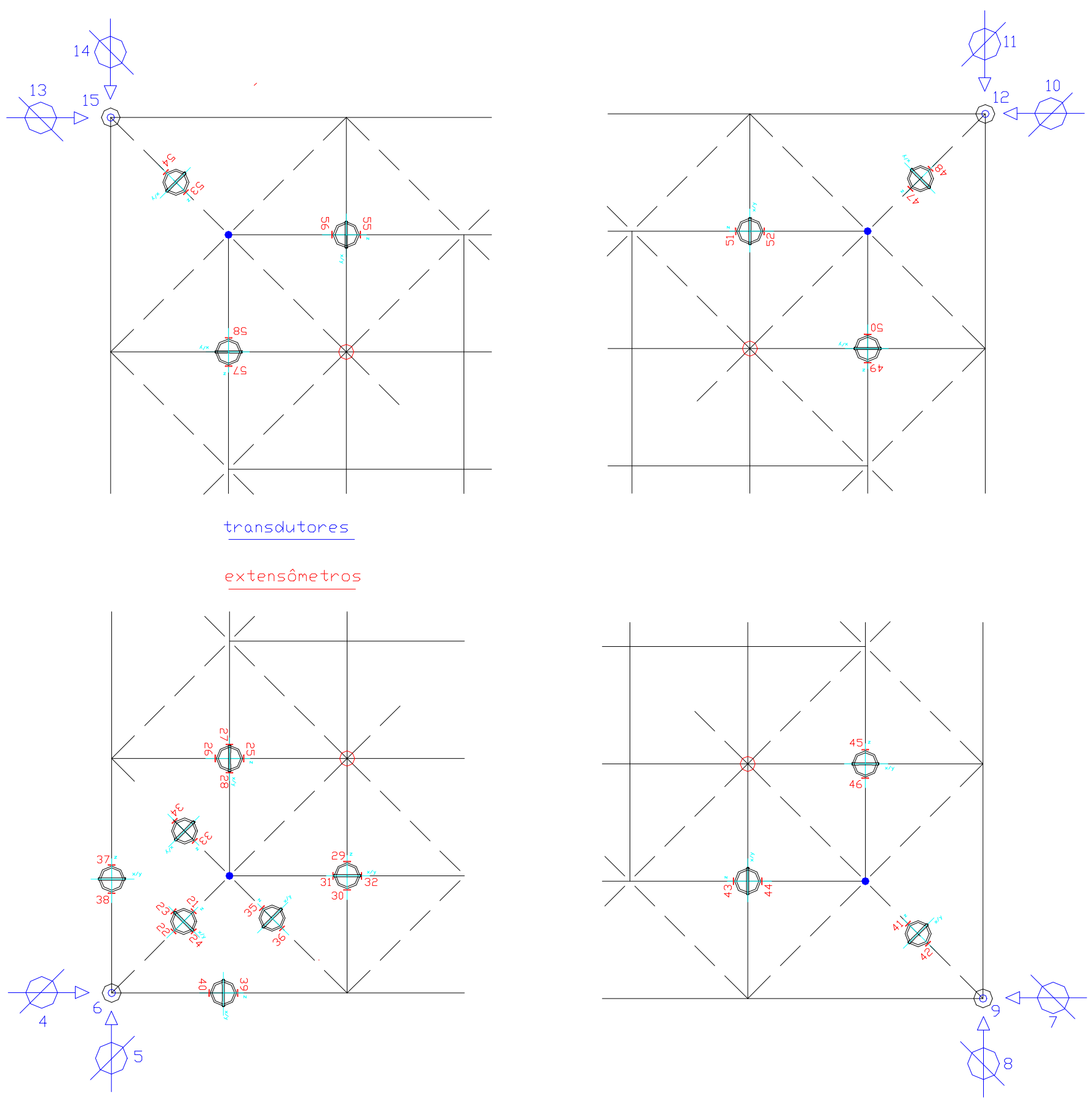

Figura 5.5 Detalhe da instrumentação da estrutura.

As forças foram aplicadas nos nós do banzo inferior (4 nós ver fig 5.4 ) por meio de atuadores hidráulicos com pistão vazado da marca ENERPAC, modelo $\mathrm{RCH}$ com capacidade de $300,0 \mathrm{kN}$. Para a medição das forças aplicadas utilizou-se células de carga com capacidade de 300,0kN, 
fabricadas no LE-EESC. A foto da Figura 5.6 apresenta detalhe do sistema de aplicação de força e a Figura 5.7 uma visão geral do ensaio.

Toda a instrumentação foi conectada a um sistema de aquisição automática de dados, o SYSTEM 4000.

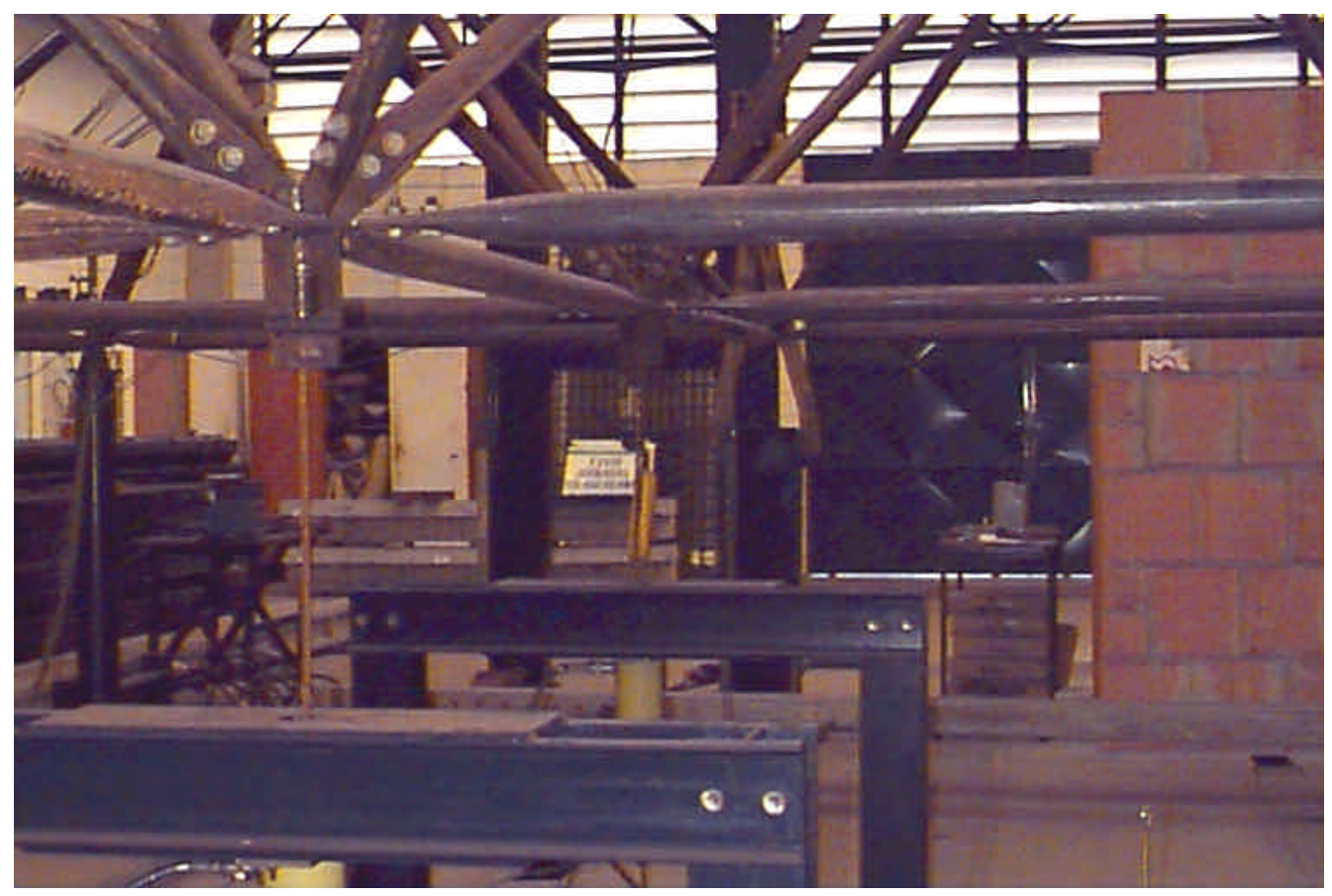

Figura 5.6 Detalhe do sistema de aplicação de força na estrutura.

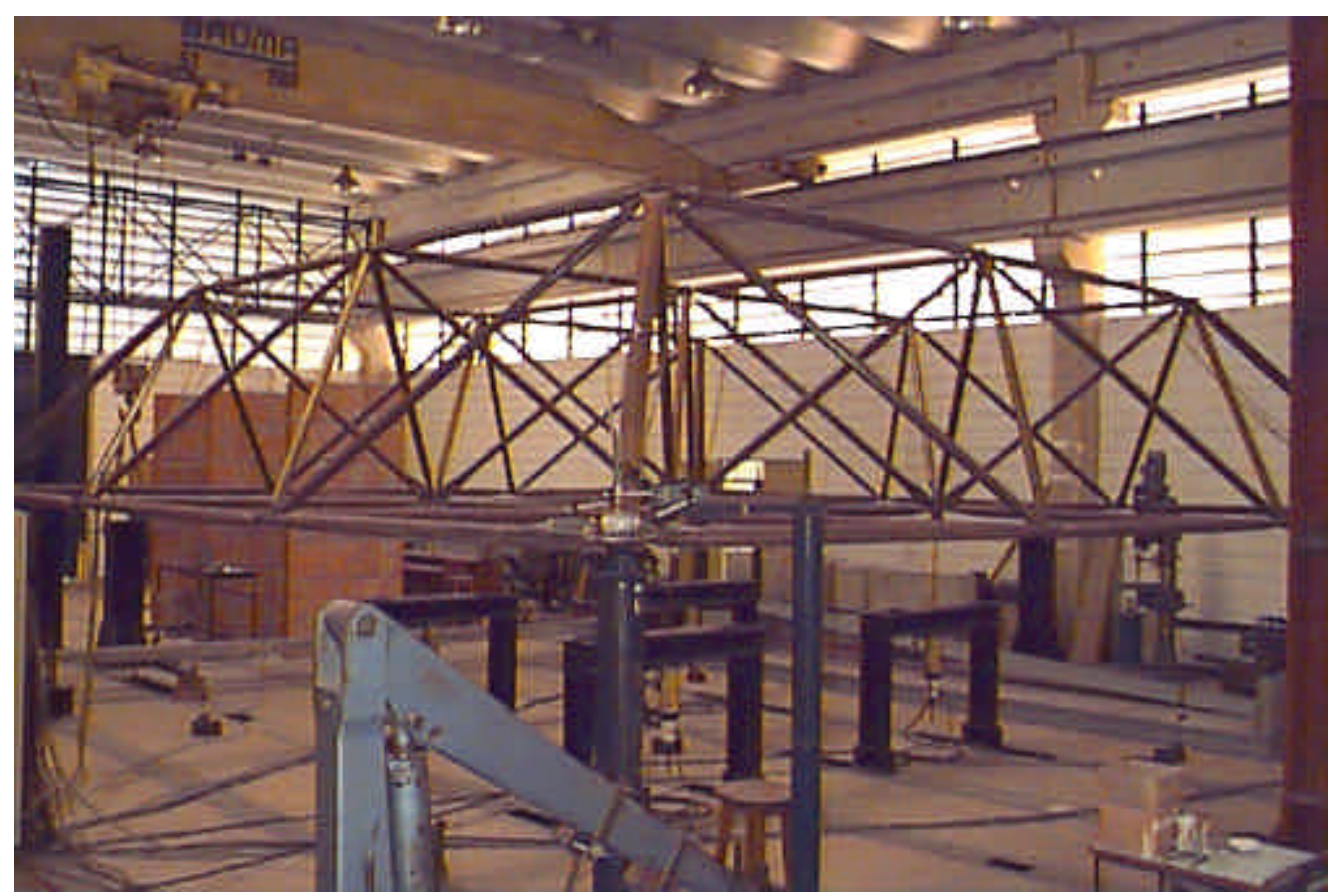

Figura 5.7 Visão geral do ensaio. 
A primeira fase do ensaio correspondeu ao escorvamento da estrutura, a fim de detectar possíveis falhas nos equipamentos e garantir a perfeita acomodação da estrutura. Para isso aplicou-se à estrutura uma força total de $12,5 \mathrm{kN}$ por nó dividida em três etapas de carregamento. Após esta fase, a estrutura foi descarregada e iniciado o ensaio propriamente dito com incrementos de carga de 5,0kN por nó.

A título de ilustração, na etapa de escorvamento a estrutura apresentou grandes deslocamentos de acomodação, e após o descarregamento os deslocamentos residuais foram bastante elevados como pode ser visto no gráfico da Figura 5.8.

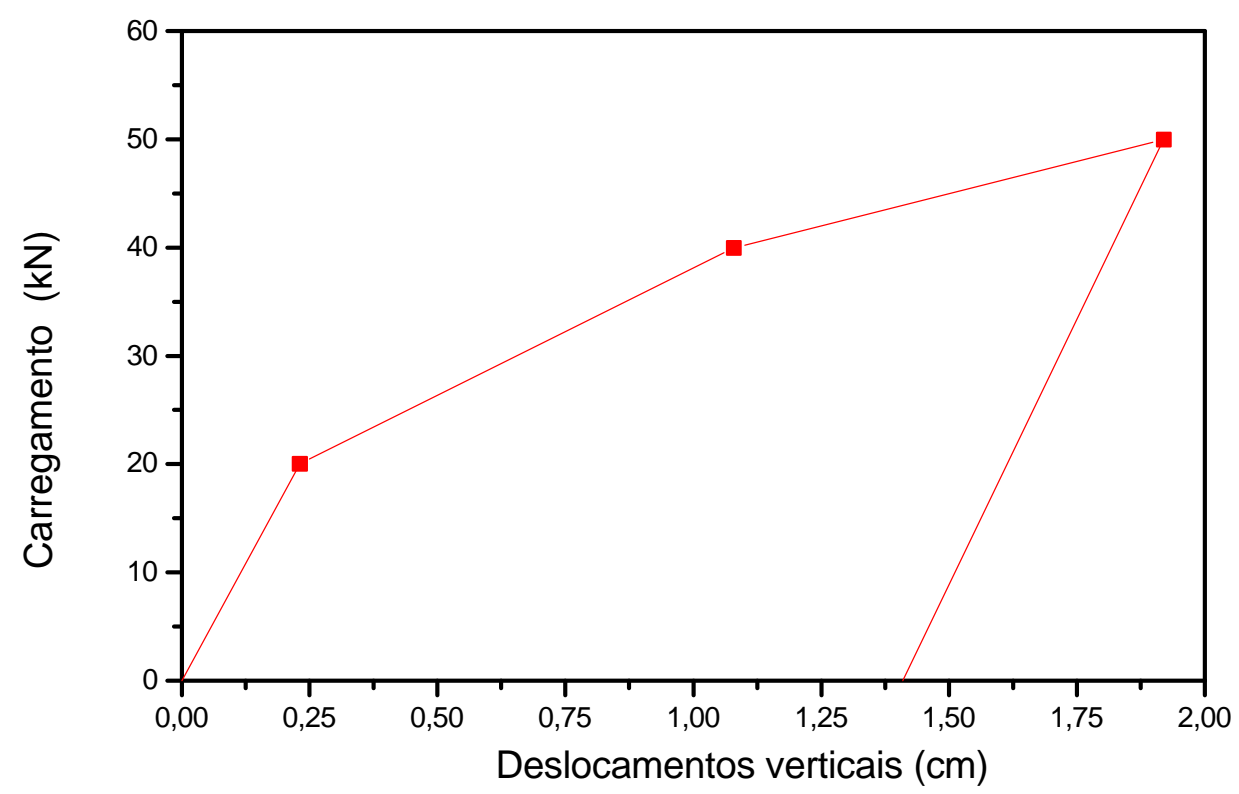

Figura 5.8 Deslocamentos verticais máximos durante 0 escorvamento. 


\subsection{Resultados experimentais}

\subsubsection{Ensaio de caracterização mecânica do aço}

A caracterização mecânica do aço foi feita mediante ensaio de tração axial, conforme especificação ASTM-A370-92 (Standard test methods and definitions for mechanical testing of steel products).

Para cada diâmetro de tubo utilizado na estrutura foram retirados quatro corpos de prova. As dimensões dos corpos de prova são apresentadas na Figura 5.9.

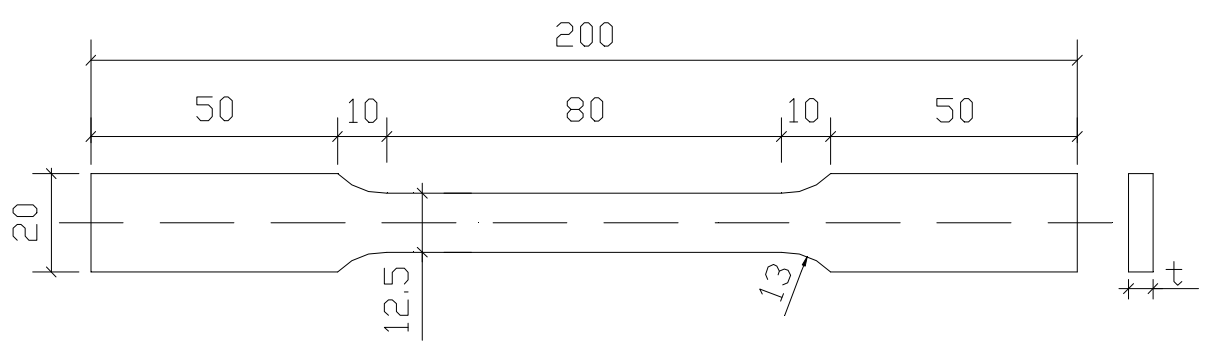

Figura 5.9 Dimensões dos corpos de prova para ensaio de Tração (ASTM-A370-92) - medidas em mm.

Os corpos de prova foram ensaiados em máquina universal da marca INSTRON instrumentados com extensômetro removível (clip gage). Os resultados da caracterização são apresentados na Tabela 5.2.

Ressalta-se que o aço ensaiado deve apresentar propriedades mecânicas diferentes das do aço virgem, uma vez que os mesmos foram retirados de tubos submetidos a trabalho a frio (conformação). 
Tabela 5.2 Resultados da caracterização mecânica do aço

\begin{tabular}{|c|c|c|c|c|c|c|}
\hline Tubo & C.P. & $\begin{array}{c}A \\
(\%)\end{array}$ & $\begin{array}{c}f_{\mathrm{y}} \\
(\mathrm{Mpa})\end{array}$ & $\begin{array}{l}f_{\mathrm{y}(\mathrm{med})} \\
(\mathrm{Mpa})\end{array}$ & $\begin{array}{c}\mathbf{f}_{\mathrm{u}} \\
(\mathrm{Mpa})\end{array}$ & $\begin{array}{l}f_{\mathrm{u}(\mathrm{med})} \\
(\mathrm{Mpa})\end{array}$ \\
\hline \multirow{4}{*}{$\phi 60 \times 2,0$} & $1^{*}$ & 17,6 & 542,7 & 542,7 & 575,2 & 575,2 \\
\hline & 2 & \multirow{3}{*}{24,9} & 447,4 & \multirow{3}{*}{420,5} & 475,7 & \multirow{3}{*}{477,9} \\
\hline & 3 & & 404,8 & & 482,1 & \\
\hline & 4 & & 409,3 & & 475,8 & \\
\hline \multirow{4}{*}{$\phi 76 \times 2,0$} & $1^{*}$ & 15,6 & 504,0 & 504,0 & 544,0 & 544,0 \\
\hline & 2 & \multirow{3}{*}{26,7} & 392,0 & \multirow{3}{*}{374,0} & 452,0 & \multirow{3}{*}{457,1} \\
\hline & 3 & & 353,4 & & 457,8 & \\
\hline & 4 & & 376,5 & & 461,5 & \\
\hline \multirow{4}{*}{$\phi 88 \times 2,65$} & $1^{*}$ & 19,4 & 473,8 & 473,8 & 520,3 & 520,3 \\
\hline & 2 & \multirow{3}{*}{32,0} & 384,1 & \multirow{3}{*}{358,8} & 451,2 & \multirow{3}{*}{448,1} \\
\hline & 3 & & 343,8 & & 447,4 & \\
\hline & 4 & & 348,6 & & 445,7 & \\
\hline
\end{tabular}

$f_{y}=$ limite de escoamento convencional (offset 0,2\%)

$\mathrm{f}_{\mathrm{u}}=$ limite de resistência à tração

$A=$ alongamento máximo na ruptura (base de medida $50 \mathrm{~mm}$ )

$1^{*}=$ corpo de prova retirado na região da costura

\subsubsection{Ensaio da estrutura}

Havia sido prevista a necessidade da aplicação de uma força de 60,0kN (análise linear e barras com inércia constante) por nó para a estrutura ensaiada, neste nível de carregamento ocorreria falha dos banzos comprimidos (carga crítica de flambagem).

No entanto, o ensaio foi interrompido quando o nível de carga atingiu $40,0 \mathrm{kN}$ por nó, sendo a ruína da estrutura caracterizada pelo colapso da ligação. Todos os nós da estrutura sofreram rotação evidenciando o aparecimento de momentos fletores devido a forças excêntricas, isso ocasionou plastificação nas seções dos banzos e diagonais comprimidas na região da estampagem. A Figura 5.10 apresenta a configuração de alguns nós da estrutura após a ruína. 

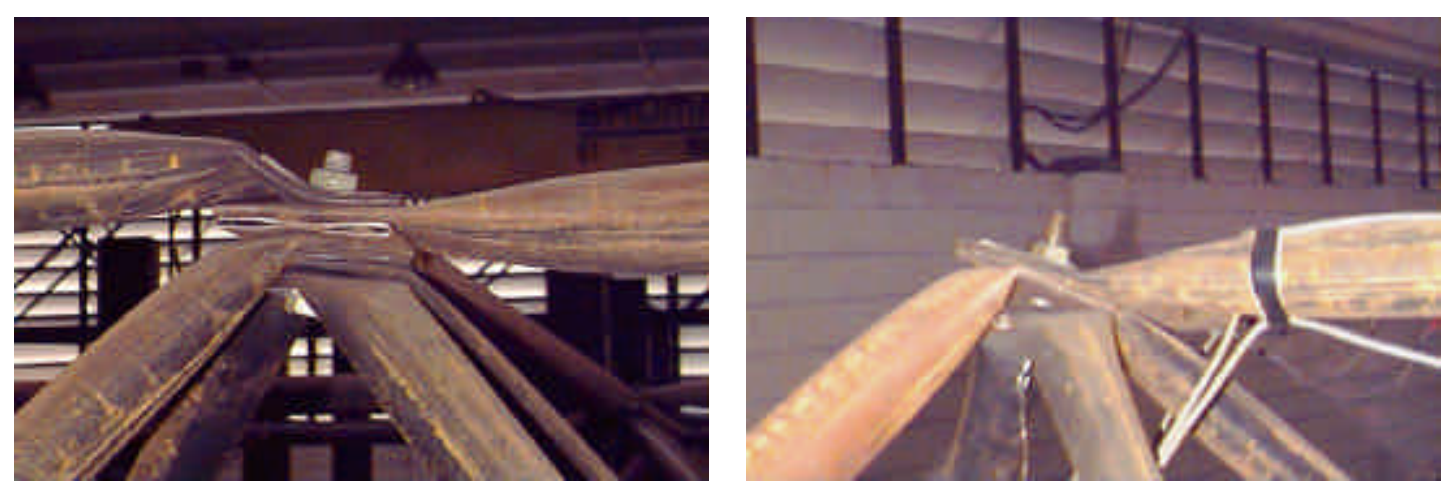

Figura 5.10 Configuração dos nós da estrutura após a ruína.

Os gráficos das figuras seguintes apresentam os resultados de deslocamentos nodais e deformações em barras registrados na estrutura ensaiada. Para as deformações são apresentadas as médias dos valores de deformação registrados pelos extensômetros elétricos de resistência para cada seção instrumentada. A figura 5.11 apresenta a numeração de barras e nós da estrutura ensaiada em correspondência com os gráficos de resultados.

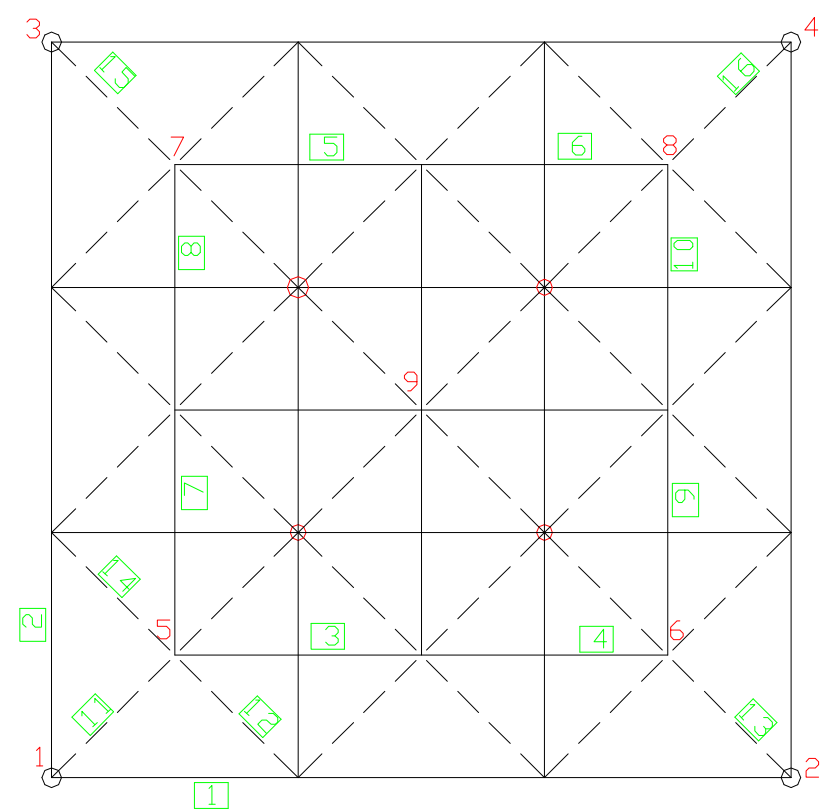

Figura 5.11 Numeração de barras e nós da estrutura ensaiada. 


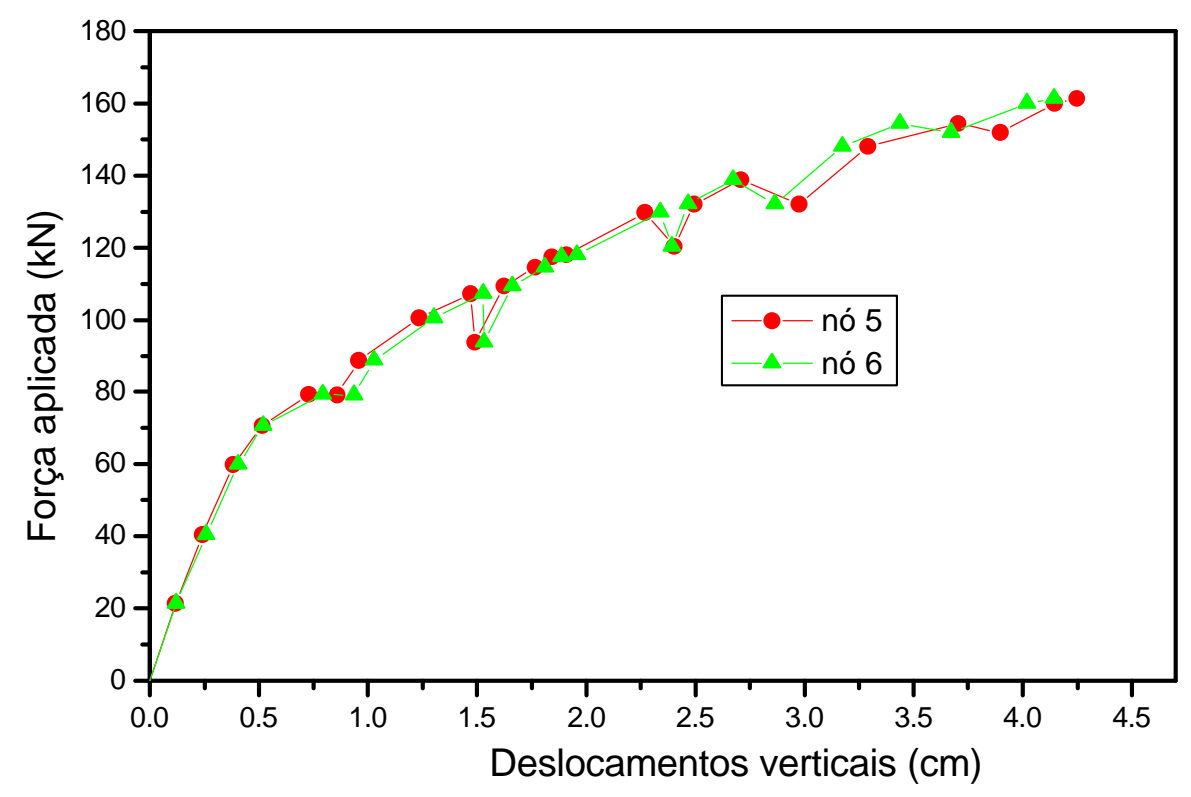

Figura 5.12 Força aplicada x deslocamentos - nó 5 e nó 6.

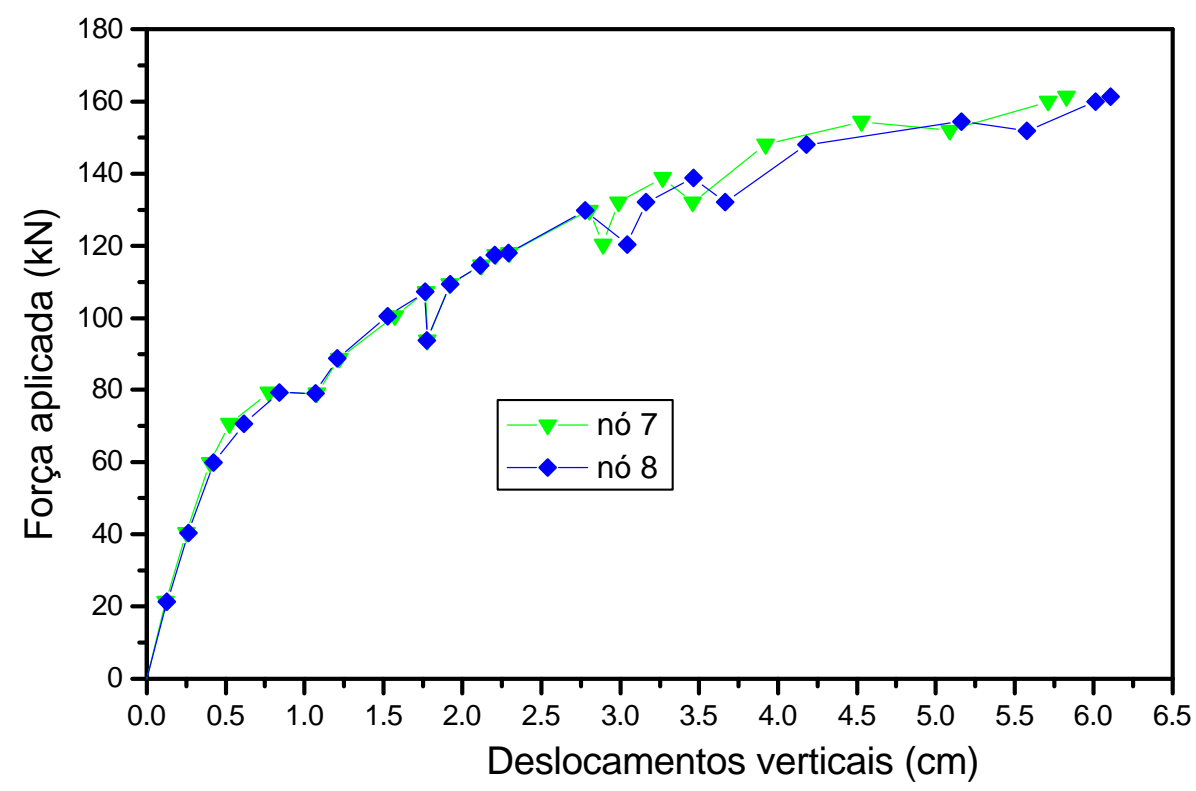

Figura 5.13 Força aplicada x deslocamentos - nó 7 e nó 8. 


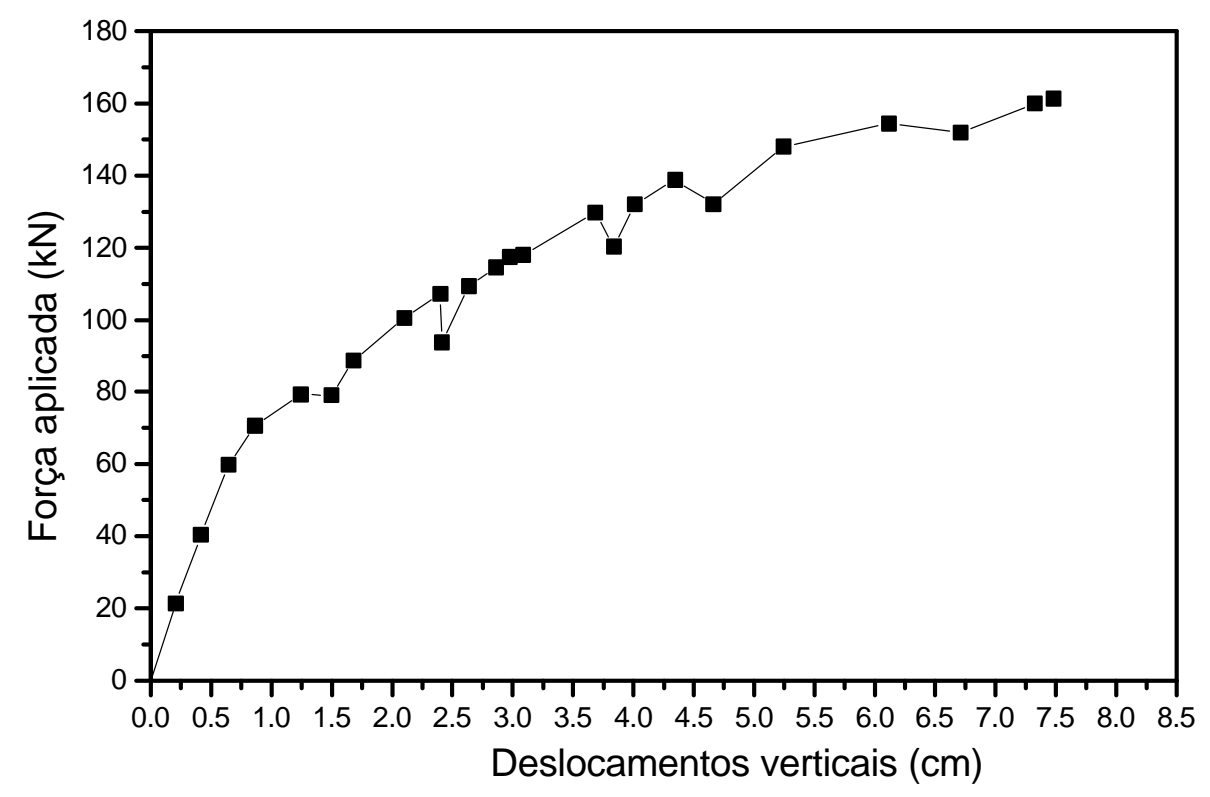

Figura 5.14 Força aplicada x deslocamentos - nó 9 (nó central).

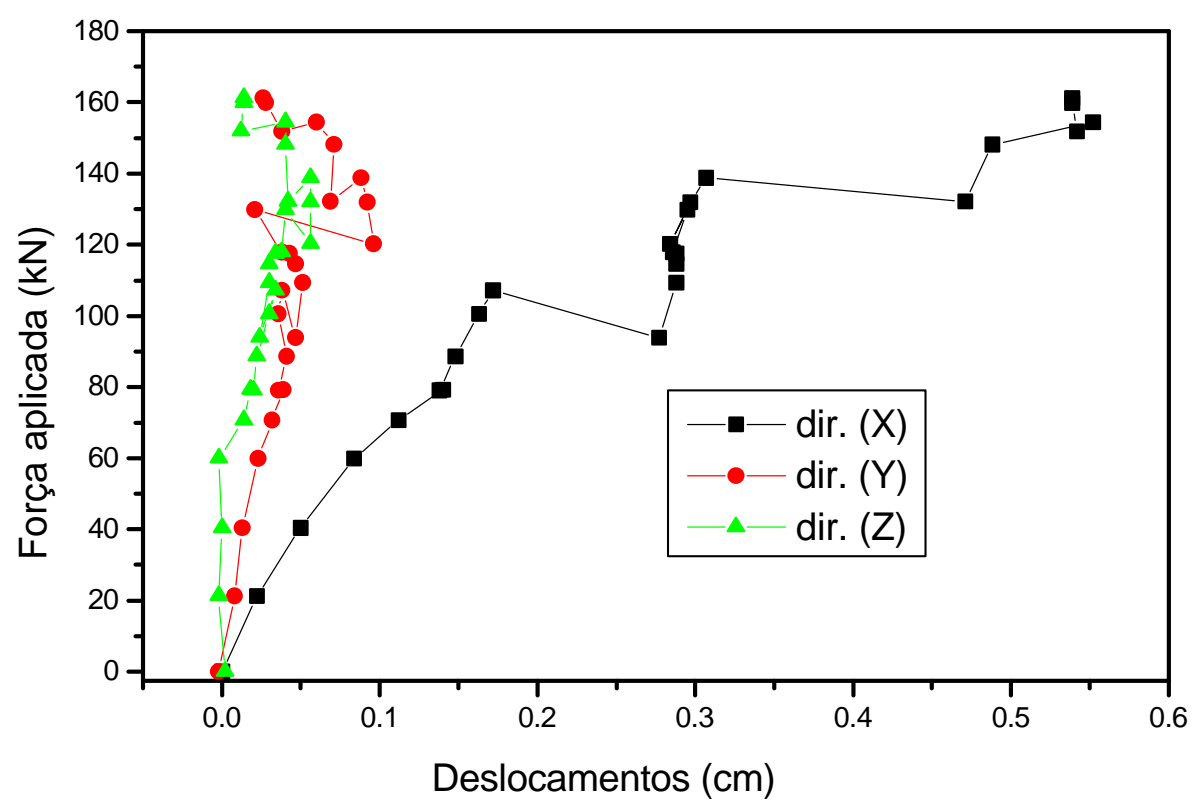

Figura 5.15 Força aplicada x deslocamento - nó 1. 


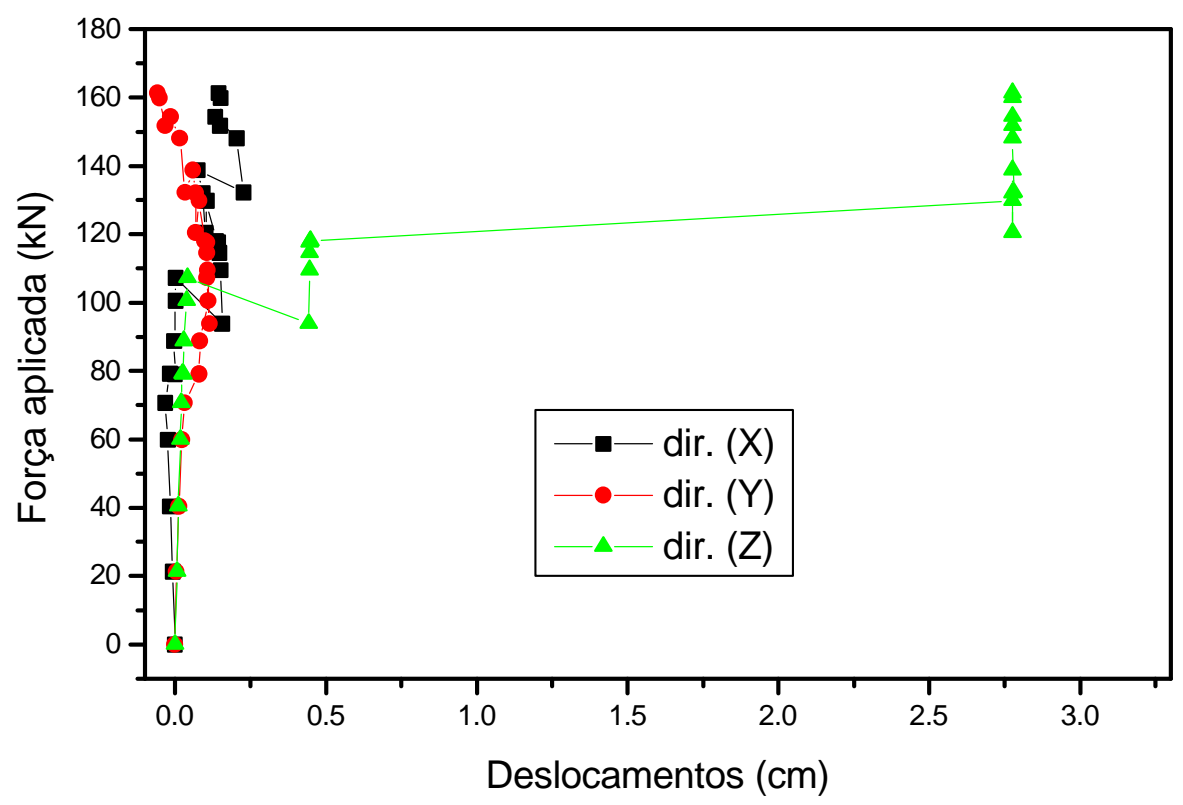

Figura 5.16 Força aplicada x deslocamentos - nó 2 .

Observando os gráficos das figuras 5.12 a 5.16 percebe-se um comportamento fortemente não linear entre força aplicada e deslocamentos, mesmo para níveis de força aplicada inferiores às cargas de serviço. Esse comportamento contraria todas as hipóteses assumidas em projetos, ou seja, treliça ideal com comportamento elástico linear. Evidencia-se que estes resultados são conseqüências do tipo de ligação(nó típico) empregado para unir as barras da estrutura.

O transdutor utilizado para medir os deslocamentos verticais apresentou problemas, justificando os deslocamentos excessivos (direção Z) no gráfico da Figura 5.16. 


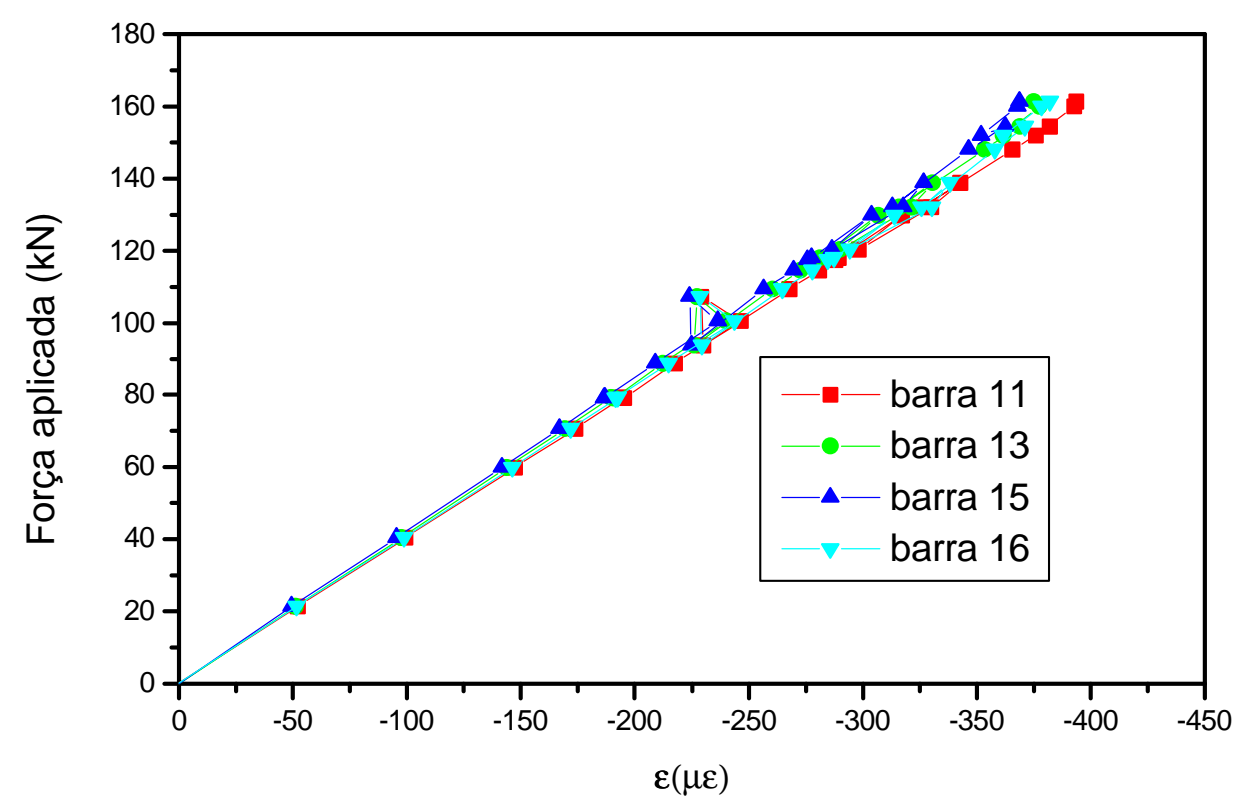

Figura 5.17 Força aplicada x deformação diagonais de apoio - barras $11,13,15$ e 16 .

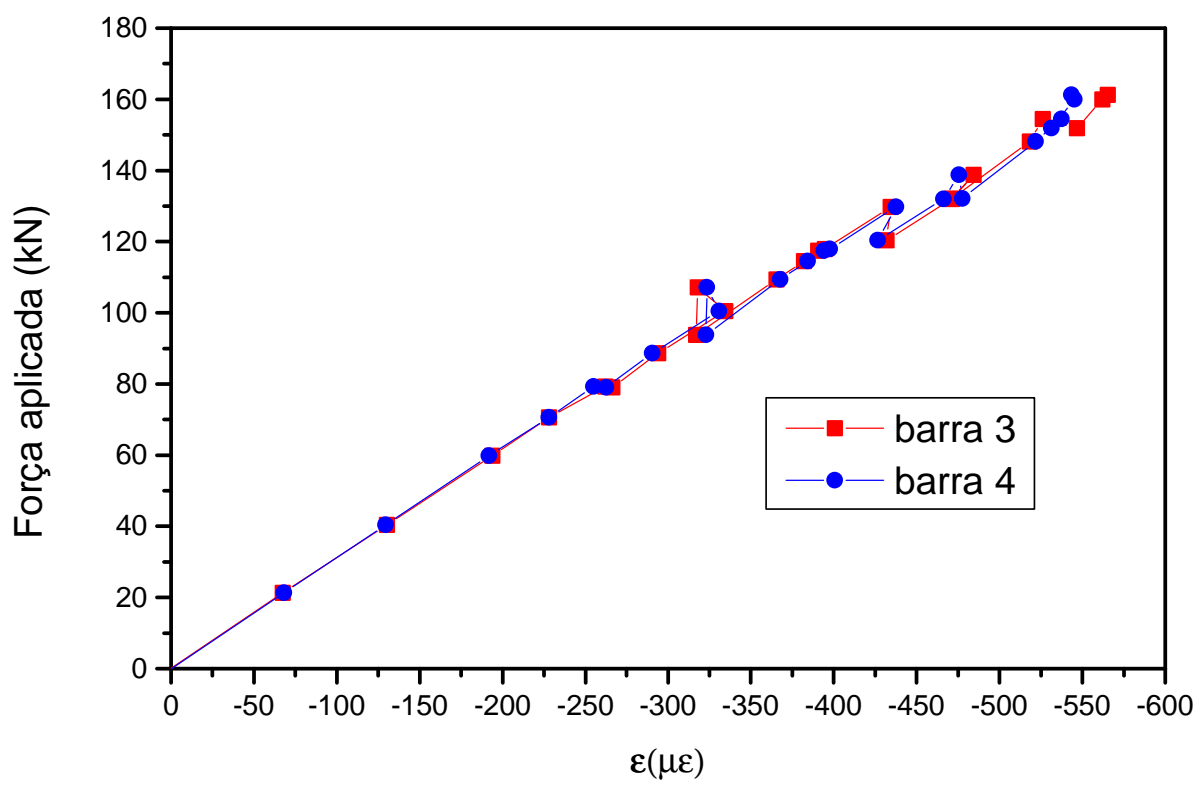

Figura 5.18 Força aplicada x deformação banzo superior - barras 3 e 4 . 


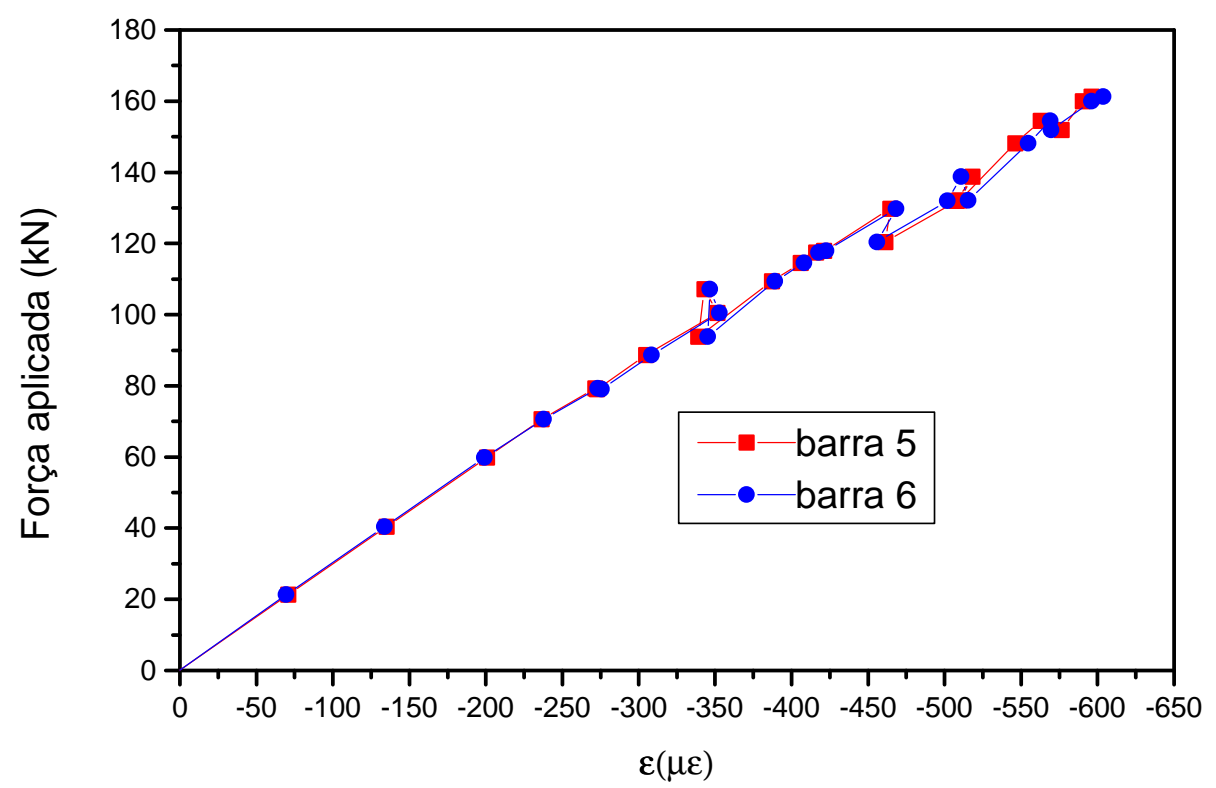

Figura 5.19 Força aplicada $x$ deformação banzo superior - barras 5 e 6.

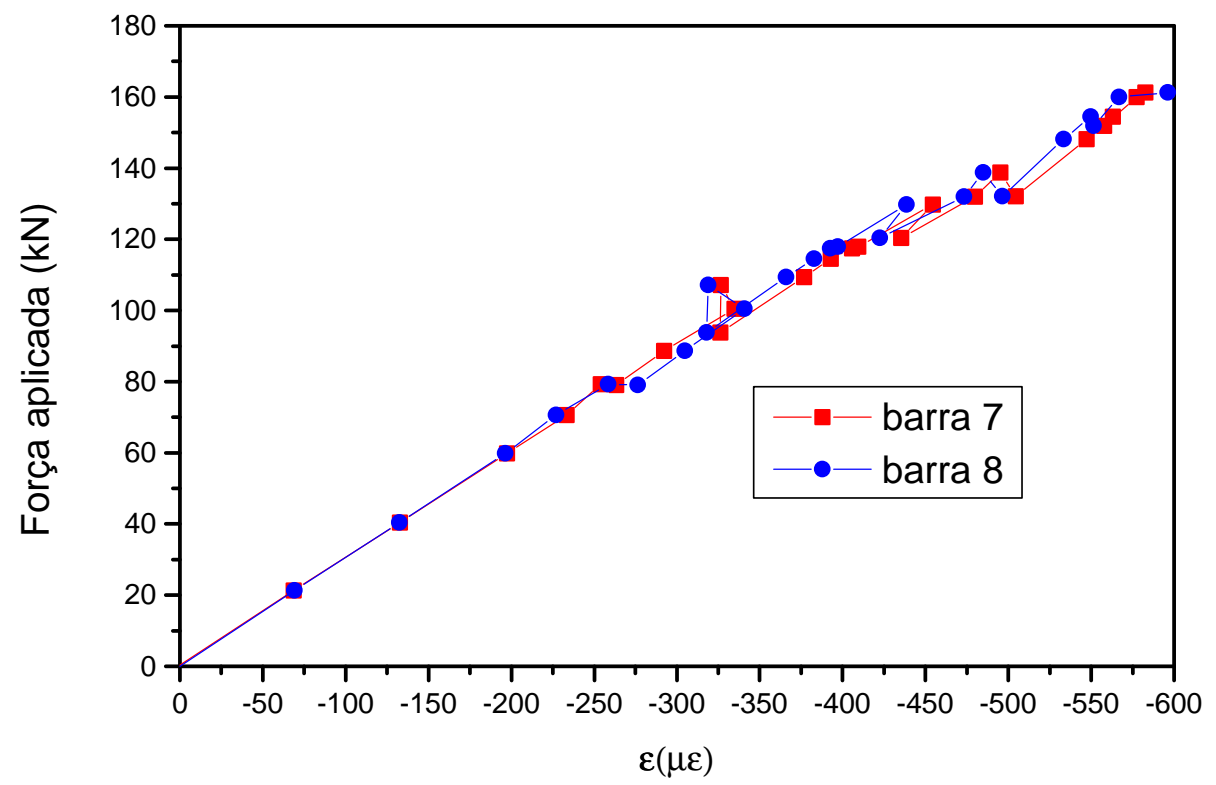

Figura 5.20 Força aplicada $x$ deformação banzo superior - barras 7e 8. 


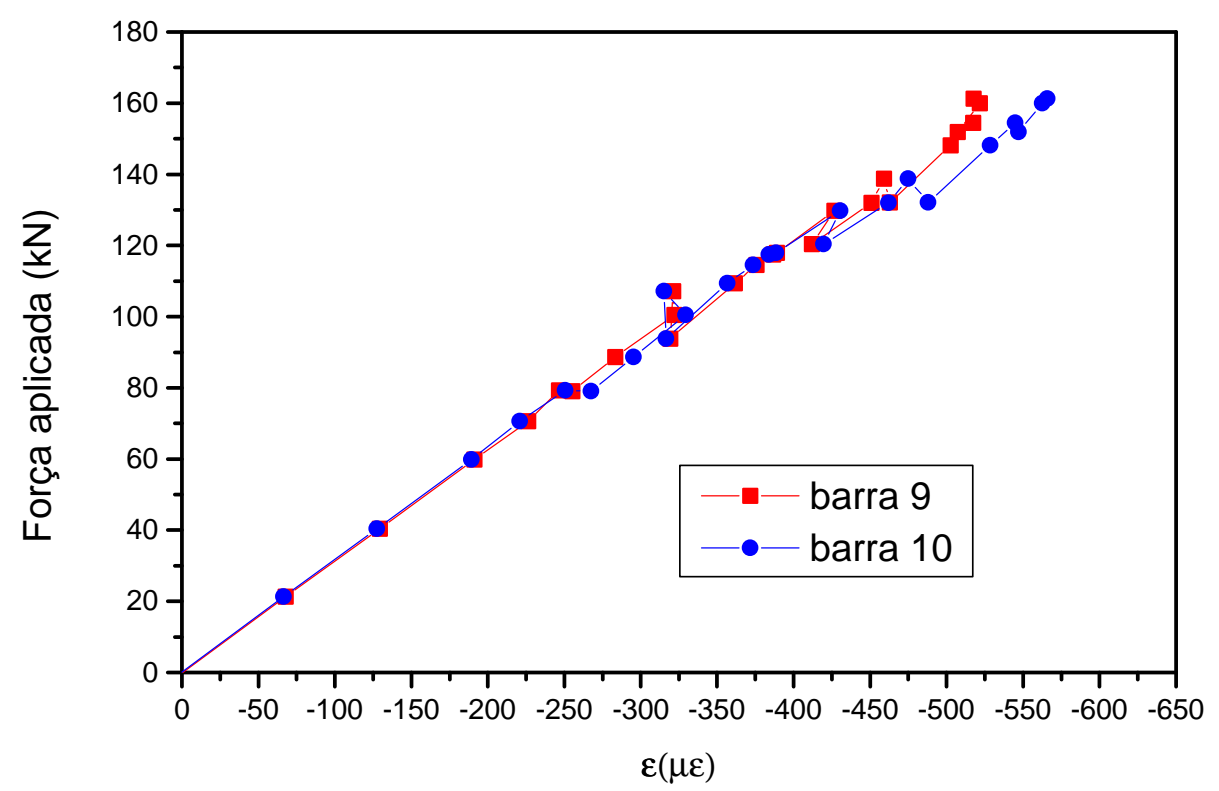

Figura 5.21 Força aplicada x deformação banzo superior - barras 9 e 10.

No caso das deformações e por conseguinte, esforços em barras, 0 comportamento pode ser admitido linear conforme observação dos respectivos gráficos carregamento $x$ deformação (Figuras 5.17 a 5.22). As perturbações percebidas nestes gráficos são conseqüência de acomodações na estrutura devido ao escorregamento relativo entre barras, resultado da precariedade do sistema de ligação utilizado. Vale ressaltar que esse comportamento pode não se verificar nas seções da região nodal que não foram instrumentadas, uma vez que essas seções entram em regime plástico enquanto as seções centrais(instrumentadas) das barras permaneceram em regime elástico. 


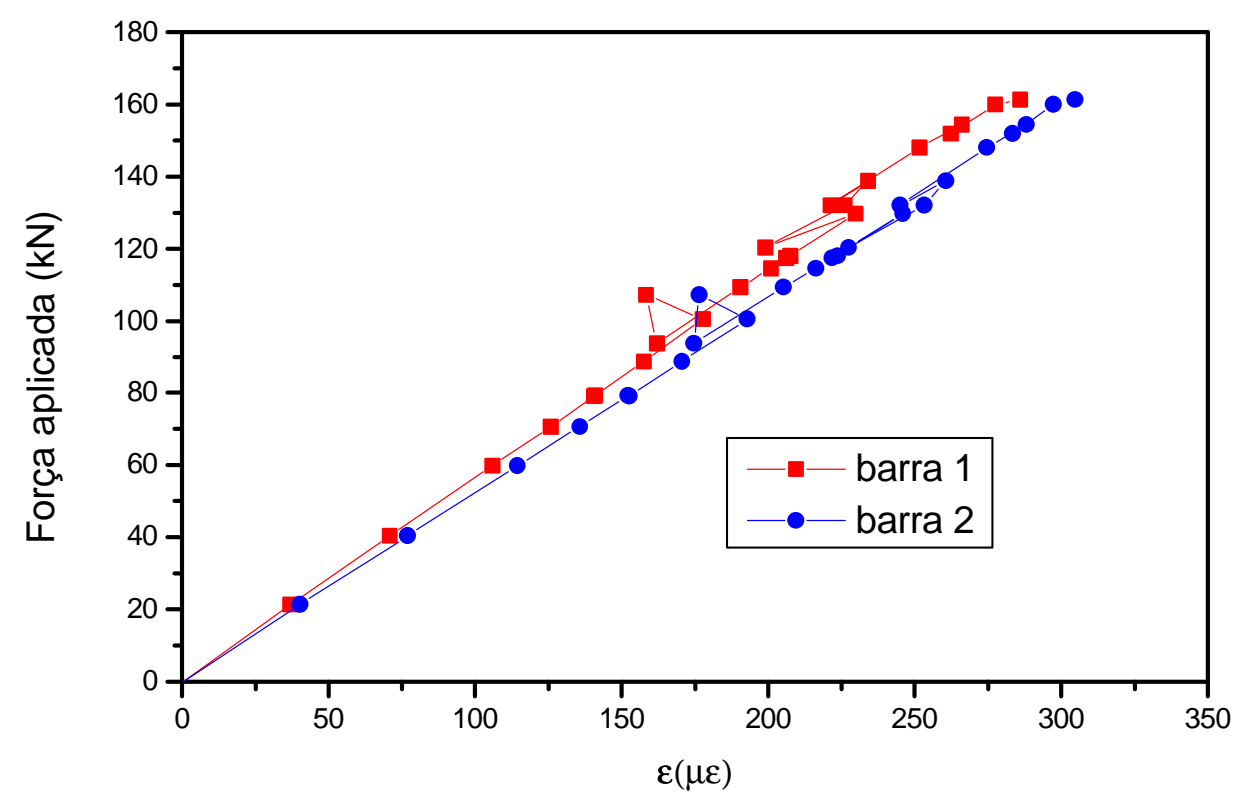

Figura 5.22 Força aplicada x deformação banzo inferior - barras 1 e 2.

Para a diagonal tracionada (Figura 5.23) o comportamento força aplicada $x$ deformação apresenta alívio de deformação com acréscimo de carregamento. Esse comportamento evidencia alívio de tensões nas barras, no entanto, observando as tensões nas outras barras da estrutura conclui-se que esse alívio de tensões não é devido à redistribuição de esforços e sim ao escorregamento da barra na região do nó ou uma possível plastificação localizada na região nodal, o que deve provocar alterações nas vinculações de extremidades da barra. 


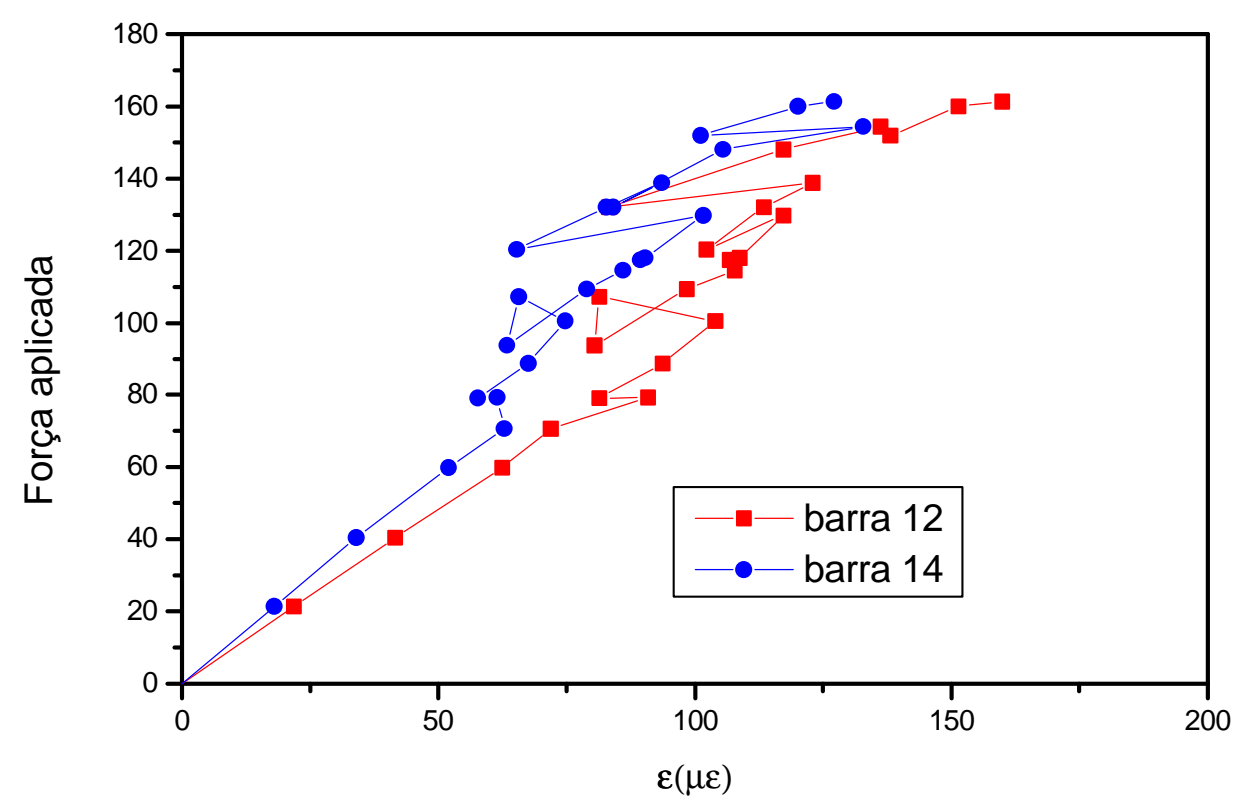

Figura 5.23 Força aplicada $\mathrm{x}$ deformação diagonais tracionadas barra 12 e 14.

As observações e conclusões deste ensaio, obviamente, não podem ser extrapolados por tratar-se de apenas um protótipo, no entanto, alguns problemas conhecidos e outros nem tanto, foram detectados no ensaio. $\mathrm{O}$ principal deles é a constatação de que o modelo teórico para análise de esforços e deslocamentos, comumente utilizados (treliça ideal e comportamento elástico linear), não representa, com fidelidade, o modelo físico. Uma prova deste fato são os deslocamentos cujos valores experimentais resultaram cerca de quatro vezes maiores que os obtidos teoricamente através de modelos clássicos.

No próximo capítulo far-se-á uma análise teórica da estrutura ensaiada utilizando-se modelos mais realísticos em que são consideradas a variação de inércia nas extremidades das barras e os efeitos não lineares físico e geométrico. 


\section{ANÁLISE NÃO LINEAR DE TRELIÇAS}

ESPACIAIS

As estruturas, de modo geral, são calculadas sem considerar o comportamento não linear, sendo projetadas em regime elástico linear.

No caso das estruturas espaciais a situação não é diferente, entretanto, a análise não linear tanto física quanto geométrica, deve ser realizada afim de se avaliar o comportamento real destas estruturas até a ruína. As estruturas espaciais, normalmente projetadas para grandes vãos, devem ser calculadas considerando os efeitos não lineares, principalmente a não linearidade geométrica.

O objetivo deste capítulo é avaliar o comportamento não linear de treliças espaciais formadas por tubos de seção circular com extremidades estampadas e comparar os resultados teóricos com os resultados experimentais para o caso da estrutura apresentada no Capítulo 5.

Inicialmente serão realizadas análises numéricas da treliça espacial ensaiada, apresentada no capítulo anterior, comparando os resultados teóricos e experimentais com o objetivo de aferir a validade dos modelos teóricos adotados. Em seguida serão analisados modelos de estruturas com dimensões maiores (22,5 x 22,5m-22,5m x 37,5m ), em que a sensibilidade aos efeitos não lineares é mais evidente. 


\subsection{Descrição da análise teórica não linear}

\subsubsection{Elemento finito utilizado}

Os protótipos serão analisados, via elementos finitos, utilizando-se o programa LUSAS. O elemento finito utilizado na análise é o $B S 3$, com seis graus de liberdade por nó (três translações e três rotações), constante na biblioteca de elementos do programa e apresentado na Figura 6.1. Utilizouse elemento finito de viga com a intenção de avaliar os momentos fletores que surgem nas ligações devido a excentricidades e também para considerar a variação de inércia nas extremidades das barras.

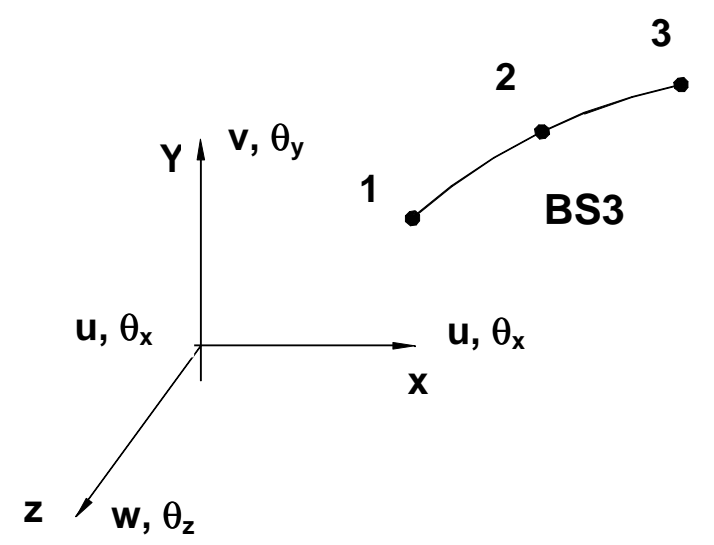

Figura 6.1 Elemento finito utilizado na análise numérica.

Serão consideradas nas análises as variações de inércia nas extremidades das barras, conseqüência do tipo de ligação utilizado no protótipo ensaiado. Para isso, cada elemento da treliça espacial, adotado na análise teórica, constitui-se de um trecho com seção constante, um trecho de seção variável (extremidades estampadas) e um trecho que corresponde ao nó. A Figura 6.2 ilustra o modelo de barra utilizado na análise teórica. 


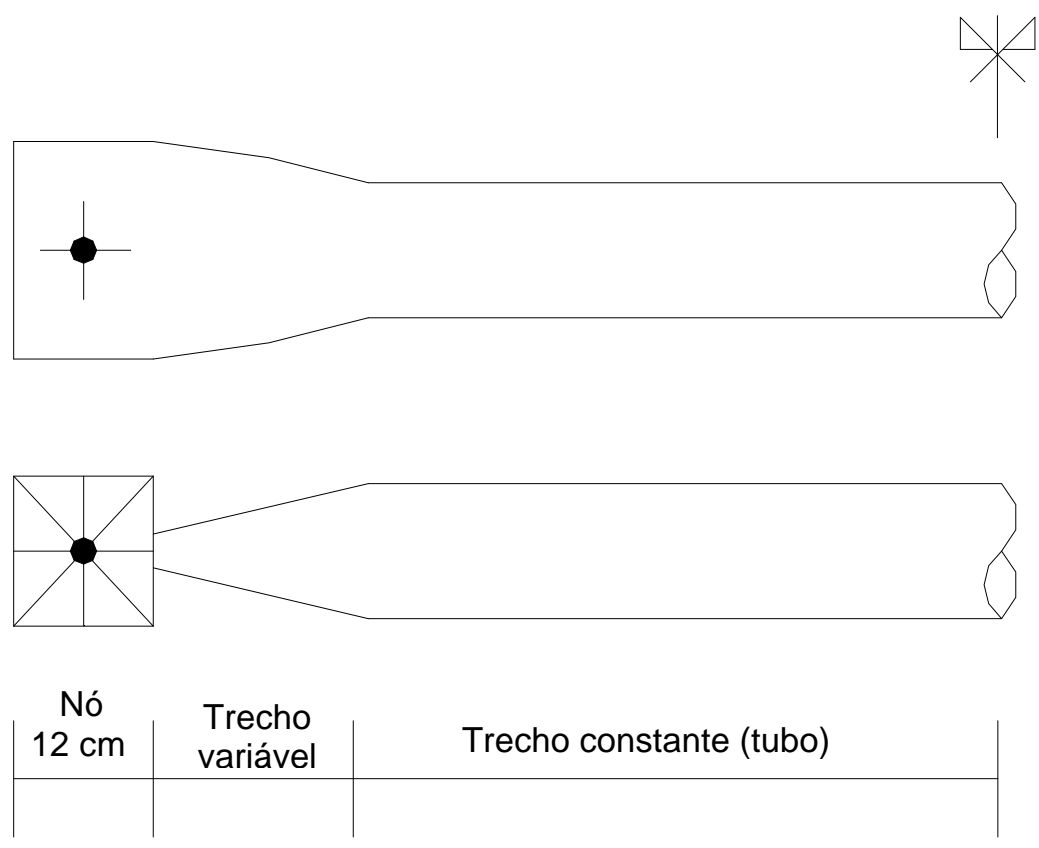

Figura 6.2 Modelo de barra adotado na análise teórica.

Para o caso de nós típicos não se pode determinar, com precisão, a rigidez do trecho correspondente ao nó. Portanto, idealizou-se duas situações extremas:

- na primeira hipótese, o nó foi formada por uma barra equivalente com largura igual ao tubo estampado e espessura igual a altura dos tubos superpostos na região da ligação. Esta barra possui comprimento de $6,0 \mathrm{~cm}$ a partir do PT ( eixo do parafuso) até o início do trecho de seção variável.

- na segunda hipótese foi considerado o trecho nodal com a inércia correspondente somente a um tubo com a extremidade estampada.

Entre esses dois extremos foram feitas análises intermediárias com inércia do trecho nodal equivalendo a $5 \%$ e $10 \%$ da inércia do nó formado por superposição dos tubos.

\subsubsection{Critérios para análise não linear geométrica}

Os protótipos e modelos serão analisados através do programa LUSAS considerando o efeito da não linearidade geométrica. A formulação adotada foi a Lagrangeana Total (Total Lagragian) disponível no programa e a única aplicável ao elemento finito (BS3) utilizado. Para solução dos 
sistemas de equações de equilíbrio foi utilizado o método incremental interativo de Newton-Raphosn.

\subsubsection{Critérios para análise não linear física}

Uma discussão mais detalhada sobre os modelos constitutivos possíveis de serem utilizados em análise não linear física de estruturas espaciais foi apresentada no Capítulo 2. Infelizmente a grande maioria desses modelos constitutivos não foram utilizados devido às limitações do LUSAS, programa de elementos finitos disponível no Departamento de Estruturas.

Devido a tais limitações adotou-se um modelo elasto-plástico perfeito para representar o material tanto na tração (hipótese razoável) como na compressão (hipótese muito pobre). Os modelos constitutivos adotados são apresentados na Figura 6.3. Este modelo é denominado pelo LUSAS de "Material Model 29".
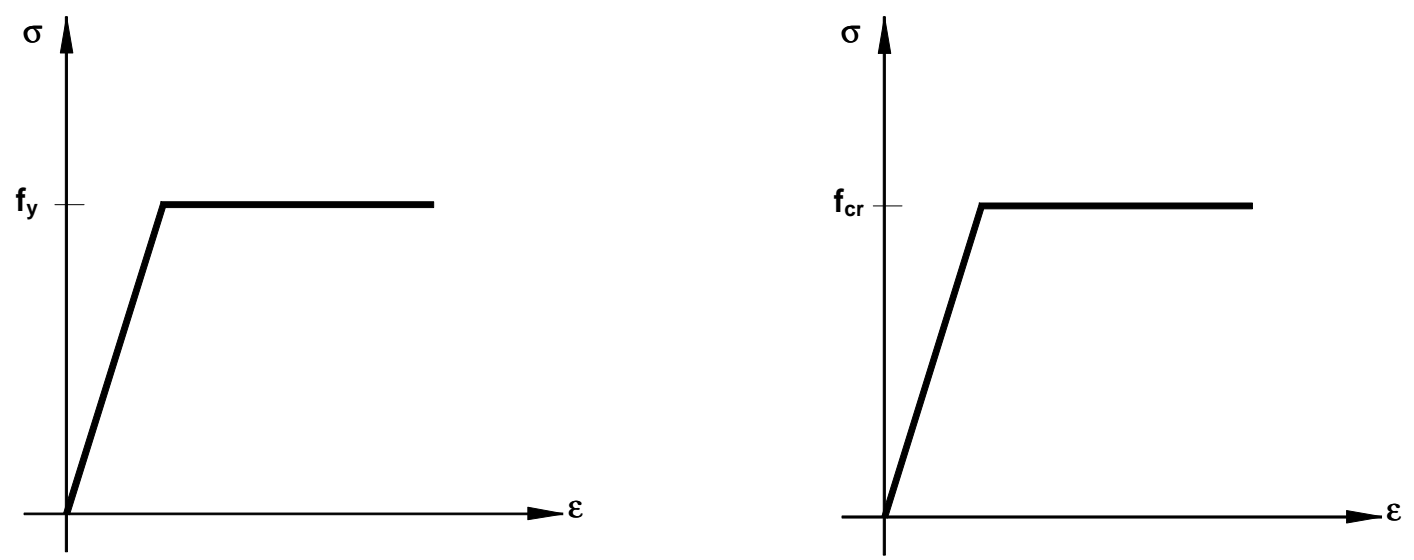

Figura 6.3 Modelos constitutivos do material adotados na análise numérica.

O primeiro modelo considera o início da plastificação com um nível de tensão equivalente ao limite de escoamento do material, enquanto no segundo modelo, a plastificação inicia-se com tensões correspondentes a tensão de flambagem do elemento determinado pela NBR-8800 (1986). 


\subsection{Resultados teóricos do ensaio de treliça espacial}

Neste item a estrutura ensaiada no capítulo anterior será analisada numericamente e os resultados comparados com os experimentais.

As barras da estrutura foram discretizadas considerando a variação de inércia nas extremidades devido à estampagem, para isso foi realizado um levantamento das propriedades das seções transversais dessas extremidades que são apresentada na figura 6.4.

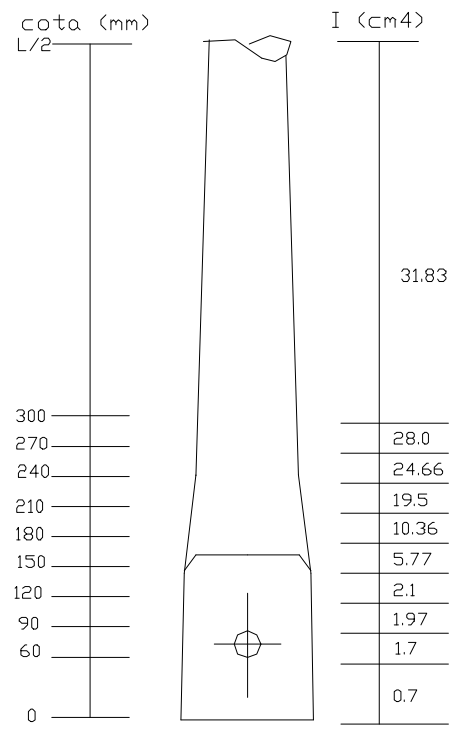

$\phi 76 \times 2,0$

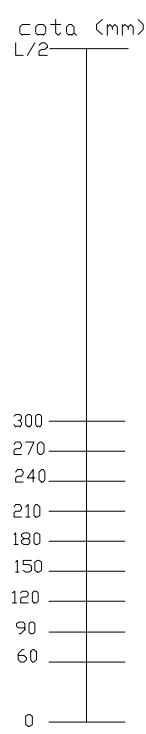

$\phi 60 \times 2,0$
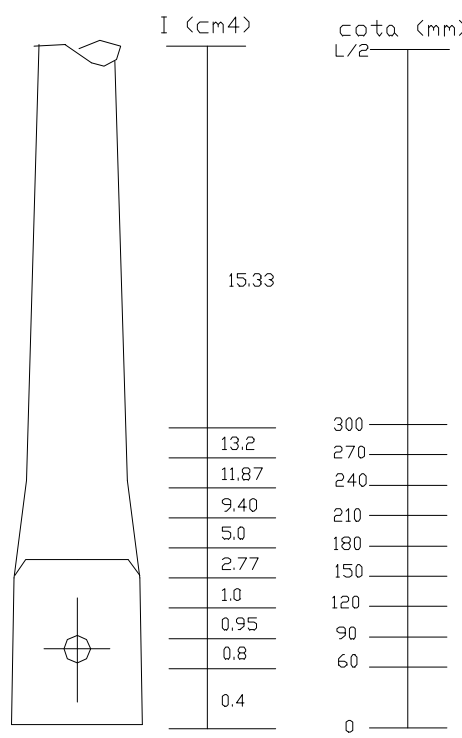

$\phi 88 \times 2,65$

Figura 6.4 Variação de inércia ao longo do comprimento das barras para nó típico.

A tabela seguinte apresenta a força normal resistente à compressão para as barras utilizadas nos protótipos. Os valores de força normal resistente foram calculados pela NBR-8800(1986) considerando a barra birotulada e com inércia constante ao longo do comprimento. Calculou-se também a força normal resistente dessas barras, considerando o efeito da variação de inércia segundo o procedimento apresentado no capítulo 3 . 
Tabela 6.1- Força normal resistente das barras utilizadas nos protótipos.

\begin{tabular}{|c|c|c|c|c|c|}
\hline Tubo & Utilização & Comp. (mm) & Esbeltez & $\mathbf{N}_{c}(\mathbf{k N})$ & $\mathbf{N}_{c}{ }^{*}(\mathbf{k N})$ \\
\hline$\phi 60 \times 2,0$ & diagonal & 2318 & 113,0 & 41,0 & 35,3 \\
\hline \multirow{2}{*}{$\phi 76 \times 2,0$} & banzo & 2500 & 95,4 & 70,7 & 66,6 \\
\cline { 2 - 6 } & diagonal & 2318 & 88,5 & 65,6 & 61,5 \\
\hline$\phi 88 \times 2,65$ & diagonal & 2318 & 77,0 & 120,5 & 112,7 \\
\hline
\end{tabular}

$\mathrm{N}_{\mathrm{c}}{ }^{*}$ Força normal resistente considerando variação de inércia na barra.

\subsubsection{Análise não linear geométrica protótipo ensaiado}

O gráfico da Figura 6.5 apresenta os resultados de deslocamentos verticais para vários valores de rigidez do nó (conforme exposto em 6.6.1) em comparação com deslocamentos obtidos experimentalmente.

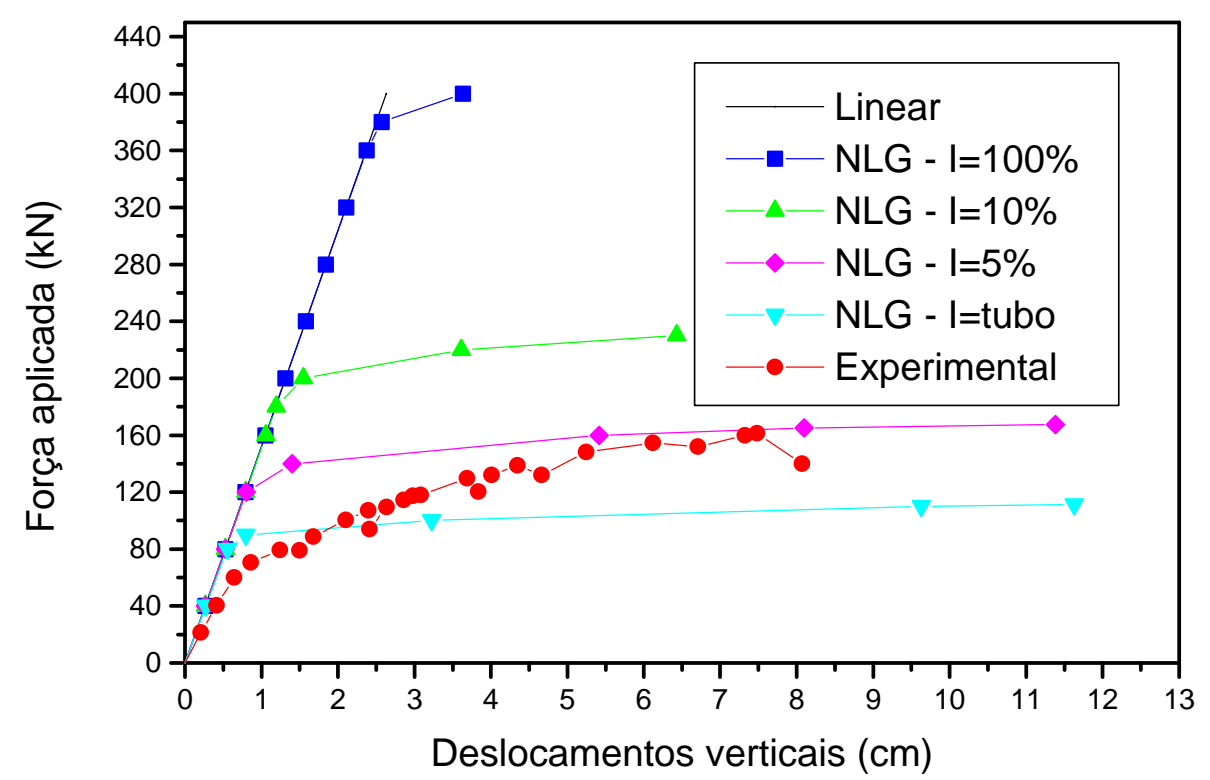

Figura 6.5 Deslocamentos verticais teóricos e experimentais.

\section{NOTAS - FIGURA 6.5}

1. $I=100 \%$ - inércia do trecho nodal correspondente a inércia da seção formada pela superposição de todas as barras estampadas concorrentes no nó.

2. $I=10 \%$ e I=5\%- porcentagens relativas à inércia da seção definida em 1 . 
3. I = tubo - inércia do trecho nodal correspondente à inércia da seção formada pelo tubo com extremidade estampada.

Pelo gráfico da Figura 6.5 percebe-se que o modelo teórico comumente utilizado, ou seja, treliça ideal e análise linear, não representa o modelo físico fornecendo resultados muito discrepantes dos resultados experimentais.

Quando são inseridos no modelo teórico a variação de inércia nas extremidades das barras e realizada a análise não linear geométrica, os resultados teóricos tornam-se mais próximos dos experimentais. Neste modelo os resultados são significativamente afetados pela rigidez dos trechos de barras que formam os nós.

Analisando as várias possibilidades de simulação do trecho de variação de inércia, percebe-se que considerando o trecho nodal como uma barra de inércia equivalente à sobreposição das barras nesta região, não produz bons resultados quando comparado aos resultados experimentais. A melhor correlação entre resultados teóricos e experimentais foi obtida quando utiliza-se, para inércia do trecho nodal, apenas a inércia da extremidade estampada do tubo ou uma inércia equivalente a $5 \%$ da inércia do nó formado pela superposição das barras concorrentes neste nó.

Para deformações axiais, os valores teóricos adotados para comparação com os resultados experimentais são os correspondentes ao modelo cuja inércia da seção do trecho nodal corresponde a inércia do tubo com extremidade estampada. Esse procedimento foi adotado por duas razões: primeiro, este é o modelo que mais se aproxima do modelo físico e segundo, não existiram grandes variações nas deformações entre os modelos teóricos analisados anteriormente. 


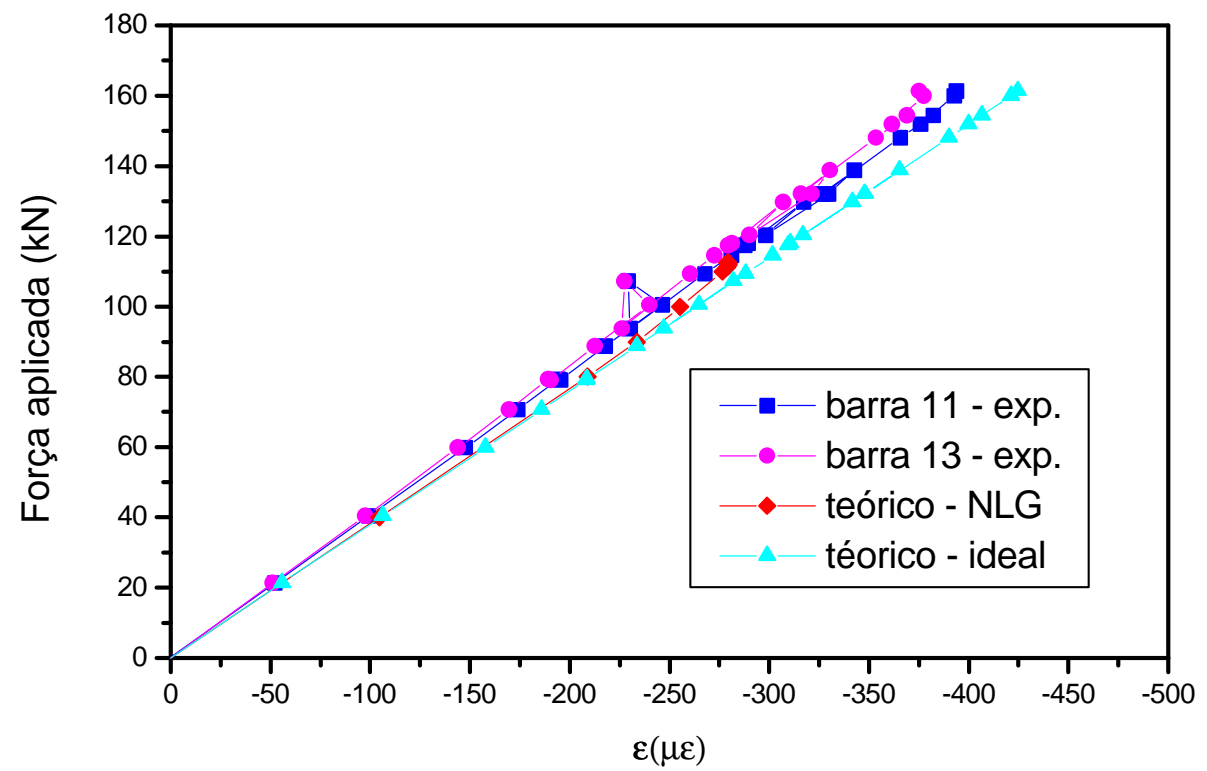

Figura 6.6 Deformações axiais teóricas e experimentais diagonais de apoio - barras 11 e 13.

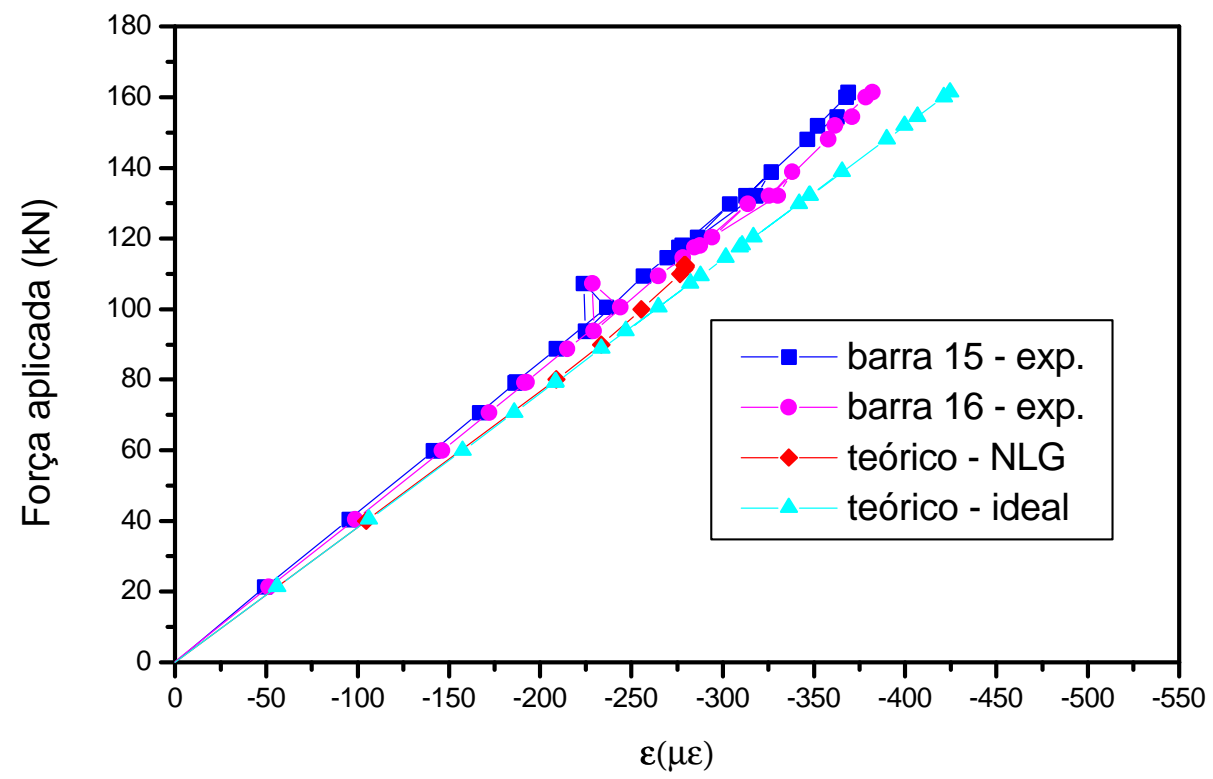

Figura 6.7 Deformações axiais teóricas e experimentais diagonais de apoio barras 15 e 16 . 


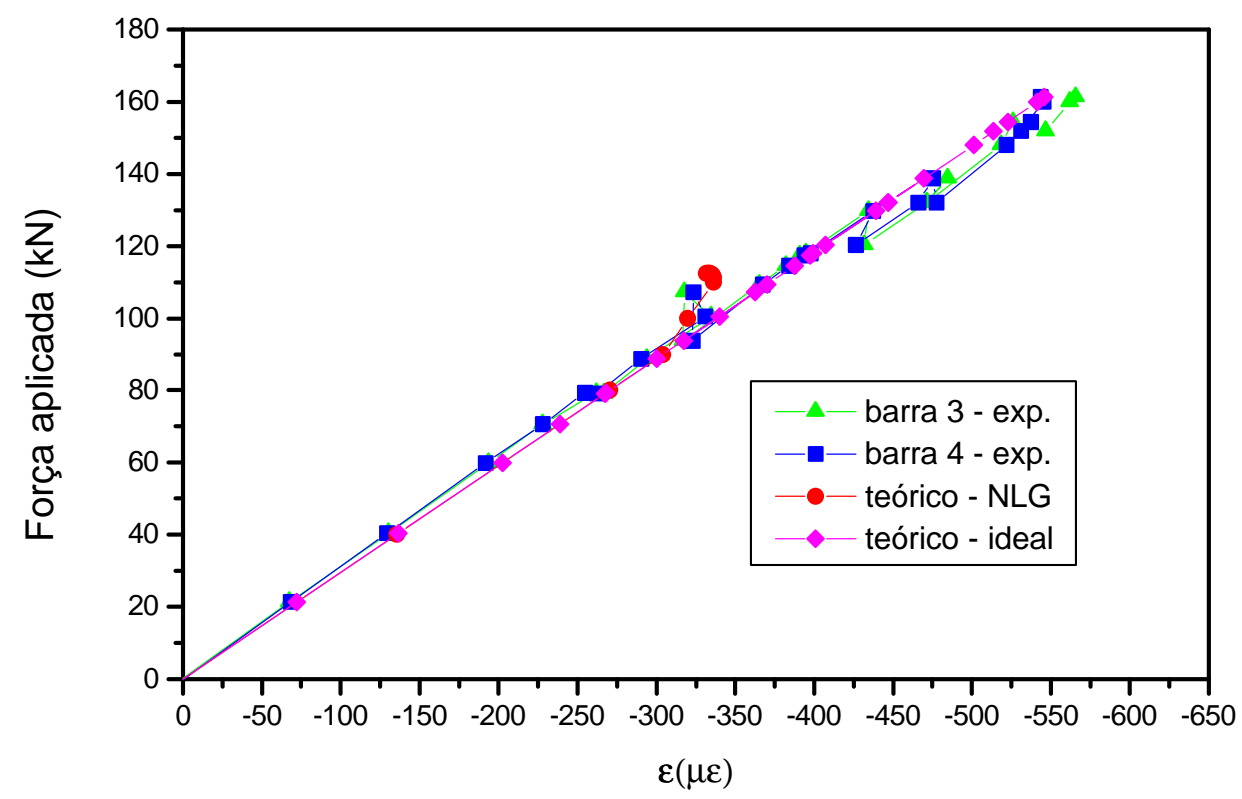

Figura 6.8 Deformações axiais teóricas e experimentais banzos superiores - barras 3 e 4.

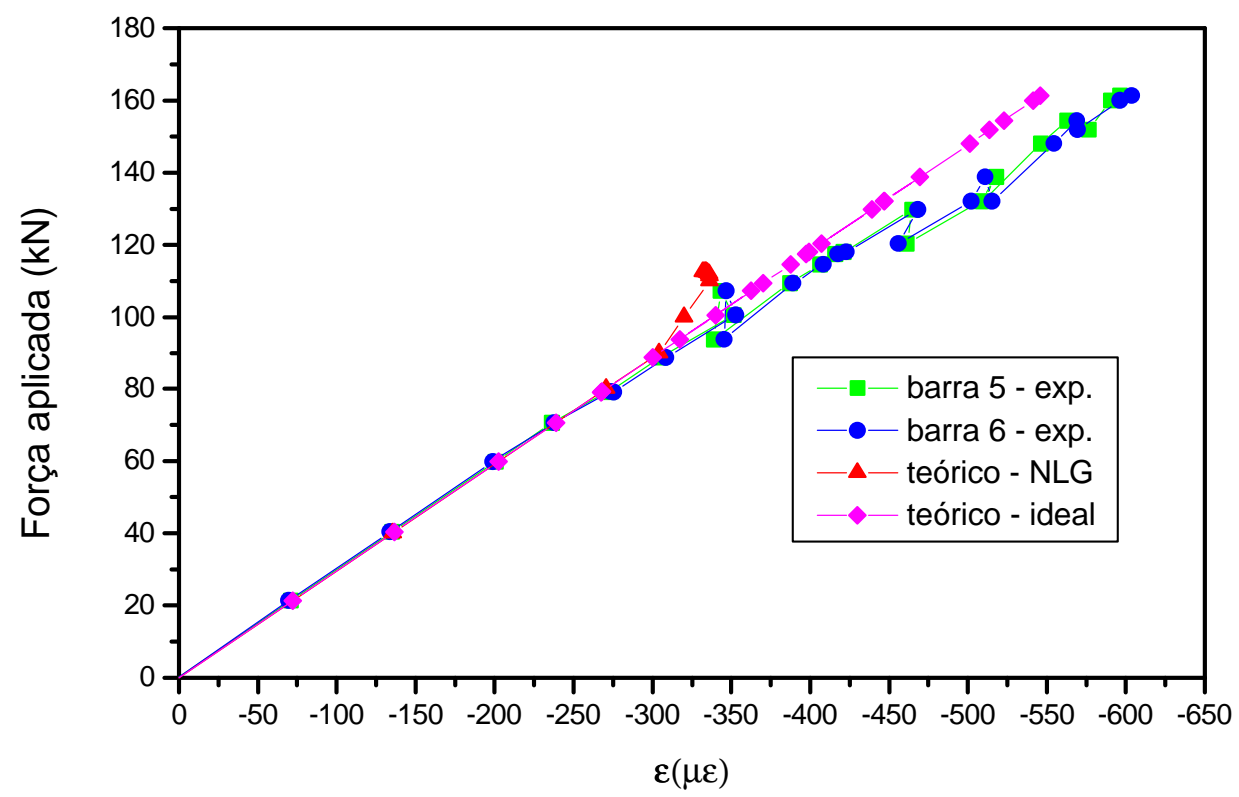

Figura 6.9 Deformações axiais teóricas e experimentais banzos superiores - barras 5 e 6. 


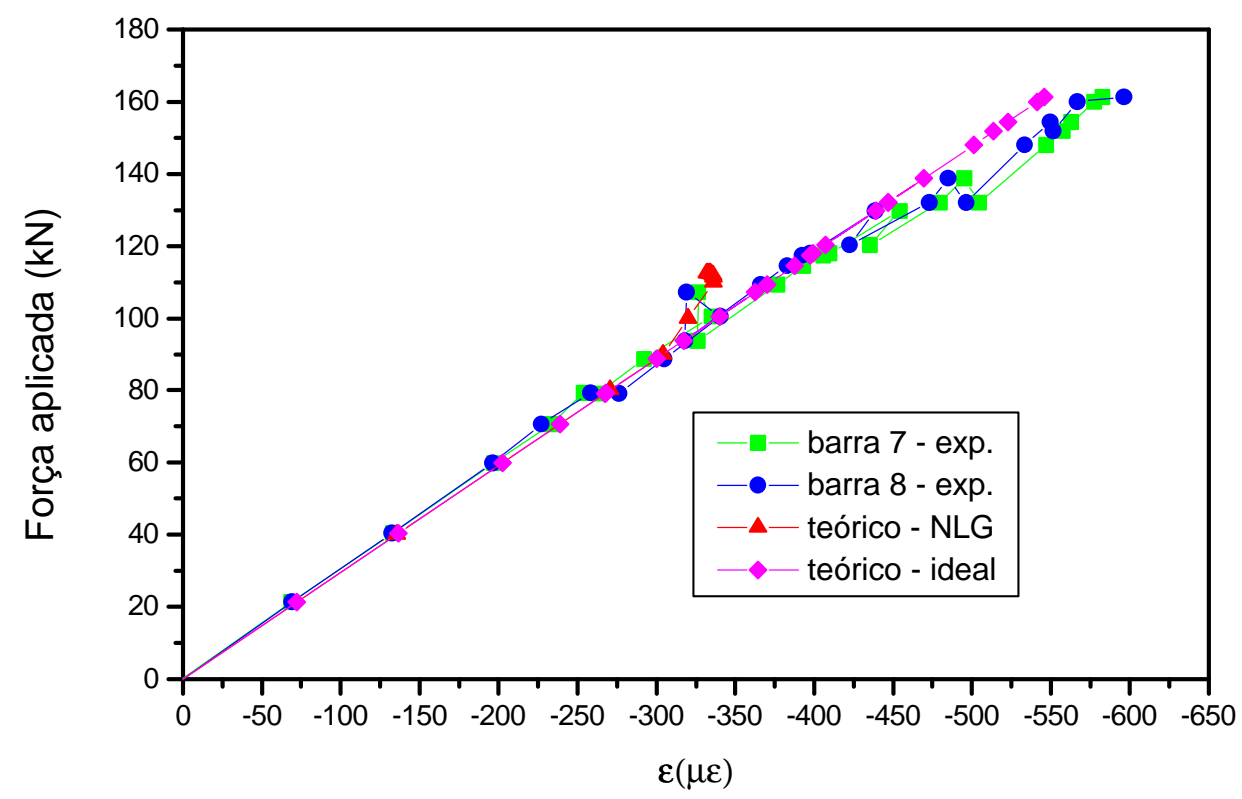

Figura 6.10 Deformações axiais teóricas e experimentais banzos superiores - barras 7 e 8.

Como era esperado, os efeitos da não linearidade geométrica não afetam, de maneira significativa as deformações nas barras (nas seções onde foram medidas). No entanto, os deslocamentos são sensivelmente afetados pelos efeitos da não linearidade geométrica quando a estrutura é modelada considerando a variação de inércia nas extremidades das barras. 


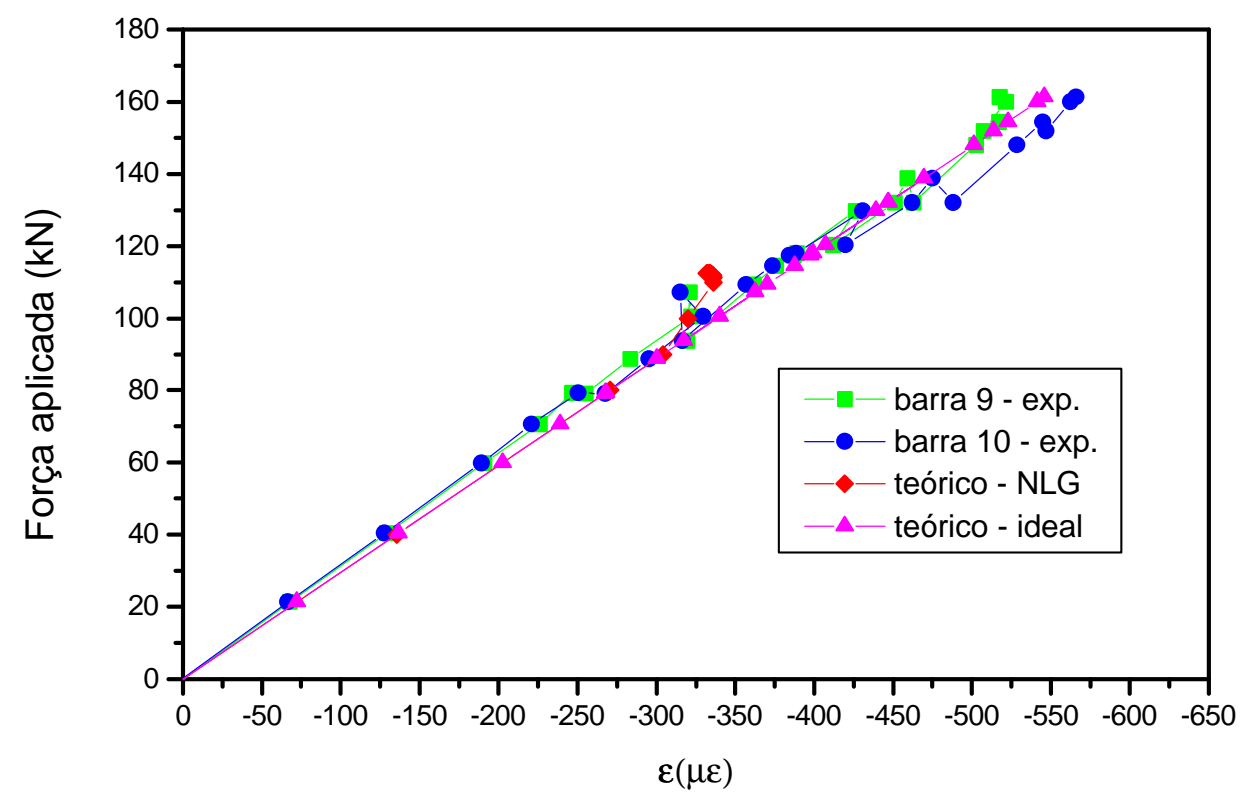

Figura 6.11 Deformações axiais teóricas e experimentais banzos superiores - barras 9 e 10.

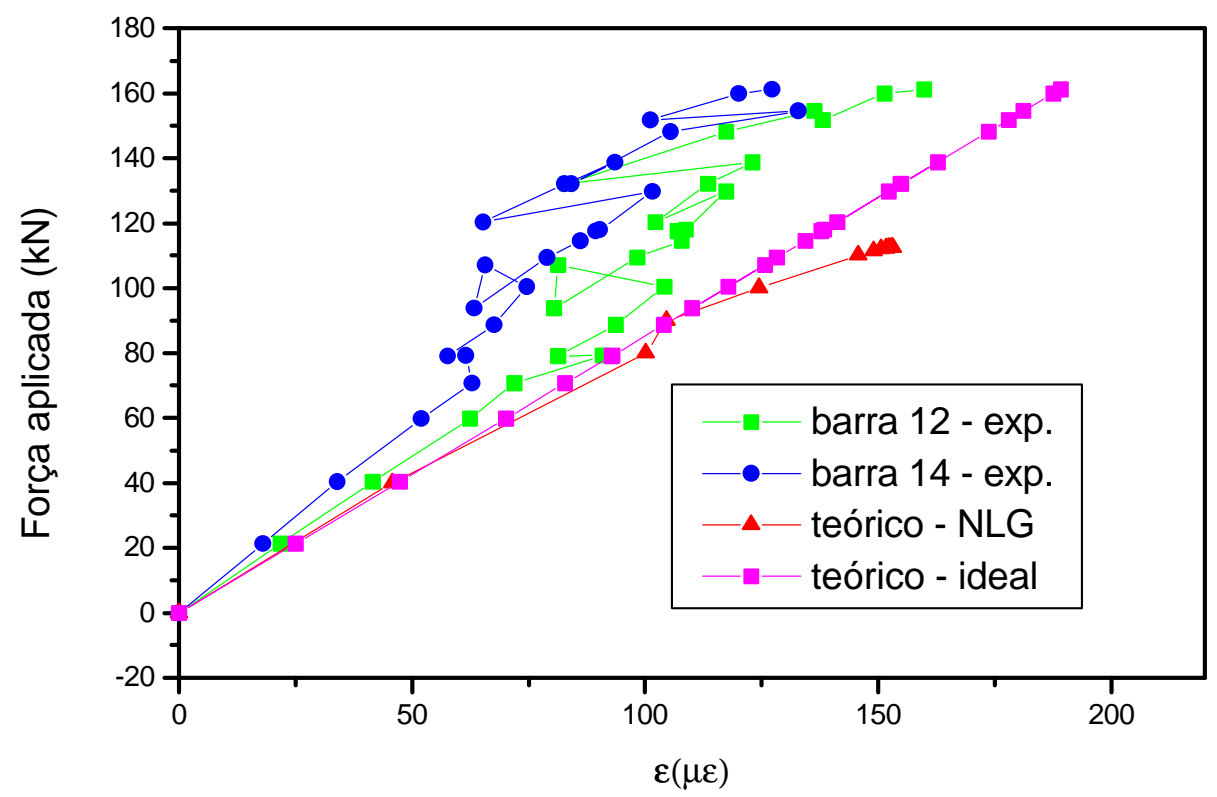

Figura 6.12 Deformações axiais teóricas e experimentais diagonais tracionadas. 


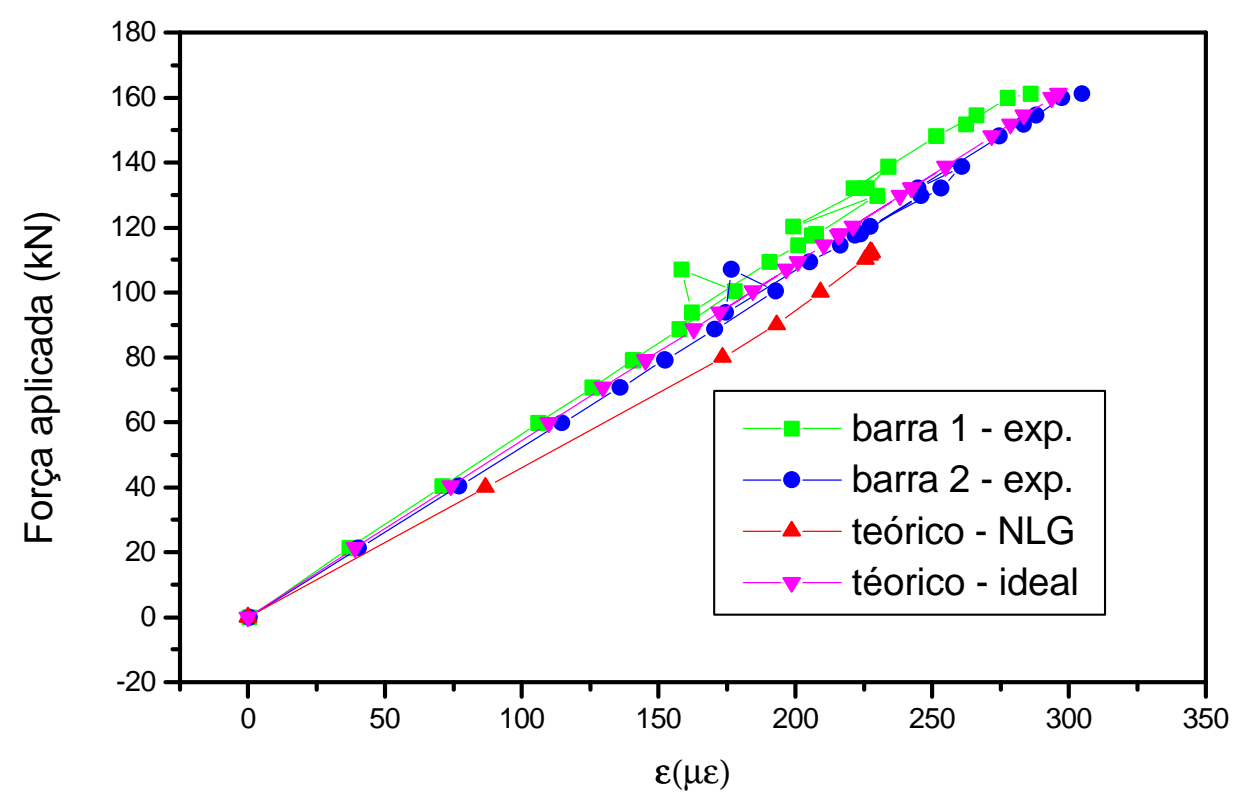

Figura 6.13 Deformações axiais teóricas e experimentais banzos inferiores tracionados.

Ao contrário do que ocorre para os deslocamentos, o modelo de treliça ideal representa bem o modelo físico para o caso de esforços axiais em barras. Os gráficos das Figuras 6.6 a 6.11 mostram que os resultados experimentais para deformações em barras, salvo perturbações devido a escorregamento relativo entre barras nos nós, são praticamente lineares e apresentam boa correlação com os resultados experimentais, tanto para o modelo de treliça ideal como para o modelo com variação de inércia nas barras e análise não linear geométrica.

Ressalta-se, no entanto, que nenhum dos modelos teóricos é capaz de avaliar os efeitos dos momentos fletores que surgem nas ligações devido às forças excêntricas nos nós, causando rotações nos mesmos, o que é uma das causas da ruína precoce da estrutura. 


\subsubsection{Análise não linear física do protótipo ensaiado}

O gráfico da figura 6.14 apresenta os resultados teóricos para deslocamentos verticais obtidos como modelo teórico de treliça com barras com inércia constante e análise não linear física; implementada conforme exposto em 6.1.2.

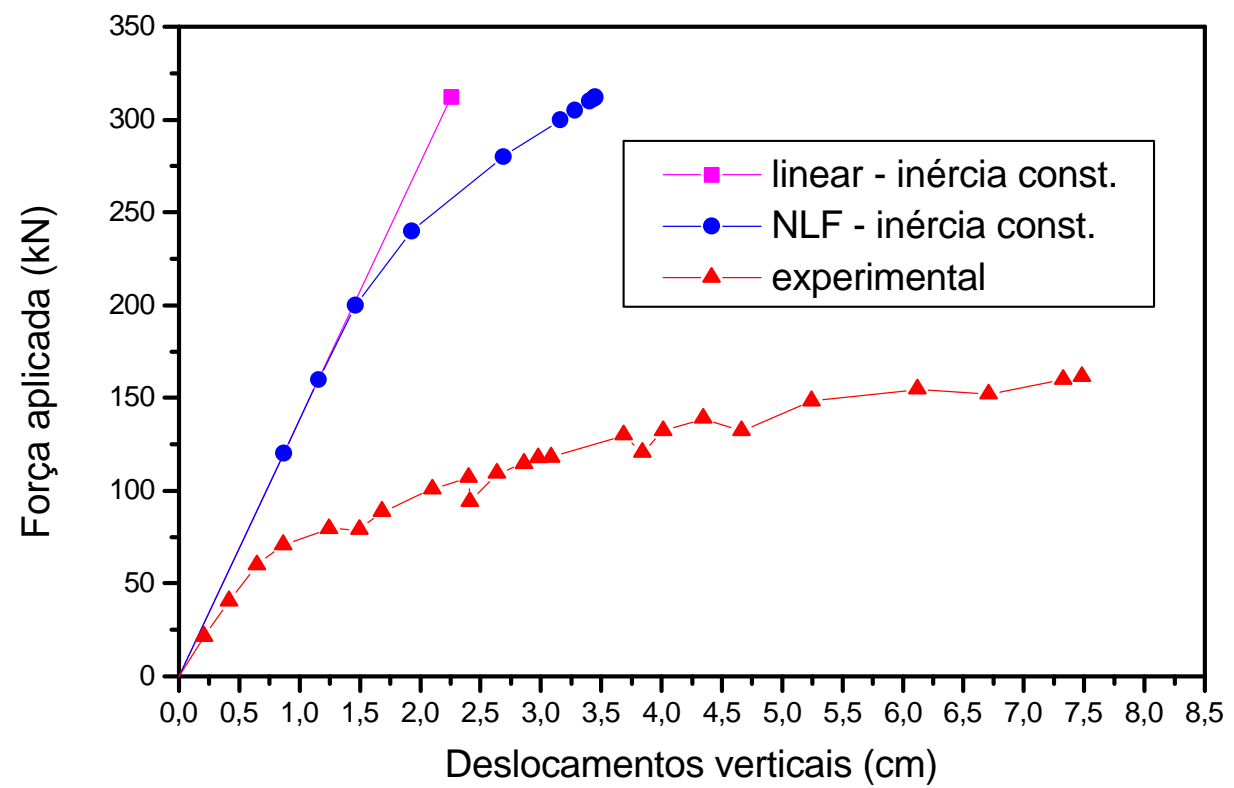

Figura 6.14 Força aplicada $\mathrm{x}$ deslocamentos verticais modelo com NLF

Como era esperado os resultados teóricos ficaram muito acima dos resultados experimentais. Nesse tipo de estruturas, com nó típico, os efeitos da não linearidade física tem menor influência no comportamento da estrutura do que a não linearidade geométrica.

Como já foi dito o modelo constitutivo utilizado (elastoplástico perfeito) não é a hipótese que melhor reflete o comportamento dos elementos de treliças espaciais. No entanto, esse era o único modelo constitutivo disponível, no programa LUSAS, para elementos de barra. 
A análise não linear física para o modelo de treliça considerando a variação de inércia nas barras não foi possível de ser implementada devido a limitações no programa LUSAS que não puderam ser contonadas.

Os gráficos das figuras a seguir apresentam uma comparação entre os resultados experimentais e teórico para análise não linear física com barras de inércia constante.

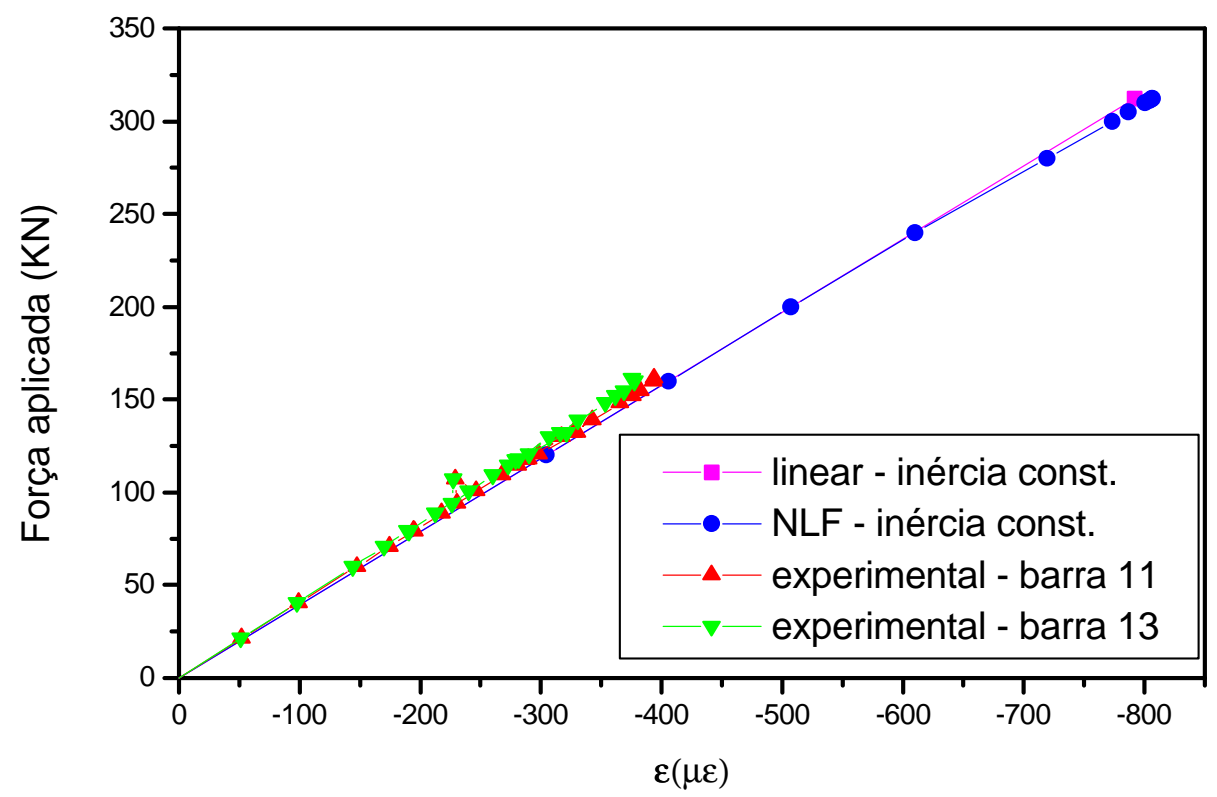

Figura 6.15 Força aplicada x deformação diagonal de apoio - barras 11 e 13. 


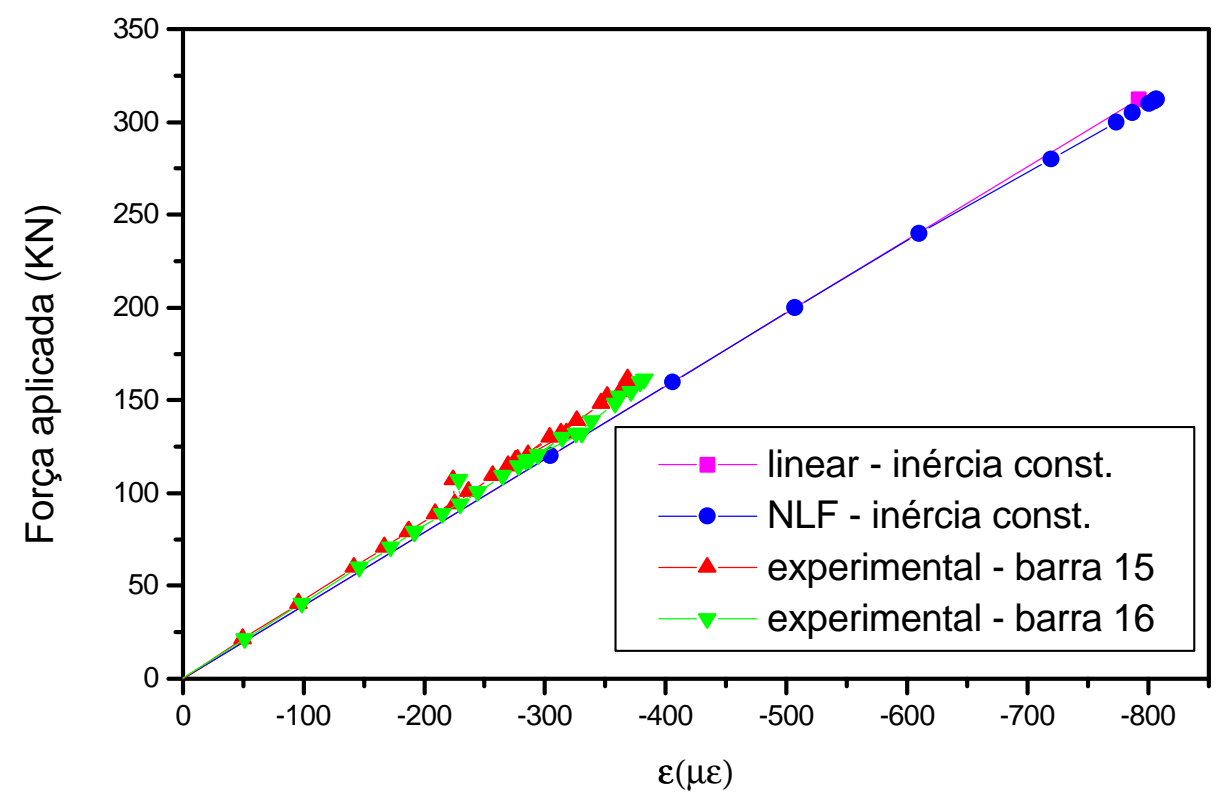

Figura 6.16 Força aplicada x deformação diagonal de apoio - barras 15 e 16.

Como pode se observar pelos gráficos das figuras 6.15 e 6.16, até a força aplicada final de ensaio os valores teóricos se aproximam bastante dos experimentais e apresentam comportamento linear. Isso se justifica pelo fato do carregamento última de ensaio ter sido inferior ao que conduziria a plastificação das seções instrumentadas. O mesmo comportamento se repete para as demais barras da estrutura, como pode ser visto nos gráficos abaixo. 


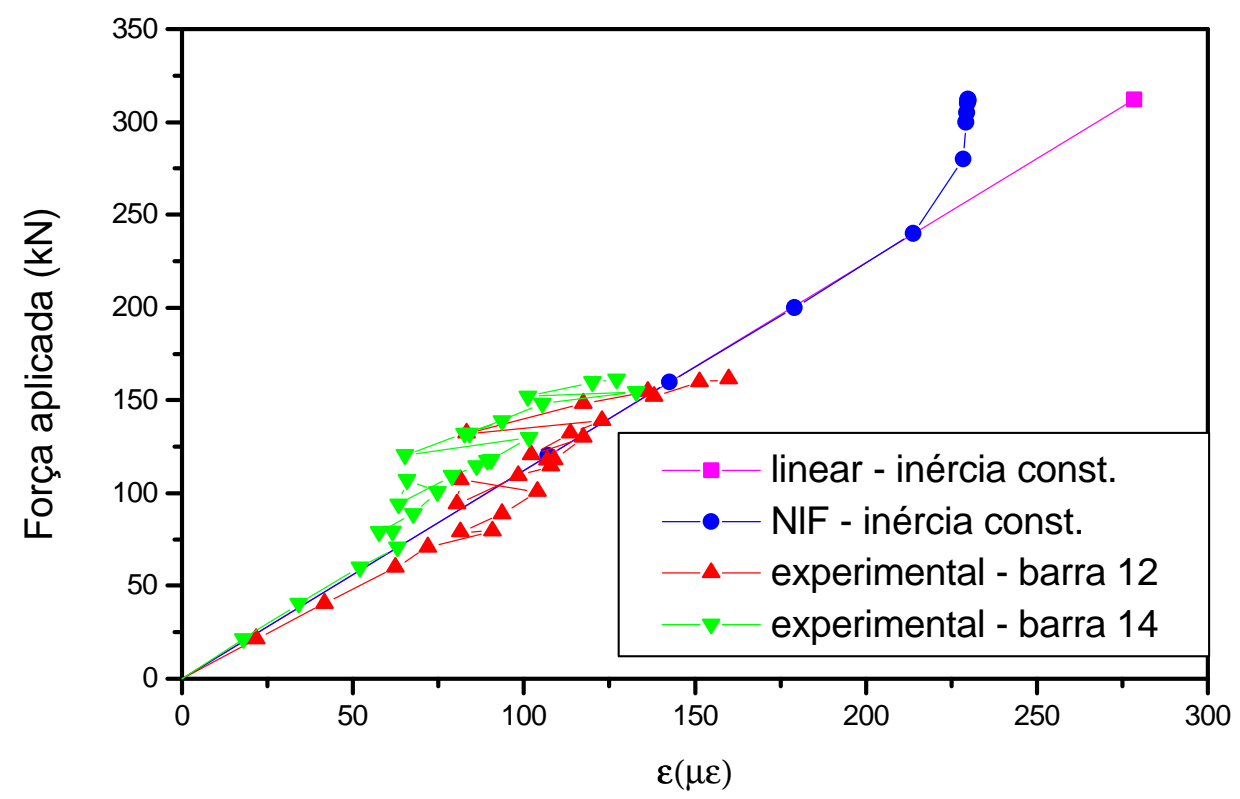

Figura 6.17 Força aplicada $x$ deformação diagonal tracionada - barras 12 e 14.

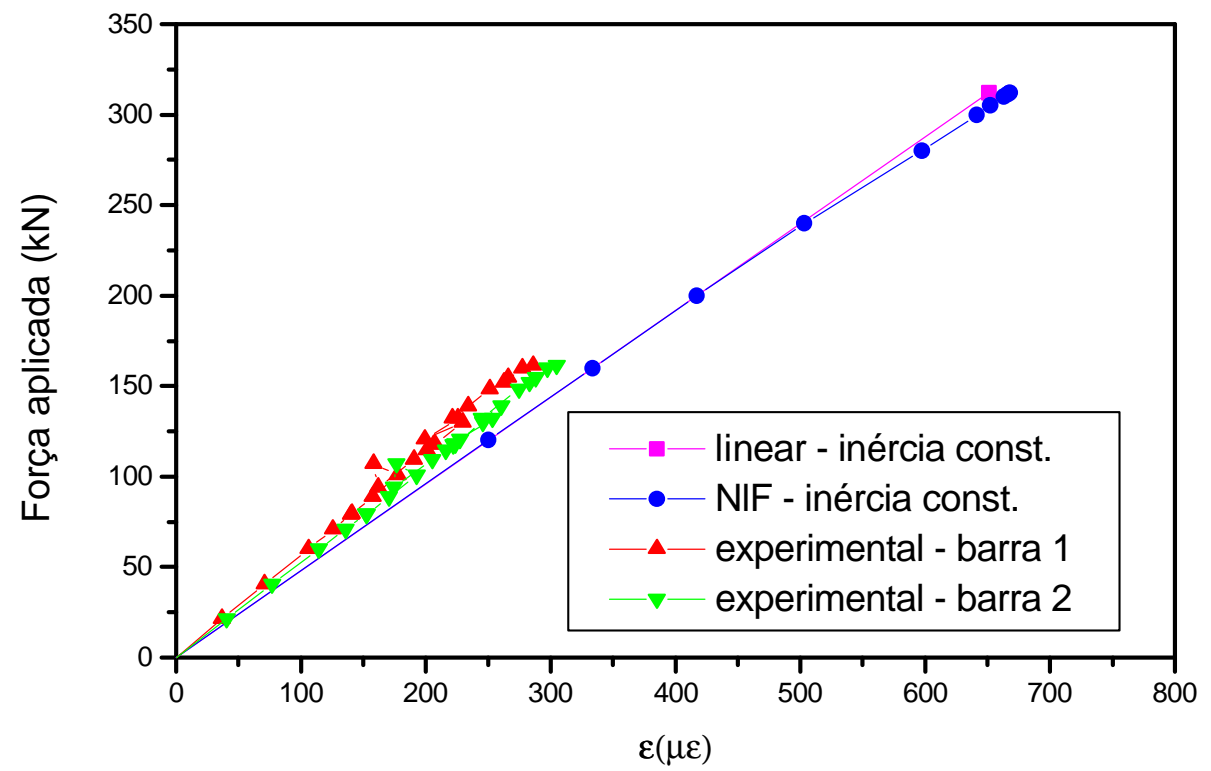

Figura 6.18 Força aplicada $x$ deformação banzo tracionado - barras 1 e 2 . 


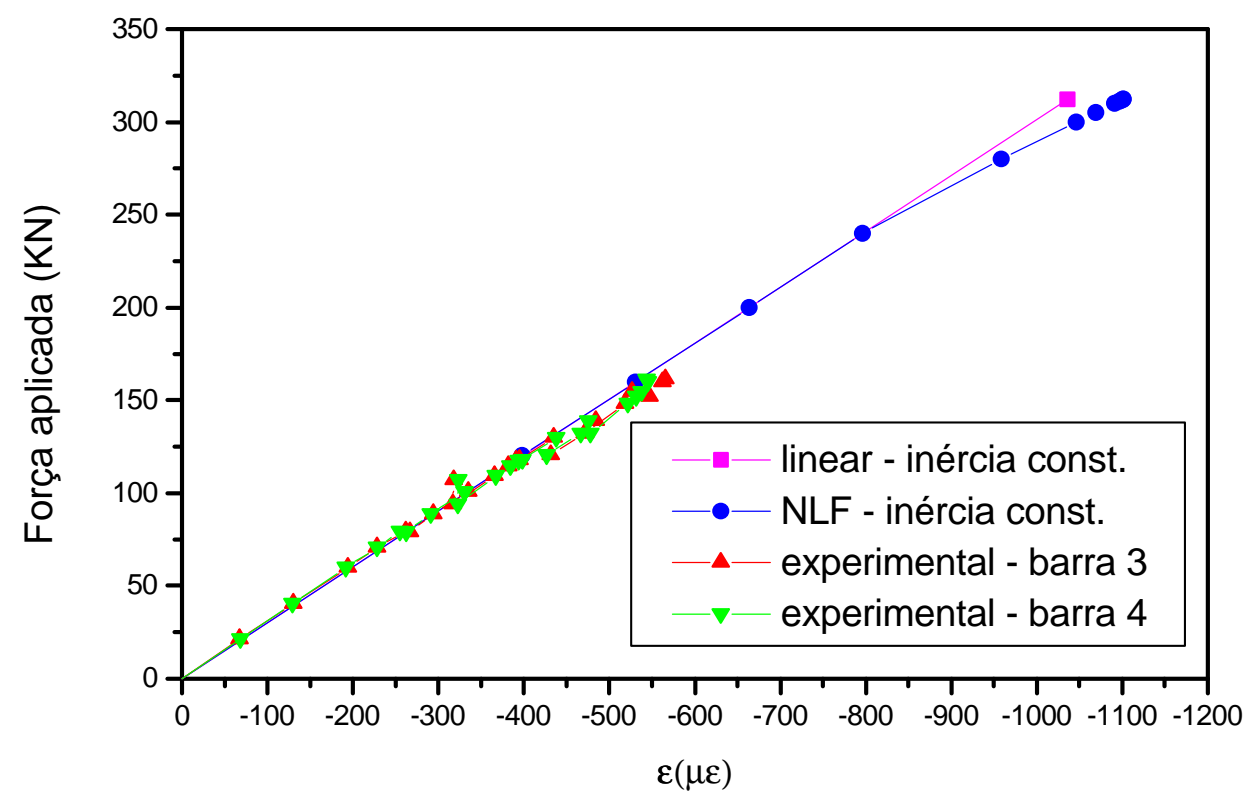

Figura 6.19 Força aplicada x deformação banzo superior - barras 3 e 4.

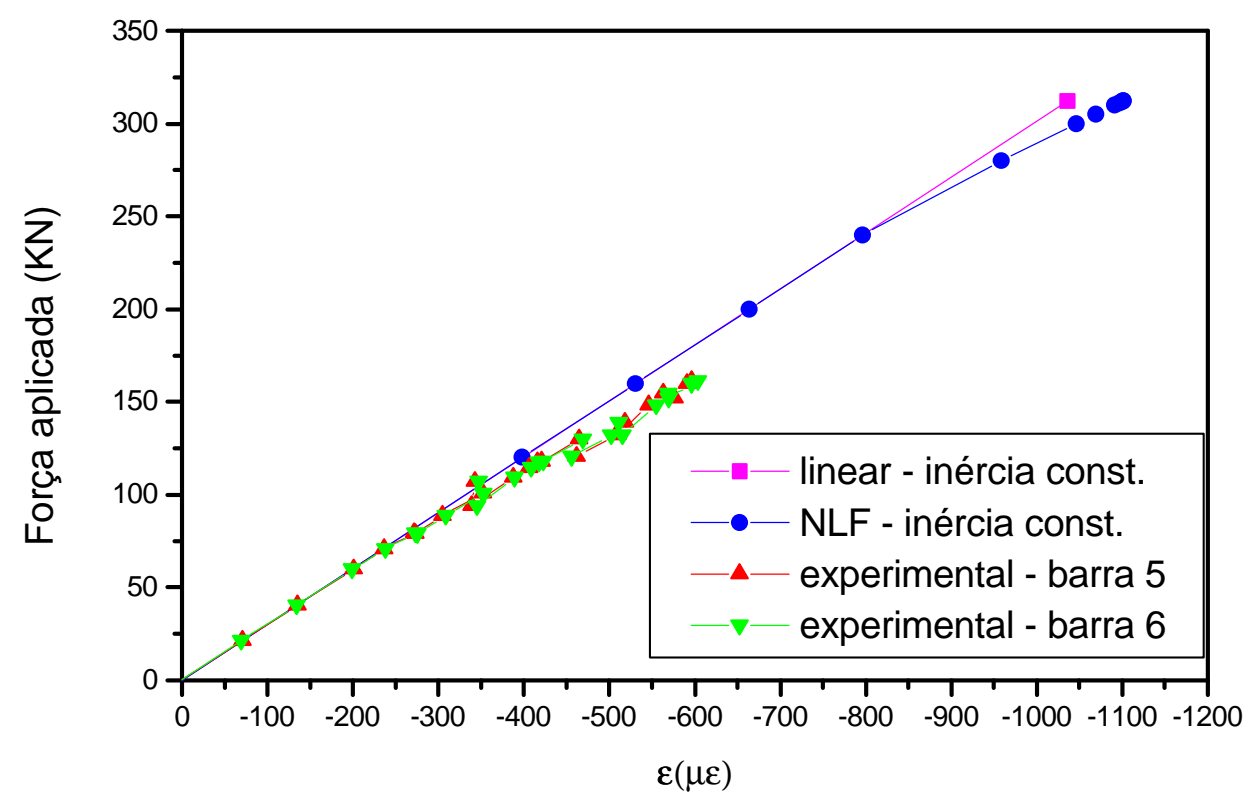

Figura 6.20 Força aplicada $x$ deformação banzo superior - barras 5 e 6. 


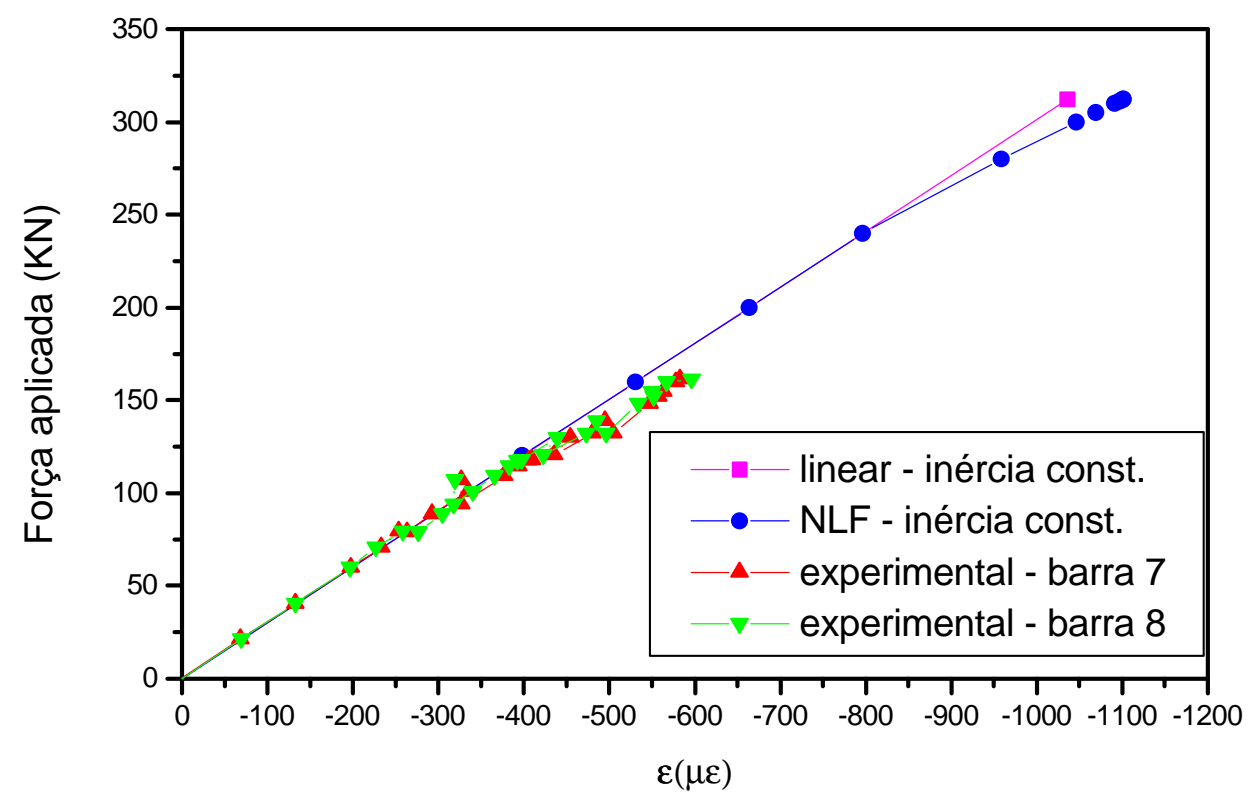

Figura 6.21 Força aplica x deformação banzo superior - barras 7 e 8 .

Percebe-se, que os esforços nas barras, medidos experimentalmente, são praticamente lineares, no entanto, o nível de solicitação das mesmas está baixo do previsto teoricamente. Ocorre, porém, plastificação nas seções extremas das barras, seções essas que não foram instrumentadas e cujo comportamento não pode ser previsto pelo modelo teórico adotado nesta análise.

O modelo de treliça de barras com inércia variável e análise não linear física poderia aproximar os resultados teóricos e experimentais mas, com já foi dito, não foi possível realizar. Espera-se que na continuidade deste trabalho e a utilização de outros programas de análise, via elementos finitos, esse problema seja sanado. 


\subsection{Exemplos de análise não linear de treliça espacial}

Com base nos protótipos básicos ensaiados foram gerados dois modelos de treliças espaciais com dimensões maiores, nos quais a sensibilidade à variação de inércia nas barras e aos efeitos não lineares devem ser mais evidentes. Estes modelos estão apresentados nas figuras seguintes.
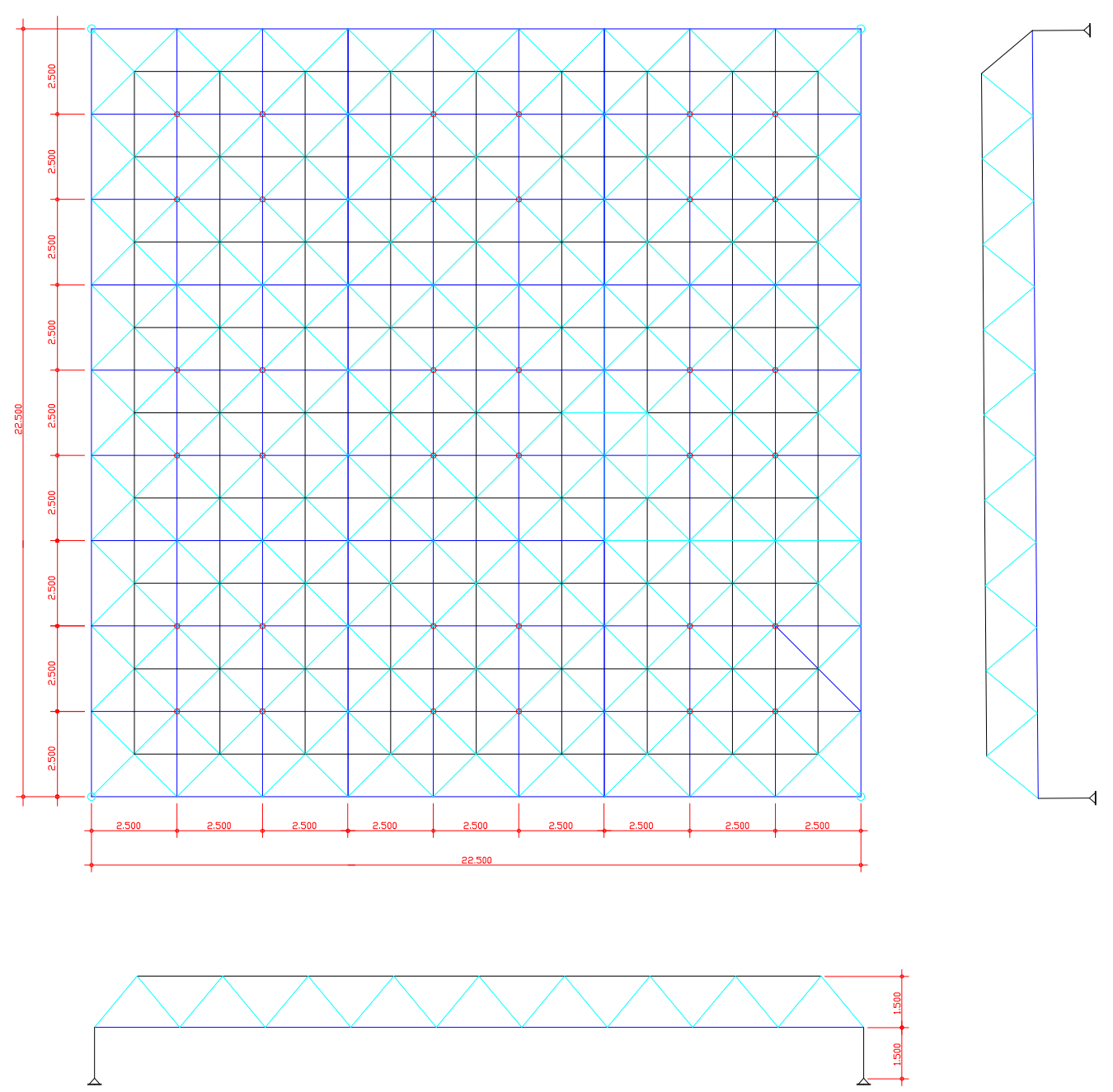

Figura 6.22 - Treliça espacial.- modelo 1. 

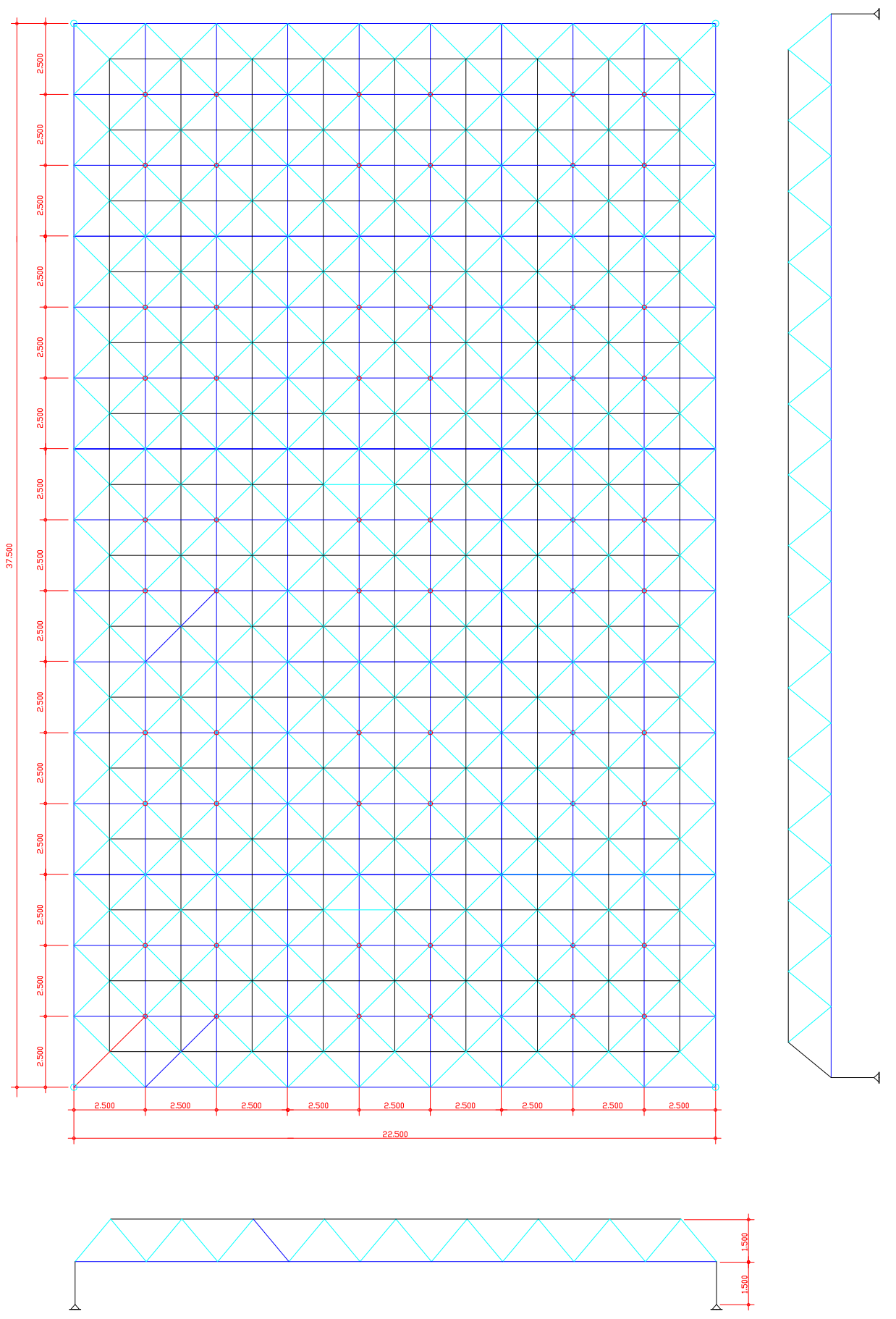

Figura 6.23 - Treliça espacial. - modelo 2. 
Os modelos foram dimensionados com todos os critérios e os programas específicos utilizados em escritórios de projetos. Esse dimensionamento foi gentilmente realizado pela Alusud, que dispõe de programas com recursos de geração, dimensionamento e otimização próprios para treliças espaciais. Os carregamentos básicos adotados são os seguintes:

\section{Ações permanentes}

$\begin{array}{lr}\text { terça } & 0,03 \mathrm{kN} / \mathrm{m}^{2} \\ \text { telhas (em aço - esp. 0,65mm) } & 0,07 \mathrm{kN} / \mathrm{m}^{2} \\ \text { peso próprio } & \text { gerado }\end{array}$

\section{sobrecarga}

sobrecarga $\quad 0,3 \mathrm{kN} / \mathrm{m}^{2}$

\section{Ação do vento (NBR-6123 -1988)}

$\mathrm{V}_{\mathrm{o}}=45,0 \mathrm{~m} / \mathrm{s}$

$\mathrm{S}_{1}=1,0$

$\mathrm{S}_{3}=1,0$

$\mathrm{h}=7,5 \mathrm{~m}$, classe $\mathrm{B}$, rugosidade $\| \rightarrow \mathrm{S}_{2}=0,955$

$\mathrm{V}_{\mathrm{k}}=42,97 \mathrm{~m} / \mathrm{s}$

$\mathrm{q}=1,16 \mathrm{kN} / \mathrm{m}^{2}$

coeficientes de pressão (NBR-6123 -1988)

coeficientes de pressão externo:

$$
C_{p e}=0,8 ; C_{p e}=0,6 ; C_{p e}=0,4
$$

coeficientes de pressão interno:

$$
C_{p i}=0,2 ; C_{p i}=-0,3
$$

O programa dimensiona automaticamente a estrutura fornecendo os resultados em arquivos gráficos do formato CAD. A figura 6.25 apresenta os resultados do dimensionamento para o banzo inferior do modelo 1. 


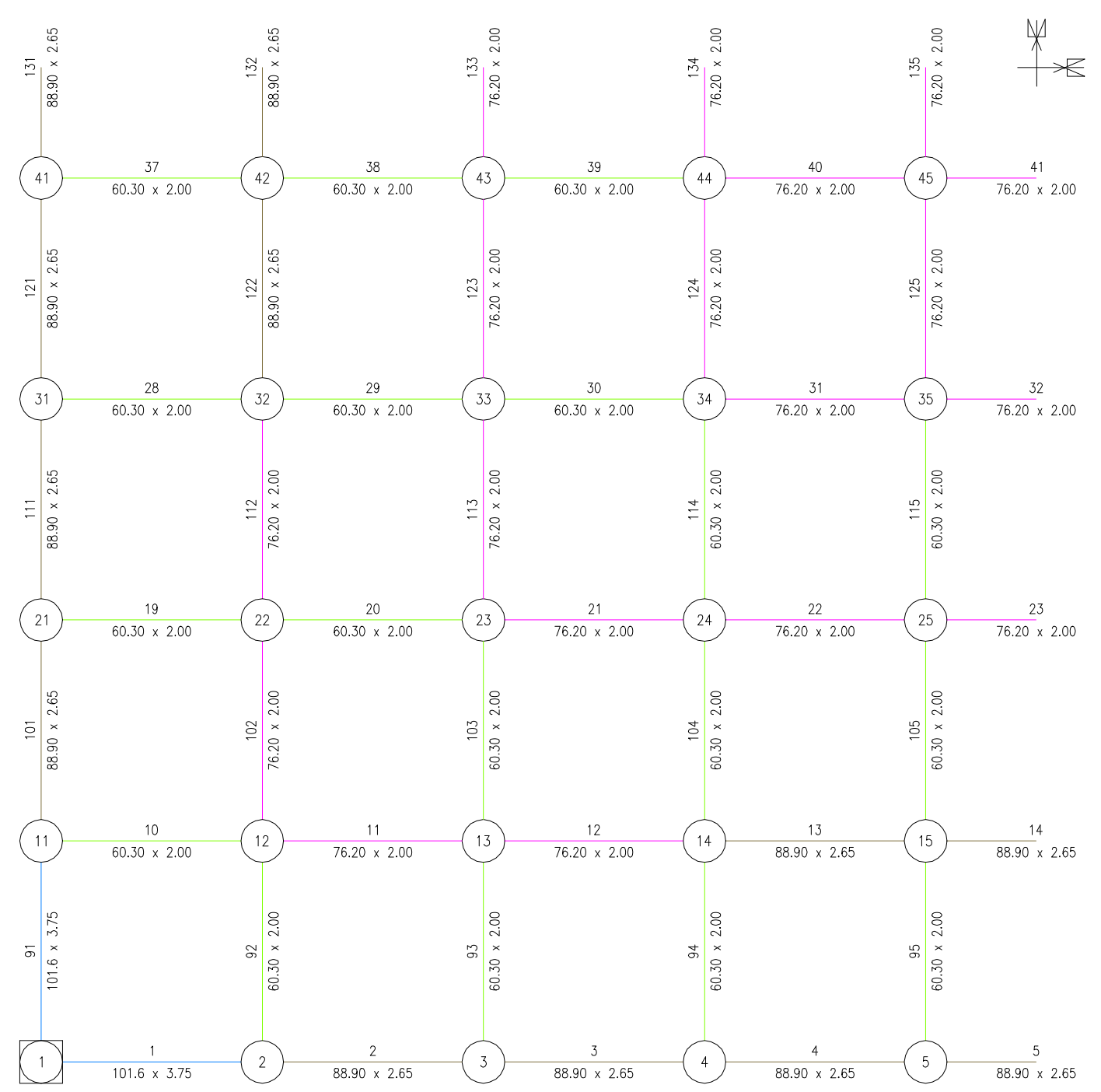

Figura 6.24 -Diemensionamento banzo inferior - modelo 1.

Para a análise não linear e consideração da variação de inércia nas extremidades das barras adotou-se, baseado no dimensionamento, apenas um tipo de seção respectivamente, para as barras dos banzos, diagonais e diagonais junto ao apoio. Não variou-se seções nos banzos nem em diagonais o que não é usual na prática, no entanto, adotou-se esse artifício para facilitar a geração e análise estrutural, que com a consideração da variação de inércia torna-se uma tarefa bastante trabalhosa.

Portanto, as dimensões dos tubos adotados para cada modelo são as apresentadas na Tabela 6.2. 
Tabela 6.2 Seções dos tubos utilizados nos modelos.

\begin{tabular}{|c|c|c|c|}
\hline Modelos & Seção & Utilização & Esbeltez \\
\hline \multirow{4}{*}{ Modelo 1 } & $\phi 76 \times 2,0$ & diagonal & 89 \\
\cline { 2 - 4 } & $\phi 88 \times 2,65$ & banzos & 82 \\
\cline { 2 - 4 } & $\phi 101 \times 3,25$ & banzo. apoio & 74 \\
\cline { 2 - 4 } & $\phi 101 \times 3,25$ & diag. apoio & 68 \\
\cline { 2 - 4 } Modelo 2 & $\phi 101 \times 2,65$ & banzos & 74 \\
\cline { 2 - 4 } & $\phi 114 \times 2,25$ & banzo. apoio & 64 \\
\cline { 2 - 4 } & $\phi 114 \times 2,25$ & diag. apoio & 59 \\
\cline { 2 - 4 } & $\phi 1650$ diagonal & 88 \\
\hline
\end{tabular}

O carregamento dos modelos foi realizado de forma incremental iterativa, sendo o primeiro passo de carga e os incrementos equivalentes a $0,5^{\star}(\mathrm{CP}+\mathrm{SC})$. Quando não era possível aplicar a estrutura um incremento de $0,5^{\star}(\mathrm{CP}+\mathrm{SC})$ o programa LUSAS divide o mesmo automaticamente até que a estrutura encontre um nova posição de equilíbrio.

As figuras 6.25 e 6.26 apresentam a variação de inércia nas extremidades das barras que compõem cada um dos três modelos de treliças espaciais. Ressalta-se que as inércias no trecho variável foram determinadas com uma proporção em relação aos tubos do protótipo ensaiado, cujas características geométricas foram devidamente medidas. 


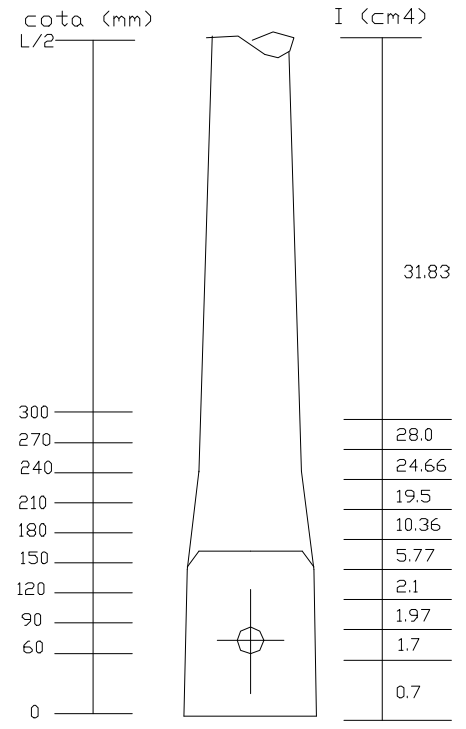

$\phi 76 \times 2,0$
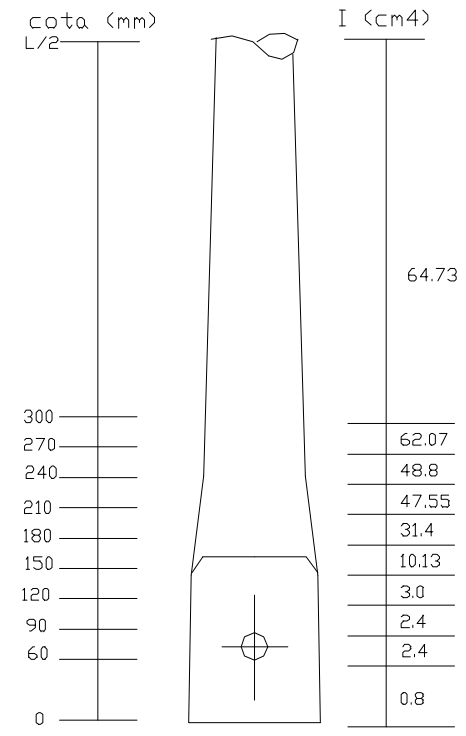

$\phi 88 \times 2,65$
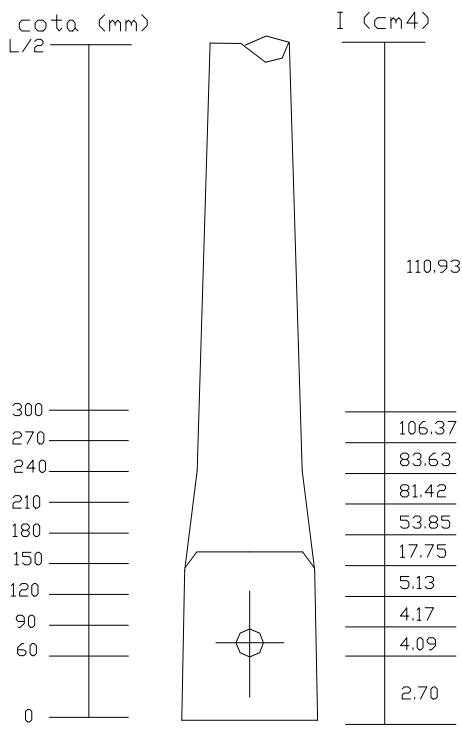

$\phi 101 \times 3,25$

Figura 6.25 Variação de inércia ao longo do comprimento das barras para o modelo 1.
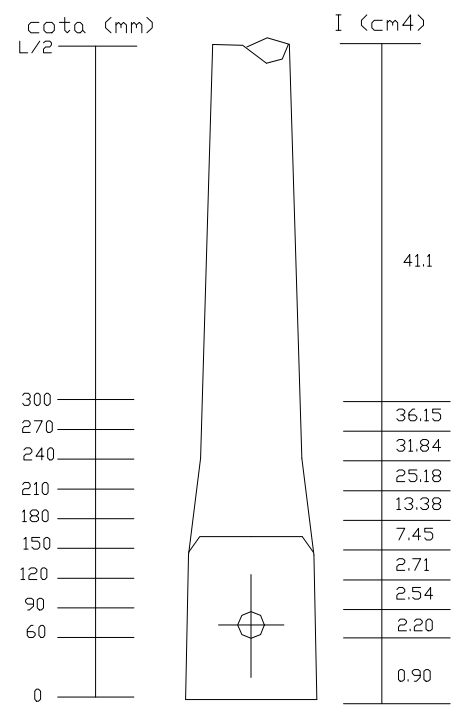

$\phi 76 \times 2,65$
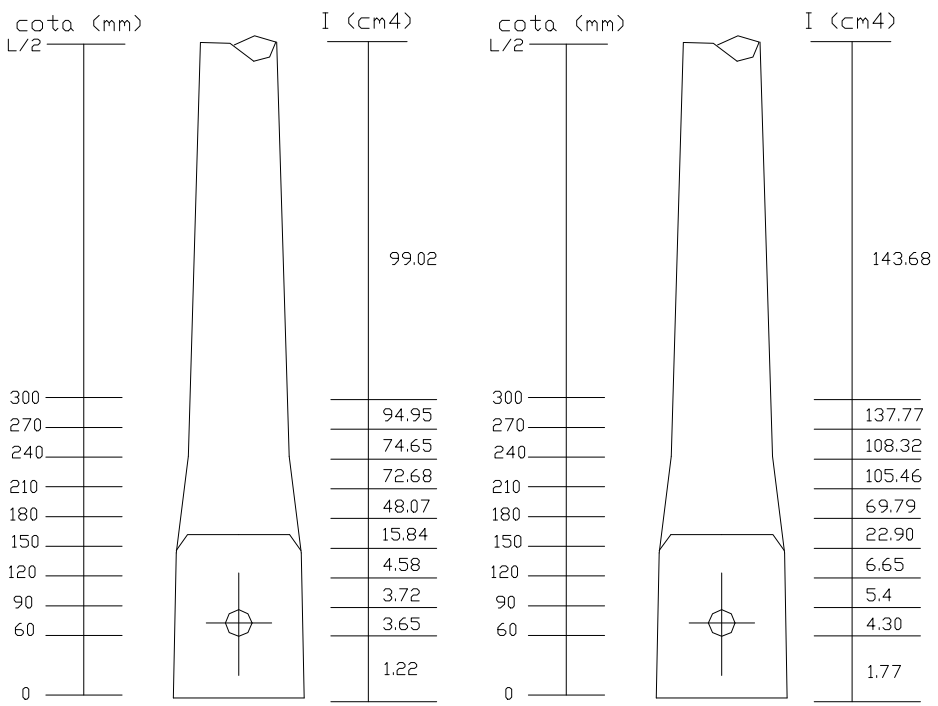

$\phi 101 \times 2,65$

$\phi 114 \times 2,25$

Figura 6.26 Variação de inércia ao longo do comprimento das barras para o modelo 2.

Apresenta-se os resultados da análise não linear geométrica do modelo 1 para deslocamentos e esforços máximos. Compara-se esses 
resultados como os obtidos através do modelo de treliça ideal sem variações de inércia nas barras.

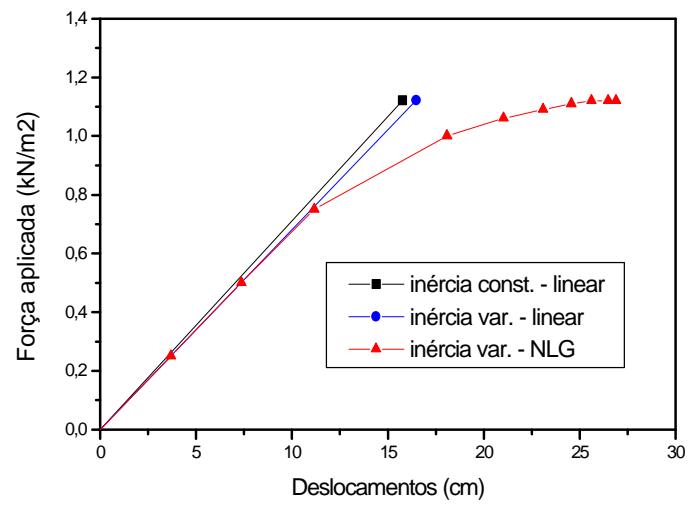

modelo 1

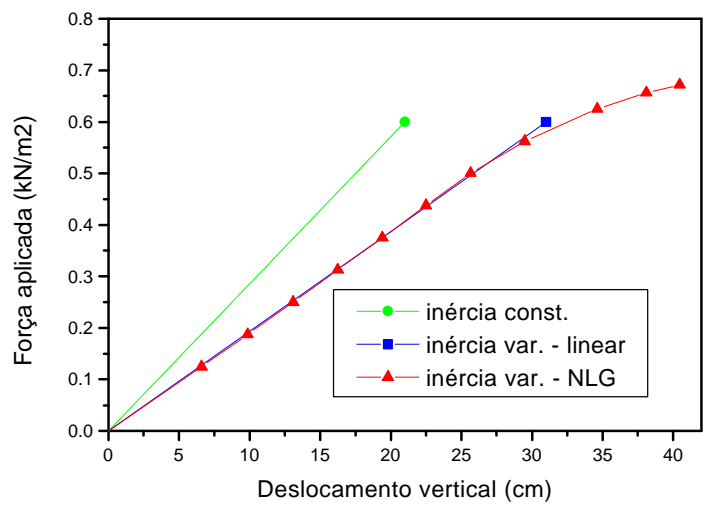

modelo 2

Figura 6.27 Força aplicada x deslocamentos máximos.

Como pode ser observado pelos gráficos da figura 6.27 os modelos 1 e 2 apresentam comportamento não linear, de força aplicada x deslocamentos, para cargas de serviço. O modelo 1 apresenta perda de rigidez a partir de um nível de carregamento correspondente a $1,40(\mathrm{CP}+\mathrm{SC})$, enquanto para 0 modelo 2 a redução de rigidez ocorre acima de um carregamento equivalente a $1,10(C P+S C)$.

Comparando os resultados de deslocamentos, no caso da análise linear com e sem variação de inércia nas barras, percebe-se como era esperado, maiores deslocamentos quando se considera o efeito da variação de inércia nas barras, sendo esse efeito mais pronunciado no modelo 2 que tem dimensões maiores.

Os gráficos, das figuras a seguir apresentam, para os modelos 1 e 2 , os resultados teóricos da análise não linear geométrica para os esforços nas barras, foram escolhidas para análise de resultados as barras mais solicitadas de cada categoria, ou seja, banzos, diagonais e diagonais de apoio. 


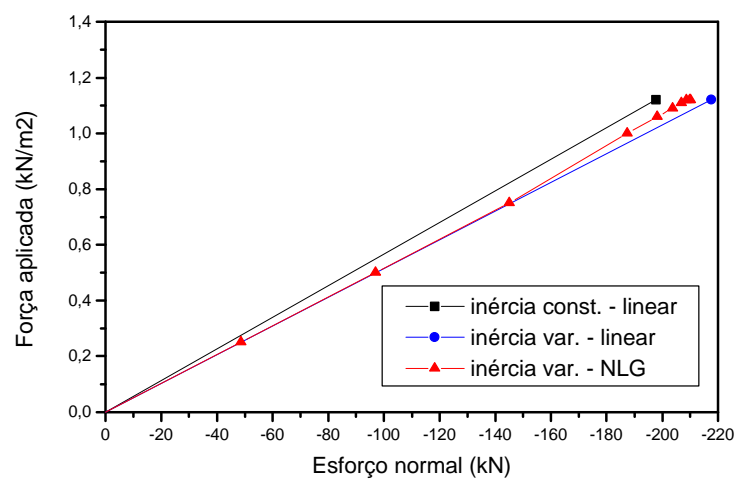

modelo 1

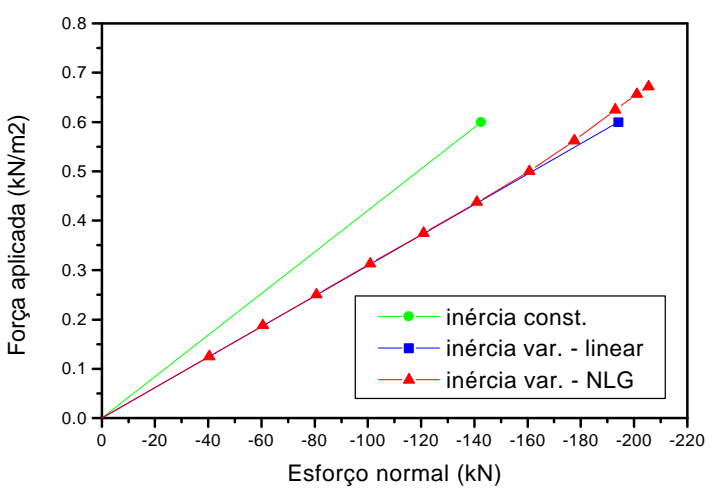

modelo 2

Figura 6.28 Força aplicada x esforço normal - diagonal de apoio.

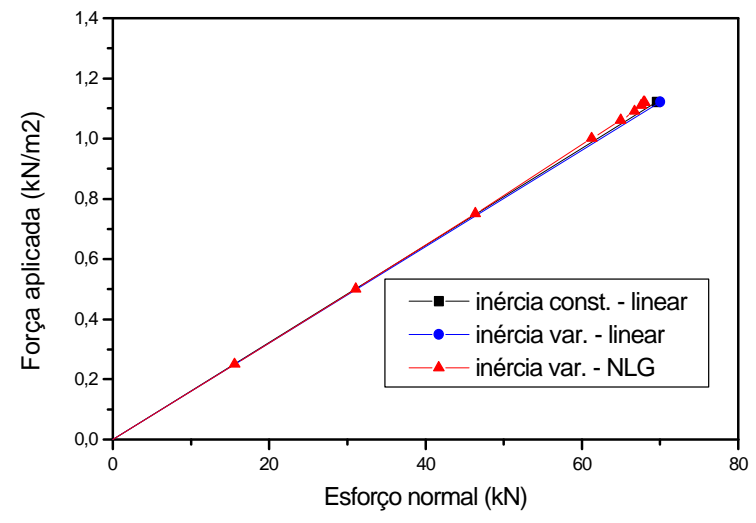

modelo 1

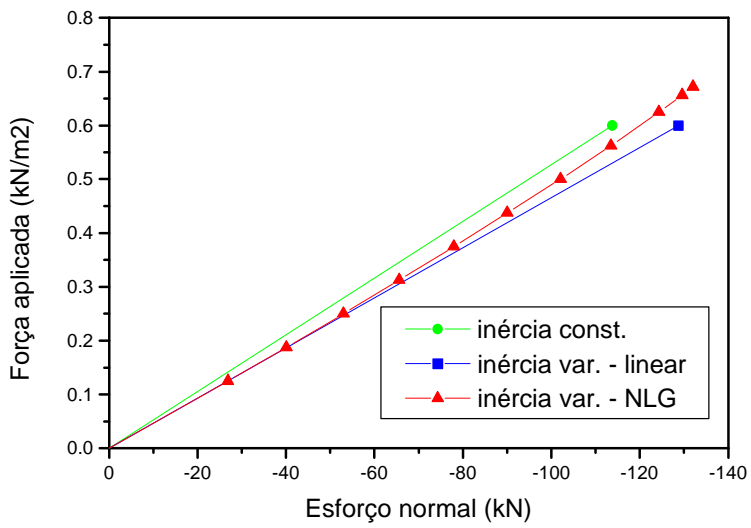

modelo 2

Figura 6.29 Força aplicada x esforço normal - diagonal tracionada. 


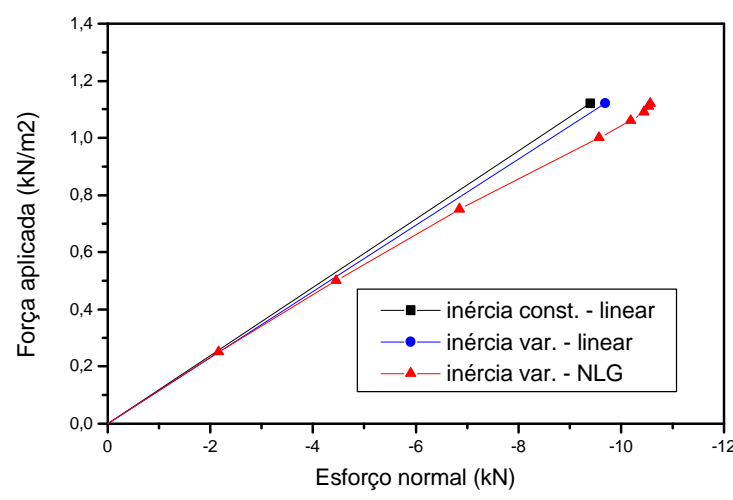

modelo 1

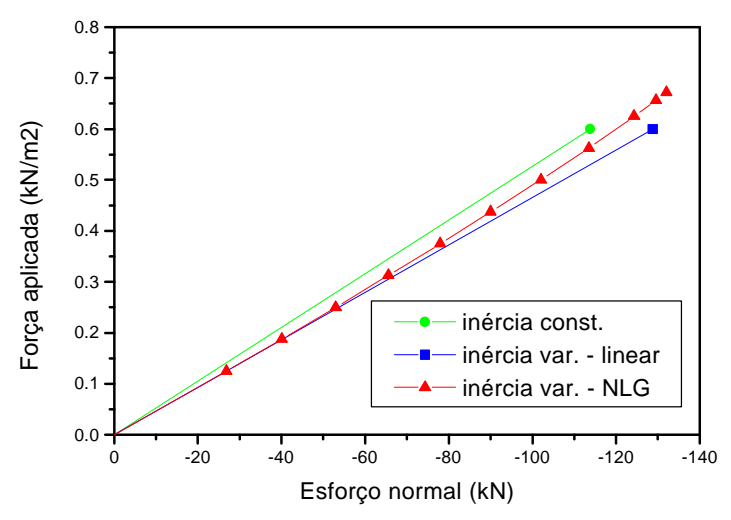

modelo 2

Figura 6.30 Força aplicada x esforço normal - banzo superior comprimido.

O comportamento força aplicada $x$ esforço normal em barras é bastante semelhante para os dois modelos e pode ser considerado praticamente linear, pois os acréscimos e, ou alívio de tensões nas barras analisadas é muito pequeno, como pode se observar nos gráficos das figuras 6.28 a 6.30 .

Observa-se também um pequeno acréscimo de esforços do modelo teórico com consideração da variação de inércia em relação ao modelo com barras de inércia constante.

Ressalta-se, mais um vez que os modelos teóricos normalmente adotados, ou seja, treliça ideal em análise linear não reflete bem 0 comportamento das estruturas espaciais com nó típico. Os resultados experimentais e teóricos mostraram que esses modelos não conseguem prever com precisão o comportamento força aplicada $\mathrm{x}$ deslocamentos para essas estruturas. Esse problema tende a se agravar, como pode ser observado nas figuras acima, com o aumento das dimensões da estrutura.

Outros fatores que podem influir no comportamento das treliças espaciais construídas no Brasil, e que ficam aqui com sugestão de novos estudos são a relação maior e menor vão, relação comprimentos dos módulos e vãos, como também a relação entre comprimento e altura dos 
módulos. Por módulo entende-se o tetraedro básico que forma a treliça espacial. 


\section{CONCLUSÕES

Inicialmente é interessante ressaltar a grande carência de pesquisas específicas sobre as tipologias de estruturas espaciais construídas no Brasil, são poucos os trabalhos desenvolvidos neste campo da engenharia estrutural em nosso país.

$\mathrm{Na}$ bibliografia estrangeira pesquisada existe constante interação entre as áreas de estruturas espaciais propriamente dita e a área de métodos numéricos. Este fato, que não está ocorrendo no Brasil, possibilita grande desenvolvimento do sistema estrutural em treliça espacial.

Os elementos tubulares são os mais utilizados nas estruturas espaciais no Brasil e em virtude dos sistemas de ligação empregados, apresentam grandes variações de inércia nas regiões das extremidades deste elementos.

Os elementos tubulares comprimidos com variação de inércia apresentam reduções na força normal resistente; este fato foi comprovado por resultados teóricos e experimentais apresentados neste trabalho e em trabalhos anteriores desenvolvidos no Departamento de Engenharia de Estruturas da EESC.

A metodologia utilizada no cálculo corrente não considera a redução na força normal resistente advinda da variação de inércia; este fato poderia ser explicado pela ausência de recomendações explícitas em códigos de projeto sobre a consideração da variação de inércia no dimensionamento de barras comprimidas, exceção feita ao Eurocode 3 . 
Para os elementos tubulares com extremidades estampadas e extremidades com ponteiras, analisados teórica e experimentalmente neste trabalho, a redução na força normal resistente é, em geral, superior a $20 \%$ quando estes elementos apresentam flambagem em regime inelástico, principalmente para índices de esbeltez inferiores a 60.

Para as barras com extremidades estampadas analisadas, com esbeltez entre 70 e 120, tem-se reduções na força normal resistente variando entre $5 \%$ e $10 \%$.

Em barras com chapas de ponteiras e extremidades estampadas utilizando aparelhos de apoio, constituído de chapas de aço soldadas, a redução na capacidade resistente, para esbeltezes usuais é da ordem de $10 \%$, no entanto, a sensibilidade destas ligações está associada às espessuras e comprimentos não enrijecidos das chapas e regiões amassadas, que geralmente controlam a falha do elemento.

Ressalta-se, portanto, a necessidade de continuidade das pesquisas no sentido de se criar rotinas práticas para se considerar a variação de inércia no dimensionamento de barras ou coeficientes de redução adequados.

Resultados teóricos e experimentais, além da análise de estruturas que apresentaram colapso, revelam deficiências nas ligações utilizadas no Brasil, principalmente o nó típico, no entanto, esses sistemas apresentam baixo custo e facilidade de execução sendo, portanto, importante o desenvolvimento de estudos mais detalhados que permitam sua utilização com segurança.

Neste trabalho foi apresentado o ensaio de um protótipo, que é o primeiro de um série de ensaios de um programa experimental em treliças espacial que se inicia no Departamento de Estruturas da EESC-USP. Acredita-se ser a análise experimental o caminho natural para o estudo do comportamento das treliças espaciais, associado ao desenvolvimento de programas de computador, que melhor representem essas estruturas. 
A estrutura ensaiada apresentou comportamento força aplicada $x$ deslocamento fortemente não linear, comportamento este que não pode ser previsto com os modelos teóricos normalmente utilizados.

A capacidade resistente da estrutura resultou em cerca de $60 \%$ da prevista com análise linear e barras com inércia constante, a falha foi caracterizada pela ruína das ligações, com rotações excessivas, escorregamento relativo entre barras e plastificação das seções das barras na região do nó.

A rotação dos nós aconteceu, principalmente, devido a forças excêntricas que concorrem no nó.

O escorregamento relativo entre barras conduziu a aumento significativo nos deslocamentos verticais da estrutura e constitui-se em um aspecto deste sistema de ligação que deve ser considerado.

As treliças espaciais são sistemas estruturais cujo concepção está atrelada a utilização de grandes vãos. Ressalta-se, portanto, que no protótipo ensaiado, por apresentar dimensões proporcionalmente reduzidas, é necessário cuidados na interpretação e extrapolação dos resultados para as estruturas normalmente construídas com vãos maiores .

Dentre os modelos teórico, adotados na análise numérica da estrutura espacial ensaiada, o que mais aproxima aos resultados experimentais é o modelo de pórtico espacial considerando a variação de inércia nas barras e utilizando análise não linear geométrica.

Os resultados obtidos em simulações numéricas (NLG, barras com variação de inércia) em dois modelos de treliças espaciais $(22,5 \mathrm{~m} \times 22,5 \mathrm{~m}$ e $22,5 \mathrm{~m} \times 37,5 \mathrm{~m}$ ) mostram a necessidade de análises mais refinadas para essas estruturas. Os modelos analisados apresentam comportamento força aplicada $x$ deslocamento fortemente não linear para níveis de carregamento de serviço, $1,10(\mathrm{CP}+\mathrm{SC})$ e $1,40(\mathrm{CP}+\mathrm{SC})$ respectivamente para os modelos 1 e 2 .

Um aprofundamento na análise experimental de protótipos de grandes dimensões e dos nós utilizados nestas estruturas poderão conduzir a um maior entendimento do comportamento global das treliças espaciais e 
principalmente dos sistemas de ligação, cujo comportamento estrutural poderia ser considerado de forma limitada e estabelecendo critérios adequados, que permitam a sua utilização com segurança, tirando partido de suas vantagens econômicas e construtivas

Aliado as análises experimentais, estudos utilizando técnicas numéricas deverão se realizadas para conduzir a modelos mais próximos do comportamento das estruturas espaciais. Um dos trabalhos poderia desenvolver, por exemplo, um elemento finito específico para treliças espaciais com barras de seções variáveis que incorporasse esses efeitos, mesmo que de forma simplificada, facilitando e agilizando o trabalho dos projetistas de estruturas espaciais.

A continuidade nas pesquisas em torno do comportamento das estruturas espaciais com os sistemas de ligações utilizados no Brasil, bem como de novos sistemas alternativos e de modelos teóricos simplificados que melhor os representassem, iriam contribuir para melhorar nossa capacidade potencial de projetar e construir estruturas espaciais com mais qualidade e segurança.

Espera-se que esse trabalho possa dar sua devida contribuição ao processo de pesquisa e conhecimento sobre estruturas espaciais. 


\section{8 - REFERÊNCIAS BIBLIOGRÁFICAS}

AGERSKOV, H. (1986). Optimum geometry design of double-layer space structure. Journal of Structural Engineering, v.112, n.6, p.1454-1463, Jun.

AMERICAN INSTITUTE OF STEEL CONSTRUCTION (1994). LRFD - Load and resistance factor design. AISC, Chicago.

AMERICAN IRON AND STEEL INSTITUTE (1991) LRFD - Load and resistance factor design specification for cold-formed steel design manual. Washington, DC.

AMERICAN SOCIETY OF CIVIL ENGINEERS (1972). Bibliography on latticed structures. Journal of the Structural Division, v.98, n.7, p.1545-1566, July.

AMERICAN SOCIETY OF CIVIL ENGINEERS (1976). Latticed structures: state-of-the-art report. Journal of the Structural Division, v.102, n.11, p.2197-2230, Nov.

ASHRAF, M. et al. (1993). Composite double-layer bridge grids. In: INTERNATIONAL CONFERENCE ON SPACE STRUCTURES, 4, Guildford, UK, Sept. 1993, Proceedings, London, Thomas Telford. v.1, p.1518-1525.

ASSOCIAÇÃO BRASILEIRA DE NORMAS TÉCNICAS (1986). NBR-8800 Projeto e execução de estruturas de aço de edifícios: método dos estados limites. Rio de Janeiro. 
BALLERINI, M. et al. (1995). The Flowdrill system for the bolted connection of steel hollow sections. Costruzioni Metalliche, v.2, n.5, p.25-43. Set.

BATISTA, R.C. ; BATISTA, E.M. (1997). Determinação experimental dos mecanismos de colapso de uma junta típica de estruturas metálicas reticuladas espaciais. In: JORNADAS SUDAMERICANAS DE INGENIERIA ESTRUCTURAL, 28., São Carlos, Brasil, 01-05 Setembro 1997. Memórias.. v.3, p.665-674.

BATISTA, R.C. ; PFEIL, M.S. ; CARVALHO, E.M.L. (1997). Habilitação via reforço da estrutura metálica de uma grande calota esférica de cobertura. In: JORNADAS SUDAMERICANAS DE INGENIERIA ESTRUCTURAL, 28., São Carlos, Brasil, 01-05 Setembro 1997. Memórias.. v.3, p.1127-1137.

BLANDFORD, G.E. (1996). Large deformation analysis of inelastic space truss structures. Journal of Structural Engineering, v.122, n.4, p.407415, Apr.

BLANDFORD, G.E. (1996). Review of progressive failure analysis for truss structures. Journal of Structural Engineering, v.123, n.2, p.122-129, Feb.

BJORHOVDE, R. (1980). Research needs in stability of metal structures. Journal of the Structural Division, v.106, n.12, p.2425-2441, Dec.

BJORHOVDE, R. (1988). Columns: from theory to practice. Engineering Journal American Institute of steel construction, p.21-34.

BUTTERWORTH, J.W. (1981). Analysis of double-layer grids, In: MAKOWSKI, Z.S., ed. Analysis, design and construction of Doublelayer grids, Applied Science. p.57-91. 
CANADIAN STANDARDS ASSOCIATION (1989). CAN3-S136-M89 - Coldformed steel structural members . CSA, Toronto.

CANADIAN STANDARDS ASSOCIATION (1989). CAN3-S161-M89 Steel structure for buildings (limit states design). CSA, Toronto.

CHEN, W.F. (1968). Review of columns under biaxial loading, Journal of the Structural Division, v.94, n.12, p.2999-3021, Dec.

CHEN, W.F. ; LUI, E.M. (1985a). Columns with end restraint and bending in loads and resistance design factor. AISC Engineering Journal, p.105-131.

CHEN, W.F. ; LUI, E.M. (1985b). Stability design criteria for steel members and frames in the United States. Journal of Constructional Steel Research, v.5, n.1, p.31-74.

CHEN, W.F.; ROSS, D.A. (1977). Tests of fabricated tubular columns. Journal of the Structural Division, v.103, n.3, p.619-634, Mar.

EL-SHEIKH, A.I. (1996a). Experimental study of behaviour of new space truss system. Journal of Structural Engineering, v.122, n.8, p.845853, Aug.

EL-SHEIKH, A.I. (1996b). Development of a new space truss system. Journal of Constructional Steel Research, v.37, n.3 , p.205-227, Jan.

EUROPEAN COMMITEE FOR STANDARDIZATION (1992). Eurocode 3, Design of steel structures. Part.1.1. General rules and rules for buildings. 
GANDOLFI, A. (1991). New hangar of the Tessera factory of Officine Aeronavali Venezia Co. Ltd. Costruzioni Metalliche, n.5, p.271-279, Set.

GIORDANO, G. (1992). The steel frames for a new university building in via Marittima - Naples. Costruzioni Metalliche, n.1, p.1-54, Jan.

GIULIANE, A. ; GIULIANE, M.E. (1996). Innovative composite spatial Irge span structures for the new Milano Fair exhibition facilities. Costruzioni Metalliche, n.2, p.33-48, mar-abr.

GONÇALVES, R.M.; RIBEIRO, L.F.R. (1995). Analysis of the behaviour and numerical simulation of nodes that are characteristic of spatial tubular structures. In: JORNADAS SUDAMERICANAS DE INGENIERIA ESTRUCTURAL, 27., Tucumán, Argentina, 18-22 Septiembre 1995. Memórias. Tucumám, ASAIE/ Laboratório de Estructuras - FCET UNT. v.4, p.507-518.

GONÇALVES, R.M.; RIBEIRO, L.F.R. (1996). Behaviour of steel tubular elements submitted to compression: analysis by finite element method, In: JOINT CONFERENCE OF ITALIAN GROUP OF COMPUTACIONAL MECHANICS AND IBERO-LATIN AMERICAN ASSOCIATION OF COMPUTACIONAL METHODS IN ENGINEERING, Padova, Italy, Sept, 25-27, 1996, Proceedings. Padova, Italy, 1996, p.106-115.

GONÇALVES, R.M. ; FAKURY, R.H. ; MAGALHÃES, J.R.M. (1996). Peformance of tubular steel sections subjected to compression: theorical and experimental analysis. In: INTERNATIONAL COLOQUIUM ON STRUCTURAL STABILITY, 5, Rio de Janeiro, August 5-7, 1996. Stability problems in designing, construction and rehabilitation of metal structures: Proceedings. COPPE-UFRJ. p.439-449. 
HANAOR, A. ; MARSH, C. (1989). Modification of behaviour of double-layer grids: overview. Journal of Structural Engineering, v.115, n.5, p.1021-1570, May.

HILL, C.D. ; BLANDFORD, G.E.; WANG, S.T. (1989). Post-buckling analysis of steel space trusses, Journal of Structural Engineering, v.115, n.4, p.900-919, Apr.

IFFLAND, J. (1982). Preliminary planning of steel roof space trusses. Journal of the Structural Division, v.108, n.11, p.2578-2589, Nov.

IMAI, K. et al. (1994). The KT space truss system. In: INTERNATIONAL CONFERENCE ON SPACE STRUCTURES, 4, Guildford, UK, Sept. 1994, Proceedings, London, Thomas Telford. v.2, p.1374-1382.

IWATA, M. ; KAMIYAMA, K. (1993). Development and projects of the NS space truss system. In: INTERNATIONAL CONFERENCE ON SPACE STRUCTURES, 4, Guildford, UK, Sept. 1993, Proceedings, London, Thomas Telford. v.2, p.1417-1426.

JOHNSTON, B.G. (1976). Guide to stability design criteria for metal structures. 3. ed. New York, John Wiley \& Sons.

KOO, B. (1984). Analysis of compression members in spatial roof structures. In: INTERNATIONAL CONFERENCE ON SPACE STRUCTURES, 3., Guildford, UK, Sept. 1984, Guildford, UK, sept. 1984. Proceedings. London/New York, Elsevier Applied Science. p.442-445.

LAN, T.T. (1994). Structural failure and quality assurance of space frames. In: IASS-ASCE International Symposium on Spatial, lattice and tension structures, Atlanta, USA, 1994. p.123-132. 
MADI, U.R (1984). Idealising the members behaviour in the analysis of pinjointed spatial structures. In: INTENATIONAL CONFERENCE ON SPACE STRUCTURES, 3., Guildford, UK, Sept. 1984, Proceedings. London/New York, Elsevier Applied Science p.462-467.

MADI, U.R. ; EL-TAYEM, A. (1994). Collapse patterns for double-layer grids. In: INTERNATIONAL CONFERENCE ON SPACE STRUCTURES, 4, Guildford, UK, Sept. 1994, Proceedings, London, Thomas Telford. v.1, p.631-639.

MAGALHÃES, J.R.M.; MALITE, M (1996). Alguns aspectos relativos ao projeto e à construção de estruturas metálicas espaciais. In: CONGRESSO DE ENGENHARIA CIVIL DA UFJF, 2., Juiz de Fora, maio 1996. Anais. Juiz de Fora, UFJF-FEC, 1996. v.1, p.282-291.

MAGALHÃES, J.R.M. (1996). Sobre o projeto e a construção de estruturas metálicas espaciais. São Carlos. Dissertação (Mestrado)Escola de Engenharia de São Carlos, Universidade de São Paulo.

MAKOWSKI, Z.S. (1981). Review of development of various types of doublelayer grids, In: MAKOWSKI, Z.S., ed. Analysis, design and construction of Double-layer grids, Applied Science., p.1-55.

MAKOWSKI, Z.S. (1984). Space structures of today and tomorrow, In: INTENATIONAL CONFERENCE ON SPACE STRUCTURES, 3., Guildford, UK, Sept. 1984, Proceedings. London/New York, Elsevier Applied Science p.1-8.

MAKOWSKI, Z.S.(1987). A worldwide review of space structures in sports buildings. In: INTERNATINAL COLLOQUIUM ON SPACE STRUCTURES FOR SPORTS BUILDINGS, Beijing, oct. 1987. Proceedings. London, Elsevier Applied Publishers. 
MALITE, M. et al. (1997). Barras de aço comprimidas de seção tubular com extremidades estampadas - análise teórica e experimental. In: JORNADAS SUDAMERICANAS DE INGENIERIA ESTRUCTURAL, 28., São Carlos, Brasil, 01-05 Setembro 1997. Memórias.. v.1, p.417426

MALITE, M. (1997). Ensaio de compressão em barras de aço com extremidades estampadas. Laboratório de Estruturas da Escola de Engenharia de São Carlos, São Carlos - SP. Relatório técnico. Dez.

MALLA, R.B. ; SERRETTE, R.L. (1996a). Double-layer grids: review of static and thermal analysis methods. Journal of Structural Engineering, v.122, n.8, p.873-881, Aug.

MALLA, R.B. ; SERRETTE, R.L. (1996b). Double-layer grids: review of dynamic analysis methods and special topics. Journal of Structural Engineering, v.122, n.8, p.882-889, Aug.

MAQUOI, R.; RONDAL, J. (1978). Analytical formulation of the new european buckling curves. Acier- Stahl-Steel, n.1 p.23-28.

MARSH, C. (1988). Improving space truss performance by member removal. In: IASS SYMPOSIUM ON SHELL, MEBRANES AND SPACE FRAMES, Osaka, 1988, Proceedings. Amsterdam,. Elsevier Science, v.3, p.215-220.

MORINI, F. (1976). Coperture spaziale. Costruzione Metalliche, n.6, p328332. 
MURTHA-SMITH, E. (1988). Alternate path analysis of space trusses for progressive colapse, Journal of Structural Engineering, v.114, n., p., March.

MURTHA-SMITH, E.; LEARY, S.F. (1993). Space truss structural integrity, In: INTERNATIONAL CONFERENCE ON SPACE STRUCTURES, 4, Guildford, UK, Sept. 1993, Proceedings, London, Thomas Telford. v.1, p.640-648.

MURTHA-SMITH, E. ; HWANG, S.H. ; CHOU, Y.H. (1993). Space truss testing. In: INTERNATIONAL CONFERENCE ON SPACE STRUCTURES, 4, Guildford, UK, Sept. 1993, Proceedings, London, Thomas Telford. v.1.

MURTHA-SMITH, E. (1994). Compression-member models for space trusses: review, Journal of Structural Engineering, v.120, n.8, p.2399-2407, Aug.

MURTHA-SMITH, E.; CHATURVEDI, A.; LEARY, S.F. (1994). Structural integrity of space truss. In: INTERNATIONAL ASSOCIATION FOR SHELL AND SPATIAL STRUCTURES, Proceedings, p.409-418.

OSTAPENKO, A. (1977). Local buckling of welded tubular columns. In: IASS-ASCE International Symposium on Spatial, lattice and tension structures, Atlanta, USA, 1994. p-367-394

PIMENTA, R.J. (1997). Proposição de uma curva de flambagem para perfis I soldados formados por chapas cortadas a maçarico. Belo Horizonte. (dissertação de mestrado). Universidade Federal de Minas Gerais. 
PAPADRAKAKIS, M. (1983). Inelastic post-buckling analysis of trusses. Journal of Structural Engineering, v.109, n.9, p.2129-2145, Sept.

PRION, H. G. ; BIRKEMOE, P. C. (1992). Beam-column behavior of fabricated steel tubular members. Journal of Structural Engineering, v.118, n.5, p.1213-1233, May.

RONDAL, J. ; MAQUOI, R. (1979). Single equation for SSRC colunmstrength curves. Journal of the Structural Division, v.105, n.1, Jan.

SAKA, T. ; HEKI, K. (1984). The effect of joints on the strength of space trusses. In: INTENATIONAL CONFERENCE ON SPACE STRUCTURES, 3., Guildford, UK, Sept. 1984, Proceedings. London/New York, Elsevier Applied Science p.417-422.

SCHMIDT, L.C. ; MORGAN, P.R. (1982). Ultimate load of testing of space trusses. Journal of the Structural Division, v.118, n.6, p.1324-1335, June.

SCHMIDT, L.C.; MORGAN, P.R.; CLARKSON, J.A. (1976). Space trusses with brittle-type strut buckling. Journal of the Structural Division, v.102, n.7, p.1479-1492, July.

SCHMIDT, L.C. ; HANAOR, A. (1979). Force limiting device in space trusses. Journal of the Structural Division, v.105, n.5, p.939-951, May.

SEBASTIAN, W.M. et al.(1993). An investigation into the possibility of a composite space truss bridge. In: INTERNATIONAL CONFERENCE ON SPACE STRUCTURES, 4, Guildford, UK, Sept. 1993, Proceedings, London, Thomas Telford. v.2, p.1640-1649. 
SHERMAN, D.R. (1991). Impact of code differences for tubular members. Journal Constructional Steel Research, n.18, p.317-325.

SMITH, E.A. (1984). Space truss nonlinear analysis. Journal of Structural Engineering, v.110, n.4, p.688-705, Apr.

$\mathrm{SOH}$, A. ; SOH, C. (1993). Hot spot stresses of tubular joints subjected to combined loading. Journal of Structural Engineering, v.119, n.2, p.

SOROUCHIA, P.; ALAWA, M.S. (1990). Hysteretic modeling of steel struts: a refined physical theory approach. Journal of Structural Engineering, v.116, n.11, p.2903-2916, Nov.

SUPPLE, W.J. ; COLLINS, I. (1981). Limit state analysis of double-layer grids. In: MAKOWSKI, Z.S., ed. Analysis, design and construction of Double-layer grids, Applied Science., p.93-95.

THORNTON, C.H. ; LEW, I.P. (1984). Investigation of the causes of Hartford Coliseum collapse. INTENATIONAL CONFERENCE ON SPACE STRUCTURES, 3., Guildford, UK, Sept. 1984, Proceedings. London/New York, Elsevier Applied Science p.636-641.

TOMA, S.; CHEN, W.F. (1983). Post-buckling behavior of tubular beam columns. Journal of Structural Engineering, v.109, n.8, p.1918-1932, Aug.

TOMA, S.; CHEN, W.F. (1992). European calibration frames for secondorder inelastic analysis. Journal of Structural Engineering, v.14, n.1 p.7-14, Jan.

WALKER, H.B. (1981). The design and construction of double-layer space frame grids. In: In: MAKOWSKI, Z.S., ed. Analysis, design and construction of Double-layer grids, Applied Science., p.331-354. 